\title{
THE EXPERIENCE OF DEEP LEARNING BY ACCOUNTING STUDENTS IN A UNIVERSITY ACCOUNTING COURSE
}

\author{
By \\ Martin Craig Turner
}

A thesis

Submitted to the Victoria University of Wellington in fulfilment of the requirements for the degree of

Doctor of Philosophy in Accounting

Victoria University of Wellington 

- - - - 1 


\begin{abstract}
Higher education in accounting faces a challenge to shift its emphasis from reproducing technical knowledge to developing personal capabilities such as critical thinking, creative thinking, problem-solving, communication and teamwork. The educational psychology literature suggests students will not make the cognitive effort to develop personal capabilities unless they first experience a deep approach to learning; and the experience of high-level relevance structure, high-level conception of learning and intrinsic motivation strongly support deep learning. This study examines how accounting students can be supported to experience high-level relevance structure, high-level conception of learning, intrinsic motivation and deep learning in the context of a university accounting course. Phenomenography is used to study the experience of learning of students in a third year undergraduate accounting course into which an integrated set of interventions involving Assessment, Teamwork, Teacher-Student Relationship and Instruction was introduced. An assignment in five stages and five session preparation assignments, supplemented with a focus group and surveys of students, identified and captured the ways students experience key aspects of how they learn. A key finding of this study is that it is possible to transform the design and delivery of a single university course to support a large proportion of students to experience change in how they learn accounting (and, in particular, to experience deep learning) through the careful adaptation of education theory. An implication of this study is the need to support students to experience change in how they learn in first year courses to enable them to develop personal capabilities in their later university studies.
\end{abstract}




\section{Acknowledgements}

I would like to thank each of the 81 students who studied Financial Statement Analysis in 2008 at Victoria University of Wellington. I appreciate each one of you - and have been privileged to be your teacher and to also research each of your individual journeys in learning how to analyse firms.

My special thanks to Rachel Baskerville and Tom Angelo. You have been wonderful supervisors. Thank you for your support, encouragement and for coming with me on this journey. I will always remember and value the help each of you has given me.

My thanks also to my wife, Margie, and my three children Mark, Claire and Paul. Each of you have been supportive and appreciative of my desire to pursue one of my dreams, of which this study is an important stepping stone ... to support a meaningful transformation of the experience of learning for students at university.

Martin Turner

February 2011 


\section{Contents}

Page

Abstract $i$

Acknowledgements $\quad$ ii

1. Introduction and Accounting Education Literature Review 1

1.1. Research Question and Theoretical Model 2

1.2. Interventions to Support Personal Capabilities 14

1.3. How Accounting Students Approach their Learning 18

$\begin{array}{ll}\text { 1.4. Overview } 28 & 28\end{array}$

2. Literature Review: Interdisciplinary Research 33

2.1. Key Theoretical Concepts 34

2.2. Conception of Learning and Motivation 44

2.3. Interdisciplinary Research 51

3. Research Method 59

3.1. Research Method and Interventions 59

3.2. Measures of Students' Perceptions 74

4. Challenging Previous Ways of Experiencing Relevance Structure and Conception of Learning $\quad 83$

4.1. Previous Relevance Structures 85

4.2. Challenging Previous Relevance Structures 93

4.3. Creating Awareness 100

4.4. Implications for Conception of Learning 106

5. Experience of Intrinsic Motivation and the Assignment 116

$\begin{array}{ll}\text { 5.1. Supporting Intrinsic Motivation } & 117\end{array}$

5.2. Response to Assessed Learning Tasks 125

5.3. Response to Increasing Challenges 133

5.4. Experience of Intrinsic Motivation 141 
6. Further Interventions to Support the Experience of Intrinsic Motivation 149

6.1. Session Preparation Assignments (SPAs) 150

6.2. Relating to Others 158

6.3. Teacher-Student Relationship and Awareness 165

6.4. Interactions with Intrinsic Motivation 173

7. Deep Approach to Learning 180

7.1. Adjusting to Deep Learning 181

7.2. Experience of Deep Learning 190

7.3. Constructing Knowledge 196

7.4. Design of the Assessed Learning Tasks 202

8. Challenges of Deep Learning 211

8.1. Relationships With Others 213

8.2. Confidence to Make Judgements 221

8.3. Ongoing Challenges 228

8.4. Two Key Internal Relations and Deep Learning 234

9. Findings and Conclusions 242

9.1. Key Findings 243

9.2. Implications for Accounting Education 257

9.3. Institutional Context 261

9.4. Future Research 263

$\begin{array}{ll}\text { References } & 268\end{array}$

\section{Appendices}

1. SPAs and Assignment 286

2. Discussion Board 310

3. Identifiers of Accounting Students and Distribution of Number 311 of Narratives From Each Student

4. Data Analysis of 10 Reflective Assignments Using N-Vivo 314

5. Instruction to Support Accounting Students to Develop Awareness 315 about Conception of Learning

6. Surveys and Questionnaires 


\section{Figures}

Figure 1.1 How University Students Learn in a University Course

Figure 1.2 Interventions to Support Accounting Studerts to Change the Way They Experience Learning in Accounting

Figure 4.1 Variation in Ways of Experiencing Relevanse Structure and Deep Learning

Figure 5.1 Interventions to Support Accounting Students to Experience Intrinsic Motivation

Figure 6.1 Interventions to Support Accounting Students to Experience Intrinsic Motivation

Figure 6.2 Pre-Course Survey: How Often Do You Read Before Lectures in Your Previous Accounting Courses?

Figure 7.1 Interventions to Support Accounting Students to Change the Way They Experience Learning Accounting

Figure 7.2 Initial Experience of Deep Learning

Figure 8.1 Interventions to Support Accounting Students to Change the Way They Experience Learning Accounting

Figure 9.1 Initial Experience of Deep Learning

Figure 9.2 Interventions to Support Accounting Students to Change the Way They Experience Learning Accounting

\section{Tables}

Table 2.1 Characteristic Features of a Student Adopting a Deep Approach to their Learning

Table 2.2 Characteristic Features of a Student Adopting a Surface Approach to the Learning

Table 2.3 Conceptions of Learning

Table 3.1 Response Rates and Timing: Assignment, SPAs, CIQs, AEQ and Student Surveys 


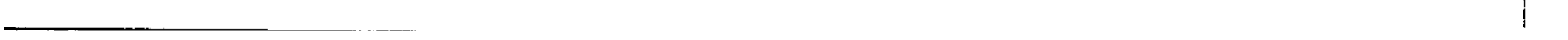
$-$ 



\section{INTRODUCTION AND ACCOUNTING EDUCATION LITERATURE REVIEW}

... the real problem for accounting education is not student attitudes and [learning] strategies per se. It is the extent to which preferences and associated [learning] strategies are challenged and modified by teaching and assessment strategies which students encounter.

Boyce et al (2001: 54)

This study addresses a key challenge in accounting education: how to support students to change the way they learn accounting in a university accounting course as a necessary precondition for them to be able to develop personal capabilities such as critical thinking, creative thinking, problem-solving, communication and teamwork. In this chapter, the research question which this study will answer is outlined. This is followed by a discussion of the theoretical model used to adapt concepts from the educational psychology literature and the education literature more generally to the context of a university accounting course. This theoretical model focuses on the experience by students of relevance structure, conception of learning, motivation and approach to learning in a university accounting course. The model suggests students need to experience at a more complete and complex level each of these key aspects of how they learn accounting as necessary preconditions for them to be able to make the substantial cognitive effort involved in developing personal capabilities.

The accounting education literature has largely proposed specific, 'decontextualised' interventions to meet the challenge of supporting accounting students to develop personal capabilities, such as critical thinking. It will be discussed that there is little evidence these interventions have been effective. This would be consistent with a key insight of the approach to learning conception of human learning that students will not experience change in personal capabilities such as critical thinking unless they first experience deep learning. There is evidence of widespread experience by accounting students of low-level relevance structure, low-level conception of learning, extrinsic motivation and surface learning which presents a significant challenge for them to be able to develop personal capabilities in the context of a university accounting course. 
The focus of this study is to examine how to support students to change the way they experience these key aspects of how they learn as a necessary foundation, or precondition, for them to be able to respond to interventions designed to support the development of personal capabilities. This is an important issue for accounting education because students need to change these aspects of how they experience learning accounting before interventions designed to support the development of personal capabilities can be effective.

\subsection{Research Question and Theoretical Model}

Business is not about the certainties of clear-cut, black-and-white facts from experts. It is about a world of making judgements about an uncertain future. It is this world of business reality that accounting professionals need to be able to engage with. Accounting professionals need to be able to engage with business realities and make commercial judgements which require personal capabilities in areas such as critical thinking, creative thinking, problem-solving, communication and teamwork. How to support accounting students to develop these capabilities is a significant challenge facing accounting education.

This section sets out the research question to be answered in this study and why it is an important question about which to seek answers. This is followed by a discussion of the theoretical model developed to assist to answer this question. This model is designed to support the careful adaptation of concepts from the educational psychology literature to the context of a university accounting course. It also includes a set of integrated interventions developed from the education literature more generally. The influence on these interventions of the concept of constructive alignment is also discussed.

\section{Research question}

This study will answer the following research question:

In what ways can accounting students be supported to experience high-level relevance structure, high-level conception of learning, intrinsic motivation and a deep approach to learning in the context of a university accounting course? 
The key theoretical concepts of human learning used in this study of approach to learning, relevance structure, conception of learning and motivation are discussed and defined in Section 2.1 in Chapter 2 below.

The motivation for this study is to provide evidence of whether and if so, in what ways, accounting students can be supported to change the ways they experience learning. Previous research has found this to be a challenging issue for accounting students (English et al, 2004; Hall et al, 2004; Ballantine et al, 2008; Fox et al, 2010); and also for students in a range of other disciplines including, for example, education, science, psychology, nursing and medicine (Baeten et al, 2010). However, such a change in the ways students experience learning accounting is not an end in itself. The reason this research question is important is because this change is considered to be a necessary precondition for students to be able to develop desirable personal capabilities while studying at university (Trigwell and Prosser, 1991).

As a private equity professional, the author often found it difficult to identify chief financial officers for investee companies who combined accounting training with the capacity to use accounting numbers to engage with the economic and business realities of firms and to make quality commercial judgements. Also, the use of accounting professionals from the 'big four' accounting firms to complete accounting due diligences on firms prior to their acquisition also displayed to the author the tendency of accounting professionals to focus on the accounting numbers (the 'signs') as if they were the 'answer' rather than on using the accounting numbers to help make judgements about the economic and business realities of firms (the 'signified'). The author has also heard similar criticisms of accounting professionals by other business people, heads of government departments, 'head hunters' and those involved regularly in recruiting accounting graduates to major accounting firms and large corporates. Supporting accounting students to change the ways they experience how they learn accounting in a university accounting course is a necessary precondition for developing the personal capabilities needed to engage with business reality (the 'signified') and make commercial judgements, rather than simply focusing on accounting numbers (the 'signs').

Such a change in the ways students experience learning can open up a new world of learning for accounting students, a world of new possibilities enabling 
and supporting them to develop personal capabilities in areas such as critical thinking, creative thinking, problem-solving, communication and teamwork (Trigwell and Prosser, 1991; Mattick et al, 2004). These capabilities are needed for accounting students to develop the ability to make the commercial judgements required of accounting professionals; and, indeed, are relevant and valuable for all aspects of their lives. It is this opening up of these new possibilities of learning that makes this research question exciting and worthwhile to study. It is hypothesised that a careful, systematic and integrated application of education theory to the design and delivery of a university accounting course will provide powerful insights into answers to this research question. For this reason, a theoretical model, grounded firmly in education theory, was developed to support the research design in this study and to address what is expected to be a challenging issue: understanding how to support accounting students to change the way they experience how they learn accounting in a university accounting course.

\section{Theoretical model}

An interpretivist stance was used as a lens in this study to identify systematic forms of thought in terms of which people interpret significant aspects of reality. This study aims to describe, analyse and understand the ways accounting students experience aspects of the learning context of a university accounting course. This research seeks to provide "experiential descriptions, that is, content-oriented and interpretive descriptions of the qualitatively different ways in which people perceive and understand their reality" (Marton, 1981: 177). This study aims to examine the effectiveness of certain interventions to support students to change the ways they experience key aspects of how they learn accounting.

This study has used categories of variation for conception of learning (discussed further in Section 2.1 in Chapter 2 below), motivation (extrinsic and intrinsic) and approach to learning (surface and deep) from the educational psychology literature to represent a hierarchy of more complete or complex ways of experiencing these aspects of learning. For relevance structure, categories of variation for accounting students in the specific context of a university accounting course were identified as part of the findings of this study. These categories of 
variation for relevance structure are discussed in Chapter 4 below and represent an important part of the findings of this research.

This study seeks to identify and describe critical differences in students' capabilities for experiencing particular phenomenon (that is, aspects of how they learn accounting) as a result of the interventions made to the learning context of a course. This study uses a phenomenographic approach to measure the effectiveness of interventions designed to support students to experience more effective ways of experiencing how they learn. The phenomenographic approach used in this study is discussed in greater detail in Chapter 3 below.

This study has used a theoretical model that summarises some key findings and insights from the educational psychology literature and the education literature more generally. Learning and the student's experience of learning is complex, but a theoretical model can isolate key concepts and the relationships between these concepts. This can support a focus on certain aspects of the undivided whole of the experience of learning to support students in an educational context to improve the quality of their learning outcomes. All learning takes place in a context (Marton, 1988; Biggs, 1993). This theoretical model suggests that students must experience more complex and complete ways of experiencing certain aspects of how they learn for them to be able to develop personal capabilities such as critical thinking. The development of this theoretical model is an important research output of this study and has been a key means for designing and applying the interventions adopted in this research to address the challenges of effectively supporting students to change the ways they experience how they learn.

\section{Key concepts and interventions}

The model used in this study sets out general concepts, processes and principles. It does not suggest there is one universal, true method or approach that can be used like a 'cookie-cutter' in all learning contexts. Rather, this model is designed to assist the careful adaptation of the theoretical concepts from approach to learning research in the educational psychology literature and the education literature more generally, to the learning context of accounting education. The purpose of this theoretical model is to support the design of an integrated set of interventions to support students to experience change in the way they learn 
accounting in a university accounting course and thus be able to develop personal capabilities.

This model focuses attention on the individual cognitive preconditions students need to experience before they are able to make the substantial cognitive effort involved in developing capabilities in a university accounting course. As discussed in Chapter 2 below, the educational psychology literature strongly suggests students will not develop capabilities in areas such as critical thinking, creative thinking, problem-solving, communication and teamwork unless they experience a deep approach to their learning (that is, learning for understanding and developing personal meaning) rather than a surface approach to their learning (that is, reproducing clear-cut, black-and-white facts from experts) (Trigwell and Prosser, 1991; Mattick et al, 2004). Further, the experience by students of a deep approach to their learning is strongly related to experiencing intrinsic motivation (Fransson, 1977; Marton and Säljö, 1984; Entwistle and Tait, 1990; Entwistle et al, 2002; Thomas and Gadbois, 2007) and to having a clear conceptual view (that is, a conception of learning) that learning is about understanding and developing personal meaning and is not simply about reproducing clear-cut, black-and-white facts from experts (Van Rossum and Schenk, 1984). Also related to an accounting student's deep approach to learning, intrinsic motivation and conception of learning is their experience of the relevance structure of a university accounting course, which is their experience of where the learning tasks are heading towards, where completing the learning tasks might take them and what the learning tasks will demand from them (Laurillard, 1979; Marton and Booth, 1997). These insights from the educational psychology literature have been summarised in the theoretical model set out in Figure 1.1 below.

\section{Figure 1.1: How University Students Learn in a University Course}

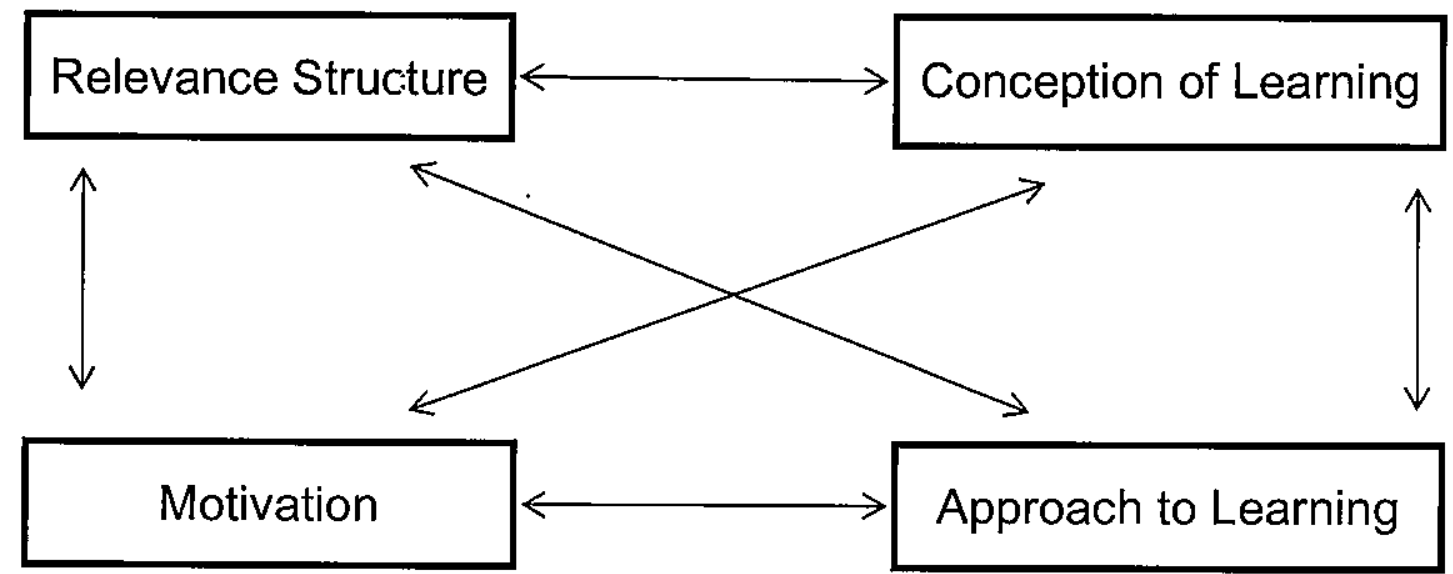

Page 6 
This theoretical model focuses on how students experience the way they learn accounting in a university accounting course rather than on the type of learning outcomes they experience and achieve. Learning accounting is a single, integrated activity. However, the educational psychology iterature has identified a number of theoretical concepts or variables of how students learn. These variables cannot be defined or categorised separately from each other and there is an internal relation between each concept (Martin and Svensson, 1979). Figure 1.1 above shows the four concepts of relevance structure, zonception of learning, motivation and approach to learning, with the internal relations between each of these variables indicated by double-headed arrows.

These theoretical concepts are well-researched and evidence-based in the educational psychology literature, with the initial researci typically focused on studying how students experience specific learning tasks, such as reading a text, writing an essay or solving a problem (see Chapter 2 below). In this initial research, these learning tasks were typically not experienced by students as part of a university course. In adapting and applying these concepts to this research, the unit of study shifts from a focus on the ways students experience specific learning tasks in isolation to a focus on the ways students experience learning tasks within the context of a university course:

For the identification of the contrasting worlds of engagement and detachment [by accounting students] and the existence of alternative conceptions of accounting raise important issues ... and provide a foundation for further research ... into motivation, relevance and the impact of these different experiences on approaches to learning ... accounting.

Lucas (2000: 498)

With this shift in focus, Lucas (2000) advocated use of phenomenographic research to develop specific categories of variation for experiencing aspects of learning accounting such as conception of learning, motivation and relevance structure. As noted above, this study has used 'generalised' categories of variation for conception of learning, motivation and arproach to learning as developed in the educational psychology literature to represent a hierarchy of more complete or complex ways of experiencing these aspects of learning 
accounting in a university accounting course. In this study, these 'generalised' concepts are considered to be applicable for accounting students in a university accounting course. For relevance structure, categories of variation for accounting students in the specif:c context of a university accounting course were identified as part of the findings of this study.

Given the evidence, discussed in Section 1.3 below, that many accounting students experience low-level relevance structure, low-level conception of learning, extrinsic motivation and surface learning, a challenge for accounting education is to design and deliver accounting courses that support students to change the way they experience these four aspects of how they learn. Or in other words, the challenge is to design and deliver courses that support students to learn about learning accounting. Such a change in how accounting students learn is needed before they will be able to develop personal capabilities in the context of a university accounting course.

The purpose of this study is to explore the effect of an integrated set of interventions designed to support students to change the ways they experience how they learn acco-anting in a university accounting course. The education literature provides evidence-based insights specifically related to the context of university courses and this has been relied on to develop a framework of interventions involving Assessment, Teamwork, Teacher-Student Relationship and Instruction (as shown in Figure 1.2 below). These four categories represent an integrated set of interventions with each category supporting accounting students to experiense more complex and complete ways of experiencing relevance structure, ccnception of learning, motivation and approach to learning. 
Figure 1.2: Interventions to Support Accounting Students to Change the Way They Experience Learning Accounting

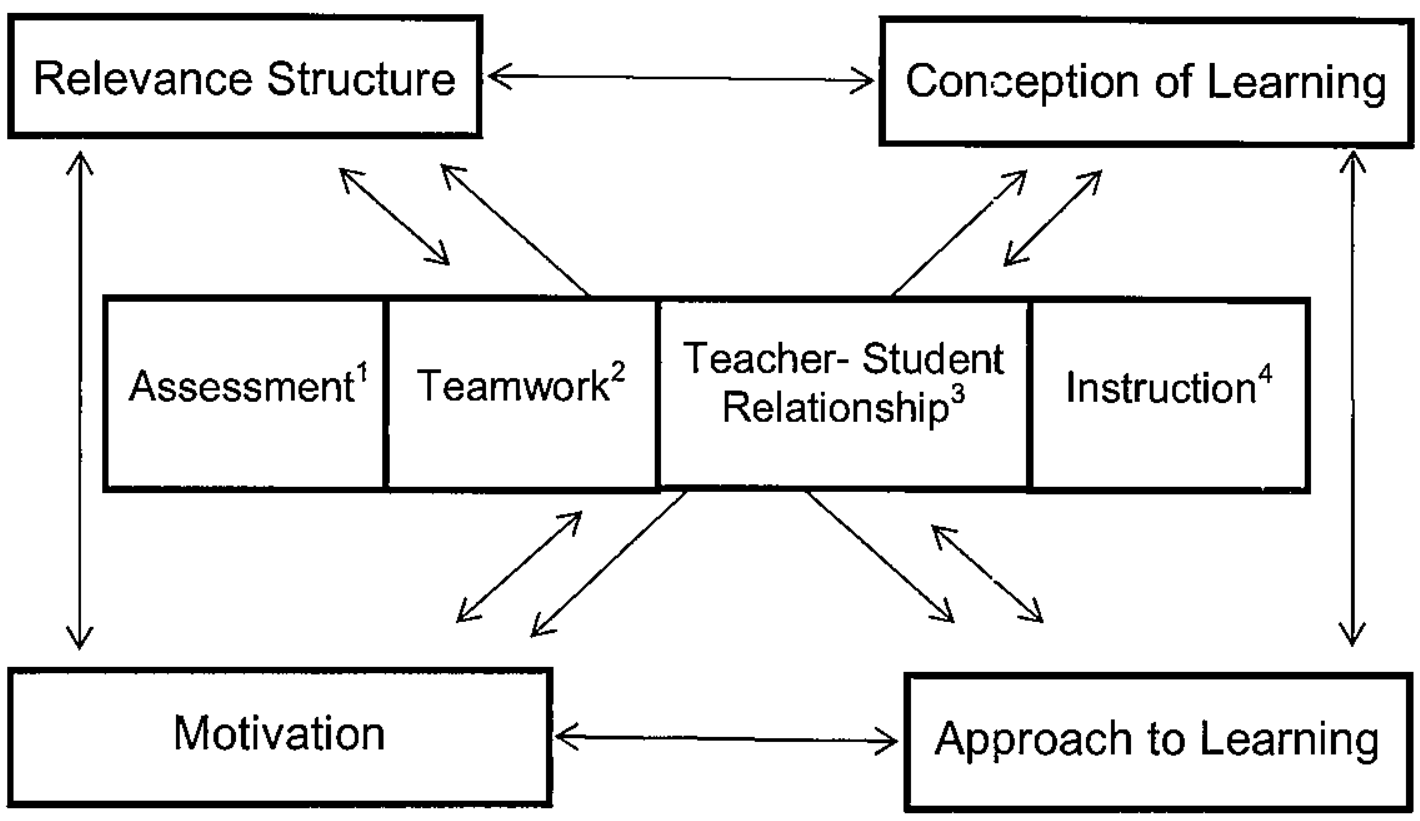

Footnotes for Figure 1.2:

1. Hand et al (1996); Biggs (1999); Entwistle and Ramsden (1983); Thomas and Bain (1984); Sambell et al (1997); Struyven et al (2005).

2. Cottell and Millis (1993).

3. Ramsden and Entwistle (1981); Entwistle and Ramsden (1983).

4. Biggs \& Rihn (1984); Martin and Ramsden (1987); Marton et al (1993); Weimer (2002); Ramsden (2003); Nijhuis et al (20C5).

Assessment can strongly influence the approach to learning adopted by students in a course (Entwistle and Ramsden, 1983; Sambell et al, 1997; Struyven et al, 2005). In particular, assessment structures can be developed to encourage students to actively search for understanding and personal meaning while they organise the content of what they are learning into a coherent and meaningful whole, that is, to support a deep approach to learning (Lacrillard, 1984; Scouller, 1998). For example, there is evidence authentic assessments can support the experience of deep learning (Frederiksen, 1984; McDowell, 1995; Birenbaum, 1996; Dochy and McDowell, 1997; Gijbels et al, 2005a). With greater difficulty, assessment structures can be designed to support students to experience intrinsic motivation in the subject being studied (Hand et al, 1996; Biggs, 1999); and authenticity can be an important aspect of assessment to support the experience of intrinsic motivation, with a particular link to the experience of relevance structure 
(McDowell, 1995; Herrington and Herrington, 1998; Lizzio and Wilson, 2004;

Martens et al, 2004). Limited interventions in assessment design that are not part of an integrated set of interventions have been shown to not support change in the approach to learning of students, for example in the case of nursing students (Leung et al, 2008; also see Baeten et al, 2010: 5).

It is perception by students of the assessment that will influence student learning (Van Rossum and Schenk, 1984; Entwistle, 1991; Gulikers et al, 2008: Watty et al, 2009). As noted by Stein, et al (2004):

...learning opportunities will be authentic in the sense that they are personally meaningful and relevant to students, socially relevant to the field and in harmony with the nature of the discipline (Brown et al, 1988; Lave and Wenger, 1991; Tochon, 2000).

The relationship between assessment, motivation and approach to learning is described by Franssen (1977: 256) in these terms:

A student motivated by test demands to read a text for which he [or she] has very limited interest is very probable to adopt a surface-learning strategy, while deep-level learning seems to be the normal strategy chosen by a student motivated only by the relevance of the content of the text to his [or her] personal needs and interests ... if deep-level processing is valued every effort must be made tc avoid threatening conditions, which rely mainly on extrinsic motivation. This is especially important when the initial interest of the students in the learning task is low. The results support the arguments by Edfeldt (1976) and Dewey (1913) that the natural impulse of the intrinsically motivated learner, unthreatened by expectations of a factual knowledge test, is deep-level processing.

'Quality' feedback (as perceived by students) has a role to play with assessment, and "prior studies have indicated that the provision of an unembellished grade or feedback that is vague and difficult to interpret is of limited value to learning: Higgins, et al (2002): Yorke (2001)" (Byrne et al, 2009). Rather, as noted by Hounsell et al (2008: 55): “...effective formative assessment involves not simply 
providing constructive and timely feedback comments, is also entails assisting students to come to hold a conception of what counts as good quality work in the subject area.". Nicol and Macfarlane-Dick (2006: 201) also note that each student "actively constructs his or her own understanding of feedback messages (Black and William, 1998; Ivanic et al, 2000)."

Assessment design and delivery was central to the integrated set of interventions used in this study. The assessed learning tasks were individualised (different for each student), authentic (involve the real world) and included regular formative feedback (involving a grade and clear feedback on how to improve performance in the next assessed learning task); and generally did not have 'right' answers but involved the increasing use of personal judgement.

Teamwork involved a comprehensive use of a range of co-operative learning techniques, including the use of study groups, to support students to draw on each other's experiences, insights and perspectives in addition to their own to support them to develop understanding and personal meaning of the content being studied (Cottell and Millis, 1993; Ballantine and Larres, 2009).

Teacher-Student Relationship involved a student-centred and facilitative teaching style where 'right' answers were not imposed but curiosity, questioning and exploration were encouraged (Ramsden, 2003; Fink, 2003). There is evidence such a student-focused teaching approach that encourages high levels of participation can support deep learning (Trigwell et al, 1998; Campbell et al, 2001; Byrne et al, 2009).

Instruction involved direct teaching to support accounting students to have a clear conceptual view that learning is about understanding and developing personal meaning (Biggs \& Rihn, 1984; Martin and Ramsden, 1987; Marton et al, 1993). It also included use of reading materials that had a deep approach to learning embedded in them (Nijhuis et al, 2005) and the use of authentic examples (including the ongoing application of concepts being taugh- throughout the course to an exemplar company) in both the classroom teaching and the reading materials (Herrington and Kervin, 2007). These integrated interventions are discussed in greater detail in Section 3.1 (in Chapter 3) below. 


\section{Constructive alignment}

The framework of interventions was influenced by the concept of constructive alignment (Biggs, 1999). Constructive alignment is the combination of two central concepts from the education literature:

Constructive: the zoncept that students construct their own knowledge rather than passively receive clear-cut, 'pre-digested' facts from experts. An implication of this concept is that the design and delivery of university courses should be primarily focused on student learning and not on the content being taught or on the teaching methods (that is, on what the teacher is doing). Thus the focus of course design and delivery should not be focused on 'covering' content in a way that is disconnected or separated from how students might learn that content. The course design should also not be focused on using some particular teaching methods, as if there were some universal 'good' teaching methods. Rather, the course design should use any teaching methods that might support the objective of student learning.

Alignment: the concept that each aspect of the design and delivery of a university course should be focused on supporting the desired student learning outcomes. The concept of alignment is often used to refer particularly to the intervention of Assessment, all aspects of which should be carefully aligned to support the desired student learning outcomes. However, the concept of constructive alignment can be used for all aspects of course design and delivery (Fink, 2003).

An important aspect to the theoretical model used in this study is the integrated nature of the interventions of Assessment, Teamwork, Teacher-Student Relationship and Instruction. In particular, the influence of the concept of constructive alignmert can be seen in the central importance in the theoretical model of Assessment within a comprehensive set of interdependent interventions aligned in such a way as to support students to experience change in the ways they experience how they learn accounting in a university accounting course. 
This section has set out the research question which will be answered by this study and has discussed why it is an exciting and worthwhile question about which to seek answers. A theoretical model has also been set out that summarises some key findings from approach to learning research in the educational psychology literature relevant to the design and delivery of university accounting courses. These are represented in Figure 1.2 above by the four key concepts of relevance structure, conception of learning, motivation and approach to learning and by the internal relations between them. The theoretical model also includes a set of integrated interventions drawing on insights from the education literature more generally. This model is designed to support the careful application of these ideas to the specific learning context of a university accounting course and thus assist in the challenging process of transferring these insights to interdisciplinary approach to learning research in the accounting education literature.

This theoretical model focuses attention on the individual cognitive preconditions accounting students need to experience before they are able to make the substantial cognitive effort involved to develop personal capabilities. The model suggests that where students think the learning tasks in a university accounting course might take them (relevance structure), what students think learning accounting is (conception of learning), why students are learning what they are studying (motivation) and the overall qualitative way in which students experience their learning in a university accounting course (approach to learning) matter. They matter a lot. They matter because each of these four aspects of learning need to be experienced by accounting students in more complex and complete ways before they will be able to develop personal capabilities in the context of a university accounting course. In the next section, the challenges outlined in the accounting education literature to support accounting students to develop personal capabilities will be discussed and described. 


\subsection{Interventions to Support Personal Capabilities}

Since the mid 1980s there has been increasing disquiet among accounting educators and professional bodies around the world as to the adequacy and relevance of educational programs ... designed to prepare [accounting students] for entry to the accounting profession.

Cotton et al (2002)

In this section, there is a discussion about the challenges facing accounting education to support accounting students to develop personal capabilities in areas such as critical thinking, creative thinking, problem-solving, communication and teamwork. These capabilities are considered valuable both for accounting professionals and also for life in general. In part, the response of the accounting education literature to these challenges has been to propose specific, 'decontextualised' interventions designed to develop capabilities in accounting students. There is little evidence these interventions have been effective. Such a result would be consistent with a key insight of the approach to learning conception of human learning that suggests accounting students will not experience change in personal capabilities unless they first change the way they experience how they learn accounting in a university accounting course.

\section{Need to develop personal capabilities}

There have been long-standing calls for accounting education to support accounting students to develop personal capabilities rather than simply supporting students to reproduce technical accounting rules. The Bedford Committee Report (American Accounting Association) in 1986 stated that "[m]any accounting educators ... feel that the teaching process should be expanded to assure that students not only learn the technical professional accounting body of knowledge, but also develop the ability to use that knowledge analytically, in creative and innovative ways in accordance with high standards of professional ethics." (Bedford, 1986: 178).

The Accounting Education Change Commission (AECC) considered an accounting education "should lay the base on which life-long learning can be built. In other words, graduates should be taught how to learn." (AECC, 1990: 
307). The AECC considered an accounting education should 'focus ... on developing analytical and conceptual thinking, not on memorising professional standards" and that an accounting education "should develop in students the capacity for inquiry, abstract logical thinking, and critical analysis and should train them to understand and use quantitative data." (AECC, 1990: 308). Similar sentiments were expressed by the then eight main accounting firms in 1989 (BEWP, 1989), the American Institute of Certified Public Accountants (AICPA, 1999), the International Federation of Accountants (IFAC, 1994; IFAC, 1996; IFAC, 1998; IFAC, 2001) and the Institute of Chartered Accountants of England and Wales (ICAEW, 1993). These calls and debates for fundamental change in accounting education from the accounting profession in the United States and United Kingdom have also been reflected in New Zealand and Australia (Marrian and Lothian, 1992; Birkett, 1993; ICAA/ASCPA, 1996) and from various accounting academics (for example Ekroth, 1990; Sundem et al, 1990; Deppe et al, 1991; Sharma, 1997; Baril et al, 1998; and Hassell et al, 1999). Indeed, there has been a "long-held criticism of accounting education regarding overloaded, technically-oriented syllabi (Bandy, 1994; Power, 1991; Tinker, 1985; Zeff, 1979)" (Byrne et al, 2009: 163).

\section{'De-contextualised' interventions}

In response to these calls, there have been attempts to focus accounting education on the development by students of personal capabilities and less on the transfer of technical accounting knowledge. This has been reflected ir many examples in the accounting education literature of interventions to support students to develop capabilities such as critical thinking skills. These interventions have typically focused on supporting the development of specific aspects of these capabilities, such as elements of critical thinking, as reflected in these comments by Doney and Lephardt (1993: 299):

Accounting teachers must recognise that students do not learn critical thinking merely by acquiring increasingly complex layers of discipline content ... Accounting students need to be taught the adaptive skills of critical thinking within the accounting curriculum by skilled professionals who are capable 
of guiding and assessing the process of developing critical thinking in their students.

There have been attempts to identify the key elements of capabilities such as critical thinking skills as they could be incorporated into accounting curriculum (Kimmel, 1995). There are many specific examples of course design and implementation to support students to develop personal capabilities, including those involving financial statement analysis courses (Sullivan, 1996; Kern, 2000; Montano et al, 2004). Interventions include use of authentic case studies (Stewart and Dougherty, 1993; Stice and Stice, 2006), individualised problem assignments (Davis et al, 2001); cooperative learning techniques (Cottell and Millis, 1993; Bonk and Smith, 1998); reflective learning techniques (Mintz, 2006); learning journals (McGuigan and Kern, 2009); learning portfolios (Samkin and Francis, 2008); academic and professional journal articles as readings (Hoque, 2002); writing journal articles (Tonge and Willett, 2009); problem-based learning (Milne and McConnell, 2001); developing business plans (Nikolai, 2006); service learning (Chiang, 2008); experiential learning (McCarthy and McCarthy, 2006); international study tours (Webb et al, 2009); use of class presentation formats (Foran and Olds, 2002); and use of student teams (Kennedy and Dull, 2008).

A feature of these many examples in the accounting education literature of interventions designed to support accounting students to develop personal capabilities is that typically the total learning context of a university accounting course in which the specific interventions were made, and also what accounting students actually did in response to these interventions, were not explicitly considered. In many cases it was largely assumed accounting students would develop capabilities in areas such as critical thinking in response to these interventions. Thus many of the interventions in the accounting education literature designed to change aspects of the learning context for accounting students (for example, the use of authentic case studies) were examples of implementing 'de-contextualised' ideas; that is, they were not grounded in the context of how students learn accounting in a university accounting course.

\section{Continued focus on technical knowledge}

Despite the desire expressed by many over more than two decades for changes in accounting education to support the development of personal capabilities, there is 
little evidence that much has been achieved. For example, there is evidence little was achieved in the United States in the 1990s to transform accounting education (Albrecht and Sack, 2000) and that accounting education continues to be characterised by a focus on the transfer of technical accounting knowledge (Howieson, 2003; Ahern et al, 2007; Jackling and De Lange, 2009).

Also, as the technical content of accounting as a discipline continues to expand there is a risk accounting courses will simply increase the quantity of technical content they seek to 'cover' which could actually encourage greater focus on the transfer of technical knowledge and less on the development of personal capabilities. There is evidence the study of accounting can actually discourage the development of personal capabilities (Stewart and Dougherty, 1993; Hand et al, 1996) and be perceived by students as a discipline that simply applies technical rules (Boyce, 1996). There is also evidence students who are more inclined to engage in and develop capabilities in areas such as critical thinking may be less likely to commence accounting studies (Saemann and Crooker, 1999).

As discussed in this section, there is little evidence the large number of 'decontextualised' interventions in course design and delivery documented in the accounting education literature have been effective in changing the learning experience of accounting students and in supporting them to develop personal capabilities. It is suggested a reason for this may be that students have not first been supported to change the way they experience how they learn accounting. As noted in Section 1.1 above and discussed in Chapter 2 below, a key insight of the approach to learning conception of human learning is that students will not experience change in personal capabilities unless they first experience high-level relevance structure, high-level conception of learning, intrinsic motivation and deep learning (Trigwell and Prosser, 1991).

In the next section, evidence of widespread experience by accounting students of low-level conception of learning, extrinsic motivation and surface learning will be discussed. The educational psychology literature and the education literature more generally suggests students need to be supported to change these aspects of how they experience learning accounting before interventions designed to support the development of personal capabilities will be effective. 


\subsection{How Accounting Students Approach their Learning}

The approaches to learning research framework ... assumes that an approach to learning is a student's response to a context and that, accordingly, the response may change depending on how the student perceives the context. Since one important aspect of context is the nature of the discipline being studied, this emphasises the importance of research carried out within an accounting education context.

Lucas and Mladenovic (2004: 400)

As noted in Section 1.2 above, the accounting education literature contains many instructional resources and examples of specific interventions in courses. These were often provided with limited empirical or theoretical justification that might ground them in educational scholarship. Approach to learning research in the education literature has the potential to address this deficiency by providing theoretical concepts and research methods. In this section, the extent to which the accounting education literature has adapted these concepts and research methods to the specific context of accounting education will be discussed. It will be noted that approach to learning research in the accounting education literature has often adapted specific aspects of the approach to learning literature in isolation from other aspects. This research also faces a number of challenges common to interdisciplinary research, including the need to have a strong understanding of two distinct academic literatures and an appreciation of how the insights from one discipline can be adapted to the context-specific concerns of another discipline. These challenges will also be discussed.

\section{Limited connections}

The approach to learning research in the educational psychology literature developed quickly in the late 1970s after Marton and Säljö's research in 1976. However, more than 20 years after Marton and Säljö (1976a), Booth et al (1999: 278) said:

... the accounting education literature, with the recent exceptions of two empirical studies (Chan et al, 1989; Gow et al, 1994) and two literature reviews (Lucas, 1996; Beattie et al, 1997) has not 
explored the implications of this mainstream educational [approach to learning] framework for improving the quality of accounting education.

Adding Hand et al (1996), Sharma (1997), Duff (1997), Jones and Hassall (1997) and Hassall et al (1999) would bring Booth et al's list to seven empirical studies, without changing their conclusion that by the end of the 1990s insights from approach to learning research in the educational psycholcigy literature had made little impact on the accounting education literature. At much the same time as demands on accounting education to support the development of personal capabilities were beginning to occur in the mid-1980s, approach to learning research in the educational psychology literature had been developing theoretical concepts to support students to change the ways they experience learning and thus be able to respond to interventions designed to support the development of personal 'capabilities. Yet as discussed in Section 1.2 above, the accounting education literature remained largely disconnected from these theoretical concepts.

\section{Need for integrated interventions}

...it is important to realise that the indicators of a deep approach, isolated in the research, are symptoms of a rather fundamental attitude towards what it takes to learn from texts. Thus, one cannot treat these observations on what characterises a deep approach as pointing to causal factors that can be isolated and manipulated through rather simple means to achieve the desired end ... It is quite easy to induce a surface approach ... however, when attempting to induce a deep approach the difficulties are quite profound.

\section{Marton and Säljö (1997: 53)}

In the past decade, approach to learning research has developed as a relatively small but potentially significant part of the accounting edacation literature. This research seeks to link the theoretical concepts and insights from approach to learning research in the educational psychology literature to accounting education. Approach to learning research in the accounting education literature has tended to 
utilise specific approach to learning concepts and insights in isolation. This has included examining accounting students' conceptions of learning (Byrne and Flood, 2004; Lord and Robertson, 2006); accounting students' approach to learning (Booth et al, 1999; Lucas, 2000; Byrne et al, 2009); approach to learning of accounting graduates in post-tertiary professional accounting education (Flood and Wilson, 2008); comparing accounting students' approach to learning with those of other disciplines (Byrne et al, 2010); the relationship of accounting students' approach to learning and assessment grades (Tan and Choo, 1990; Booth et al, 1999; Byrne et al, 2002; Davidson, 2002; Duff, 2004a; Elias, 2005); the relationship of accounting students' approach to learning and assessed learning journals (Bisman, 2010); the relationship of accounting students' approach to learning and their perceptions of assessment (Watty et al, 2009); the relationship of accounting students' context of learning and learning outcomes (Jackling, 2005); the relationship of accounting students' context of learning and their approach to learning (Lucas, 2001); the relationship of accounting students' gender and motivation to learning approaches (de Lange and Mavondo, 2004); the relationship of accounting students' constructed gender, approach to learning and assessment grades (Paver and Gammie, 2005); the relationship of accounting students' approach to learning and learning outcomes (Ramburuth and Mladenovic, 2004); the learning approaches of Chinese students studying accounting (Cooper, 2004); validating various self-test inventories for accounting students (Duff, 1999; Byrne et al, 2004; Duff, 2004b; Lucas and Meyer, 2004); and developing subject-specific self-test inventories for accounting students (Lucas and Meyer, 2005).

There have been few approach to learning studies that have addressed a central concern of this study: how to support accounting students to change the way they experience their approach to learning from surface to deep as a necessary precondition for accounting students to be able to develop personal capabilities. Five such studies have been identified: Boyce et al (2001); English et al (2004); Hall et al (2004); Ballantine et al (2008); and Fox et al (2010). Boyce et al (2001) was a descriptive study suggesting authentic case studies could support students to adopt a deep approach to their learning. The other four studies were empirical studies which found limited success in supporting accounting students to change the way they experience their approach to learning from 
surface to deep as the result of introducing specific interventions into university accounting courses. Some of these studies also suggested heavy reliance by accounting students on extrinsic motivation was an impediment to experiencing a deep approach to learning in a university accounting course.

There have been various studies in other disciplines on how to support change in the way students experience approach to learning: for example, medical students (Eizenberg, 1988; Reid et al, 2005; Balasooriya, 2009a, 2009b); education students (Gordon and Debus, 2002; Struyven et al, 2006; Gijbels et al, 2008, 2009); business students (Herington and Weaven, 2008); engineering students (Case and Gunstone, 2002); information systems students (Cope and Staehr, 2005); behavioural science students (Wilson and Fowler, 2005); and criminology students (Gijbels and Dochy, 2006). These studies in both accounting and other disciplines have indicated that supporting students to experience a deep approach to learning appears to be difficult and not straightforward; and support comments made by Marton and Säljö (1997: 53) noted above about the 'profound' difficulties that can be expected in supporting students to experience deep learning. Indeed, a recent literature review of various studies across a range of disciplines designed to stimulate deep learning concluded that "[the] mixed findings [from these studies] make clear that influencing students' approaches towards deep learning ... is a complex process" (Baeten et al, 2010: 4).

This study seeks to contribute to approach to learning research in the accounting education literature, and potentially to the education literature more generally, by adapting in an integrated way the theoretical concepts and insights from approach to learning research in the education literature to support accounting students to change the way they experience relevance structure, conception of learning, motivation and approach to learnirg.

\section{Challenge to develop personal capabilities}

The pre-existing learning preferences of accounting students and the effect traditional accounting education has on them helps to explain the continued lack of generic skills [which include communication and interpersonal skills, problem-solving skills, conceptual/analytical and critical skills, visual, oral and aural 
skills, and judgement and synthesis skills] in accounting

graduates.

Boyce et al (200i: 41)

Accounting education faces a number of context-specific challenges to support accounting students to develop personal capabilities. These will now be discussed.

\section{High levels of surface learning}

There is evidence accounting students may be more likely to experience a surface approach to learning than students in arts, education and science (Eley, 1992; Booth et al, 1999; Byrne et al, 2010). There is also evidence business students may be more likely to experience a surface approach than psychology students (Smith and Miller, 2005); and there are also some studies that have not found such differences, such as between business students and sociology and biosciences students (Edmunds and Richardson, 2009). There is also evidence that a significant proportion of accounting students (and accounting practitioners) prefer to experience a surface approach to their learning in accounting (Carland et al, 1994; Sharma, 1998). There is also evidence of widespread experience of surface learning amongst students in many disciplines (Watkins and Hattie, 1981), including nursing students (Snelgrove, 2004), science students (Zeegers, 2001), education students (Biggs, 1987), economics students (Volet, Renshaw and Tietzel, 1994) and medical students (Balasooriya et al, 2009).

Although there is evidence of the widespread experience of surface learning by tertiary students across a range of disciplines, there is evidence accounting students can be expected to experience even higher levels of surface learning than students in other disciplines. As noted by Byrne et al (2009: 159): "Ín light of the high quality learning outcomes desired by higher education and the accounting profession ... the absence of a preference for a deep approach [by accounting students] is particularly worrying." Also, as it may be more challenging to support accounting students to experience change in their approach to learning than students in other disciplines, insights gained from supporting accounting students to experience deep learning may be valuable across the tertiary sector. 


\section{Studying accounting can support surface learning}

There is some evidence that studying accounting can support or encourage students to experience surface learning. There is evidence that accounting students' surface approaches to learning increase and deep approaches to learning decrease in first year at university as a result of studying accounting (Gow et al, 1994). Further, Boyce et al (2001: 43) have said:

A predisposition to view the learning of accounting as consisting of rote memorization, which is confirmed by traditional teaching methods and heavy content-oriented workloads, leads to learning behaviours that are inconsistent with the development of generic skills (Inman et al, 1989: 44; Gow et al, 1994). As accounting students progress into their studies, they are less inclined to use deep processing approaches ... (Brown and Burke, 1987: 204; Gow et al, 1994). This suggests that conventional accounting education actually promotes learning style preferences that are antithetical to the development of generic skills.

There may be a combination of factors in the relationship between accounting students and their learning context in university accounting courses that may be encouraging them to experience surface learning. This would be consistent with longitudinal studies of the approach to learning over a number of years of science students (Zeegers, 2001) and education students (Biggs, 1987), where the results showed that "tertiary students are not encouraged to engage in ... deep learning, as a result of the tertiary experience" (Zeegers, 2001: 130).

\section{Low-level conception of learning}

There is also evidence large numbers of accounting students experience low-level conception of learning in university accounting courses (Sharma, 1997; Byrne and Flood, 2004; Lord and Robertson, 2006). As discussed in Section 1.1 above and Chapter 2 below, experiencing low-level conception of learning has been shown to have a strong relationship with surface learning. Thus experiencing low-level conception of learning by accounting students may be one factor encouraging them to experience surface learning and preventing them from experiencing deep learning in university accounting courses. 


\section{Negative stereotypes of accounting}

There is also evidence a number of accounting students may have negative stereotypes or preconceptions of accounting. These include viewing introductory accounting as dull, boring and lacking in interest; and as a subject to be feared or worried about (Mladenovic, 2000; Lucas, 2001). These negative stereotypes could be thought of as commonsense misconceptions of accounting held by people in the community generally and which accounting students can bring to their study of accounting. Existence of such negative stereotypes amongst accounting students may also be indicative of extrinsic motivation.

\section{Lack of preparation for classes}

There is evidence large numbers of accounting students prepare inadequately for classes, either by not reading at all before classes, or when they do, simply skimming the readings rather than seeking to understand the concepts and ideas in the readings (Phillips and Phillips, 2007). This is also an issue with nonaccounting students; for example, Clump et al (2004) found that undergraduate psychology students completed only $27 \%$ of the assigned readings before class; and Burchfield and Sappington (2000) found first year psychology students read only $24.5 \%$ of readings prior to class. However, lack of preparation for class does appear to be worse for accounting students, for example Phillips and Phillips (2007) found that first year accounting students only read $17 \%$ of the assigned readings before class, with many who did read before class employing a skimming strategy of merely turning pages to reduce anxiety. Large numbers of accounting students not reading before class would constitute a significant barrier to understanding key concepts (McKeachie and Hofer, 2002; Phillips and Phillips, 2007) and to meaningful class participation by students who attend class unprepared (Valde, 1997; Chizmar, 2005). There is also evidence that targeted interventions can support accounting students to read before class, such as the hot seat' set of interventions discussed in Bentley et al (2009).

\section{High levels of extrinsic motivation}

There are assertions in the accounting education literature that accounting students are typically extrinsically (rather than intrinsically) motivated in their studies of accounting (Boyce et al, 2001). The accounting education literature also contains some limited empirical evidence concerning motivation amongst accounting 
students. For example, in a study of US and Irish accounting students, it was found that "neither group has a strong intrinsic interest in learning accounting" (Byrne et al, 2009: 163); and in a study of UK students, it was found that "[a]t the commencement of their course the students had a reasonably positive attitude towards accounting ... however, the overall score fell significantly by the end of their studies ... finding the subject less interesting and the prospect of being employed as an accountant less enjoyable" (Marriott and Marriott, 2003). There is also evidence that one common reason (among others) for students to study accounting are "market-related factors (high initial salary and future earnings, and greater job opportunities)..." (Tan and Laswad, 2009: 249); and that accounting students can be motivated to study accounting "by a mixture of extrinsic and intrinsic goals" (Byrne and Flood, 2005: 120).

\section{Difficulty in intervening in accounting courses to support deep learning}

As referred to above, four empirical studies have been identified in approach to learning research in the accounting education literature that have sought to change the way accounting students experience approach to learning from surface to deep, through certain interventions in the learning context of students (English $e t$ al, 2004; Hall et al, 2004; Ballantine et al, 2008; Fox et al, 2010). All four studies found it to be difficult and challenging. English et al (2004) found the decline in deep learning amongst first year accounting students was reduced by their interventions compared to a control group. This is not a particularly encouraging finding. English et al studied 1,060 students studying a first year accounting course at two Australian universities and used self-test inventories to measure the approach to learning of accounting students. The interventions used were the use in tutorials of interactive reading guides and problem-solving activities involving case studies and also the type of exam questions asked in the course.

Hall et al (2004) reported a "small but significant increase" in the number of first year accounting students experiencing deep learning and a "small but significant decline" in the number experiencing surface learning as a result of their intervention. By 'significant' Hall et al meant statistically significant, that is some degree of correlation or relationship between the approach to learning of students generally in the course and the intervention; the change in approach to 
learning was not particularly meaningful in terms of numbers of students shifting from surface to deep learning. Hall et al measured the approaches to learning of 158 students at a university in Australia at the beginning and end of a first year accounting course using self-test inventories. The interventions used were the use in tutorials of group problem-solving exercises, group presentations and group assignments.

Ballantine et al (2008) reported a "statistically significant increase" in the surface approach and no change in the deep approach to learning of final year accounting and business students as a result of their intervention. Ballantine et al measured the approaches' to learning of 286 accounting and business studies students at the beginning and end of their final undergraduate year at three universities in Ireland using self-test inventories. The interventions used were the use of a case study method within a final year strategic management accounting course within the overall context of traditional course design and delivery (weekly lectures and tutorials with continuous assessment and a final examination).

Fox et al (2010) reported no "statistically significant" change in approach to learning of first year accounting students as the result of their intervention of peer mentoring. Fox et al measured the approach to learning of 112 first year accounting students in the fourth and tenth week of a first year accounting course using self-test inventories.

These studies highlight one of the challenges of using self-test inventories (or questionnaires) in this type of research. For example, in the Hall et al (2004) study there is no way of knowing whether the small change in the reported approach to learning by accounting students in that study was the result of the interventions in the study or was caused by other factors (that is, the study had low internal validity). This is because the approach to learning conception of human learning is focussed on "ways in which people use, experience or understand aspects of the world around them ... and ... there is no intention to explain human behaviour" (Van Rossum and Schenk, 1984: 74). It does not provide a theoretical basis to explain how the intervention used in the Hall et al study may have changed the way some students experienced approach to learning. Hall et al (2004: 503) noted: "Qualitative research, perhaps using in-depth interviews with accounting students, may be needed to determine how changes in the learning environment affect the way students approach their learning." 
It has also been challenging to support students to experience change in their approach to learning in disciplines other than accounting. Although a number of studies in other disciplines used self-test inventories to measure approach to learning and found (like Hall et al, 2004) 'statistically significant' movements from surface to deep learning in response to various interventions in course design and delivery, the actual movements in numbers of students shifting from an experience of surface to deep learning was typically not particularly meaningful. Interventions involving interactive lectures and workshops; a major fieldwork project; student learning groups; and assessment comprising a reflective essay, design and conduct of a peer teaching workshop and an exam have been shown to be "comparatively modest in practical terms" in supporting deep learning for behavioural science students (Wilson and Fowler, 2005: 98). Cooperative group problem-based learning methods; refocusing teaching content and delivery to a personalised dimension; reflective journals; and exposition of personal theories of learning across a number of courses were shown to have a statistically significant (but not particularly meaningful in terms of number of students) effect on supporting deep learning by education students (Gordon and Debus, 2002). The use of more student-focused teaching styles within tutorial groups had "no noticeable change" for business students (Herington and Weaven, 2008). The use of some problem based learning interventions and changes to assessment design had little impact on the approach to learning of medical students (Reid et al, 2005). Formative feedback increased the surface approach to learning of first year criminology students (Gijbels and Dochy, 2006); use of authentic assessment "did not change their approach to learning towards a more deep approach" of education students (Gijbels et al, 2008); and two authentic group assignments with formative written peer-feedback resulted in no significant change in the experience of deep learning by education students (Gijbels et al, 2009).

There is evidence it is a challenging issue to support students to experience change in their approach to learning in many academic disciplines, and that supporting a surface approach is relatively easy but supporting a deep approach is much more challenging (Marton and Säljö, 1997). Indeed, some have questioned whether it is possible to support students to experience a deep approach to learning if it is not "already there" (Haggis, 2003: 94); and whether learning 
approaches are "constitutionally based and relatively fixed... or are ... flexible and open to change" (Lucas and Mladenovic, 2004: 400).

The context-specific issues for approach to learning research in accounting education appear to include the widespread experience by accounting students of surface learning, low-level conception of learning and extrinsic motivation. The educational psychology literature suggests these ways of experiencing how they learn accounting in a university accounting course are likely to represent a significant barrier for accounting students to develop personal capabilities. This appears to be a key issue that needs to be addressed before interventions to support accounting students to develop personal capabilities can be successful. In the next section, an overview of the remaining chapters describes how this study has investigated an integrated set of interventions designed to support students to experience change in key aspects of how they learn in a university course.

\subsection{Overview}

This section sets out a summary of the remaining chapters. A literature review of key relevant aspects of the educational psychology literature and education literature more generally is provided in Chapter 2. This is followed by an outline in Chapter 3 of the research method adopted in this study, including reliance on a phenomenographic approach to research. This is then followed by the core of the data analysis of the study in Chapters 4 to 8 . These chapters set out the key findings. The broader implications of these key findings (and directions for future research) are reviewed and discussed in Chapter 9.

This research studies a third-year university accounting course, with about $45 \%$ of students expecting to complete their university studies on completion of the course. The students had extensive, recent previous experience of learning accounting in a university accounting course. In Chapter 4 , evidence about the ways of experiencing relevance structure and conception of learning by students in their previous accounting courses is examined. Evidence is also considered about the effectiveness of interventions used in this study to support accounting students to experience in different ways these aspects of how they learn accounting. Categories of variation in the ways accounting students experience relevance structure in a university accounting course are also identified. 
An important part of this study is to examine how to support students in a university accounting course to experience intrinsic motivation. As discussed in Section 1.3 above, there are assertions in the accounting education literature (and some limited empirical evidence) that accounting students are typically extrinsically motivated in their studies of accounting. The widespread experience of extrinsic motivation would represent a significant challenge to supporting accounting students to change the ways they experience learning in a university accounting course and thus be able to develop personal capabilities. Within the theoretical model set out in Figure 1.2 above, motivation is a particularly challenging aspect of learning to research due to the difficulty of studying motivation in students in isolated learning tasks such as reading a text. There is a need to study students' ways of experiencing motivation in learning tasks in the more complex context of university courses. The findings from this aspect of the study have the potential to contribute not only to the accounting education literature, but also more widely to the education literature.

In Chapters 5 and 6, evidence about the effectiveness of interventions used in this study to support students to experience intrinsic motivation in the learning tasks in a university accounting course is considered. The interventions used to change the way students experience this aspect of how they learn accounting were designed to directly support them to experience intrinsic motivation, and indirectly support them through changes in the ways they experience relevance structure, conception of learning and approach to learning. In Chapter 5, evidence is discussed about the effectiveness of the five stages of the Assignment (a central part of the intervention of Assessment in this study) to support accounting students to experience intrinsic motivation. In Chapter 6 , the effectiveness of the five session preparation assignments (SPAs) (the remaining part of Assessment) as well as the interventions of Teamwork, Teacher-Student Relationship and Instruction are considered.

The focus of Chapter 7 is on the experience of deep learning by students in a university accounting course. The experience of deep learning is a key objective to support students to change the way they experience how they learn accounting. This is because an experience of deep learning supports the development of desired personal capabilities, such as critical thinking, which in turn are considered to be strongly related to success as an accounting professional, in 
business and more broadly in life. In Chapter 7, the initial adjustments students made to experience deep learning in a university accounting course are considered. Given their extensive previous experience of surface learning in university accounting courses, these adjustments were considerable. Aspects of the experience of deep learning by students and how they constructed knowledge in a university accounting course are then examined. Evidence about how the intervention of Assessment (involving individualised, authentic assessments with regular formative feedback) related directly to the experience of deep learning by students is also considered.

In Chapter 8 , evidence is examined about the significant challenges faced by accounting students as they began to experience deep learning, particularly given their limited (or lack of) prior experience of deep learning in the context of a university accounting course. The ways accounting students experience confidence (or self-efficacy) in their own learning capacities and abilities to make judgements in response to the significant cognitive challenges of experiencing deep learning in a university accounting course is explored. The findings about the internal relation between the experience by accounting students of relevance structure and deep learning are also considered in Chapter 8. In addition, evidence about the importance of the internal relation between the experience by students of intrinsic motivation and deep learning in a university accounting course is examined. After experiencing struggles, challenges, difficulties and adjustments, there was evidence students found they enjoyed the experience of deep learning which reinforced and supported their developing intrinsic motivation in the learning tasks.

In Chapter 9, the broader implications of the findings of this study are reviewed and discussed in the light of the relevant educational psychology literature, education literature and accounting education literature. Directions for future research are also explored. 


\section{Conclusion}

The development by accounting students of personal capabilities, such as critical thinking, creative thinking, problem-solving, communication and teamwork, is seen as valuable in professional accounting and other business roles they may fulfil in the future and in their lives in general. A key challenge for accounting education is to support students to change the way they experience how they learn accounting as a necessary precondition for them to be able to develop personal capabilities. This challenge is the focus of this study.

In this chapter, the research question was outlined as well as why this question is worthwhile and important to explore. The motivation for this study is to provide evidence of whether, and if so in what ways, students can be supported to change the way they experience learning accounting in a university accounting course. The theoretical model used to adapt concepts from the educational psychology literature and the education literature more generally to the context of an accounting course was outlined. This theoretical model focuses on the experience by students of relevance structure, conception of learning, motivation and approach to learning. The model suggests these are key, inter-related, cognitive preconditions accounting students need to experience before they are able to make the substantial cognitive effort involved to develop personal capabilities.

Evidence of widespread experience by accounting students of low-level conception of learning, extrinsic motivation and surface learning in the approach to learning research in the accounting education literature was then discussed. It was also discussed that there is little evidence the large number of specific, 'decontextualised' interventions proposed in the accounting education literature have been effective to meet the challenge of supporting accounting students to develop personal capabilities. Such a result is consistent with a key insight of the approach to learning conception of human learning that students will not experience change in personal capabilities unless they first change the way they experience how they learn. The focus of this study is to examine how to support students to change the way they experience key aspects of how they learn accounting in a university accounting course as a necessary precondition for them 
to be able to respond to subsequent interventions designed to support the development of personal capabilities.

In the next chapter, a review of the key theoretical concepts of human learning from the educational psychology literature and the education literature more generally will be provided. Some key issues involved with interdisciplinary approach to learning research in the accounting education literature will also be discussed. 


\section{$-$}





\title{
2. LITERATURE REVIEW: INTERDISCIPLINARY RESEARCH
}

\author{
Although the knowledge-transmission paradigm and the \\ behaviorist view of learning have been replaced by ... \\ constructivist approaches in research on learning, educational \\ practices in general have been much slower to change.
}

Tynjälä (1999: 425)

In this chapter, a review of key theoretical approach to learning concepts of human learning from the educational psychology literature and the education literature more generally is provided. The challenge of interdisciplinary research that seeks to adapt these concepts to the practice of accounting education is discussed. The approach to learning conceptualisation of human learning sees learning as taking place not simply within an individual but in relationship to a learning context (Trigwell and Prosser, 1991; Mattick et al, 2004). A student's response to their learning context, that is their approach to learning, will lead to qualitatively different and distinct types of learning outcomes (Marton and Säljö, 1976a). Further, the ways students experience relevance structure, conception of learning and motivation will significantly interact with and influence their experience of approach to learning.

Evidence will also be examined from the educational psychology literature about how to support accounting students to experience a high-level conception of learning and intrinsic motivation which will help them to experience deep learning in the context of a university accounting course. Also, some key issues involved with interdisciplinary approach to learning research in the accounting education literature will be discussed, in particular the use of self-test inventories (or questionnaires) to measure the approach to learning experienced by accounting students in university accounting courses. Narratives from students who participated in the study are included and these will typically be reported as quotes from "Accounting Student" with an indicator as to the number of the student in Appendix 3. 


\subsection{Key Theoretical Concepts}

A deep approach is one in which students have an intention to understand the material being studied, and in so doing attempt, for example, to relate the various parts of the material being studied to one another and to construct a whole, to relate that material to what they already know and to the real world. On the other hand, a surface approach is one in which the intention is to reproduce the material. Rote learning of parts of the material and memorising templates for the solution of problems are just two of the strategies used by students adopting this approach.

Trigwell and Prosser (1991: 266)

The approach to learning conceptualisation of human learning sees learning as taking place not simply within an individual but in relationship to a learning context (Trigwell and Prosser, 1991; Mattick et al, 2004). Two qualitatively distinct and different ways students can relate to their learning context are deep and surface approaches to learning. A key finding from approach to learning research is that a student's response to their learning context, that is their approach to learning, will lead to qualitatively different and distinct types of learning outcomes (Martin and Svensson, 1979). Further, the ways students experience relevance structure, conception of learning and motivation will significantly interact with and influence their experience of approach to learning (Van Rossum and Schenk, 1984; Dart et al, 2000). These key theoretical concepts of approach to learning, relevance structure, conception of learning and motivation are discussed in this section.

\section{Theoretical concepts of human learning}

The educational psychology literature includes a number of ways of conceptualising human learning, including the approach to learning viewpoint which conceives learning as occurring not simply within a person but in relationship to a learning context. This conception of learning focuses on how students approach their learning in specific learning contexts. Approach to learning research varies significantly to other educational psychology research traditions in that there is no attempt to control the conditions of learning: "the 
underlying theory [of approach to learning research] demands an acceptance of the essential uniqueness of each student's attempts at learning under uncontrolled conditions." (Entwistle, 1976: 2-3).

Approach to learning research conceives learning to take place within the learning context. This relational perspective sees a student's approach to learning as being either surface or deep (Marton and Säljö, 1976a). A student's approach to learning is not a personal characteristic of a student but rather a way of describing how a student interacts with a particular learning task (Marton, 1988; Biggs, 1993). Thus a student's approach to learning will be affected by personal factors which they bring to a learning task and by their perception of the particular learning context in which they find themselves (Trigwell et al, 2000). The approach to learning which students experience in response to their learning context will lead to qualitatively different and distinct types of learning outcomes (Trigwell and Prosser, 1991; Mattick et al, 2004)".

\section{Approach to learning}

The finding by Marton and Säljö (1976a) that students' approaches to learning can be categorised as either surface or deep has been strongly supported by subsequent research findings in the educational psychology literature and has laid the foundation for a significant research program. It is noted that Entwistle and Ramsden (1983) and Biggs (1993) also identified an achieving/strategic approach to learning in addition to surface and deep approaches. An achieving/strategic approach essentially involves students selecting between a surface and deep approach to learning, and allocating time and intellectual resources, according to the demands of the assessment structure. A primary motivation is competing with others and satisfying high achievement needs (Entwistle, 1988: 60, 69). Also, a situation in which students adopt neither a surface nor a deep approach has been described as non-engagement (Eizenberg, 1988). In this study the position has been taken that neither the achieving/strategic approach nor the non-engagement approach represents a qualitatively distinct approach to learning separate from a surface or deep approach to learning (Kember et al, 1999; Biggs et al, 2001; Zeegers, 2002).

A deep approach to learning typically focuses on understanding and developing personal meaning, and in particular integrating new material into pre- 
existing knowledge and thus changing the way a person sees aspects of reality. Some of the characteristic features of a student adopting a deep approach to their learning are set out in Table 2.1 below. In contrast, a surface approach to learning focuses on completing task requirements, relies on memory and seeks to reproduce clear-cut, black-and-white facts from experts with little or no personal understanding. Some of the characteristic features of a student adopting a surface approach to their learning are set out in Table 2.2 below.

Table 2.1 Characteristic Features of a Student Adopting a Deep Approach to their Learning

Interested in the academic task and derives enjoyment from carrying it out.

Searches for the meaning inherent in the task (e.g., if a prose passage, the intention of the author).

Personalizes the task, making it meaningful to his or her own experience and to the real world.

Integrates aspects or parts of [the] task into a whole (e.g., relates evidence to a conclusion), and sees relationships between this whole and previous knowledge.

Tries to theorize about the task, and forms hypothesis.

Source: Biggs and Rihn (1984: 281)

Table 2.2 Characteristic Features of a Student Adopting a Surface Approach to their Learning

Sees the task as a demand to be met, a necessary imposition if he or she is to reach some other goal (e.g., a qualification).

Sees the aspects of parts of the task as discrete and unrelated either to each other or to other tasks.

Worried about the time the task is taking.

Avoids personal or other meanings the task may have.

Relies on memorisation, attempting to reproduce the surface aspects of the task (e.g., the words used, a diagram, or a mnemonic).

Source: Biggs and Rihn (1984: 281)

One irony of the surface approach to learning with its reliance on memorisation and reproduction is that it leads to rapid forgetting of the material memorised as it 
is difficult for students to remember and recall (other than in the short-term) material they do not understand and in which they are not interested (Marton and Säljö, 1976a, 1976b; Biggs, 1987). Further, there is clear evidence students who adopt a surface approach to their learning will not develop personal capabilities (Trigwell and Prosser, 1991; Mattick et al, 2004).

\section{Relevance structure}

...what's the point of University? Do I remember these facts that I've just learned off by heart to reproduce? And then just forgotten, how is that going to help me in the future?

\section{Accounting student $(66)$}

A learning situation, such as a university accounting course, has a relevance structure for students who experience that learning situation. A relevance structure is a person's experience of what a learning situation demands, or calls for, or its direction, or its aim for them; that is, "...his [or her] reasons for doing it, and on what he [or she] aims to get out of it." (Laurillard, 1979: 403). A person's relevance structure of a learning situation is "the way the learner experiences the [learning] situation as a whole ... that renders the perspective on its component parts." (Marton and Booth, 1997: 143).

As discussed in Section 2.2 below, approach to learning research conceives human learning as being a change between qualitatively distinct and different ways of experiencing a phenomenon (Prosser and Millar, 1989). Categories of variation seek to capture these differences, with some categories being more complete or complex than others. A deep approach to learning is a more complex and complete way of experiencing learning than a surface approach to learning (Biggs and Rihn, 1984). However, we do not experience a phenomenon in isolation. We experience a phenomenon as part of a situation in which we find ourselves. It is a person's experience of the demands of a situation that causes the person to see various aspects of a situation to be more or less relevant to them (Marton and Booth, 1997). Thus the way a student experiences a learning situation as a whole (such as a university accounting course as part of a business degree) is important. This relevance structure of a situation - the person's experience of what the situation demands of them - is one of the driving forces of 
learning (Lucas, 2000). This is one important reason why it is valuable to study learning in the context of each discipline:

Learning should be studied in the context in which it occurs, rather than in the laboratory, and one way of beginning this difficult task is ... to make use of students' awareness of what they are doing and why."

\section{Laurillard (1979: 408)}

The relevance structure of a university accounting course is the experience by an accounting student of the aim or direction of participating in a university accounting course (Marton and Booth, 1997). It is what they experience as being potentially in it for them of completing the various learning tasks in a course. This is different to the formal learning objectives for a course set by an instructor and goes 'beyond learners' endorsement of instructional objectives, as they reflect their perceptions of the situation as a whole, and express personal intentions..." (Volet and Chalmers, 1992: 20). It is the perspective of an accounting student in which different learning tasks in a course appear to be more or less relevant to them. The relevance structure is thus how a student experiences a university accounting course as a whole that gives perspective and relevance to the learning tasks within a course (Lucas, 2000).

It is the experience of this perspective which can influence the experience of conception of learning, motivation and approach to learning by accounting students in a university accounting course. In other words, there is an internal relation between the experience of relevance structure and the experience of each of conception of learning, motivation and approach to learning in any learning situation (Martin and Svensson, 1979; Marton and Booth, 1997). There appears to be limited previous approach to learning research in the accounting education literature into the categories of variation of relevance structure of accounting students in a university accounting course; for example, Lucas (2000: 502) states: "Studies are now required on specific aspects of the experiences of [accounting] students, for example, on the nature of student ... perceptions of relevance ... we need to continue the process of their "mapping'." One important aspect of the findings in this study involves the identification of categories of variation of 
relevance structure experienced by accounting students. These findings are discussed in Chapter 4 below.

\section{Conception of learning}

Conception of learning is what students think or conceive learning to be. This differs to their approach to learning, which is what students actually do or experience in their learning. Säljö (1979) identified five qualitatively distinct and different conceptions of learning, with learning being seen as:

A. A quantitative increase in knowledge.

B. Memorising and reproducing.

C. The acquisition of facts, methods, etc to apply.

D. The abstraction of meaning - understanding.

E. An interpretative process aimed at understanding reality - seeing something in a different way.

Marton et al (1993) identified a sixth conception of learning:

F. Changing as a person.

A description of each of these six conceptions of learning is set out in Table 2.3 below.

Table 2.3 Conceptions of Learning

\begin{tabular}{|l|l|}
\hline $\begin{array}{l}\text { Conception A: } \\
\text { increase in }\end{array}$ & $\begin{array}{l}\text { A principal feature of this conception is its } \\
\text { knowledge }\end{array}$ \\
vagueness. Also, the nature of learning is taken for \\
granted and is something which is external to the \\
learner (Säljö, 1979). There is a strong quantitative \\
flavour to this conception, as students view learning \\
as consisting predominately of the acquisition of \\
knowledge in the form of discrete pieces of \\
information. There is very little recognition of a \\
need to relate elements of the knowledge acquired \\
(Pillay and Boulton-Lewis, 2000).
\end{tabular}




\begin{tabular}{|c|c|}
\hline $\begin{array}{l}\text { Conception } B \text { : } \\
\text { Learning as } \\
\text { memorising }\end{array}$ & $\begin{array}{l}\text { This conception views learning as the acquisition } \\
\text { and memorization of knowledge with the intention } \\
\text { of reproducing it for assessment purposes. It } \\
\text { incorporates learning by repetition and, while it is } \\
\text { still quantitative and impersonal in nature, it is } \\
\text { distinguished from the previous conception in that } \\
\text { the acquisition of knowledge has gained a } \\
\text { functional aspect (Van Rossumet al, 1985). }\end{array}$ \\
\hline $\begin{array}{l}\text { Conception } C \text { : } \\
\text { Learning as the } \\
\text { acquisition of } \\
\text { facts, } \\
\text { procedures, etc., } \\
\text { which can be } \\
\text { retained and/or } \\
\text { used in practice }\end{array}$ & $\begin{array}{l}\text { The predominant feature of this conception is the } \\
\text { emphasis placed on applying knowledge acquired. } \\
\text { The application of knowledge encompasses } \\
\text { retrieving and adapting what has been learnt and } \\
\text { using it in a wide variety of circumstances. Unlike } \\
\text { Conception B, application is not confined to } \\
\text { reproduction for assessment purposes. }\end{array}$ \\
\hline $\begin{array}{l}\text { Conception } D \text { : } \\
\text { Learning as the } \\
\text { abstraction of } \\
\text { meaning }\end{array}$ & $\begin{array}{l}\text { Learners holding this conception take a more } \\
\text { holistic view of learning. They conceive learning as } \\
\text { centring on the abstraction of meaning or } \\
\text { understanding. Furthermore, they internalize } \\
\text { learning and view it as a personal experience. } \\
\text { Students actively engage in the learning process and } \\
\text { they see the importance of integrating newly- } \\
\text { acquired knowledge with their prior learning and } \\
\text { personal experiences (Marton and Booth, 1997: } 37 \text { ). } \\
\text { However, learning in this case is limited to a study } \\
\text { situation (Marton et al, 1993). }\end{array}$ \\
\hline
\end{tabular}




\begin{tabular}{|c|c|}
\hline $\begin{array}{l}\text { Conception } E \text { : } \\
\text { Learning as an } \\
\text { interpretative } \\
\text { process aimed at } \\
\text { the } \\
\text { understanding of } \\
\text { reality }\end{array}$ & $\begin{array}{l}\text { This conception extends the previous one, in that } \\
\text { abstracting meaning helps students to interpret the } \\
\text { world around them and it changes their perspectives } \\
\text { (Marton et al, 1993). In addition, this conception } \\
\text { embraces an emotional aspect and the learning is } \\
\text { located in the real world (Van Rossum et al, 1985). } \\
\text { Students expressing this conception see learning as } \\
\text { an individualised, self-determined process (Van } \\
\text { Rossum et al, 1985). }\end{array}$ \\
\hline $\begin{array}{l}\text { Conception } F \text { : } \\
\text { Learning as } \\
\text { changing as a } \\
\text { person }\end{array}$ & $\begin{array}{l}\text { This conception adds an existential aspect to learning } \\
\text { (Marton et al, 1993). By developing new insights } \\
\text { into phenomena and seeing the world differently, the } \\
\text { learner changes as a person. Learning is not bound } \\
\text { by time or content, it is a voyage of personal } \\
\text { discovery. }\end{array}$ \\
\hline
\end{tabular}

Source: Byrne and Flood (2004: 27-28)

Each of these six ways of experiencing conception of learning are cumulative, with each conception including those at a lower level, for example a student conceiving learning as conception $\mathrm{C}$ (the acquisition of facts, methods, etc to apply) would also include conceptions $A$ and $B$ (a quantitative increase in knowledge and memorising) as part of their conception of what learning is; and a student conceiving learning as conception $\mathrm{F}$ (changing as a person) would also include conceptions $\mathrm{A}-\mathrm{E}$ in their conception of learning.

Students' conceptions of learning are related to the approach to learning they adopt (Van Rossum and Schenk, 1984; Prosser and Millar, 1989; Trigwell and Prosser, 1991, 1997; Dart, 1998; Dart et al, 2000). Säljö's conceptions A-C (where learning is seen as reproductive, impersonal and as something external to themselves; and involves being able to reproduce clear-cut, black-and-white facts from experts) are strongly related to a surface approach to learning. Säljö's conceptions D-E and Marton et al's sixth conception F (where learning is seen as constructive, personal and being more engaged with and reflective about their 
learning; and involves searching for understanding and personal meaning while they organise the content into a coherent and meaningful whole) are related to a deep approach to learning. Most importantly, there is strong evidence that students who conceive learning as Säljö's conceptions A-C will not engage in a deep approach to learning. In other words, it is a necessary, but not sufficient, condition that students are able to conceive learning as one of Säljö's conceptions D-E or Marton et al's sixth conception F for them to be able to experience a deep approach to their learning (Van Rossum and Schenk, 1984; Byrne and Flood, 2004; Edmunds and Richardson, 2009).

There has, however, been limited research on how to support students to change their conception of learning, although it has been observed that "the learning environment might be an important factor influencing students' learning conceptions" (Tynjälä, 1997: 278; also see Vermunt and van Rijswijk, 1988). There is evidence that it can be difficult to support students to change their conception of learning (Boulton-Lewis et al, 2004; Vermunt and Vermetten, 2004). However, there is also evidence that students can be supported to change their conception of learning as a result of explicit instruction (Tynjälä, 1997), particularly where instruction on conception of learning is "in a context where it is integrated with the content matter that students are primarily involved in studying" (Case and Gunstone, 2002: 461; for example, with first year physics students in Linder and Marshall, 1997a, 1997b). This issue is discussed further in Section 2.2 below.

\section{Motivation}

Intrinsic motivation for learning is a state where the relevance for the learner of the content of the learning material is the main reasons for learning ... Extrinsic motivation for learning is a state where reasons for the learning effort have nothing to do with the content of the learning material. A good learning performance serves merely as a means for achieving some desired end results.

Fransson, 1977: 245-6 
The motivation experienced by an accounting student in relation to the learning tasks of a university accounting course can be categorised as extrinsic or intrinsic (Ryan and Deci, 2000b). These are two qualitatively distinct and different ways of experiencing motivation. Extrinsic motivation occurs when the accounting student is doing the learning task solely because of some other benefit external and separable to the learning task, for example to help them gain a job or to gain skills to help them to do a job (such as being an accountant). Extrinsic motivation is a less complete and less complex form of motivation compared to intrinsic motivation. As noted by Moneta and Spada (2009: 664):

Intrinsic motivation is the tendency to engage in tasks because one finds them interesting, challenging, and enjoyable, whereas extrinsic motivation is the tendency to engage in tasks because of task-unrelated factors such as anticipation of rewards or punishments and dictates from superiors...

Intrinsic motivation occurs when a student experiences a learning task in a university accounting course in such a way that this experience itself makes them want to do more of that learning task. In this way, doing the learning task becomes an 'end in itself' for the student, something that is inherently interesting or in some way satisfying for them (Amabile, 1993). As noted by Ryan and Deci (2000b: 56), "...intrinsic motivation exists in the relation between individuals and activities. People are intrinsically motivated for some activities and not others, and not everyone is intrinsically motivated for any particular task ... intrinsic motivation exists in the nexus between a person and a task." Also, "intrinsic motivation will occur only for activities that hold intrinsic interest for an individual - those that have the appeal of novelty, challenge, or aesthetic value for that individual." (Ryan and Deci, 2000b: 58-59).

Current theories on motivation tend to be grounded in the idea that people "initiate and persist at behaviours to the extent that they believe the behaviours will lead to desired outcomes or goals" (Deci and Ryan, 2000: 227). One of these theories, social determination theory (SDT), suggests "that social contextual conditions that support one's feelings of competence, autonomy, and relatedness are the basis for one maintaining intrinsic motivation" (Ryan and Deci, 2000b: 65). 
Intrinsic motivation does not preclude an awareness of and experience of extrinsic motivation, but can include and add a qualitatively distinct dimension to extrinsic motivation (Pintrich and Garcia, 1991; Byrne and Flood, 2005). For a student to experience intrinsic motivation, their focus of awareness is on their personal interest in the experience of the learning tasks. The internal relation between motivation and approach to learning is highly important as the experience of deep learning is strongly related to experiencing intrinsic motivation (Entwistle et al, 1974; Fransson, 1977; Entwistle and Wilson, 1977; Marton and Säljö, 1984). It has been suggested that intrinsic motivation can be supported by learning tasks that are interesting and novel and that give students the opportunity to develop personal capabilities and be self-determining (Stipek, 2002).

In this section, key theoretical concepts used in this study have been discussed. These key concepts are approach to learning, relevance structure, conception of learning and motivation and they are shown in Figure 1.1 in Section 1.1 (in Chapter 1) above. The approach to learning conceptualisation of human learning sees learning as taking place not simply within an individual but in relationship to a learning context. The response of accounting students to their learning context, that is their approach to learning, will lead to qualitatively distinct and different types of learning outcomes. The ways accounting students experience relevance structure, conception of learning and motivation will significantly interact with and influence their experience of approach to learning. In the next section, evidence will be examined and adapted from the educational psychology literature about how to support accounting students to experience a high-level conception of learning and intrinsic motivation in the context of a university accounting course.

\subsection{Conception of Learning and Motivation}

...people who embark on learning activities have different ways of thinking about, of understanding, what it is they are doing. Some conceptualize learning as acquiring knowledge, as memorizing for later reproduction, as being able to use what one knows. Others view learning as coming to an understanding of things, taking perspectives, getting a new way of viewing the world, and as ultimately changing as a person. The former think 
about learning as if it were limited totally to the tasks of learning imposed by a study situation, whereas the latter look beyond the tasks in themselves to the world that the tasks open for them.

Marton and Booth (1997: 38)

For students to experience deep learning in a university accounting course they need to see that learning accounting is about understanding and developing personal meaning (that is, experience a high-level conception of learning) and they also need to be intrinsically motivated in the learning tasks (Dart et al, 2000; Fransson, 1977; Entwistle and Wilson, 1977). This section discusses how accounting students can be supported to experience a more complete and complex way of understanding what learning is (high-level conception of learning) and of why they are learning (intrinsic motivation) in the context of a university accounting course, based on evidence from the approach to learning research in the educational psychology literature.

\section{Learning to learn}

...attempts at integrating students' learning of content with 'learning to learn' are related to a ... view [of] learning ... [where] ... learning is seen to be intimately inter related with the content to be learnt ... Such an approach sees context and the content to be learnt as significant variables impacting on that learning.

Case and Gunstone (2002: 462)

...focusing on the object of learning as well as and in conjunction with the way of going about it is found to produce desired [learning] approaches and [learning] outcomes, whereas separating the what from the how of learning and attempting to train the how without reference to the what is doomed to failure.

Marton and Booth (1997: 171)

It is vital accounting students experience a high-level conception of learning if they are to experience a deep approach to their learning of accounting. As discussed in Section 2.1 above, they need to see their learning in a university 
accounting course in terms of conceptions D or E of Säljö (1979) or conception F of Marton et al (1993). If they instead see learning in terms of conceptions A-C of Säljő (1979) there is strong evidence they will not experience deep learning (Van Rossum and Schenk, 1984). The way accounting students understand, conceptualise or view what learning is in the actual setting of a university accounting course will strongly influence the way they approach their learning in that context.

This raises the issue of how to support students to develop a conception of learning that will support them to experience deep learning in a university accounting course. This involves supporting accounting students to learn about learning: to learn about the 'how' of learning (rather than the content being learnt, or the 'what' of learning), to reflect on their understanding of learning, of their experience of learning, of what learning means to them in the particular context of a university accounting course. Recognising that there is no one universal method to achieve this in all specific situations and contexts, there are some concepts and insights from the educational psychology literature that can assist in identifying the type of interventions more likely to be successful in supporting students to experience a high-level conception of learning in the context of studying accounting.

There have been a series of studies in the educational psychology literature where specific interventions were made to the design of learning tasks to support students to focus on the 'how' of their learning (and thus implicitly on their conception of learning that they brought to the learning task) with a view to encouraging students to experience deep learning. These interventions included inserting questions in a text given to students to read that were designed to support deep learning and comparing these students with a control group that did not have the questions inserted (Marton, 1976); inserting questions in a text designed to support deep learning for one group of students and inserting different questions in a text designed to support surface learning for another group of students (Säljö, 1975); and giving different instructions on how to read a text, one set of instructions designed to support surface learning and the other deep learning (Marton et al, 1994) (see discussion of these studies in Marton and Booth, 1997: 169-170). 
In the Marton (1976) and Marton et al (1994) studies, the effects were in the opposite direction to that intended. The interventions in the learning tasks designed to support a high-level conception of learning and deep approach to learning actually had the opposite effect. In the Säljö (1975) study the intervention had no overall effect, with the intervention designed to support a high-level conception of learning and deep learning leading to a wider variation of outcomes compared to the intervention designed to support a low-level conception of learning and surface learning. These studies have demonstrated that interventions in the design of a learning task (such as, for example, the insertion of questions within the text designed to support a high-level conception of learning and deep learning) will be ineffective if the student's conception of learning is not explicitly challenged or discussed. This has also been demonstrated by a number of documented interventions in university courses designed to support deep learning which have not explicitly challenged students' conception of learning (but only indirectly and implicitly through various changes in the learning tasks) and which found the interventions were ineffective in supporting deep learning (for example, Balasooriya et al, 2009a, 2009b).

These studies suggest that direct instruction designed to support accounting students to experience a high-level conception of learning is likely to be more successful than interventions that only address students' conception of learning implicitly. There is also evidence that direct instruction on high-level conceptions of learning (the 'how' of learning) needs to be part of an integrated learning context of, for example, a university accounting course (that is, be an integrated part of the content being learnt or the 'what' of learning) and should not be taught as generic study skills separated from the specific learning context of a university course (Ramsden et al, 1986). However, Biggs and Moore (1993) reported a generic study skills course that was effective in supporting change in conception of learning, although there were some specific factors concerning participants in that course that may have led to this result.

The need to integrate instruction on conception of learning with the content being learnt was demonstrated in a study by Martin and Ramsden (1987) which compared two programs designed to improve the learning skills of students. One program used material that was not connected to the learning content of the course. The other program used material from the content of the course to support 
students to reflect on their conception of learning. Students in the latter program experienced higher-level conceptions of learning than students in the former program. There have also been studies in specific disciplines (for example, physics) where explicit teaching about the 'how' of learning as an integrated part of the 'what' of learning have been effective in supporting students to experience higher-level conceptions of learning (Linder and Marshall, 1997a).

In the education literature, it is common for many interventions designed to support students to experience change in the way they experience approach to learning (for example, with accounting students in English et al, 2004; Hall et al, 2004; Ballantine et al, 2008; and Fox et al, 2010) to not include explicit instruction on conception of learning as an integrated part of the course redesigns. Also see, for example, studies involving medical students (Eizenberg, 1988; Reid, et al, 2005; Balasooriya et al, 2009a, 2009b); education students (Gordon and Debus, 2002; Struyven et al, 2006; Gijbels et al, 2008, 2009); business students (Herington and Weaven, 2008); engineering students (Case and Gunstone, 2002); information systems students (Cope and Staehr, 2005); behavioural science students (Wilson and Fowler, 2005); and criminology students (Gijbels and Dochy, 2006) which did not include explicit instruction on conception of learning as an integrated part of the course redesigns. All these studies have indicated that supporting students to experience deep learning appears to be difficult and not straightforward.

Based on evidence from the educational psychology literature, the lack of interventions to support students to experience high-level conception of learning in these studies is a significant omission and likely to be one of the reasons students continued to experience surface learning. This would particularly be the case for accounting students, with evidence of their widespread experience of low-level conception of learning (Sharma, 1997; Byrne and Flood, 2004; Lord and Robertson, 2006).

A recent literature review of various studies across a range of disciplines designed to stimulate deep learning concluded that "[the] mixed findings [from these studies] make clear that influencing students' approaches towards deep learning ... is a complex process" (Baeten et al, 2010: 4). This supports comments made by Marton and Säljö (1997: 53) referred to in Section 1.3 in Chapter 1 above about the 'profound' difficulties that can be expected to be faced to support 
students to experience deep learning. It is critical to carefully adapt findings from the educational psychology literature (such as the strong finding that the experience of high-level conception of learning is a necessary, but not sufficient, condition for students to experience deep learning) into discipline-specific education literature such as the accounting education literature, and into teaching practice. This underlines the value of a simple, evidence-based model (as outlined in Figure 1.2, Section 1.1 in Chapter 1 above) to support the careful application of these insights into the design and delivery of university accounting courses.

There is evidence that supporting students to develop a high-level conception of learning by simply adjusting the learning tasks or by teaching them generic study skills in stand-alone courses is likely to be ineffective. Rather, the key is to explicitly support students to experience a high-level conception of learning through direct instruction as part of an integrated course design. In this study, the intervention of Instruction was designed to support accounting students to experience a high-level conception of learning through explicit instruction about conception of learning in a way that was integrated into the course content. The intervention of Instruction used in this study is described in Section 3.1 (in Chapter 3) below.

\section{Learning tasks and motivation}

For accounting students to experience deep learning it is also vital they experience intrinsic motivation in the specific learning tasks in a university accounting course. As noted by Heikkilä and Lonka (2006: 99-100): "Currently the idea of motivation as a personality trait has been largely abandoned and researchers acknowledge that motivation may vary in terms of context and subject area." Thus learning tasks in a university course need to be designed in such a way that they are intrinsically motivating to each student in the course.

This appears to be a rather daunting task. However, the education literature provides some guidance. For example, individualised authentic learning tasks with regular formative feedback are highly likely to support students to experience intrinsic motivation in these learning tasks (Entwistle and Ramsden, 1983; Ramsden, 2003). 'Individualised' tasks are tasks that are different for each person in a course. 'Authentic' tasks are tasks that involve the real world and are not simplified or abstract examples disconnected from the real world. Regular 
formative feedback means a learning task is broken into a number of stages with students receiving feedback at the end of each stage aimed at assisting them to complete the next stage of the learning task.

The design of the assessed learning tasks in this study played a central role to support accounting students to experience intrinsic motivation. There is evidence most accounting students are motivated by the grading system (Boyce et al, 2001). This is, of course, a form of extrinsic motivation. Extrinsic motivation is where a learning task is completed by a person because it will help them to gain another objective, such as a university degree or a good job at the end of their studies. Grades are generally seen by accounting students as assisting them to achieve these sorts of objectives.

So how can assessment design with its emphasis on extrinsic motivation support accounting students to develop intrinsic motivation in specific learning tasks? There is some evidence use of external rewards can reduce the experience of intrinsic motivation (Lepper, et al, 1973). However, this is not always the case. For example, Finkelstien (2009: 657) has noted that "performance contingent rewards, those reserved for a task done well, were not the threat to intrinsic motivation that task-contingent rewards were (Deci and Ryan, 1985)." Also, feedback as part of assessment can support intrinsic motivation (Deci, 1971). The extrinsic motivation of accounting students can support them to complete assessed learning tasks for the purposes of gaining a grade. If the assessed learning tasks are designed to support students to experience intrinsic motivation and deep learning, completion of these learning tasks may help them to experience intrinsic motivation because they will each experience the learning tasks to be personally interesting and relevant: "A person might originally get exposed to an activity because of an external regulation (e.g. a reward), and (if the reward is not perceived as too controlling) such exposure might allow the person to experience the activity's intrinsically interesting properties, resulting in an orientation shift [to intrinsic motivation]." (Ryan and Deci, 2000b: 63).

In this study, the assessed learning tasks were an Assignment (in five stages) and five session preparation assignments (SPAs). These assessed learning tasks are included as Appendix 1 and are described in Section 1.1 (in Chapter 1) above and in Section 3.1 (in Chapter 3) below. They were designed to support students to experience increasing intrinsic motivation and deep learning as they completed 
each learning task. This included scaffolding and feedback to support students' feelings of competence, individualised assessments with no clear 'correct' answer to support students' feelings of autonomy and authentic assessments to support students' feelings of relatedness (Ryan and Deci, 2000b).

This section has discussed insights from the education literature about how accounting students can be supported to experience high-level conception of learning and intrinsic motivation in a university accounting course. In the next section, some interdisciplinary research issues involved with approach to learning research in the accounting education literature will be discussed; in particular, the use of self-test inventories (or questionnaires) to measure the approach to learning experienced by accounting students in university accounting courses.

\subsection{Interdisciplinary Research}

Bringing together the interdisciplinary components and getting them working truly in collaboration is a key challenge.

Ruth Duncan, professor of cell biology

Approach to learning research in the accounting education literature is interdisciplinary. It adapts concepts and research methods from approach to learning research in the educational psychology literature and the education literature more generally to accounting education. Despite some concerns in the educational psychology literature about the use of self-test inventories, they are widely used in the accounting education literature (and in other discipline-specific education literatures) to measure the approach to learning experienced by students. This issue is discussed in this section.

\section{Meaning from internal relations}

Approach to learning research in the educational psychology literature has identified general categories of human learning processes by studying students' experiences of their learning in the context of specific learning tasks, such as reading a text, writing an essay or solving a problem. This research has involved studying variables (such as the use of memorisation by students) to indicate general categories of human learning processes such as the experience of deep or surface learning. It has long been recognised that the variables studied in 
approach to learning research actually influence the nature (or definition) of each other and thus these variables cannot be defined or categorised separately from each other, as noted by Van Rossum and Schenk (1984: 82):

During the analysis of these answers [to the open questions] it became clearer that the investigated variables actually cannot be categorised separately. This favours in our opinion the future treatment of this relationship [between learning approach and learning outcome] as an internal relationship (Marton and Svensson, 1979), with the extra benefit of less loss of information ... it can be concluded that further use of multiple choice questions in this kind of research is to be dissuaded.

Martin and Svensson (1979) suggest that if we see learning in its context as the starting point of our research, we will start with an assumption of a relation with that context as we attempt to find the meaning of the terms and the relations between them:

In research using contextualized descriptions, the main results are the meaning of related categories and the character of the relations existing between them $\ldots$ one proceeds from the assumption of a relation in an attempt to find the meaning of the terms and the relation between them ... when relations are interpreted as internal ... they "modify" their terms. If item A has an internal relation $P$ then anything which had not had $P$ would necessarily have been different from it.

If we see various aspects of student learning, such as relevance structure, conception of learning, motivation and approach to learning, as interdependent aspects of one single learning activity, and that each gains its significance or meaning from the internal relations between them and from its context, then Marton and Svensson (1979: 480) point out that we cannot view these aspects independently of their context:

The meaning of data has to be found in their context, since characteristics which seem very similar when isolated often in fact have very different meanings. 
Marton and Svensson (1979: 481) also make a distinction between research explanations that can describe student learning in a general way and research seeking understanding by examining unique contextual descriptions and internal relations:

There seems to be a difference between research aiming at explanation and research aiming at understanding in the concern for generalization. In stressing explanation the intention is to describe student learning in a general way, viewing the individual cases as instances to be used in developing and testing general external relations. In stressing understanding, by contrast, there is often an emphasis on what is specific and unique to the individual cases.

Marton and Svensson (1979: 482) argue generalisations in approach to learning research are not fruitful because of contextual differences:

"If the internal relations and the terms related do not have the same meaning across different cases, there is no basis for generalisation."

However, Marton and Svensson (1979: 482) also suggest generalisations can be made based on similarities in context:

Explicit descriptions of internal relations delimited in specific contexts, when combined with generalizations on the basis of comparisons between contexts, could perhaps integrate the aims of understanding and explanation in research into student learning.

\section{Self-test inventories}

When generic, self-test inventories (or questionnaires) are used in approach to learning research, the internal relations between variables are necessarily not considered. For this reason, self-test inventories can have difficulty identifying variables as their meaning depends on their internal relations with other variables. Marton and Svensson (1979: 478) note: "each alternative answer to the items in the questionnaires is given a general meaning (the same for all individuals having the 'same' answer) irrespective of other data from the same individual." For 
example, the use of memorisation could be used to aid simple regurgitation of material in assessments or to support personal understanding and thus could indicate the experience of either surface or deep learning. The nature of the variable of memorisation would be defined by its internal relations with relevance structure, conception of learning, motivation, approach to learning and other factors specific to the particular context being studied (such as the type of assessments being used).

The use of generic, self-test inventories to arrive at generalisations is also inconsistent with the context-dependent nature of a student's approach to learning (Lucas and Meyer, 2005). Since the variables in approach to learning research cannot be interpreted independently of their context, this makes it difficult to generalise the nature of the variables and the relationships between them and to meaningfully interpret the results of self-test inventories. As discussed in Section 2.1 above, a student's approach to learning will depend on the context and is not a personal characteristic of the student, but rather a way of describing how a student experiences a specific learning task (Marton and Säljö, 1976a); or as Van Rossum and Schenk (1984: 74) have said, "learning must be described in terms of its content." Attempts to overcome this issue have included developing disciplinespecific self-test inventories (for example, Lucas and Meyer, 2005). Such attempts can only partially off-set this issue as discipline-specific self-test inventories still "ask [students] what they usually do while learning and studying. In other words, the inventories are measuring general dispositions [regardless of the context], not actual processes [in specific contexts]" (Heikkilä and Lonka, 2006: 104).

As an approach to research, phenomenography does not seek explanations but rather understanding of the ways students experience specific learning contexts (Marton, 1993; Duff, 2007a). It treats the relations between variables as internal relations and generalisations can be made only on the basis of similarities in context (Martin and Svensson, 1979). For this reason, phenomenography is central to approach to learning research in the educational psychology literature. Yet approach to learning research in the accounting education literature is dominated by self-test inventories with only limited use of phenomenography, as noted by Duff (2007a): 
A literature search of accounting education reveals five investigations that employ qualitative or phenomenographic methods to identify students' approaches to learning [and] ... 17 published quantitative [that is, self-test inventories] studies of accounting students' approaches to learning.

In defence of the use of self-test inventories in approach to learning research in the accounting education literature, Lucas and Meyer (2005) suggest the results of self-test inventories can be more generalisable, have greater external validity and thus provide greater insights into populations of students than phenomenographic research; and that phenomenographic research can supply more depth, greater internal validity and thus provide insights into, for example, the questions to include in self-test inventories. They suggest that when used together, self-test inventories (particularly when tailored to specific discipline contexts) and phenomenographic research can provide both external and internal validity to research findings. Lucas and Meyer (2005: 182) have suggested:

[Self-test] [i]nventory research provides quantitative results and may confirm (or disconfirm) variation across a population sample. It may also, in providing further data about relationships between different aspects of learning engagement, raise questions that may only be addressed by a reiterative retreat into further phenomenographic research. Phenomenographic and [self-test] inventory research can thus be regarded as complementary in what amounts to a powerful methodological synergy.

The use of self-test inventories permits the study of the ways much larger numbers of students experience aspects of how they learn accounting in a university accounting course than phenomenography. Hundreds or thousands of accounting students can complete self-test inventories and their results analysed. By contrast, the intensive nature of phenomenography necessarily limits this research to the study of the ways much fewer numbers of accounting students experience aspects of how they learn. However, if generalisations can only be made on the basis of similarity of context, then the number or quantity of students researched is not particularly relevant. Research results based on a small or large number of 
accounting students would be similarly generalisable depending on similarity of the context.

\section{Categories of variation}

A key focus of approach to learning research in the educational psychology literature is to identify categories of variation in the ways students experience aspects of their learning, such as relevance structure, conception of learning, motivation and approach to learning. Given this research conceives human learning as occurring not simply within a person but in relationship to a learning context, exploring these categories of variation within the context of students studying accounting in a university accounting course is valuable (Lucas and Mladenovic, 2004). As noted by Franssen (1977) in Section 2.2 above, aspects such as experiencing intrinsic motivation and its internal relations with other aspects of learning may only be able to be studied effectively in more complex situations (such as a university accounting course) rather than in the less complex contexts of specific learning tasks (such as reading a text) as often used in the educational psychology literature. Similar considerations may also apply for example to studying students' ways of experiencing relevance structure in the context of university courses (Lucas, 2000).

It is always theoretically possible to find additional categories of variation in the ways students experience aspects of how they learn accounting in a university accounting course by looking at the experience of an additional student (Byrne and Flood, 2004). This would be the case until the experience of every accounting student in every university accounting course in the world is studied. However, it is not necessary to have a large number of students to identify categories of variation. These categories of variation can be discovered from the study of a relatively small number of students. For example, Marton and Säljö (1976a) identified deep and surface approaches to learning from a few studies each involving about 30 to 40 students.

A benefit of researching large numbers of students in a university accounting course is the increased possibility of finding a rare or unusual way of experiencing a university accounting course. This would identify an additional new way of experiencing or category of variation of an aspect of learning accounting in a university accounting course. However, if we conceive human learning as 
occurring within a learning context, a focus of our research will be on how specific interventions into that learning context influence the way students experience aspects of how they learn accounting in a university accounting course (Duff and McKinstry, 2007). This can be studied effectively with relatively small numbers of students.

The theoretical difficulties of self-test inventories in identifying variables independently of the context-specific relations between them and in making meaningful generalisations are substantial (Martin and Svensson, 1979). These difficulties remain, despite the development of many self-test inventories and their wide use in approach to learning research (Lonka, et al 2004); and the various defences that have been made for their use (for example, Biggs, 1993). Integrating insights from different disciplines and truly getting them to work in collaboration is a key challenge; to meet this challenge, requires staying firmly rooted in the concepts and insights from approach to learning research in the educational psychology literature, as these ideas are adapted to the context of accounting education. It appears concerns in approach to learning research in the educational psychology literature about the value and relevance of self-test inventories in approach to learning research may not yet be fully appreciated in the accounting education literature (Duff, 2007a). These concerns would suggest approach to learning research in accounting education should place less emphasis on self-test inventories and more on phenomenographic research.

\section{Conclusion}

In this chapter, key theoretical concepts of approach to learning, relevance structure, conception of learning and motivation were discussed. The way students experience relevance structure, conception of learning and motivation significantly interact with and influence their experience of approach to learning. Evidence was also examined from the educational psychology literature about how to support accounting students to experience a high-level conception of learning and intrinsic motivation in the context of a university accounting course. In addition, issues with the use of self-test inventories and phenomenography to measure the ways students experience their learning in university accounting courses were discussed. 
In the next chapter, key aspects of the research method employed to answer the research question set out in Section 1.1 (in Chapter 1) above will be outlined. The research method involved introducing into the design and delivery of a thirdyear undergraduate accounting course an integrated set of interventions grounded firmly in education theory. Key aspects of the phenomenographic approach used in this research and the data collected to measure students' experience of how they learn accounting in a university accounting course will also be discussed. 



\section{RESEARCH METHOD}

...small changes in a learning environment do not necessarily lead to changes in students' approaches [to learning] ... it is difficult to incite a deep approach in students ... One has to be wary of how one implements new measures, how different innovations affect each other and how students perceive these measures. Investigating complex learning in new learning environments in higher education remains a challenge for future research.

Gijbels et al (2009: 509-10)

In this chapter, the research method used in this study is described. A framework of integrated interventions grounded firmly in education theory has been applied to a third-year undergraduate accounting course. The second-order perspective taken in this study is outlined, which has involved seeking to describe the ways accounting students experience aspects of how they learn accounting in the context of a university accounting course. Some key aspects of the phenomenographic approach used in this study and the data collected to measure students' experience of how they learn accounting is discussed. An Assignment in five stages and five SPAs, supplemented with a focus group and surveys of students, were designed to identify and capture the ways accounting students experience relevance structure, conception of learning, motivation and approach to learning.

\subsection{Research Method and Interventions}

This section sets out the key aspects of the research method employed to answer the research question set out in Section 1.1 (in Chapter 1) above. The research method involved introducing into the design and delivery of a third-year undergraduate accounting course an integrated set of interventions grounded firmly in education theory. Using phenomenography as the research approach, the effect of these interventions on the way accounting students experience relevance structure, conception of learning, motivation and approach to learning in a university accounting course was examined. The author in this study 
combined the roles of researcher and teacher, and also graded some of the assessments (along with two tutors) and designed the interventions.

\section{Participants}

This study examined the learning of 81 students in a third-year undergraduate accounting course in financial statement analysis in New Zealand in July-October 2008: 51\% had English as a second language, 52\% were female (and 48\% male), $95 \%$ were majoring in accounting in a business degree and $45 \%$ expected to complete their university studies upon completion of this course (with a further $19 \%$ unsure whether or not they would complete their studies upon completion of this course). A number of students did not expect to complete their university studies at the end of the course because they were in the second year of their studies (even though the course was a third-year course), or they planned to complete an honours year, or they were studying an additional degree to their business degree. The student identifier and also the ethnicity and gender for each student are included in Appendix 3.

The undergraduate accounting course was situated in a university with about 21,000 students and a business school of about 4,500 students. At this university about 1,500 students studied first year accounting (with a pass rate of about twothirds), with about 500 students progressing to second and third year accounting courses.

\section{Pilot study}

A pilot study was conducted in the previous year on the same third-year undergraduate accounting course. The pilot study was designed to test some of the interventions and the instruments being used to measure the ways accounting students experienced aspects of how they learn accounting. The findings of the pilot study were encouraging and have been reported as an unpublished research project for a Post Graduate Certificate in Higher Education Learning and Teaching (Turner, 2008a). The interventions of Assessment and Teacher-Student Relationship used in this study were not significantly altered as a result of the pilot study, other than some minor changes and improvements. The primary learning from the pilot study was the need for significant changes to be made to the intervention of Teamwork to support students to experience deep learning and 
to improve the quality of their judgements. These changes included the use of study groups, study group workshops, informal Class Lunches, online journals and wikis. Another key learning was the need to make some changes to the intervention of Instruction. These changes included attendance at the first lecture of a panel of five top-performing students from the previous year's course, to support students to experience high-level relevance structure, and the use of reading materials that taught conception of learning as an integrated part of the content of the course.

\section{Key interventions}

The key interventions used in the research design were based on the theoretical model outlined in Figure 1.2 in Section 1.1 (in Chapter 1) above. This theoretical model is designed to support the adaptation of education theory to the development of interventions in the design and delivery of university accounting courses. The key interventions used to support accounting students to change their experience of their own learning were:

- Individualised, authentic Assessment involving regular formative feedback.

- Cooperative learning interventions, including the use of study groups, to support Teamwork.

- Teacher-Student Relationship involving an informal, student-centred and facilitative teaching style where 'right' answers were not imposed but curiosity, questioning and exploration were encouraged.

- Instruction involving:

- Direct instruction on conception of learning and the critical importance of experiencing high-level conceptions of learning to be able to successfully negotiate the assessments in the course.

- Use of reading materials that had a deep approach to learning embedded in them.

- Use of authentic examples (including the ongoing application of concepts being taught throughout the course to an exemplar company) in both the classroom teaching and the reading materials. 


\section{Assessment}

The Assessment design involved structured, sequenced assignments in which students received regular formative feedback, involving:

- five reflective Session Preparation Assignments (SPAs) (25\% of the total assessment for the course)

- one large Assignment (broken into five stages) $(75 \%$ of the total assessment for the course).

The SPAs involved students reading before classes and recording their personal reflections on the key ideas and concepts in the readings. They were a structured form of learning journal:

Learning journals represent 'self-directed methods that facilitate reflection' (Lockyer et al, 2004). The journal is a narrative, personal disquisition in which students can record and relay their thoughts, feelings, attitudes, comments and reflections on the content of a course and their learning journey in that course ... where the focus is on ... how the learner learns and thinks...

Bisman (2010: 2)

There were five SPAs (each worth $5 \%$ of the total grade) with students receiving formative feedback after completing each SPA. It was considered important that the SPAs formed part of the assessment and that students received regular formative feedback:

...lack of assessment or one-shot assessment of a learning journal is unlikely to deliver a number of the benefits of journaling which are commonly suggested in the literature ... assessment ... based ... on the learning journal and students receiv[ing] feedback on each submission of the journal ... [provide] a gateway for students to shift from surface ... learn[ing] ... and move towards deep [learning]...

Bisman (2010: 12)

The SPAs were designed to be 'authentic' in the sense that "learning experiences are perceived as authentic when they engage students' lived experience, and students can find meaningful connections with their current views, understandings 
and experiences and 'newer' views, understandings and experiences they meet as they learn in and about a 'real-world' or authentic community of practice." (Stein et al, 2004: 240). They were also 'individualised' in the sense that every student brought their own perspectives and backgrounds to their personal engagement with the readings.

The Assignment involved each student analysing a different listed New Zealand or Australian company (that is, were 'individualised' or different for each student); and adapting the concepts and ideas taught in the course to a real company (that is, were 'authentic' in the sense that they were "designed to give students 'real-world' experiences" (Stein et al, 2004: 240)). For each stage of the Assignment, there were increasingly no 'right' or 'wrong' answers, as the analysis and valuation of companies increasingly depended on uncertain information, such as students' own forecasts of an uncertain future. Thus there were only solutions that were more or less convincing or compelling than others. SPAs and Assignments also included questions to support students to reflect on their learning and to discuss aspects of teamwork they had engaged in.

Besides a grade, students were also given formative feedback on each of their five SPAs and on completion of each of the five stages of the Assignment. This feedback involved:

- Individual feedback to each student, provided by the teacher and two tutors.

- General feedback to all students.

- Exemplars of other students' work, as examples of good practice on different elements of the assessed learning tasks (Nicol and MacfarlaneDick, 2006; Sadler, 1989).

Higgins et al (2002: 62) have noted that "the meaning and impact of assessment feedback for students is an area that still remains relatively underresearched, particularly from the student's perspective." However, there is evidence students place a high value on feedback (Quinton and Smallbone, 2010: 127): "Students are interested in and value feedback and there is evidence in the literature that it can prompt reflection and deeper learning..."; and that "...the value that students place on feedback echoes the study by Higgins et al (2002), which portrays students as 'conscientious consumers' seeking feedback that will help them to 
engage with their subject in ways that will facilitate high-quality learning outcomes." (Hounsell et al, 2008: 65).

However, Hounsell et al (2008: 56) have noted that “...although feedback seemed to be widely valued by students, their experiences of getting feedback had been uneven (Hounsell, 2003)." Quinton and Smallbone (2010: 127) have noted this is supported by "[e]vidence from institutional audit [in the UK that] suggests ... [feedback] is not always done well in higher education (Quality Assurance Agency for Higher Education (QAA), 2006)" and that "[i]n more that $40 \%$ of business schools inspected by the QAA, feedback was of variable quality, lacked focus, was too brief and provided too late to be of value (QAA, 2001)." "Good quality' formative feedback has the potential to have a key role in supporting student learning:

Good feedback practice 'facilitates the development of selfassessment (reflection) in learning' (Nicol and Macfarlane-Dick, 2006: 207) and indicates things to build on (Hyland, 2000). Feedback is the most powerful single factor that enhances achievement and increases the probability that learning will happen (Hattie and Jaeger, 1998), though in order to achieve this, good feedback practice is essential (Juwah et al, 2004) ... Good quality feedback must be accurate, timely, comprehensive, and appropriate but also accessible to the learner, have catalytic and coaching value, and inspire confidence and hope (Gibbs and Simpson, 2004; Sadler, 1998; Weaver, 2006).

Quinton and Smallbone (2010: 127-128)

Nicol and Macfarlane-Dick (2006) suggested a model and seven principles of good feedback practice that were used in this study to support the provision of 'good quality' formative feedback to students. These seven principles are:

1. Helps clarify what good performance is: exemplars, as well as written documents describing assessment criteria and standards that defined different levels of achievement were provided to students;

2. Facilitates the development of self-assessment (reflection) in learning: supported through the frequency of regular formative feedback provided to students; 


\section{Delivers high quality information to students about their learning:}

supported through written feedback, individual and general, that was timely - that is, was close to the act of learning production - so it could be used in the next steps of the assessed learning tasks, focused not just on strengths and weaknesses but also on offering corrective advice, that it directed students to higher order learning goals, and involved some praise alongside constructive criticism;

4. Encourages teacher and peer dialogue around learning: A few students gave feedback on their feedback back to their marker (by email). The key areas in which dialogue about learning were encouraged in the course were the use of one-minute papers (Angelo and Cross, 1993), Critical Incident Questionnaires (CIQs) (see Section 3.2 below) and the use of 'FSA Happy Hours' and an online discussion board (see under the sub-heading 'Teamwork' below);

5. Encourages positive motivational beliefs and self-esteem: Assessment in the course was designed to have many low-stakes assessments, with five SPAs - each worth 5\% - and five stages of the Assignment - each worth $10 \%, 15 \%, 15 \%, 15 \%$ and $20 \%$ - and with formative feedback provided at each stage to support further progress and achievement. Along with learning tasks that were novel and interesting, this was designed to support students to experience intrinsic motivation;

6. Provides opportunities to close the gap between current and desired performance: (Nicol and Macfarlane-Dick (2006: 213) noted that "...feedback should support ...students to recognise the next steps in learning and how to take them" and this can be achieved with the assessment task "broken down into components each associated with its own feedback." In this study, this was achieved by breaking down the main Assignment into five component parts and providing formative feedback at each stage, where the feedback supported students to complete the next stage. This was combined with five SPAs each involving formative feedback, which supported students to complete readings that supported them with the next stages of their Assignment;

7. Provides information to teachers that can be used to help shape the teaching: as noted above, in this study one-minute papers (Angelo and 
Cross, 1993), Critical Incident Questionnaires (CIQs) (see Section 3.2 below), 'FSA Happy Hours' and an online discussion board (see under the sub-heading 'Teamwork' below) were used. Responses of students were also shared with other students. Along with frequent assessments tasks (almost every week in the course) this data about students' progress was reviewed and reflected on by the teacher to help support student learning in the course.

The time involved in marking and providing formative feedback in the course was between 2 and 2.5 hours per student and involved the teacher and two tutors. This involved a total of about 50-70 hours (on average about 5 hours each week for the 12-week course) for each teacher/tutor. The SPAs and Assignments are included in Appendix 1.

\section{Teamwork}

The characteristics of cooperative learning are positive interdependence, individual accountability, heterogeneous teams, social skills and group monitoring (Cottell and Millis, 1993). These characteristics distinguish cooperative learning from other forms of collaborative learning, such as those that use group assessed learning tasks (Kagan, 1989; Johnson et al, 1984, Johnson and Johnson, 1989).

Positive interdependence is achieved by "structuring the task such that group members are dependent on each other and have a vested interest in working together to successfully complete the ... task." (Ballantine and McCourt, 2007: 164). In this study, the Assignment was designed in such a way that the quality of the judgements required of students at each stage of the Assignment would be greatly improved if students worked cooperatively with others, drawing on a wider range of previous knowledge and prior experience than if they attempted to do the work alone. Also, both the SPAs and each stage of the Assignment required students to discuss the outcomes of their discussions with other students and the insights they gained from these interactions.

Individual accountability was supported through each student receiving an individual grade for each of their SPAs and for each stage of the Assignment, ensuring each student was held accountable for their own work. Also, the SPAs and Assignment were individualised. The SPAs require students to connect what they were learning with their prior knowledge and previous experience, which 
was necessarily different for each student. The Assignment involved each student analysing a different firm. The individualised nature of the SPAs and Assignments allowed students to be able to freely discuss their assessed learning tasks with other students without fear of being accused of 'cheating' or 'plagiarism'.

Heterogeneous teams were established, with study groups of 3-5 students each with a mix of domestic and international students. These study groups were formed in Week 3 of the course and continued throughout the course. Students were also supported to interact with members of other study groups through the use of online journals, wikis, a discussion board and study group workshops.

Social skills were supported through the use of study group workshops and 'FSA Happy Hours'. Group monitoring involves students receiving feedback not just from the teacher, but from each other. This was supported through the sharing with students of exemplars of other students' work, as well as the sharing of other forms of student feedback, such as students' responses from the CIQs.

A range of cooperative learning techniques were employed to support students to engage in Teamwork. The interventions used in this study included:

- Direct instruction in lectures that engaging in Teamwork would be essential to make the judgements necessary to complete the assessments in the course, particularly in the third, fourth and fifth stages of the Assignment. This instruction was provided both by the teacher and by a panel of five top-performing students from the course in the previous year who attended the first lecture in the course.

- An informal discussion in the second hour of the first lecture (with soft drinks and snacks) to assist students to meet each other and informally talk with students from the previous year's course. This informal discussion included an ice-breaking exercise and was held in a common area immediately outside the lecture theatre.

- Students were allocated by the teacher to study groups of 3-5 students. These groups were heterogeneous groups in relation to domestic and international students. Each student also had defined, purposeful roles within their study group. Students sat in their study groups in lectures for Weeks $3-12$ of the course. 
- Two weeks of study group workshops were held. Each workshop involved four study groups. The first week of study group workshops involved ice-breaking and team building exercises. These were held in Week 3 of the course. The second week of study group workshops were held in Week 7 and were designed to support students to discuss and communicate aspects of their experience of teamwork in each study group. These were particularly designed to support students to discuss with other members of their study group any difficulties or challenges they were experiencing with teamwork in their study group.

- 25 'FSA Happy Hours' were held throughout the course (FSA stood for 'Financial Statement Analysis', the name of the course). These were voluntary, informal, small group mentoring sessions which provided a vehicle for students to discuss with each other and with the teacher issues they were experiencing in the course, thoughts they were having and ideas they wanted to discuss, clarify and understand further. These sessions were open to all students and were not organised around study groups. The discussions were unstructured, although some sessions earlier in the course had a topic to help focus discussions. The 'FSA Happy Hours' were held in a waterfront coffee shop near the university and also in an informal communal area within the university.

- Two informal Class Lunches, held in an informal communal area within the university, were opportunities for relaxed, unstructured conversations between students and with the teacher.

- Online journals were each set up for groups of four study groups to share excerpts from their draft SPAs to facilitate discussion and reflection on the pre-readings before classes. The online journals were monitored by the teacher.

- Wikis (collaborative spaces in the learning management system designed for multiple people to collaborate by adding and editing content) were set up for each study group to facilitate sharing of details about each of the firms the students were analysing and to encourage discussion about specific challenges and difficulties each student was experiencing in their analysis of their firm. Each study group was able to open up its wiki to 
other study groups and a few study groups did this, with one study group in particular acting as a hub for a number of study groups to share aspects of their assignments. The wikis were monitored by the teacher.

- A discussion board was set up to facilitate online discussion amongst all students in the course. This was widely used, with a total of 557 posts under 11 forums, with 53 students ( $65 \%$ of students in the course) making on average 10.5 posts each. Also, the learning management system recorded considerable observation of the discussion board by almost every student in the course. Further details on the use of the discussion board are included as Appendix 2.

- Exemplars of students' work on SPAs and Assignments were provided through the learning management system for each SPA and for each stage of the Assignment as part of the regular formative feedback to students throughout the course.

- Various cooperative learning techniques were used in lectures, particularly small group discussions by students within their study groups in lectures.

- In the assessed learning tasks (SPAs and Assignment) students were required to answer questions about the outcomes of discussions with other students and the insights of other students.

The SPAs and the Assignment required students to develop their own understanding and personal meaning about aspects of the content of the course. Each successive stage of the Assignment also required students to make increasingly difficult, complex judgements about the analysis of their own firm. As each student had a different firm they could not 'copy' the work of other students and could freely share their work with others without fear of being accused of plagiarism or 'cheating'. Students needed to understand the course material themselves to adapt it to the particular circumstances of their firm and to form judgements about their firm. Indeed, the better their experience of Teamwork the more they were able to draw on the prior knowledge and previous experience of other people in the course in addition to their own and thus improve the quality of their judgements. In these ways, the social aspect of learning was strongly emphasised, both by the provision of various structures to support 
cooperative learning and by the assessment structure which rewarded students who engaged in Teamwork.

\section{Teacher-student relationship}

The key aspect of the intervention of Teacher-Student Relationship used in this study was a focus on supporting conceptual change by students rather than on information transmission. This was supported by an informal, student-centred and facilitative teaching style where 'right' answers were not imposed but curiosity, questioning and exploration were encouraged (Ramsden, 2003; Fink, 2003). This was in contrast to an 'information-transmission' or 'teacher-focused' approach to the teacher-student relationship. The distinction between student-centred (or 'student-focused') and 'teacher-focused' teaching has been described as:

In educational literature, approaches to teaching are commonly defined on the basis of the distinction between student-focused and teacher-focused teaching, which are respectively associated with the intention of conceptual change or information transmission, as described by Prosser and Trigwell (1999). Teachers with an 'information transmission/teacher-focused (IF/TF)' approach to teaching help students to acquire knowledge by transmission. These teachers do not assume that their students need to be active for the teaching/learning process to be successful. Teachers with a 'conceptual change/studentfocused (CC/SF)' approach to teaching, on the other hand, help students to change their world views and their conceptions of the phenomena they are studying. Students are seen as active knowledge constructors and this activity of students is considered to be a necessary part of the learning process. Conceptual change/student-focused teachers do not consider themselves as transmitters of new worldviews or conceptions (Prosser and Trigwell 1999).

Struyven et al (2010: 44)

The Teacher-Student Relationship used in this study was grounded in constructivist theories of learning (Vygotsky, 1997; Oxford, 1997). 
Constructivist, active teaching methods were used to "challenge students to (1) learn by discovery, in groups or individually, by means of (2) authentic assignments, being (3) supported by the help of a coaching teacher ... [with a] teacher ... present to help students out with questions or problems and [to] safeguard the learning process of the students." (Struyven et al, 2010: 44). The informal, student-centred and facilitative teaching style used in this study is "...believed to enhance the type of student learning which is desirable to occur: that is, learning which is active, deep, transitive and aims for understanding and conceptual change..." (Struyven et al, 2010: 44).

The Teacher-Student Relationship used in this study included direct instruction through lectures. This was done in a way consistent with a focus on student-learning and on supporting conceptual change. As the students had completed the pre-readings before each lecture by completing their SPAs, lectures could be used to support students to reflect on and deepen their understanding about key concepts rather than be focused on simply transmitting facts and concepts:

Although it is generally assumed that constructivist teaching practices promoting deep approaches to learning, such as student-activating teaching methods, are ... examples of, and associated (more or better) with conceptual change/studentfocused practices than direct instruction through lectures (De Corte, 1996; Prosser and Trigwell, 1999), these assumptions are not supported by empirical evidence. In fact, is it not possible for 'traditional' teachers to be as much oriented towards conceptual changes with their students by adopting direct instruction and teacher/learner interactions as 'alternative' teachers adopting more activating teaching methods, involving particularly learner/learner interactions?

Struyven et al (2010: 59)

Aspects of the lectures designed to support conceptual change by students included: 
- The teacher communicating to students the responses of students to the SPAs and critical incident questionnaires (CIQs) for that part of the course. A description of the CIQs is provided in Section 3.2 below.

- The asking of questions by the teacher, which students discussed in their study groups and then the responses of the study groups were discussed in the wider lecture.

- Some lectures started with a request by the teacher for each study group to provide one question they wanted answered in the lecture. The teacher collected the questions and then structured the lecture around answering each specific question. In some of the lectures, the two tutors (two top-performing students from the previous year's course) participated as co-teachers and joined the teacher in answering questions.

- The use of 25 'FSA Happy Hours' as informal mentoring sessions (and also the two Class Lunches) facilitated an egalitarian, informal relationship between the teacher and students. Also, the part of the course materials written by the teacher were written in an informal, personal style which further facilitated an egalitarian, informal relationship between the teacher and students.

\section{Instruction}

At the beginning of the course, students were given direct Instruction on different conceptions of learning and of the need to experience high-level conceptions of learning in the course to be able to successfully negotiate the assessments. This included:

- General feedback on their responses to a pre-course survey (the pre-course survey questions are included in Appendix 6).

- Attendance at the first lecture of a panel of five top-performing students from the previous year's course. This panel discussed with students, without the lecturer being present, issues about how to succeed in the course. This included issues such as the conception of learning required to be successful in the course and also support for students to build a relevance structure for the course. It was considered these top-performing students from the previous year's course would have more credibility with 
students than the teacher, particularly at the beginning of the course before the teacher had had the opportunity to establish their own credibility with students.

- Clear instruction in the early lectures of the course on six categories of conception of learning and on other aspects of learning to learn.

The intervention of Instruction also included use of reading materials that had a deep approach to learning embedded in them (Nijhuis et al, 2005) and the use of authentic examples (including the ongoing application of concepts being taught throughout the course to an exemplar company) in both the classroom teaching and the reading materials (Herrington and Kervin, 2007). The materials included an unpublished textbook, Financial Statement Analysis: To Know What Adds Value (Turner, 2008b), and other reading materials designed to be supportive of deep learning by students. These reading materials were integrated into the assessed learning tasks (including the spreadsheets) used to support the Assessment. The other reading materials included a range of academic and professional articles and book chapters, with some providing a range of views and opinions on different aspects of the content of the course. Each reading was designed to support the reader to make their own assessments of the material being covered, rather than to simply reproduce clear-cut, black-and-white facts from 'experts'. This allowed students to consider their response to some of the 'shades of grey' that exist in the 'real world'. For the readings, students were instructed to "Read this quickly, skimming and also jumping over parts that may be of less interest to you". These instructions were designed to support students to not seek to 'read every word' necessarily of all the readings, with a view to remembering each 'fact' for later reproduction (which would be surface learning), but rather to spend time reflecting on the material of most interest to them with a view to developing their own understanding and personal meaning (which would be deep learning) (Fink, 2003).

This section has set out background information on the research method. The next section discusses key aspects of the phenomenographic approach used in this study and the data collected to measure students' experience of how they learn accounting in a university accounting course. 


\subsection{Measures of Students' Perceptions}

...I think it's been quite good because when we read ... we actually have to understand and think hard, and critique and apply it. But it's also been kind of painful for the same reasons, so I mean it actually takes a bit of work to read something and understand it, and think hard and apply it...

Accounting student (57)

This study takes a second-order perspective, seeking to describe the ways accounting students perceive or experience aspects of how they learn accounting in a university accounting course. This includes, for example, their experience of reading before classes. This section describes key aspects of the use of phenomenography in this study, including issues about generalisability of the findings. This gives a context to the description of the approach to data collection and analysis used in this study to measure the ways students experience how they learn accounting. The five SPAs and five stages of the Assignment, supplemented by a focus group and surveys of students, were designed to identify and capture the ways accounting students experience relevance structure, conception of learning, motivation and approach to learning.

The meaning ascribed to the word 'evidence' used in this study, is grounded in the phenomenographic approach that has been adopted. This study takes a second-order perspective, seeking to identify students' experience of how they learn. The key measures of students' experience of how they learn were five SPAs and five stages of the Assignment, supplemented by a focus group and various surveys from students. A total of 3,360 quotes were coded to a series of themes, some of which were pre-determined and others were identified during the analysis and included as additional themes. N-Vivo software was used to support the data coding and analysis.

\section{Phenomenography}

This study has adopted a phenomenographic approach. Phenomenography is an approach to research that is particularly effective for handling research questions relevant to student learning in an educational context where the most fundamental aspect of learning is considered to be the way students experience phenomenon. 
The second-order perspective taken by phenomenographic research, the distinction between phenomenographic research and phenomenology and the value of phenomenography as a research approach to address the research question of this particular study will now be discussed.

The unit of study of phenomenographic research is a way of experiencing phenomenon. The purpose or object of phenomenographic research is the identification of variation in the ways of experiencing phenomenon (Marton and Booth, 1997). Phenomenography seeks to describe aspects of the world as others see them. Thus it takes a second-order perspective. By contrast, research that takes a first-order perspective seeks to describe the way the researcher sees aspects of the world. This study examines the ways accounting students experience the phenomenon of how they learn in a formal educational context. This is examined with a view to understanding how these ways of experiencing this phenomenon vary particularly in response to interventions introduced into the design and delivery of a course.

In phenomenographic research the identified variations people can have in the way they experience particular phenomenon can often be ranked, with some ways of experiencing a particular phenomenon being seen as more advanced, complex or effective than others. This ranking of variations in ways of experiencing phenomena involves researchers imposing value judgements (Marton, 1993). In this study, it is the differences or variations in ways of experiencing aspects of how accounting students learn accounting that are seen as being of central importance to understanding how to support students to learn (or experience change in) how to learn accounting in a university accounting course.

The unit of study of this research is the internal relationship between an accounting student and the learning task they are experiencing within a university accounting course. This internal relationship is 'a way of experiencing something' or a 'category of variation'. Thus neither the accounting student nor the learning task in a course would be the same without the relationship between them. Another way of saying this is that in this study there is no attempt to separate the student and the learning tasks. A learning task cannot be described independently of the ways students experience it. Phenomenography sees the world as a real world (it does not take a constructivist perspective) but the unit of study is the world experienced by particular people (Marton and Booth, 1997). 
This study takes a second-order perspective, studying how learning tasks in a university accounting course are experienced by accounting students.

This second-order perspective is taken at a collective level (Marton and Säljö, 1976a; Marton and Booth, 1997). The objective is to identify variations in the ways accounting students experience a learning task or other aspect of a university accounting course in response to specific interventions in course design and delivery. The focus of this study is not on an individual student's way of experiencing these learning tasks but on the key aspects of meaning in the different ways of students experiencing this phenomenon. Phenomenography focuses on the ways of experiencing a phenomenon, not on the psychological or cognitive processes in a person (Marton, 1988; Biggs, 1993). For example, 'conception of learning' is not viewed as something internal psychologically or cognitively to a student but is viewed as ways of experiencing (or being aware of) how a student learns within the particular learning context of a university accounting course.

Tynjälä (1999: 364) has noted that "phenomenography ... has fundamental similarities with social constructivist views". Both social constructivism and individual or cognitive constructivism conceive learning as involving students constructing their own knowledge and as occurring in the interaction or relationship between a student and their learning context. Social constructivism emphasises the influence of the context on this interaction; individual or cognitive constructivism emphasises the influence of the individual on this interaction. This study has been strongly influenced by social constructivist views.

Phenomenography sees the various concepts or aspects of learning as an internal relationship between a person and the world. It is through studying specific examples of accounting students' ways of experiencing aspects of a university accounting course that general ideas or descriptions of variations in the way of experiencing aspects of a university accounting course (particularly in response to interventions in the design and delivery of that learning context) can be identified. These general ideas or principles are thus independent of any individual. Most importantly for this research, because these general ideas or principles represent internal relationships they need to be examined, developed and identified within the specific context of a university accounting course. 
Phenomenography is not the same as, nor is it a part of, phenomenology. Both phenomenography and phenomenology have as their object of study human experience. However, they approach researching human experience in quite different ways with different goals and with different theories about the nature of experience. Phenomenology seeks to understand the essential nature of human experience through the study of the richness and completeness of an individual's experiences and descriptions of a phenomenon. By contrast, phenomenography seeks to abstract aspects of a person's experience to identify ways in which people vary in their experience of a phenomenon (Marton and Booth, 1997: 117).

The focus of this study is on categories of variation of accounting students' ways of experiencing learning tasks in a university accounting course rather than on the full richness of an individual student's experience of this phenomenon. This study is not seeking to understand the essence of human experience of learning tasks in a university accounting course. Rather, it has the purpose of seeking to understand variation in certain critical aspects of human experience of learning accounting in a university accounting course and how students can be supported to experience how they learn accounting in more effective ways.

\section{Generalisability}

In this study, learning is viewed as changing between qualitatively different ways of experiencing a phenomenon or aspect of the world (Marton, 1993). The phenomenographic approach adopted in this study examines a number of qualitatively different ways in which specific aspects of learning by accounting students are experienced. This is measured or identified by ways in which this is experienced by accounting students in a particular course in terms of qualitatively distinct categories of variation. The theoretical model, set out in Figure 1.2 in Section 1.1 (in Chapter 1) above, has been used to focus this study on certain aspects of how accounting students learn, namely relevance structure, conception of learning, motivation and approach to learning. The theoretical model has also been used to focus this study on the effectiveness of the interventions in the design and delivery of a course to support students to experience more complete or complex categories of variation for these aspects of learning. Generalisability of the findings of this study comes from the generalisability of the context and content of learning in the course examined in this study to other situations. 


\section{Measures of students' experience of how they learn}

Phenomenography usually uses interviews of students to measure their experience of how they learn (Marton, 1993). In this study, the key measures of students' experience of how they learn were five Session Preparation Assignments (SPAs) and five stages of a major Assignment which they completed. As an integral part of these learning tasks, students expressed the ways in which they experienced aspects of their learning. The SPAs and the Assignment were the central learning tasks in the course and comprised $100 \%$ of the assessment for the course; further details are included in Section 3.1 above. The five SPAs and the five stages of the Assignment are also included in Appendix 1. This data provided a rich source of material to identify and capture students' experience of key aspects of how they learn accounting in the context of a university accounting course. This data was supplemented by a focus group and various surveys from students.

A focus group of students was held in Week 11 of the course. A total of 13 students, comprising $16 \%$ of the students enrolled in the course, participated in the focus group. Attendance at the focus group was voluntary. The focus group was led by an academic (who was not a lecturer in the course) who was a member of the school of the university in which the course was conducted. A transcript of the focus group was completed and studied by the researcher after all grades of the course were finalised.

The surveys of accounting students in the course were:

- Assessment Experience Questionnaire (AEQ)

The AEQ is a standardised questionnaire designed to measure the response of students to assessment (Gibbs \& Simpson, 2004). It is a useful tool to gain evidence from students about the extent to which assessment best supports their learning. The AEQ was administered to students in Week 11 of the course. Student responses were anonymous. The questions in the AEQ are included in Appendix 6.

- Student surveys

In addition to the $\mathrm{AEQ}$, the following surveys were also completed by students in the course:

Pre-Course Survey $\quad$ Week 1

$\begin{array}{ll}\text { Course Outline Feedback } & \text { Week } 1\end{array}$ 
Critical Incident Questionnaires

Wks 1 - 9

Informal Feedback on Learning Environment

Week 5

Formal Student Evaluation on Teaching \& Course

Week 10

Post-Course Survey

Week 12

One-Year-On Survey

Nov 09

Critical Incident Questionnaires (CIQs) are a means to find out how students are experiencing their learning and the teaching. Critical incidents are vivid happenings that people remember as being significant (Brookfield, 1995; Tripp, 1993; Woods, 1993). The CIQs seek to identify specific, actual events or experiences that were significant to each student (not what they 'liked' or 'disliked'). The CIQs comprised five questions, each of which asked students to write down some details about events that happened in the classes that week. The questions were adapted from the CIQ example included in Brookfield (1995: 115). The questions included in these surveys are included in Appendix 6.

The response rates for each of the five stages for the Assignment, the SPAs, the CIQs, AEQ and student surveys are include in Table 3.1 below. Human ethics approvals were obtained for the above activities from the Human Ethics Committee of the university in which this study was conducted. Students signed consent forms and processes were put in place to ensure that confidentiality of data from students was maintained.

\section{Data analysis}

Data analysis focused on identifying students' ways of experiencing certain aspects of how they learn accounting in a university accounting course. This was done through coding of the five SPAs and the five stages of the Assignment for each of the 81 students in the course using N-Vivo software. The responses of students were analysed based on a number of pre-determined topics of interest or themes related to the research question and to the theoretical model being applied in this study. Other topics or themes were also identified during the analysis and included as additional themes in the N-Vivo software. For some themes, further coding was completed into sub-themes (parent-child), and on occasion sub-subthemes (parent-child-grandchild), in the N-Vivo software. 
Table 3.1 Response Rates and Timing: Assignment, SPAs, CIQs, AEQ and Student Surveys

\begin{tabular}{|c|c|c|c|c|c|}
\hline & Nos & Timing & & Nos & Timing \\
\hline Assignment & & & CIQs & & \\
\hline Stage 1 & $80 / 81$ & Wk 3 & 1 & $80 / 81$ & Wk 1 \\
\hline Stage 2 & $81 / 81$ & Wk 6 & 2 & $80 / 81$ & Wk 2 \\
\hline Stage 3 & $80 / 81$ & Wk 7 & 3 & $81 / 81$ & Wk 3 \\
\hline Stage 4 & $80 / 81$ & Wk 11 & 4 & $80 / 81$ & Wk 4 \\
\hline Stage 5 & $79 / 81$ & Wk 12 & 5 & $80 / 81$ & Wk 5 \\
\hline SPAs & & & 6 & $79 / 81$ & Wk 6 \\
\hline 1 & $80 / 81$ & Wk 1 & 7 & $78 / 81$ & Wk 7 \\
\hline 2 & $81 / 81$ & Wk 2 & 8 & $78 / 81$ & Wk 8 \\
\hline 3 & $80 / 81$ & Wk 4 & 9 & $78 / 81$ & Wk 9 \\
\hline 4 & $80 / 81$ & Wk 7 & AEQ & $77 / 81$ & Wk 11 \\
\hline 5 & $79 / 81$ & Wk 8 & & & \\
\hline \multicolumn{6}{|l|}{ Student Surveys } \\
\hline Pre-Course Survey & $80 / 81$ & Wk 3 & $\begin{array}{l}\text { Course Outline } \\
\text { Feedback }\end{array}$ & $72 / 81$ & Wk 6 \\
\hline $\begin{array}{l}\text { Informal Feedback } \\
\text { on Learning Environ. }\end{array}$ & $72 / 81$ & Wk 7 & $\begin{array}{l}\text { Formal Student } \\
\text { Evaluation }\end{array}$ & $65 / 81$ & Wk 11 \\
\hline Post Course Survey & $76 / 81$ & Wk 12 & One-Year-On Survey & $9 / 81$ & $1 \mathrm{yr}+$ \\
\hline
\end{tabular}

A list of the themes used for the coding of data from the five SPAs and the five stages of the Assignment for each of the 81 students in the course and the number of quotes coded to each theme is included in Appendix 4. The approach was to identify and categorise quotes from students under the main themes, and then under sub-themes (and sub-sub-themes) where appropriate. A total of 3,360 quotes were coded to these themes, with many quotes coded under more than one theme. These extracted quotes were then reviewed several times by the researcher.

A transcript was produced for the focus group. This transcript was analysed in a similar way to the analysis of the five SPAs and the five stages of the Assignment. However, given the smaller amount of material involved this was done without using N-Vivo software. Responses from students were also extracted and analysed from the Critical Incident Questionnaires (CIQs) in a similar way to the analysis of the transcript of the focus group. In addition, results 
from the surveys other than the CIQs were analysed to gain background information on the students (as a group) in the study and on their overall perceptions about key aspects of interventions, such as Assessment, used in the course.

No attempt is made in this study to consider the relationship between characteristics such as ethnicity or gender of individual students and their way of experiencing how they learn. The narratives from students reported in this study are usually referred to as quotes from "Accounting Student" without any further indicator other than a number. This number refers to the student number used in Appendix 3 to indicate the number of narratives reported in this study, ethnicity and gender for each student. In a few instances, further indicators were provided, for example where chronology was considered relevant. The narratives reported in this study have been edited based on a 'standardized' approach, where the wording and meaning are preserved but some editing is done for spelling and grammar in order to facilitate the reading and accessibility of the quotes (Weiss, 1994; Sandelowski, 1994).

This section has described the application of phenomenography to this study and outlined the approach to data collection and analysis used to measure the ways students experience how they learn accounting in a university accounting course. Five SPAs and five stages of the Assignment, supplemented by a focus group and surveys, were designed to identify and capture the ways students experience relevance structure, conception of learning, motivation and approach to learning in a university accounting course into which an integrated set of interventions were introduced. The measures of students experience of how they learn relied largely on the interpretations of a single researcher of the responses of students in the five SPAs and five stages of the Assignment (and in the focus group and CIQs), supplemented by an Assessment Experience Questionnaire (AEQ) and other surveys of students.

\section{Conclusion}

In this chapter, the research method was described. A framework of integrated interventions has been applied to a university accounting course and extensive data collected on the ways accounting students experience aspects of how they 
learn. A phenomenographic approach to research was adopted. The key data collected and analysed were five SPAs and five stages of the Assignment completed by students in the course, supplemented by data from a focus group and a series of student surveys. The results of the analysis of this data will be discussed in Chapters 4 to 8 .

Students in a third-year university accounting course were studied. These students had extensive previous experience of learning accounting at university. In Chapter 4, evidence will be examined about the ways of experiencing relevance structure and conception of learning by students in their previous university accounting courses and how these were challenged in this study. After considering this evidence, the effectiveness of the interventions to support students to experience intrinsic motivation and deep learning will be considered in Chapters 5 to 8 . 



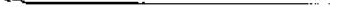

$$
a
$$




\title{
4. CHALLENGING PREVIOUS WAYS OF EXPERIENCING RELEVANCE STRUCTURE AND CONCEPTION OF LEARNING
}

\author{
... I have yet to use accounting to change the way I view \\ aspects of the reality of business as I understand, use and \\ develop my own personal meaning about the concepts and \\ ideas of accounting ... So far, none of the courses that I have \\ done are structured to be able to achieve this.
}

Accounting student (20)

This study examined a third-year university accounting course. The students in the study had extensive, recent previous experience of learning accounting at university. In this chapter, evidence about their ways of experiencing relevance structure and conception of learning in their previous courses, and how these were challenged in this study, will be examined. Evidence is provided of previous experience by students of low-level relevance structure and of the internal relations between relevance structure, conception of learning, motivation and approach to learning in a university accounting course. This evidence indicates that interventions are needed to support accounting students to experience change in the way they experience relevance structure. Evidence is then examined about how students were supported in this study to experience relevance structure in a more complex and complete way.

Students will bring their previous experience of relevance structure and conception of learning to their experience of how they learn accounting in a university accounting course (Trigwell and Prosser, 1991; Case and Gunstone, 2002). They could 'take for granted' and have little or no awareness of their previous experience of these aspects of how they learn (Marton and Booth, 1997). Evidence about interventions in this study designed to support students to experience an 'architecture of variation' to support change in how they learn accounting is discussed, drawing on insights from Marton and Booth (1997). This is followed by evidence about students' awareness of the ways they experience conception of learning in a university accounting course and the implications this has for their experience of conception of learning. "The data referred to in this chapter was taken from the Assignments, Session Preparation Assignments 
(SPAs), Critical Incident Questionnaires (CIQs) and the Pre-Course Survey completed by the students. The data from the Assignments and SPAs was collected progressively throughout the course. The data from the CIQs was taken from the first two weeks of the course. The Pre-Course Survey was completed by students by the first week of the course. The response rates for the Assignments, SPAs and CIQs are included in Table 3.1 in Section 3.2 in Chapter 3 above. The response rate for the Pre-Course Survey was 95\%.

This chapter focuses on seeking to identify the previous ways of experiencing relevance structure and conception of learning by accounting students in the context of a university accounting course; and to introduce variation in the ways of experiencing these aspects through specific interventions designed to bring them out of the background of students' thinking and into their focal awareness. Evidence is considered about the effectiveness of these interventions designed to support students to experience in different ways these aspects of how they learn. The focus of this chapter is shown in Figure 4.1 below.

Figure 4.1: Variation in Ways of Experiencing Relevance Structure and Conception of Learning

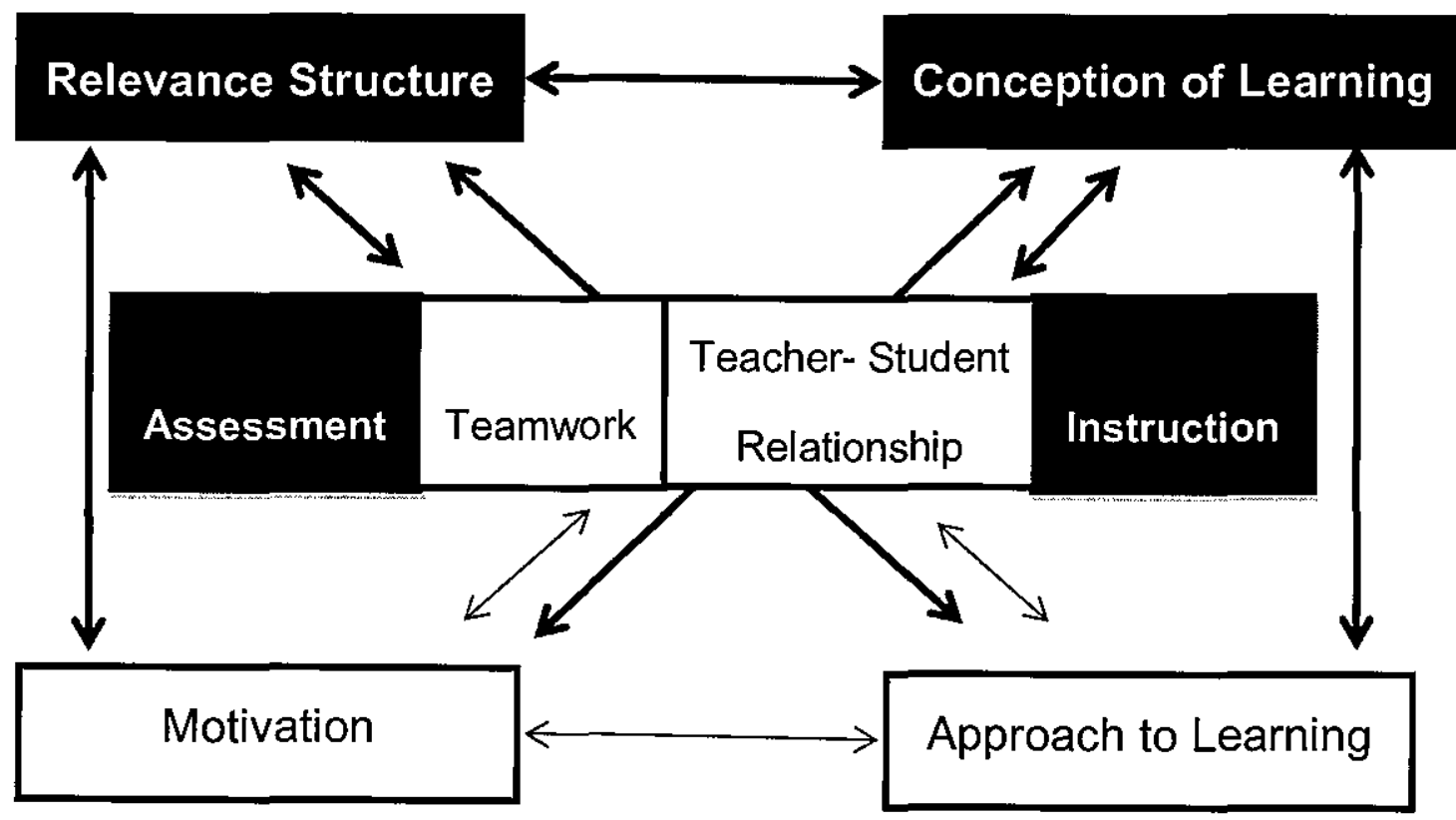




\subsection{Previous Relevance Structures}

I am at university because I want to be a professional accountant. How does university help me achieve that? Firstly by facilitating $m e$ in learning the basic foundation of accounting practice and secondly because I would not get hired until I complete a degree in accounting.

Accounting student (25)

Students experience a relevance structure in a university accounting course through aspects of a course that indicate to them where the learning tasks are heading, where doing the learning tasks might take them, and what the learning tasks will demand from them. The students in this study had extensive previous experience of relevance structure in a university accounting course. In this section, a description is offered of the categories of variation in the ways accounting students experienced relevance structure in their previous university accounting courses. As noted in Section 2.1 (in Chapter 2) above, there is limited previous research in the accounting education literature on the experience of relevance structure by accounting students.

\section{Categories of variation}

Three categories of variation of the ways accounting students experienced relevance structure in their previous university accounting courses have been identified in this study:

1. gain a job: grades gained in a university accounting course are important to help win the competitive battle with other accounting students to get the best jobs:

I ... see myself in competition with everyone at university ... there are 4 top accounting firms and everyone is vying for a spot ... the only way I see myself being able to get into one of those top 4 accounting firms is to get good grades ... At internship interviews ... with the top four ... grades were important to get a foot in the door.

Accounting student $t_{(*)}$ 
2. do a job: foundational accounting knowledge and technical skills learnt in a university accounting course can be useful to perform technical aspects of a job, particularly an accounting job:

...get skills to be a better accountant...

Accounting student(9)

...some students seemed quite obsessed with ... learning everything they need to know for when they enter the workforce...

\section{Accounting student $(68)$}

3. develop personal capacities: capabilities can be learnt in a university accounting course that would be useful in the working environment (and possibly in life more generally):

...skills are the most important thing to pick up from a course rather than knowledge of technical detail ... the ability to write well ... to sift through copious amounts of material and find the key concepts ... to understand accounting concepts ... to communicate my ideas and ... to think critically and not to accept everything I read or am told. Accounting student (6i)

These three categories of variation in the experience of relevance structure by accounting students in a university accounting course are in order of increasing complexity and completeness. In other words, the second category of 'do a job' includes 'gain a job' (as a student needs to gain a job as a necessary precondition to be able to 'do a job'). Also, 'develop personal capacities' includes both 'gain a job' and 'do a job', with the focus being on more complex and complete skills and capacities to 'do a job' in addition to foundational accounting knowledge and technical skills. These categories of variation were developed in this study based on students' experience of relevance structure as discussed by them in their Assignments, SPAs, CIQs and Pre-Course Survey (Angelo and Cross, 1993).

\section{Low-level relevance structures}

In this study, there was evidence the first relevance structure of 'gain a job' was the dominant previous experience of relevance structure by accounting students. 
Since $45 \%$ of students in this study expected to complete their university studies at the end of the course, it was initially thought this may have caused them to be more focused on gaining a job at the end of university than they may have been earlier in their university studies. However, it appears this relevance structure had been experienced by students not just in courses towards the end of their accounting studies, as many students already had gained a job at the completion of their studies and yet had retained this relevance structure:

Good grades ... seem important ... for me; that's bizarre because it's not like I have to worry about getting a job at the end of this degree and beating out the competition. I already have a job in an accounting firm...

Accounting student (3)

This experience of the first relevance structure of 'gain a job' was similar to the dominant relevance structure experienced by introductory accounting students in Lucas (2000: 486) "in which accounting is not seen to possess an inherent meaning other than as a 'subject to be passed'." Also, the experience of the second relevance structure of ' $\mathrm{do}$ a job' may have been a more prevalent relevance structure for students in courses earlier in their accounting studies. Lucas (2000: 498) found some accounting students in introductory accounting were "motivated by gaining skills and a qualification that could be applied in future employment." However, when students were experiencing a course near the end of their accounting studies at university many had become disillusioned about this relevance structure:

I have spoken to many accountants who say that what they learnt at university is irrelevant to what they do in their accounting jobs.

\section{Accounting student (17)}

It is upsetting to see how employers these days do not expect you to have any knowledge ... and you are taught everything you should have learned in ... university, when you first start the job. 
It is possible accounting students may have experienced change to a less complex and complete relevance structure (from 'do a job' to 'gain a job') in their previous experiences of accounting courses. This would be consistent with Lucas (2000: 491-2) in relation to introductory accounting students: “...most students distanced themselves from accounting and did not perceive it to be immediately relevant ... The most important aspect of relevance was that students perceived accounting to be important to their future career in business. However, this emerged more as an article of faith on the part of the students..." Students also expressed concerns about their personal competence in foundational accounting knowledge they had 'learnt' in their previous accounting courses:

I didn't really absorb what was taught, I think I just learnt it to get a good grade and then forgot about it. This worries me. I start work at an accounting firm next year ... How am I going to cope in the real world?

Accounting student (24)

Experience of either of the first two relevance structures of 'gain a job' or 'do a job' would support accounting students to experience low-level conception of learning, extrinsic motivation and surface learning in a university accounting course (Byrne et al, 2009). Good grades in assessments are perceived by accounting students as helping them 'gain a job' as they perceive recruiters of graduates consider students' grades in graduate selection processes (Tan and Laswad, 2009). Thus the first relevance structure of 'gain a job' would strongly support accounting students to conceive learning as the acquisition and memorization of knowledge with the intention of reproducing it for assessment purposes (a low-level conception of learning: see Section 2.1 in Chapter 2 above):

I now understand the systems and types of assessments at University and so I approach classes and study in a way that I know will minimise effort but maximise grades ... at the end of the day ... employers look at your grades and not at the knowledge inside your head.

Accounting student (so)

The second relevance structure of 'do a job' would support accounting students to experience a conception of learning in an accounting course as the acquisition of 
facts and procedures which can be retained and used in practice (also a low-level conception of learning: see Section 2.1 in Chapter 2 above).

...learn ... material and use them in ... my accounting career.

Accounting student ${ }^{(52)}$

The relevance structure of 'do a job' was also focused on an entry point accounting job, where regurgitation and 'doing what you are told' was thought to be more relevant to performing well in these jobs than 'thinking for myself':

When we leave university we will be starting at the bottom of the food chain where analytical skills are left for the bigger fish so why is it important to focus so much effort into developing these skills when it is so much easier to rote learn and regurgitate lecture material?!

Accounting student (24)

The first relevance structure of 'gain a job' would also support students to focus on grades as a motivation to complete the assessed learning tasks, or in other words would support the experience of extrinsic motivation:

...learning to me has always been about getting the grade...

Accounting student (5s)

...motivation can encourage people to do the things they don't

like [to do] ... the motivation for me to study in university is [to]

gain a well-paid job in the future.

Accounting student (27)

There is also a strong sense of competition between accounting students for grades in accounting courses as an important part of competition for jobs after graduation. This makes it more difficult for them to experience teamwork and cooperative learning:

I am highly competitive and strive to achieve top grades ... It is

true at times I do refuse to share my ideas with others...

Accounting student (33)

I know many students at university who are not willing to share

their work in fear that someone else might end up doing better

than them and I have learnt this the hard way myself.

Accounting student (65) 
There was also the experience that it was possible to successfully negotiate the assessments without engaging in teamwork:

...throughout my 3 years [of my business degree] I didn't have to ... talk ... much to my course mates and yet I was able to ace my courses.

Accounting student (2)

The relevance structure of 'gain a job' (with its emphasis on gaining grades to help win the competitive battle with other students to get the best jobs) would not support accounting students to respond positively to interventions designed to support the experience of teamwork and cooperative learning:

All my past experience with group activities has been unsatisfactory.

Accounting student $(6)$

One strategy adopted by students in response to interventions in previous courses designed to support teamwork is to deliberately work individually and minimise interactions with other students:

In [a previous course] we had to do group presentations in tutorials but instead of working as a group we just allocated parts of the research/presentation to each person and effectively worked by ourselves.

Accounting student ${ }_{(33)}$

These barriers to teamwork and cooperative learning can also lead to an experience of social isolation between students:

...there is ... some social isolation ... you see students who often attend the same classes as you but you do not have any relations with them.

Accounting student (37)

The low-level relevance structure of accounting students identified in this study would present a barrier to the effectiveness of interventions such as cooperative learning techniques (for example, Bonk and Smith, 1998) and student teams (for example, Kennedy and Dull, 2008) that have been documented in the accounting education literature without measuring their effectiveness on student learning. 
The relevance structure of 'gain a job' was also supportive of previous experience of surface learning. Surface learning was often expressed in terms of unthinking regurgitation of material:

...we just spit back to the lecturer and tutors some made up 'stuff' just because we think it's what they want to hear and what will get us good grades.

Accounting student $(3)$

There was awareness by students of a connection between a surface learning approach and their experience of low-level relevance structure, with this connection often being explicitly referred to:

I think most students just regurgitate. We are here to get jobs ...

The most efficient way for everyone to get what they need ... is for teachers to quickly spit it at us, us to quickly spit it back, and then forget the whole thing ever happened. We get our jobs, and teachers can get back to being academics.

Accounting student (66)

Further, students had prior experience that surface learning was rewarded by grades in accounting courses:

I have been a passive learner and relied on my abilities to rote learn and regurgitate to the examiner and anticipate what will be expected in assessments to get a good grade.

\section{Accounting student (24)}

There was also a sense of personal disconnection or dishonesty in this surface learning and regurgitation process, as students reproduce material to lecturers based on what they consider lecturers want to hear rather than from any sense of personal engagement or genuine learning:

In the 'real' world i.e. outside of university, I would like to say I'm an honest person yet as soon as I hit the books or enter the campus something seems to switch off and all honesty goes out the window. Hence, I rote learn and then regurgitate facts back to my lecturer... 
This student continued by indicating that the assessments in an accounting course can support surface learning and a lack of personal connection, as reflected in their recent experience of adopting a more honest, personally connected approach to an assignment:

...after this course I have learnt to become more honest around university and it's sucked. For example, I took [a more honest] approach ... to an assignment for another paper ... I failed ... miserably. It's the first assignment I've failed at university. So obviously honesty is not rewarded ... It seems like a trade off between honesty and therefore actually learning something and getting good grades...

Accounting student (3)

This student then commented about their experience of the internal relation between the experience of relevance structure and their approach to learning and the powerful impact of assessment design on students with a low-level relevance structure:

... It seems like a trade-off between honesty and therefore actually learning something and getting good grades. What have I chosen up to now? Well I haven't chosen anything ... because I didn't know there was a choice. I thought that they were the same thing; I thought that what I was doing was learning. What will I chose to do from now on? I have no idea. I do know that there will be times that I don't choose honesty because good grades will seem important...

Accounting student (3)

This is evidence that the experience of low-level relevance structure in a university accounting course can reduce the willingness of accounting students to experience a deep approach to learning (that is, 'actually learning something') if the assessments do not reward deep learning, even once they have become aware of high-level conceptions of learning and of the potential of different ways of experiencing these aspects of learning accounting.

This finding of widespread experience of low-level relevance structure, and of the possible movement from 'do a job' to the less complex and complete 'get a 
job' relevance structure as accounting students progress through their accounting degree, is consistent with (and can partially help explain) evidence in the accounting education literature that studying accounting at university can support increasing levels of surface learning by accounting students (Gow et al, 1994; Boyce et al, 2001).

In this section, three qualitatively distinct categories of relevance structure in a university accounting course have been identified based on evidence about the experience of accounting students in previous university accounting courses. These categories of variation in order of increasing level of content and complexity are 'gain a job', 'do a job' and 'develop personal capacities'. In Section 5.1 (in Chapter 5) below, a fourth relevance structure experienced by accounting students in the course being studied in this research is identified. As there was no evidence in this study that accounting students had experienced this relevance structure in their previous university accounting courses, a discussion of this fourth category of variation will be left to Chapter 5 .

Evidence of previous experience of both low-level relevance structure and of the internal relations between the ways of experiencing relevance structure and the ways of experiencing conception of learning, motivation and approach to learning have been described in this section. There was also evidence the experience of low-level relevance structure would present a barrier for accounting students to respond to interventions designed to support teamwork and cooperative learning. This evidence indicates interventions are needed to support accounting students to experience change in the way they experience relevance structure in a university accounting course. In the next section, evidence of scepticism by accounting students about the experience of high-level relevance structure in a university accounting course will be considered; followed by a discussion of the interventions used in this study to challenge the previous experience by accounting students of relevance structure.

\subsection{Challenging Previous Relevance Structures}

The previous experience of low-level relevance structures supports students to be sceptical about formal learning objectives in an accounting course involving highlevel relevance structures. In this section, evidence will be provided about the 
interventions made in this study at the beginning of the course to establish in a way credible to students a relevance structure that might challenge and be different to the relevance structures they had previously experienced in accounting courses. These interventions involved engagement with students from the previous year of the course and Instruction about the relevance structure of the course and how the assessed learning tasks would support their experience of this relevance structure.

To be effective, the relevance structure must first be believable to the student. This means it must be communicated in such a way as to be credible and relevant. Building a relevance structure requires much more than the teacher standing up in front of a class and telling students in what ways the learning tasks should be relevant to them (Volet and Chalmers, 1992). This will not be effective, particularly if the previous ways of experiencing relevance structure by students is to be challenged (Lucas, 2000; see Section 4.1 above). There was evidence of scepticism by students towards statements by teachers concerning the relevance structure of a university accounting course. Students can perceive statements or rhetoric from teachers regarding the development of analytical skills and other generic skills as not being matched with their previous experience:

I found that at uni we are punished greatly for taking risks in presenting our ideas that do not conform to what the lecturer expects ... in [a particular course] the lecturer [said] to us that there are no right or wrong answers ... but this is not true, the marker has a list of points that we must satisfy to gain full marks. If we go off the marking schedule the tutor will not mark us on them.

\section{Accounting student (37)}

Also, students have exposure to the views of existing accounting professionals about their experiences of relevance structure of courses when they studied accounting at university:

My dad [an accountant] even told me [that to rote learn and regurgitate lecture material] was the way to go! He even advised me to find out what [the lecturer] is thinking and his views and then agree with him because that is the way that I will get a good 
grade! Isn't this just common sense?! Some of the lecturers have been around for a while and it isn't hard to find out what makes them tick! Isn't this the university culture? Or at least what everyone (at least the smart on to it ones) at university are doing?

Accounting student (24)

The previous experience by accounting students of relevance structure needs to be challenged as part of the process to support students to change their ways of experiencing how they learn accounting in a university accounting course. How students were supported to build a high-level relevance structure in this study will now be considered. The first intervention was designed to directly address, at the beginning of the course, the issue of scepticism by accounting students and the lack of credibility of statements from the teacher about relevance structure.

\section{Intervention one: Credibility of past accounting students}

In the first lecture, a group of five top-performing students from the previous year of the course were invited to talk with students. The previous year of the course was a pilot study and contained many of the same features (such as assessment design) used in the course in this study. The teacher left the lecture theatre and the students from the previous year talked about their experience of the course, what they got out of it, and answered questions about the course. This was done instead of having the teacher talk about the course objectives, which is the formal statement of the relevance structure of the course (that is, a statement of the relevance structure the teacher would like students to experience in the course). The previous year's students were perceived by students to have credibility:

Talking to 'The Panel' of past students was very helpful. They were honest (or very good at lying) and realistic about the course. Accounting student (0)

The first class in the course was two hours. During the second hour there was an informal time over soft drinks and nibbles immediately outside the lecture theatre. This provided an opportunity for students to talk informally with previous year's students (the five top-performing students previously mentioned and other students from the previous year of the course who came only for the informal session after the lecture) and with the teacher. This further helped to challenge 
their way of experiencing relevance structure by talking with credible sources of information about the course:

In the first lecture where the course was introduced and at the 'after class mingle' time where I got to ask past students ... questions about their experience with the course ... it was great to gain first hand insights into the course from past students...

Accounting student (i)

Also, the students observed that past students were willing to attend the first lecture of the following year's course and talk with them, were enthusiastic about their experience of learning in the course, and were keeping in contact with their teacher. This gained the attention of students as being 'something different' to what they had experienced previously and supported them to be open to the possibility of variation in their experience of relevance structure:

... [the] past students ... are quite enthusiastic about the course!

Accounting student (0)

The way past students wanted to keep in contact with a past lecturer! I can't imagine choosing to keep in contact with my past lecturers thus far.

Accounting student (0)

\section{Intervention two: Formal learning objectives}

The formal learning objectives of the course were set out in the course outline. These were discussed in the second class of the course (that is, after the students had been able to interact with students from the previous year's course in the first class). There was also a course outline feedback survey which students completed early in the first week of the course. This survey was completed online through the learning management system. It was designed to support students to actually read the course outline before the classes in Week 1 . The first paragraph of the formal learning objectives sought to support students to be honest about their own learning objectives for the course:

This section sets out what your teachers in this course would like you to learn. The actual learning objectives of the course for you will be the objectives you have. 
The formal learning objectives then explicitly stated that students had the opportunity to experience deep learning rather than surface learning:

In this course you will have the opportunity to understand and remember some key concepts, principles, relationships and facts about financial statement analysis and to adapt and apply them to a real firm. However, this course is not essentially about this. This course is about giving you the opportunity to actively search for your own understanding and to develop your own personal meaning of some key concepts and ideas of accounting and finance and to organise these key ideas into a coherent and meaningful whole; and in this way to change the way you think about, see and understand aspects of what business is really about. You will have the opportunity to do this as you adapt and apply these ideas to your analysis of a real firm.

The learning objectives then referred to what the teacher desired each student would tell them in a year's time about what they had learnt (Fink, 2003):

A year after you have finished this course ... I ([the teacher]) would like you to take me out for coffee and tell me that you got the following things out of doing this course...

The desired learning outcomes were then listed and included technical knowledge and skills:

"...I remember $\mathrm{V}_{\mathrm{E}}=\mathrm{BV}$ of Equity + PV of Abnormal OI, Abnormal OI $=\left[\right.$ RNOA $\left.-\left(\rho_{\mathrm{F}}-1\right)\right] \times \mathrm{NOA}$ and $\mathrm{RNOA}=\mathrm{PM} \mathrm{x}$ ATO; and I deeply understand the difference between the operating and financial activities of a firm.

...I know I can pick up a firm's financial statements and have a way of analysing them and using them (along with other information) to form my own personal view of the value of a firm...

They also included gaining understanding and personal meaning:

...I can see how what I have learnt in my various accounting courses relates and connects to each other and I can make some 
overall sense and meaning about it...

As well as motivation and personal interest in accounting:

...I have a greater personal interest in accounting and business and could see myself being able to become, over time, an expert in accounting; hey, I am even starting to care about accounting....

...I see accounting as something more than meaningless, disconnected technical detail; and that it may be a discipline I could get excited about, be genuinely interested in and value...

They also included gaining capabilities in learning:

... In my university courses (if still studying in a year's time):

I am now in the habit of critically reading the set readings of my courses before my lectures...

I am willing to challenge and give constructive feedback (for example, through my class representatives) about teaching that does not support my learning (and not just passively 'take it')...

I learn for understanding and personal meaning, rather than simply rote-memorising stuff I do not understand."

The learning objectives also included a statement about the conception of learning students would need to experience to successfully negotiate the assessment structure for the course (Säljö, 1979; Marton et al, 1993); and also statements that they would probably need to change their conception of learning in this course (Sharma, 1997; Byrne and Flood, 2004; Lord and Robertson, 2006):

In this course you will most likely need to change the way you view what learning about accounting is. You will need to do this right at the beginning of the course. Right now. Learning is not about adding new 'facts' and 'concepts' to my memory that come from some 'authoritative' source, such as from my university lecturers or from the writers of a textbook. It is not about adding to my memory 'facts' and 'concepts' which I more than likely have very little understanding of, or even interest in. Rather, learning is about me being personally transformed in some way. It is about change. Learning about 
accounting is about changing the way I view aspects of what business is about in the light of my own understanding of the ideas and concepts of accounting. This can be unsettling, challenging and fun. Once started, it is an adventure from which there can be no turning back.

I advise you not to come on the trip of this course unless you want to go on this journey.

The learning objectives also included some quoted comments from students in the course in the previous year.

\section{Intervention three: Assessment}

As well as the learning objectives, the assessment design was discussed with students in the second class by the teacher and by two top-performing students from the previous year of the course (who were also tutors in the course). See Section 3.1 (in Chapter 3) above for details of the Assessment used in this study. This discussion was designed to give students an overall perspective about where the assessed learning tasks in the course were heading and what would be required to complete them. The key message to students was that engaging in critical thinking would be a key to gaining a good grade (particularly in the last three stages of the Assignment) and that regurgitation would not be rewarded. This sought to use Assessment to connect to students' experience of extrinsic motivation (Boyce et al, 2001; Marriott and Marriott, 2003; Byrne et al, 2009) and low-level relevance structure of 'gain a job' (see Section 4.1 above) while at the same time seeking to challenge their low-level conception of learning (learning clear-cut facts to reproduce in assessments) (Sharma, 1997; Byrne and Flood, 2004; Lord and Robertson, 2006):

I felt pleased during the lecture that I will be learning new skills of putting my own view and interpretation on information given to me. This is my final year at uni so this should not be a new concept - but it is!

Accounting student (o) (Week I)

Interventions were made at the beginning of the course to establish in a way credible to students a relevance structure that might challenge and be different to the relevance structures previously experienced by students in accounting courses. 
Having sought to address the scepticism of students to rhetoric from teachers about learning objectives and relevance structure through giving students the opportunity for direct engagement with students from the previous year of the course, students were then given Instruction about the relevance structure of the course and how the assessed learning tasks would support their experience of this relevance structure. These interventions were designed to support students to experience a more complex and complete relevance structure and to gain an overall picture, or partial understanding, which can then challenge them to complete the learning tasks and achieve the learning outcomes. In the next section, the need to create awareness by students of ways of experiencing key aspects of how they learn accounting in a university accounting course will be discussed.

\subsection{Creating Awareness}

I never realised how much I take my university education for granted and how easily I am led to giving the lecturer what they want! I didn't think of this as a bad thing until I ... started doing this paper! It just seems so much easier to learn the slides and know the key words that lecturers are looking for rather than to think for myself? It is easy to just cram before a mid term or final exam and fit in university around my life.

Accounting student (24)

Students in this study had extensive previous experience of learning accounting in a university accounting course (see Section 3.1 above). This section describes and discusses the evidence of students' awareness of how they experienced their learning in previous accounting courses. Once students focus on and become aware of how they have experienced certain aspects of how they learn accounting, they then have the potential to experience these aspects differently (Marton and Booth, 1997). The aspects of learning that are of interest in this study are ways of experiencing relevance structure, conception of learning, motivation and approach to learning. Of particular interest is the variation in the ways students experience these aspects of their learning, both variation between students in the course and 
variation for individual students at different times in the course. Learning is a change in one's capability for experiencing a phenomenon in certain ways (Marton, 1981). Thus learning about aspects of learning in the particular situation of a university accounting course involves variation or change in the capability of students to experience these aspects of the 'how' of learning accounting.

By becoming aware of aspects of how they learn accounting in a university accounting course, students can then become aware that those aspects could be experienced differently. Different aspects of their learning may be 'taken for granted' and not be discerned. Also, different aspects of their learning may be discerned but be seen as separate and not inter-related, that is the relationship between the aspects may not be discerned. Once these aspects of how they learn accounting, and the internal relations between them, come into focus and are no longer 'taken for granted', they become capable of variation, that is capable of being experienced differently (Marton and Booth, 1997). In Section 4.2 above interventions in this study designed to support accounting students to focus on and be aware of variation in relevance structure were discussed. Evidence concerning awareness of conception of learning in a university accounting course will now be considered.

\section{Awareness of conception of learning}

The interventions used in this study were designed to support students to discern aspects of their learning accounting in a university accounting course and the internal relations between them. This was done through building a relevance structure to support students to understand what could be gained from doing the learning tasks in the course. Also aspects of their learning were varied that might otherwise be fixed and taken for granted. These aspects that were varied were centred on conception of learning and motivation. Motivation will be discussed in Chapters 5 and 6 below. Awareness of possible conceptions of learning that students could adopt when learning accounting in a university accounting course was supported through Instruction in the second week of the course (with repetition and reinforcement in subsequent weeks). This was done through discussing in a lecture the reasons for the seasons ("why is it hot in summer and cold in winter?') and viewing a video of Harvard science graduates answering this question incorrectly on their graduation day. The teacher then discussed with 
students the results of one of the questions they answered in the Pre-Course Survey: 'Q12: If a company owns $60 \%$ of the equity in another company it will typically include $60 \%$ of the assets, liabilities and profits of that company in its group accounts - True, False or Don't Know?' The correct answer is False but students in the course did much worse than simply guessing, even though $51 \%$ of students in the course had studied this fundamental aspect of accounting in a previous course, completing the final exam for this course a few weeks before answering this question in the Pre-Course Survey. This was followed with a discussion about conceptions of what learning is - and that real learning is about learning for understanding and developing personal meaning and is not about regurgitating and reproducing clear-cut black-and-white facts from experts that we do not understand and which are usually quickly forgotten. The six conceptions of learning detailed in Section 2.1 (in Chapter 2) above were directly taught to students (see discussion in Section 2.2 in Chapter 2 above: Marton, 1976; Marton et al, 1994; Säljö, 1975). The teacher emphasised that every student will need to see learning as learning for understanding and developing personal meaning to negotiate successfully the assessments in the course. Further details on the Instruction used to support students to develop awareness about conceptions of learning are included in Appendix 5. The video of Harvard science graduates had a strong impact on students and helped to focus their awareness on their conception of learning:

...the Harvard graduation [video] about the reasons for the seasons ... does make me question the value of higher education. This is because generally all I have done in my previous papers is to regurgitate the lecturer's information back to them.

\section{Accounting student (o)}

Showing the video of Harvard graduates made me realise how important it is to fully understand what I learn.

\section{Accounting student (o)}

The feedback on the responses of students to Q12 of the Pre-Course Survey (referred to above) also had a strong impact:

It was really interesting, especially ... the shocking recall of the subsidiary information from the students [who had done the previous course]! 


\section{Accounting student (o)}

...it was great to see that heaps of people got the accounting question wrong, not that I got it right either.

Accounting student (0)

Further formal instruction on conception of learning and learning to learn was done in a way that was integrated with the content of the course; that is, this aspect of learning the 'how' of learning was integrated with learning the 'what' of learning (Martin and Ramsden, 1987). For example, one of the early readings (that formed part of the second SPA, due at the beginning of Week 3 in the course) was on the importance of discerning a firm's strategy when analysing a firm, and the different ways it was possible to conceive how firms could develop their strategies. Within the reading, examples were given of each type of strategy formation by referring to strategies students could adopt in their approach to learning in their studies. Students were invited to reflect on which strategy or way of learning they adopted in their own studies. For example, one of the approaches to strategy formation by firms was the 'Design School':

This approach sees strategy formation as a process of fitting a firm's internal situation with its external environment. Strategy is about designing the 'best fit' between a firm and its environment.

As university students, we could consciously and thoughtfully seek to design our approach to learning to 'fit in' with the university environment in which we find ourselves. We could seek to fit in with the way each of our courses are run, the social and physical environment of the university and the way we finance our studies ... In the same way, the 'design school' looks at firms developing their strategy as a way of consciously and thoughtfully seeking a 'best fit' between a firm and its environment.

\section{Course Materials Book}

Some students felt they had adopted the 'Design School' as their learning strategy at university:

After a few years at University I feel I have adopted the design school. I now understand the systems and types of assessments 
at university and so I approach classes and study in a way that I know will minimise effort but maximise grades.

\section{Accounting student (19)}

At a point $I$ became lazy and took on the design school of learning. I interpreted this school of learning as the most passive learning technique, doing the minimum, not being critical about what I was learning.

Accounting student (33)

This intervention was also an example of combining the 'how' of learning with the 'what' of learning:

[The reading] helped me reflect deeper than ... merely on [my firm's strategy formation] ... it encouraged me to re-think my prior learning technique and motivates me to obtain greater understanding of the concepts.

Accounting student (33)

Students had the opportunity in their SPAs and Assignments to express their own ideas and reflect on their own conception of learning in the context of a university accounting course. In this way, students were supported to become aware of the variation they could experience in conceptions of learning and that their own conception of learning was only one of a number of possible views. They also had the opportunity to reflect on the variation by other students in the way they conceived learning in a university accounting course, for example through the sharing of SPA exemplars and student feedback from CIQs. Thus students were invited to reflect on their own conception of learning and on the variation possible, making explicit the possible categories of variation of conception of learning. The purpose of this was to support them to experience more advanced conceptions of learning:

Yeah we needed a wake-up call saying, "Hey this class is going to be different!"

\section{Accounting student (2t)}

'Learning how to learn' session [was] really beneficial to me, I was really challenged to be told that this paper has been designed to get us to think for ourselves the ideas and techniques being taught in this course. 


\section{Accounting student (o)}

An important finding was that students quickly understood, appreciated and became aware of high-level conception of learning in a university accounting course in response to direct instruction on conception of learning that was integrated into the content of the course. This finding is consistent with findings in the education literature (Marton, 1976; Marton et al, 1994; Säljö, 1975; Martin and Ramsden, 1987). There was evidence accounting students had experience of high-level conception of learning in contexts of their lives other than a university accounting course and that this experience supported them to quickly respond to direct instruction on conception of learning that was integrated into the content of the course:

...the first few weeks of classes - the "learning to learn" portion ... It almost seemed as though it was taught in a way where you thought no one in the class knew how to learn. Sure very few of us were learning at university, but some of us absolutely knew how to learn to begin with. We just found other places in life to do our learning rather than at university.

Accounting student (2l)

Once awareness of the possibility of experiencing different levels of conception of learning in a university accounting course was brought into focus, students were readily able to be aware of the level of conception of learning they had been adopting in the context of their previous university accounting courses and the consequences for their learning that resulted from their conception of learning. Consistent with approach to learning research in the accounting education literature (Sharma, 1997; Byrne and Flood, 2004; Lord and Robertson, 2006), this study found that low-level conceptions of learning by accounting students dominated in the context of their previous university accounting courses:

I always seem to cram during my tests and exams and I always try to superficially memorise information that I do not understand.

Accounting student (49)

I will do the minimum throughout the term and cram for the test and exam and yes I don't remember much of those courses. 
Students also became aware of their lack of personal connection with the material in their previous courses:

University studies have taught me a lot about many great theories and the thinking behind them. However, I had not established a personal connection with the thinking, and when it comes to applying them into the real world situation, I found that I actually gained little insight in the last three years [of] being a uni student.

Accounting student (xo)

There was also awareness about the internal relation between conception of learning and relevance structure:

I didn't really absorb what was taught, I think I just learnt to get a good grade and then forgot about it. This worries me. I start work at an accounting firm next year ... How am I going to cope in the real world?

Accounting student (5s)

In this section, evidence was discussed about the effectiveness of the interventions of Instruction and Assessment to support the experience of awareness of variation in conception of learning by students in a university accounting course. In the next section, the implications of both the findings on relevance structure and on creating awareness for the ways accounting students experience conception of learning in a university accounting course will be examined. The findings on how to support change in the way students experience conception of learning in a university accounting course will then be considered.

\subsection{Implications for Conception of Learning}

I am finding it hard in this course to move from the listen, read, learn and regurgitate method of other courses to the thinking and involvement of this paper.

Accounting student $($ (s)

In this section, the implications of the findings about the awareness and experience of relevance structure and about the awareness of conception of learning for the ways accounting students experience conception of learning in a 
university accounting course will be discussed. In Section 4.1 above, three qualitatively distinct ways of experiencing relevance structure by accounting students were identified: 'gain a job', 'do a job' and 'develop personal capacities'. Also in Section 2.1 (in Chapter 2) above, the six conceptions of learning students could experience when engaging in learning tasks were outlined. These are:

A. A quantitative increase in knowledge.

B. Memorising.

C. The acquisition of facts, methods, etc.

D. The abstraction of meaning.

E. An interpretative process aimed at understanding reality.

F. Changing as a person.

The first three conceptions of learning (A-C) strongly support students to experience a surface approach to learning and the last three conceptions (D-F) can support students to experience a deep approach to learning (Van Rossum and Schenk, 1984). The first relevance structure ('gain a job') with its emphasis on grades would be supportive of conception of learning B (memorising clear-cut facts to apply in assessments):

...we only spent one 50 minute lecture on segment reporting in [a previous course], which I'll admit I didn't go to. With the limited knowledge obtained by cramming from lecture slides ... I could tell you perhaps some of the advantages and disadvantages of segment reporting because that's what I thought the exam question would be on ...

Accounting student (24)

The second relevance structure ('do a job') would be supportive of conception of learning $\mathrm{C}$ (acquiring facts, methods etc to apply in the real world):

[At] the beginning of the course [the teacher] asked us what our objectives or aims from studying [the course] ... I wrote down ... gaining skills that could benefit my future career.

Accounting student (6s)

Experience of the third relevance structure in a university accounting course ('develop personal capacities') would be supportive of one of the three high-level conceptions of learning (D-F). In this study, there was limited evidence of accounting students having previous experience in a university accounting course 
of conception of learning D, and no evidence of having previous experience of conceptions of learning $\mathrm{E}$ or $\mathrm{F}$. The conception of learning is an educationally critical, usually 'taken for granted' assumption students bring to a university accounting course. For students in this study, there was evidence their experience of how they conceive learning accounting in a university accounting course had been dominated by the experience of low-level conceptions of learning. In particular, there was an emphasis on conceiving learning accounting as memorising clear-cut, black-and-white facts (that is, technical accounting facts and concepts) and reproducing them in assessments. This was often referred to by students as regurgitation, or giving the lecture what they want to hear rather than what the student really thinks:

I believe that I have tactically manoeuvred my way through learning ... to find strategies to give the ... lecturer what they want to hear ... and I have tailored the assessment and done what I think the assessor wants to hear rather than what I believe is right.

\section{Accounting student ${ }_{(20)}$}

One student indicated they had been encouraged to focus more on 'understanding' and less on 'memorising' when learning accounting in their previous university accounting courses because they found it meant they could be more flexible in answering exam questions:

[I]n my second year of university I made it a point to understand facts although it definitely took much longer than memorizing. I realised that I could tackle any type of question given in the exam if I had thoroughly understood the material...

\section{Accounting student (2)}

For this student, the relevance of seeking to 'understand' rather than superficially 'memorize' material they did not understand was to gain marks in assessments (and thus help them 'gain a job'). This student then commented on the effect of working as an intern at an accounting firm on their conception of learning in a university accounting course, with the relevance structure of 'do a job' coming more clearly in focus for them:

...But ... the real test of my accounting knowledge was when I was interning at [a major accounting firm] over last summer. It 
definitely made me realize the importance of understanding basic accounting principles and it actually made me see the bigger picture in accounting. Many of the different aspects of accounting that I had learnt throughout my university years were now coming into play and I was expected to draw on that knowledge to help me make judgement calls. It was also interesting to see the co-relation between different aspects of accounting that I never thought would have related to one another.

\section{Accounting student (2)}

Although this student was firmly grounded in a relevance structure of 'gain a job' and then 'do a job' in relation to studying accounting in a university accounting course, and thus was focused on learning clear-cut, black-and-white facts and had lower-level conceptions of learning accounting, the student was starting to move towards a relevance structure of 'develop personal capacities' as in their internship they saw the relevance of making professional judgements to be able to 'do a job'. This required a degree of understanding (although there was no sense of this understanding being connected to the personal world of the student) which suggests a movement had been starting to take place to a conception of learning D of abstraction of meaning.

Another student had more clearly experienced a relevance structure of 'develop personal capacities' in their previous university accounting courses and was experiencing a high-level conception of learning:

My personal opinion is that we don't need to know everything about accounting ... but rather it's important to try to gain an understanding of the broad concepts of our chosen disciplines, and learn and develop the skills necessary for being a good accountant...

For example, accounting standards ... change so often, that by the time a student has been working for a couple of years (or even from the time they start their degree to when they finish), some of the accounting standards ... will inevitably have changed. In my opinion, that means ... spending time memorising standards ... is a bit of a waste of time. Further, 
anyone can pick up a standards book ... and find out what the relevant accounting standard ... says. But what everyone can't do is know how to apply that standard ... to a particular situation. And what everyone doesn't have is the necessary judgment to interpret what the consequence of the standard ... is. I think the most valuable things I ... am ... gaining in my [business] degree are the ability to read critically, the ability to write well, the ability to sift through copious amounts of material and find the key concepts or points, the ability to communicate my ideas, the ability to understand ... accounting concepts, and the ability to think critically and not to accept everything I read or am told. I think this course will be very useful to me, as it will help me in all these areas.

\section{Accounting student ${ }_{(6, k)}$}

Because this student was in a very small minority, they easily became aware of possible variation in conceptions of learning:

From talking to people in class and reading class feedback, some students seem quite obsessed with the 'real world' and learning everything they need to know for when they enter the workforce ... they are ... planning to work as accountants next year, and said that they expect to learn things in [this course] that they can use when working next year.

Accounting student (6is)

Once this student became aware of the low-level conceptions of learning of the overwhelming majority of other students, they were able to compare this with their own high-level conception of learning. Their own way of experiencing conception of learning provides the categories of variation and supports their awareness that these can be varied. However, for most students their conceptions of learning were invariably 'taken for granted' as they lacked visibility to variation both between students and within their own experience of studying accounting over time; the small minority of accounting students experiencing a high-level conception of learning could easily be 'invisible' to the large numbers of students experiencing low-level conceptions of learning. 


\section{Awareness}

Instruction in class on conception of learning was provided at an early stage in the course (as discussed in Section 4.3 above and in Appendix 5). This was supported by the integration of material about conception of learning in the early readings; by statements from past high-performing students and the teacher about the need to experience high-level conception of learning to succeed in the assessments in the course; and by the provision of feedback to students from the SPAs, Assignments and responses to critical incident questionnaires (CIQs) of other students in the course about their awareness of their conception of learning (see Section 3.1 above). This was designed to bring into focal awareness 'taken for granted' assumptions about conception of learning students were experiencing and the variation possible:

I must admit ... I have found that I have not been 'learning' in university ... I do not really understand the concepts taught and so I find myself memorising the material. I didn't realise this bad habit until this course ... In realising this I can no longer be in denial about whether I understand the concepts because it is in my subconscious now that there is no real benefit in memorising material. For this reason I have been putting in a lot of effort in trying to understand new concepts ...

\section{Accounting student ${ }^{(33)}$}

I'm very clearly seeing the difference between absorbing and regurgitating information; and understanding and applying knowledge. [The latter] is meaningful; [the former] simply generates high grades in the formal education system.

Accounting student (st)

An important finding in this study is that in response to the interventions students were able to gain awareness of the way they experience conception of learning in the context of a university accounting course; of the variation possible in their experience of conception of learning; and of the need for high-level conceptions of learning as a precondition to successfully negotiate the assessment structure and to experience deep learning. This was despite evidence of widespread 
experience of low-level conceptions of learning in previous university accounting courses. There was evidence that one of the reasons why students were able to readily understand and appreciate variation in the ways of experiencing conception of learning was because they had experience of high-level conceptions of learning in their lives outside of learning in a university accounting course (as described in Section 4.3 above).

There was evidence that awareness of variation in ways of experiencing conception of learning in a university accounting course is related to and supports deep learning by students:

I think my weakness [in] learning skill is lack of critical thinking ... my learning skill is more passive, I feel more comfortable with ... questions [that] have model answers ... I know it's not good for my study, and I really want to change it.

\section{Accounting student (59)}

The experience of deep learning by students in a university accounting course will be discussed further in Chapters 7 and 8 below. As students started to experience deep learning in the context of an accounting course the awareness of variation in ways of experiencing conception of learning supported them to be aware of different ways of experiencing their approach to learning:

I feel like the penny has dropped in terms of my own learning ... In this specific example, I gained my own understanding by searching for an answer rather than being given it. I can see that I have also been doing this for the whole paper so far and I am very excited about continuing to do so.

\section{Accounting student (20)}

The comment above also provides evidence that the experience of deep learning (learning for understanding and personal meaning) can support the experience of intrinsic motivation by students in an accounting course. This critical internal relation between the experience of deep learning and intrinsic motivation will be discussed in Section 8.4 (in Chapter 8) below.

The internal relations between conception of learning, motivation and approach to learning means more complete and complex ways of experiencing any one of them encourages and supports more complete and complex ways of 
experiencing each of the other aspects of learning accounting in a university accounting course. This is because learning is a single, integrated experience by students, with each aspect tending to be mutually reinforcing and inter-acting. It is important to support students to become aware of their built-in, "taken for granted', hidden assumptions about their conception of learning accounting as a necessary pre-condition for experiencing deep learning (Van Rossum and Schenk, 1984; Byrne and Flood, 2004).

This study also identified widespread previous experience of extrinsic motivation when studying accounting in an accounting university course, supporting contentions in the accounting education literature that this is the case (as noted in Section 1.3 in Chapter 1 above; Boyce et al, 2001). This emphasises the importance of Assessment as an intervention to connect to their awareness of variation of conception of learning and to their previous experience of extrinsic motivation to support accounting students to experience change in their approach to learning:

I am starting to understand what [the teacher] has been saying all week in respect to changing the way we learn. For the first time in four years of uni, [in this course] I am not going to be able to memorise .... and reproduce it in an exam or essay.

Accounting student (69)

The design of the assessed learning tasks supported accounting students to experience change or variation from extrinsic motivation to intrinsic motivation as they completed the learning tasks:

This is the first accounting course that has offered me the opportunity to not regurgitate black-and-white answers and to suggest answers based on my own proper judgement - there is no other explanation - I love it. I love having no definitive answers; such is the subjectivity of the real world.

Accounting student (20)

This section discussed the implications of the findings about awareness of variation in conception of learning and of the internal relations between the experience of conception of learning, relevance structure, motivation and approach to learning on how accounting students experience conception of 
learning. An important finding is that in response to the interventions in this study, students were able to gain awareness of the way they experience conception of learning in the context of a university accounting course; of the variation possible in their experience of conception of learning; and of the need for highlevel conceptions of learning as a precondition to successfully negotiate the assessment structure and to experience deep learning. This was despite evidence of widespread experience of low-level conceptions of learning in previous university accounting courses.

\section{Conclusion}

In this study, students have indicated a world of experience of learning accounting dominated by a surface approach to learning. This is consistent with previous findings in the accounting education literature (Eley, 1992; Sharma, 1998; Booth et al, 1999; Byrne et al, 2009). It could be expected that for accounting students a 'taken-for-granted' assumption about learning accounting is that it is experienced, in its very nature, by way of a surface approach to learning. This might be expressed, for example, in seeing accounting as a 'technical' subject, with clearcut, black-and-white answers that do not allow any open discussion, evaluation or search for understanding and personal meaning.

In this chapter, evidence was examined that indicated extensive previous experience by accounting students of low-level relevance structure and low-level conception of learning, which are strongly related to the experience of a surface approach to learning. The dominant previous experience of relevance structure was 'gain a job' which focused on grades as a way of supporting gaining a job. As far as the author is aware, this is the first study to identify categories of variation of the experience of relevance structure by accounting students in a university accounting course. The dominant previous experience of conception of learning was learning clear-cut, black-and white facts to reproduce in assessments. This finding was consistent with previous approach to learning research in the accounting education literature (Sharma, 1997; Byrne and Flood, 2004; Lord and Robertson, 2006).

A key focus of any set of interventions to support deep learning will be the need to vary preconditions for accounting students to experience a deep approach 
to their learning accounting. This will involve supporting students to experience high-level relevance structure and high-level conception of learning and to experience intrinsic motivation in the particular learning tasks involved in a university accounting course. In this chapter, interventions designed to support students to experience high-level relevance structure and high-level conception of learning have been considered. There was evidence that students can be supported to experience high-level relevance structure and high-level conception of learning in a university course and how this can be achieved using the interventions of Instruction and Assessment. In Chapters 5 and 6, interventions designed to support students to experience intrinsic motivation will be considered; in Chapter 7, the experience of deep learning by students will be examined; and in Chapter 8 , the focus will be on the challenges facing students to experience deep learning, including the key internal relation between intrinsic motivation and deep learning. 




\section{EXPERIENCE OF INTRINSIC MOTIVATION AND THE ASSIGNMENT}

Don't ask [the teacher] what he wants. [The teacher] doesn't want anything, instead ask yourself: 'What do I want?'

Accounting student (32)

An important element of this study is to examine how to support students in a university accounting course to experience intrinsic motivation (see Section 1.1 above). It is a key aspect of learning within the conceptual framework set out in Figure 5.1 below to support students to experience deep learning and thus be able to develop personal capabilities. In this chapter, and in Chapter 6, evidence about the effectiveness of interventions in this study to support students to experience intrinsic motivation in the learning tasks is considered. Key interventions designed to change the way students experience this aspect of how they learn accounting involve Assessment, Teamwork, Teacher-Student Relationship and Instruction.

The interventions used in this study were designed both to directly support students to experience intrinsic motivation and to indirectly support them through changes in the ways they experience relevance structure, conception of learning and deep learning. In this chapter, evidence is discussed about how the five stages of the Assignment (a central part of the intervention of Assessment in this study) supported accounting students to experience intrinsic motivation. In Chapter 6, evidence is considered about how the five SPAs (the remaining part of Assessment) as well as the interventions of Teamwork, Teacher-Student Relationship and Instruction supported the experience of intrinsic motivation. The focus now shifts from relevance structure and conception of learning to the experience of intrinsic motivation by students; while remembering that each aspect of learning accounting is inter-related and part of a single integrated experience of learning accounting in a university accounting course. The data referred to in this chapter was taken from the five stages of the Assignments completed by the students. This data was collected progressively throughout the course. The response rates for each of the five stages of the Assignments are included in Table 3.1 in Section 3.2 in Chapter 3 above. 
Figure 5.1: Interventions to Support Accounting Students to Experience Intrinsic Motivation

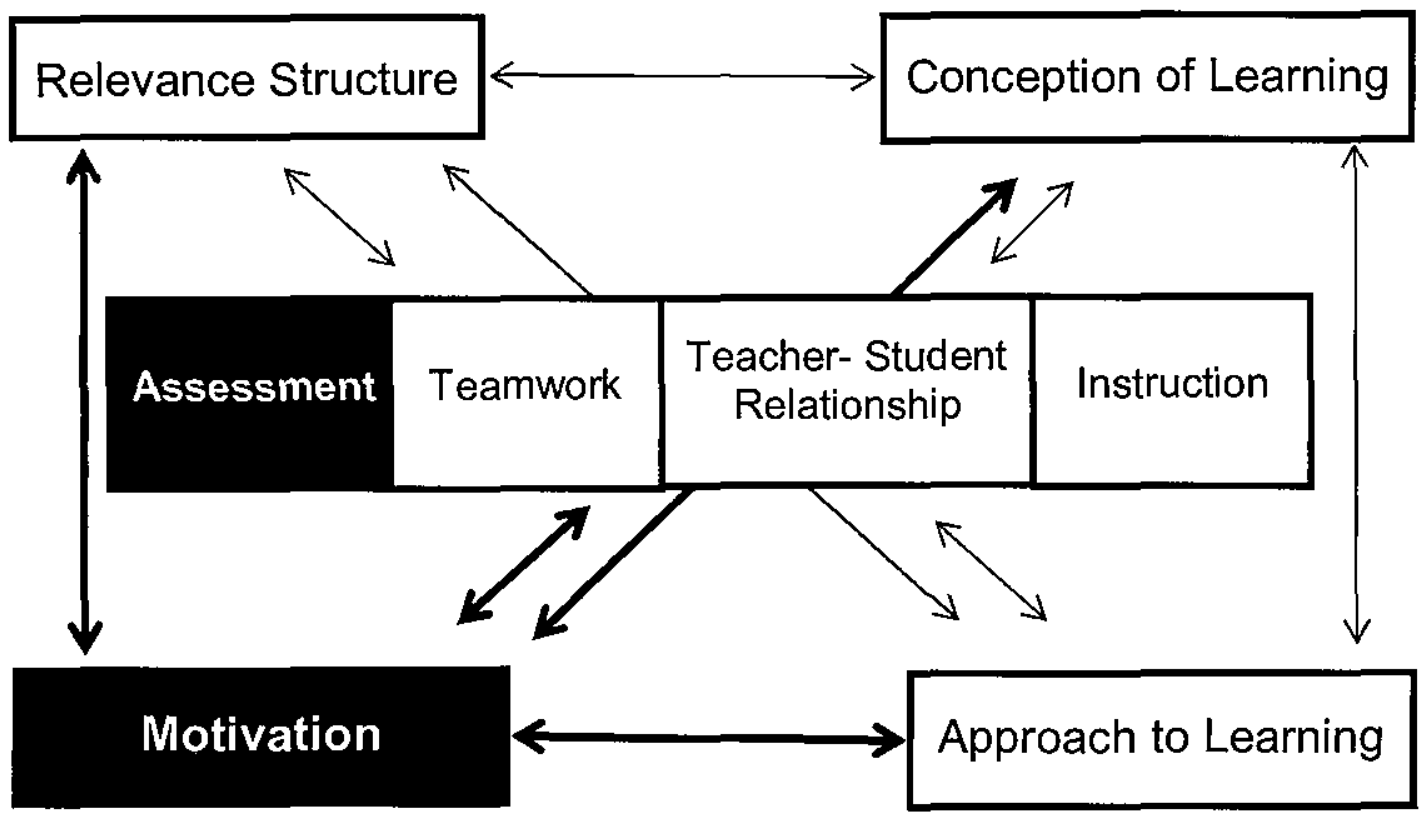

\subsection{Supporting Intrinsic Motivation}

I am surprised ... that I am getting more and more excited about coming to class.

Accounting student ${ }_{(0)}$

This section describes two qualitatively distinct types of motivation students can experience: extrinsic motivation and intrinsic motivation. Also discussed are the internal relations between motivation, relevance structure and conception of learning, and in particular how the internal relation between relevance structure and motivation can be influenced through Assessment. As discussed in Section 1.3 (in Chapter 1) above, there have been assertions (and some limited empirical evidence) in the accounting education literature that the experience of motivation by accounting students is dominated by extrinsic motivation, which is strongly supportive of a surface approach to learning (Boyce et al, 2001; Marriott and Marriott, 2003; Byrne et al, 2009). Also, there is limited research in approach to learning research in the educational psychology literature on how to support students to experience intrinsic motivation due to the difficulty of 'manufacturing' intrinsic motivation by students in relatively simple experiments involving a 
single learning task such as reading a text. For these reasons, how to support accounting students to experience intrinsic motivation in a university accounting course is currently a little understood phenomenon.

\section{Two types of motivation}

The motivation experienced by a student in relation to the learning tasks of a university accounting course can be categorised as extrinsic or intrinsic. These are two qualitatively distinct and different ways of experiencing motivation (see discussion in Section 2.1 in Chapter 2 above). The experience of intrinsic motivation does not preclude an awareness of and experience of extrinsic motivation, but can include and significantly add a qualitatively distinct dimension to extrinsic motivation. For a student to experience intrinsic motivation, their focus of awareness is on their personal interest in the experience of the learning tasks (Fransson, 1977; Marton and Booth, 1997).

As set out in Figure 5.1 above, the experience of intrinsic motivation is influenced by the internal relations between motivation, relevance structure, conception of learning and approach to learning. In Section 4.1 (in Chapter 4) above, evidence that students had extensive previous experience of low-level relevance structures of 'gain a job' and 'do a job' was considered. The experience by students of low-level relevance structures supports them to experience extrinsic motivation to do the learning tasks in a university accounting course:

... my strategy is to get good grades to increase my chances of getting a good job ...

Accounting student (4t)

In Section 4.4 (in Chapter 4) above, evidence was provided that accounting students had extensive previous experience of low-level conceptions of learning. The first relevance structure ('gain a job') was supportive of the second conception of learning (memorising clear-cut facts to apply in assessments) since the gaining of good grades in assessments was seen by students as important in gaining a job. The second relevance structure ('do a job') was supportive of the third conception of learning (acquiring facts, methods etc to apply in the real world). The dominant experience by students of low-level relevance structure and 
low-level conception of learning were mutually supportive of each other and of the experience of extrinsic motivation.

\section{Internal relations}

An important focus of this study has been to examine the effectiveness of interventions in the design and delivery of a university accounting course to support students to experience high-level relevance structure, high-level conception of learning and intrinsic motivation. There was evidence the experience of a high-level relevance structure (such as 'run a business/invest' which is identified and discussed in Section 5.2 below) and high-level conception

of learning can influence and support the experience of intrinsic motivation in the learning tasks:

This [reading] automatically caught my eye because one of the main reasons of my [business degree] is to be involved in a successful business ... This [reading] is appealing and relevant to me as I am interested in what to look for in making a good investment decision. It is especially fascinating when this advice comes from someone who had 'been there and done that' and triumphed.

\section{Accounting student (33)}

Also, there was evidence the experience of motivation can influence and support the way students experience relevance structure and conception of learning:

... if I ... am not motivated enough by the material ... I will do the minimum throughout the [course] and cram for the test and exam ...

\section{Accounting student (43)}

The experience of relevance structure is important to support students to develop personal meaning from doing the learning tasks. It can have an important influence on the type of motivation experienced by a student. For example, there was evidence that where a student sees the meaning from doing a learning task as helping them to 'gain a job' in the future, they will tend to focus on maximising grades and will tend to resist making personal connections with the learning tasks: 
... unless a university paper has material that I am interested in then I am not going to learn because the only use that paper is to me is the mark I receive from passing. I am at university because I want to be a professional accountant ... I would not get hired until I complete a degree in accounting ... That is why I will not learn anything ... other than to memorize the material the day before the exam.

\section{Accounting student (25)}

This student prefaced their comment above with the proviso that "unless a university paper has material that I am interested in..." indicating awareness about the internal relations between motivation, approach to learning and relevance structure. There was evidence that students were aware of these internal relations and that their experience of extrinsic motivation supported their experience of surface learning:

I almost forget everything I've learnt after [the] exam ... But the subject I'm really interested in I would hardly forget ... I choose money and finance because ... it involves a lot of maths and I quite like it. However, I choose accounting just because I think I can get a job later on.

Accounting student (46) ...superficial learning is the best thing for those ... papers that you just have no interest in...

\section{Accounting student (22)}

The experience of a high-level relevance structure of "develop personal capabilities' would tend to encourage students to experience intrinsic motivation as they would tend to be more likely to be focused on what they are personally gaining or learning from doing the learning task. In Chapter 4 above, the experience by students of relevance structure in previous university accounting courses was discussed as well as issues concerning supporting accounting students to experience high-level relevance structure. The focus will now turn to the internal relation between the way accounting students experience relevance 
structure and their experience of intrinsic motivation and also on how the internal relation between relevance structure and intrinsic motivation can be influenced.

\section{Connection to relevance structure}

... the reason we don't truly understand [course] work is ... because we think it's not really important or that relevant. I had to take a step back and think what has made this course so different? ... What [the teacher] has essentially done in this course ... is [to] alter our way of thinking ... challenged us ... and made us think certain facts or points were extremely important both in university and outside ...

\section{Accounting student (7)}

The experience of a high-level relevance structure can support students to experience intrinsic motivation in the learning tasks. The experience of a relevance structure assists students to understand why they are doing the learning tasks, giving them an idea of what they are aiming at or heading towards and what the learning tasks demand and where doing the learning tasks might lead them (Laurillard, 1979). Supporting students to experience a high-level relevance structure can support them to see the learning tasks as personally meaningful and can help to arouse curiosity as they gain a sense or initial limited understanding of the possible outcomes for them of completing the learning tasks and the challenge to them of actually completing the learning tasks and achieving personally relevant learning outcomes. Thus the relevance structure can prepare students to anticipate and expect in a positive way the expected learning tasks (Marton and Booth, 1997).

In this study, a key intervention designed to support a change in the way students experience relevance structure was Assessment. The Assessment used in this study involved individualised, authentic learning tasks with regular formative feedback (Entwistle and Ramsden, 1983; Ramsden, 2003). The learning tasks in the Assessment are described in Section 3.1 (in Chapter 3) above and in Appendix 1. The use of real companies supported a sense of practical relevance of the learning tasks, in particular connecting to the experience of a relevance structure of 'do a job': 
What made it so important or significant was the fact that we looked at real companies with actual data and figures, not just a hypothetical situation or made up figures. This provides that extra confidence that the work we did was practical and applicable to what we can expect outside in the field.

\section{Accounting student (7)}

This sense of relevance (or experience of relevance structure) can prepare students to anticipate and expect in a positive way the expected learning tasks. This curiosity and sense of expectation was expressed by students in a number of ways. For example, in the first stage of the Assignment there was a sense of discovery and curiosity in finding out how to use a firm's financial statements to personally engage with a firm's economic and business reality:

I feel there is a ... point to all this data that can't be shown in financial statements - it goes deeper than the ink used on those glossy figures - but how do I get to it? How do I get to the roots of these 'picture-perfect' profits?

\section{Accounting student (s)}

In this way, students were encouraged to go beyond the 'signs' (the numbers in the financial statements) to what they 'signify' (the economic and business realities of a firm). There was a sense of curiosity about going from the known to the unknown:

...I feel like I just want to rip open the financials and see what happened to make these things happen!

\section{Accounting student (6)}

This curiosity and sense of expectation supported students to experience intrinsic motivation:

I'm really interested to know what's going on! I'm seeing these numbers and I want to know what's behind them. It's like I'm reading a novel that I just can't finish quickly enough. 
This curiosity, sense of expectation and developing intrinsic motivation was strongly related to the Assessment design involving assessed learning tasks of analysing individual, real firms:

Throughout this whole semester I have been curious to see what the end result of my analysis would be.

Accounting student (50)

The answer to [the teacher's] question: 'Are you curious about how your firm works?' is absolutely.

Accounting student (20)

Thus a connection by students to their relevance structure can prepare and support them to experience intrinsic motivation in the learning tasks:

...[in] my other accounting papers ... I was forever trying to figure out when I was actually going to use what I was learning in the 'real world'. I have spoken to many accountants who say that what they learnt at university is irrelevant to what they do in their accounting jobs ... But it seems this will not be the case for this paper ...

Accounting student (I))

Once students are aware of the connection between the learning tasks and their relevance structure they have built a foundation to support them to experience intrinsic motivation in the learning tasks:

...I reminded myself why I'm so glad I took this paper. After I graduate my job is about analyzing firms and how to improve them ... to do this I will need to understand the business and learn how it operates. It won't be just about number crunching and gathering information. I think it is quite fitting that one of my last papers is truly going to be useful.

Accounting student (19) 


\section{Change in relevance structure}

...my own experience [is] that [the] learning experience is much more important than [the] grade.

Accounting student ${ }_{(45)}$

For students who commenced the course with a relevance structure of 'gain a job', their focus was on achieving a good grade for the purpose of helping them to gain a job. As discussed in Section 2.2 (in Chapter 2) above, there is evidence most accounting students are motivated by the grading system in a university accounting course (Boyce et al, 2001). For these students, Assessment design had the potential to have a potent effect on supporting change in their way of experiencing relevance structure. These students commenced the course focused on completing the learning tasks that are being assessed solely for the purpose of gaining a good grade:

...when I first started this course how much I looked forward to having done all the [assessments]; or in other words having 'ticked all the boxes' of [the course] ... my desire of actually learning something wasn't that high up on the list ... I was more concerned with just finishing the course, and more importantly finishing it with a good grade!...

\section{Accounting student (ss)}

By the time this student came to the end of the course, the intervention of the Assessment design (involving individualised, authentic learning tasks with regular formative feedback) had supported a change in the way they experienced relevance structure in the course from 'gain a job' to 'develop personal capacities'. Also, the experience of deep learning influenced their experience of relevance structure as they experienced the benefits of developing their capacities to think for themselves and the relevance to them of being able to 'develop personal capacities':

...Now that I am at the end of the course I have realised that I have gained a lot more from this course than just a mark! This paper has challenged me to think ... has been very 'real' and has taught me how to think for myself which is far more 
valuable than having another $\mathrm{A}$ on my transcript (but yes an $\mathrm{A}$ on my transcript would be very nice).

Accounting student (ss)

In this section, evidence about the effect of the intervention of Assessment on the relevance structure of accounting students was considered as well as evidence about how students were able to connect completing the assessed learning tasks to their relevance structure. In the next section, the experience by accounting students of a fourth relevance structure of 'run a business/invest' will be discussed. The effectiveness of the first two stages of the Assignment on the changes in the ways students experienced motivation in the learning tasks will then be examined.

\subsection{Response to Assessed Learning Tasks}

I must admit I could not have picked a better company to study ... [My firm] is a fun, interesting company ... that I can relate to ... I'm looking forward to continue working with [my firm].

Accounting student (Assignment slage 1) (7)

In this section, the response of students to the early assessed learning tasks in this study will be considered. However, first evidence will be presented concerning the experience by accounting students of a fourth relevance structure of 'run a business/invest' which has been identified in this study. The findings on the ways students experienced motivation in response to the learning tasks in the first two stages of the Assignment will then be provided.

As outlined in Section 3.1 (in Chapter 3) above, the Assessment design involved two types of assessment: analysis of their own individual listed company (an Assignment in five stages) and completion of reflective assignments on the readings (five SPAs). The Assignment and SPAs involved individualised, authentic assessments with regular formative feedback. The listed companies analysed were different for each student and were real companies. The Assignment was divided into five stages, with formative feedback provided to students after each stage. The SPAs required students to personalise their responses, connecting them to their prior knowledge and previous experience (that 
is, were individualised and authentic). Formative feedback was provided to students after each SPA. Further details on the assessed learning tasks for each stage of the Assignment and SPAs are included in Section 3.1 in Chapter 3 above and in Appendix 1.

\section{Run a business/invest}

As the experience of relevance structure of students in this course was examined there emerged a fourth category of relevance structure, which has been labelled 'run a business/invest'. This relevance structure is seen as more complete and complex than the relevance structures of 'gain a job' or 'do a job' and less complete and complex than 'develop personal capabilities'. 'Run a business/invest' and 'develop personal capabilities' are seen as high-level relevance structures supportive of high-level conceptions of learning, intrinsic motivation and deep learning. In this study, a number of students indicated a reason why they were studying a business degree was to help them to be able to run a business or to invest in the future:

One of the main reasons of my [business] degree is to be involved in a successful business.

\section{Accounting student ${ }_{(33)}$}

Using my accounting ... knowledge to earn income from investments is something that I hope to pursue in the future and this course will provide valuable help in this area.

\section{Accounting student (ss)}

Lucas (2000) also found some evidence of 'run a business/invest' as a latent or potential relevance structure in her study of an introductory accounting course: “...that if I do want to establish my own business then I am going to have to go back to accounts ... I know I'm going to have to try and get to grips with it and put all my fears aside. One day." (Lucas: 2000: 492). In this study, the Assessment connected to the experience by students of a relevance structure of 'run a business/invest' and in this way supported them to experience intrinsic motivation in the assessed learning tasks:

I would like to invest into a business in the near future or start my own ... [I am] interested in these readings [in a SPA] 
because they illustrate [Warren Buffett's] way of thinking and investing [Warren Buffett is the world's 'most successful' investor].

Accounting student (29)

I hope that over this course I will gain a greater understanding of how to read and 'pick apart' an Annual report, so that when I decide to begin investing I will have the knowledge and skills to utilise the information available to make a good investment decision.

Accounting student ${ }_{(65)}$

The Assessment also supported students to change to a more complex and complete way of experiencing relevance structure. For many students this involved an initial movement from experiencing a relevance structure of 'gain a job' to 'do a job'. This was often experienced in such a way as to indicate openness to potentially experiencing high-level relevance structures of 'invest/run a business' or 'develop personal capacities':

The fact that I will be gaining knowledge which I will take with me after I have finished this course is refreshing.

Accounting student (17)

I am looking forward to being taught on areas that I can apply to situations outside of university (of which I have found lacking in other papers).

Accounting student (25)

As students progressed through the Assessments this connection to their experience of higher-level relevance structures and to a sense of gaining something of personal value from completing the learning tasks supported and reinforced their developing intrinsic motivation:

I found the assignment ... to be really fun and exciting ... I feel

that this was an amazing experience for me which will help me so much in the future.

Accounting student (49) 


\section{Assignment (stage 1)}

"Everyone I spoke to seemed pretty enthusiastic about their companies too. I love how everyone is already really 'in to' their company, and everyone appears to be chomping at the bit to get their teeth into further analysis of their firms."

Accounting student (Assignment stage 1) (68)

The learning tasks in the first stage of the Assignment (involving analysis of individual, real companies) had an immediate impact on the experience of motivation by students to complete the learning tasks. In stage one of the Assignment, students were able to feel a personal connection and relationship to the particular, real firm they were analysing. Because the firm they were analysing was a real firm, it was possible they might already have a personal interest in the activities of their firm:

I am happy with my firm ... I have a particular interest in [the] aviation industry (I used to have [the] ambition to become [a] pilot before turning to [being an] accountant).

Accounting student (Assignment stage 1) (I)

After reading what [my firm] actually does I found it really exciting, because I love the IT industry.

Accounting student (Assignment stage 1) (3i)

I am very excited to have [my firm] to analyse. Although I do not have [my firm's product] connected at home, I am quite interested in the company. I enjoy all forms of entertainment and entertainment is essentially [my firm's] underlying business.

Accounting student (Assignment stage 1) (33)

It was also possible they might have a previous personal connection with their firm itself, either as an employee, from seeing their advertisements or their activities, or from buying their products:

I am very interested in [my firm] as I worked at [my firm] until recently ... I feel as though I have some "inside information" on 
the company and am really looking forward to getting to know more about the company.

Accounting student (Assignment stage 1)(ss)

[My firm] is a really famous building company in New Zealand ... I am an international student, [and] I knew this company when I walked ... to the [university] campus. [My firm] was [redeveloping a building on campus]. And later on, I ... heard [about my firm] ... from the newspapers, advertisements and [on signs on] commercial buildings, motorways, homes ...

Accounting student (Assignment stage 1) (12)

I'm happy with the firm I've been given to analyse ... The products personally interest me as my family and friends use [them] so they're all awaiting the outcome of [my] ... analysis.

Accounting student (Assignment stage 1) (s7)

My parents live in Hamilton [a provincial city in New Zealand] and, over the last few years, the number of houses in Hamilton seems to have doubled based on huge housing developments stretching from all sides of the city. A number of these developments were, in fact, done by [my firm].

Accounting student (Assignment stage 1) (2l)

Students were also able to find analysing a real firm with a real business interesting without having any previous personal connection with the firm:

I really enjoyed reading about the individuals who had had various ear implants. It made me feel like I was engaging personally with the company; getting to 'meet' some of [my firm's] ... customers. The report goes on to explain ... how an ear implant actually works, which amazed me. I did not previously have any knowledge about hearing impairments, and how they can be lessened or completely overcome.

Accounting student (Assignment stage 1) (17) 
I can't believe I say this, but I'm looking forward to analysing [my firm] some more. Considering I don't have an interest in fishing or anything like that, I'm enjoying learning about it and about the company.

Accounting student (Assignment stage 1) (29)

While talking to a few of the petrol heads I know I [asked] them about what they thought about [my firm] and whether they had been a customer before ... One of my friends ... had, for a short while, bought cars from [my firm] and then sold them privately for a bit of margin ... He said ... there have been a declining number of dealers buying from [my firm]. I thought funny you should mention that I read about that in their annual report! $\mathrm{He}$ also said that the auction environment was quite intimidating to a lot of mum and dad buyers. Of particular interest to me was his comment about Trade-Me [an auction internet competitor] causing increased competition. 'WOW' I thought, that was a really interesting and worthwhile conversation (worth the couple of beers).

Accounting student (Assignment stage 1) (42)

Because each student had a different firm to analyse this also supported them to feel a personal connection with their firm:

Generally, I am pretty happy with the company I am to analyse ... It's funny, I find myself wanting [my firm] to succeed ... Why should I care about whether they perform well or not? I will have to make sure this desire doesn't subconsciously affect my analysis - try not to get too attached?

Accounting student (Assignment stage 1) (2l)

At first I was very sceptical about [my firm] and me having the ability and drive to understand a totally new business ... I believe that [my firm] was given to me for a reason and am starting to become really interested in the workings of [its business]. 
The experience of starting to analyse their individual, real firm in the first stage of the Assignment laid a foundation for the development of intrinsic motivation in the learning tasks. Indeed, there was evidence of a significant and immediate shift in the way students experienced motivation in the learning tasks in response to the first stage of the Assignment:

I am really enjoying my firm. I think it's a clever New Zealand company and ... I can identify its business plan. I find the more I look the more questions I have! Which is a good thing; I am intrinsically motivated!

Accounting student (Assignment slage 1) (6)

I also spoke to [another student] whose analysing [another firm]. She is in love with her company. She says she read every single word in the Report as she found it to be so exhilarating.

Accounting student (Assignment stage 1) (49))

After reading for a while, I found that I was actually enjoying reading [my firm's] financial statements and I was eager to read further to learn and understand more.

Accounting student (Assignment stage 1) (19)

Students who gave no evidence of experiencing intrinsic motivation in the first stage of their Assignment tended to focus on the surface level and resisted connecting personally to the richness of the individual, real firms:

When I discuss[ed] with other group members ... I ... found similarities ... all our companies [were] operating in Australia and New Zealand and all companies adopted IFRS [International Financial Reporting Standards, as required of all listed companies in Australia and New Zealand] in their financial reports. The difference is that [we] have companies in different industries...

Accounting student (Assignnent stage 1) (77) 


\section{Assignment (stage 2)}

The second stage of the Assignment involved students completing a largely technical exercise of restating their firm's financial statements, although there was also the need for them to begin to make a range of judgements. There was evidence students found this task challenging and yet also experienced intrinsic motivation in this learning task:

I found this task to also be refreshingly challenging and once I started getting into all the finer details of the statements, I found it incredibly hard to put them away and move on to do something else.

Accounting student (Assignument stage 2) (49)

To complete the second stage of the Assignment, students needed to discuss much more with other students and with the teaching staff and there was evidence the interventions of Teamwork and Teacher-Student Relationship also supported their experience of intrinsic motivation:

Surprisingly, I had fun in restating. The method is just amazing and it was fun to talk to friends and tutors to get things sorted; at the same time I have learned a lot from them and the readings. I have to say that I definitely had a good time in doing this assignment!

Accounting student (Assignnent stage 2) (8I)

In this section, evidence of a fourth way of experiencing relevance structure by accounting students of 'run a business/invest' was provided. There was no evidence accounting students had experienced this relevance structure in their previous university accounting courses. However, experience of this relevance structure quickly emerged in response to the intervention of Assessment in this study. Evidence was outlined that the experience of relevance structure of 'run a business/invest' and 'develop personal capabilities' supported accounting students to experience intrinsic motivation. The effect of the intervention of Assessment on the experience of motivation by students was then discussed, examining evidence about how students experienced aspects of the ways of learning accounting in response to completing the learning tasks in the first two stages of 
the Assignment. In the next section, evidence about the effect of the intervention of the next two stages (stages 3 and 4) of the Assignment on the experience of intrinsic motivation by students will be considered.

\subsection{Response to Increasing Challenges}

...assessing real companies ... can be quite exciting ... Also the fact that each individual in the class ... had a different company makes us kind of special. [The teacher] sees us each as individuals and having different companies separates us from each other. No one has our company so no one can look at ours and be like hey I've done this and you haven't. We can each do our own thing without being judged by other class mates. It is our own opinions and we cannot be proved wrong until in the future when we see the outcomes of the economic and business drivers.

\section{Accounting student (10)}

In this section, the responses of students to the third and fourth stages of the Assignment are considered. As students experienced each stage of the Assignment they faced increasing challenges as they experienced the substantial cognitive effort involved with deep learning. The experience of intrinsic motivation was critical to support them to persevere in the face of these challenges and to experience sufficient confidence to believe in their capacity to make the increasingly difficult judgements involved in the Assignment.

\section{Assignment (stage 3)}

The third stage of the Assignment involved the calculation of ratios (a largely technical exercise which also involved a range of judgements) as well as a critical assessment of what these ratios told them about their firms. The complexity and difficulty of the judgements increased in this stage of the Assignment compared to the previous stage of the Assignment. This stage of the Assignment required students to focus much more on understanding and developing personal meaning to be able to make their own assessments. Students found that their focus on 
understanding and developing personal meaning in the learning tasks was personally interesting to them:

...what made the ratios so interesting for me is the meaning behind them. I think that ratios cannot be taken [at] face-value; one must know the meaning behind the figure to fully grasp why the figure is what it is.

\section{Accounting student (Assignment stage 3) (20)}

Supported by the intervention of Teamwork, students were also becoming aware of the experience of intrinsic motivation by other students in the course:

$\mathrm{He}$ [another student in the course] was really excited to find out how well [his firm] is doing ... In fact his insights from this exercise have been so thorough that he is even considering buying shares in his company.

\section{Accounting student (Assignnent stage 3) (49)}

With the focus in the third stage of the Assignment firmly on requiring students to use the accounting numbers to support them to understand the economic and business realities of their firm, students were increasingly taking the opportunity to engage directly with their firms in various ways:

I recently travelled up to Auckland and I took the time to go into a store [of my firm] as well as Dick Smith and Harvey Norman who are two of [my firm's] biggest competitors ... It was a massive contrast in customer service and retail experience!

Accounting student (Assignment stage 3) (25)

[My firm] has only one or two quite conservative sales each year, which mainly seem focused at getting rid of end of season clothes (I recently went to one of these sales, and it was mainly winter clothes and the sales assistant said they were about to get the spring/summer range in). In contrast, Country Road [a competitor to their firm] has frequent sales where clothes can be as much as $75 \%$ off ... I wonder if this could be an indicator that [my firm's] combination of ATO and PM [two key ratios] is working quite well, whereas Country Road's is not ideal. I 
suggested this to [another student analysing Country Road] and she is going to investigate this further.

Accounting student (Assignment stage 3) (68)

With their developing understanding about their firms, students were also getting more personally engaged with their firms:

...I feel like I have a pretty good idea of what the ratios I was looking at actually mean (and don't mean). We've laughed together, we've cried together, we've talked about our deepest secrets, and at the end of the day it's fair to say that we're pretty tight. I'd definitely call them "my boys," and I'd like to think that they'd say the same about me.

Accounting student (Assignment stage 3) (2t)

There was also a sense of growing expectation about completing the next stages of the Assignment. An overall view of each of the stages of the Assignment and of analysing firms had been given to students at the beginning of the course and repeated a number of times as they progressed through the course. Students were thus able to see how they were progressing in their analysis and what increasingly difficult steps were ahead of them:

I'm not sure ... how to connect these accounting drivers to [my firm's] economic and business realities. However, I'm excited about doing this and in making my own judgements, which is coming up for the next assignment!

Accounting student (Assignment stage 3) (32)

By this stage, students were finding the learning tasks of analysing their firms challenging while also experiencing intrinsic motivation in the learning tasks involved:

This assignment took me ages ... But you know what? I would have done it even if it had been worth $0 \%$. I'm learning stuff... at uni... who would [have] thought. Intrinsic value eh?

Accounting student (Assignument stage 3) (21) 
The exercise of financial statement ratios and deriving accounting drivers has been a frustrating yet very rewarding experience.

Accounting student (Assignment stage 3) (sol)

Also adding to the sense of intrinsic motivation in the learning tasks was a developing awareness of the value to them of the learning they were experiencing in doing the learning tasks, demonstrating the internal relation between relevance structure, conception of learning and intrinsic motivation:

I have learnt skills I can now apply to other companies and I value this knowledge/experience more than I first thought possible.

Accounting student (Assignment stage 3) (4t)

The individualised learning tasks (a different firm for each person) were also continuing to contribute to a sense of intrinsic motivation and personal ownership of their learning:

I gained insights as to [aspects of] my [firm] (it's my company and no one else's!!)

Accounting student (Assignment stage 3) (56)

\section{Assignment (stage 4)}

I remember I met with [another student] to discuss Assignment [stage 4], and we were supposed to meet for only 1 hour but it ended up being 2 hours. Time flew by so quick, we both laughed at the end at how we could talk about financial statement analysis for 2 hours out of class time. We began to realise that we were both really interested in our firm, how it compared with others, and how it's affected by the current economy.

\section{Accounting student (65)}

In the fourth stage of the Assignment the complexity and difficulty of the judgements required of students increased substantially compared to the previous stage of the Assignment. The focus of this stage of the Assignment was on 
students connecting their analysis of their firm's past financial statements with their firm's economic and business realities. This involved students making intuitive leaps from the accounting numbers (the 'signs') to the economic and business realities of their firm that were in their opinion causing or driving their firm's accounting numbers (the 'signified'). There were now no 'right' or 'wrong' answers; simply judgements that were more or less convincing. There was evidence students were personally identifying with 'their' firm, for example referring to 'we' and 'us' when discussing their firm:

[My firm] has ... expertise in apple products. This makes people believe we make great products. As people believe or know that we have expertise in making good products, it tends to makes people rely on us and buy product from us.

\section{Accounting student (Assignment stage 4) (31)}

Students were also feeling personally connected to and involved with 'their' firm:

[The teacher] has spoken about people 'falling in love' with their firm. I think that is essentially what is happening to me, I want [my firm] to succeed.

\section{Accounting student (Assignment stage 4) (17)}

The quality and amount of Teamwork and interaction between students continued to increase significantly with the fourth stage of the Assignment, as the value and importance of meaningful interaction with others to be able to make the increasingly challenging judgements required became increasingly apparent to them:

After the discussion with [another student] about the key economic and business drivers of our firms, we went on to discuss about ... kiwifruit. She said her grandmother who lives in the US loves kiwifruit so much and ... in the US it costs about US\$5 to US\$6 per kilogram ... compared to New Zealand which is only about NZ\$1 to NZ\$3 per kilo ... [Another student] also said that she loves kiwifruit and her friends who live in Japan also love kiwifruit, they will purchase them ... even [if] they are a little [more] expensive. Are all these discussions a waste of time? No, of course not! These discussions are critical when it 
comes to forecasting [my firm's] key economic and business drivers.

Accounting student (Assignment stage 4) (32)

Students also responded positively to the opportunity of being able to think for themselves and make judgements about their own firms:

This whole process has enthused me and is continually making me think and connect everything that is going on in the world with [my firm]. I even talked about [my firm] in a job interview I had on Friday!

Accounting student (Assignment stage 4) (24)

The benefit of authentic learning tasks involving real companies was also apparent as students were able to access information about their firms in creative and thoughtful ways:

I personally like the look of [my firm's] clothes, but I am not the target audience! Talking to my 11 year old sister and her friends, Urban Angel clothes (part of [my firm's] product [range]) are apparently very 'cool', and all of them seem to have a huge collection of Urban Angel clothes. My sister said that although she didn't think that people on the Disney channel wear [my firm's] clothes, a few of the younger stars on Home and Away [an Australian TV show] do, and [my firm's] clothes are quite similar to the Hannah Montana's clothes (apparently a popular Disney star).

My mother ... said that she likes buying [my firm's] clothes for my sister because they are very good quality, well made, and they use nice fabrics and designs. She also said that although they are more expensive than clothes from Farmers or the Warehouse, they are still reasonable for the quality you get, and are far better quality than the 'boutique' children's clothes which are very expensive, and better quality than the Just Kids brand.

Judging from that very limited amount of market research... 
[My firm] is in an upmarket apparel niche with a strong trend power. The trend power was evident yesterday when ... [my firm's] sale bags began to appear around ... campus. I soon learnt that [my firm] started their annual end of mid season sale that day. Just from the sales bags appearing in large numbers it was obvious that the company has a well known brand name within younger generations who attend university ... After class I decided to check out the sale ... After talking to one of the sale assistants I learnt that people had lined up before the store opened to get to the sale items first. She also commented that by $5 \mathrm{pm}$ nearly $60 \%$ of the sales items had gone and that they had been so busy that she had only stopped for a $5 \mathrm{~min}$ break all day.

\section{Accounting student (Assignment stage 4) (69)}

Recently I asked my sister who lives in Melbourne to go in and experience how it is like shopping at [my firm]. She ... visited the store in Dandenong. She also took two of her friends ... this is what they had to say...

Accounting student (Assignment stage 4) (50)

There was also evidence of students experiencing intrinsic motivation: I remember in [the first stage of the] Assignment I had never heard of [my firm] but now it seems as if it is a part of my knowledge and experience. When I go grocery shopping I always try to 'mystery shop' and point out to my parents which brands ... are owned by [my firm]. This makes grocery shopping just a tad bit more interesting! I also find that even out of lecture times, I and other students are always discussing our firms and recent news events that could impact it. This is amazing, definitely not what I expected from studying an [accounting] course.

Accounting student (Assignment stage 4) (65) 
...once the ball started rolling [in doing the assignment] it was

difficult to stop!

Accounting student (Assignment stage 4)(ss)

And there was a strong sense of expectation of completing the final stage of the Assignment and valuing their firm:

I am looking forward to forecasting [my firm's] activities!

Accounting student (Assignment stage 4) (33)

I am very interested in determining my final price for [my firm].

Accounting student (Assignment stage 4) (s)

Students who did not experience intrinsic motivation in the learning tasks of the fourth stage of the Assignment found they could analyse relationships between the accounting numbers (the 'signs') but could not connect the accounting numbers to their economic and business drivers (the 'signified'), which required personal judgements and an experience of deep learning:

...connecting [my] firm['s] key accounting driver[s] and my view of [my] firm's economic driver[s] ... is ... [a] struggle for me ... I feel [it] is not possible to connect [my firm's] key accounting driver[s] with [its] economic and business driver[s]... Accounting student (Assignnent stage 4) (78)

Also, students who were finding they could not make these judgements were aware of the importance of Teamwork to support students to be able to make these judgements and that their weakness in working well with others was a significant factor in the difficulties they were having:

I realise ... group work ... improve[s] your thinking and skill ...

From this course I realise ... discussion is very important. I am ... not good at this. I was very disappointed [at this].

Accounting student (Assignment stage 4) (79)

In the third and fourth stages of the Assignment, the complexity and difficulty of the judgements required of students increased substantially. These stages of the Assignment required students to focus much more on understanding and developing personal meaning to be able to make their own assessments. The experience of intrinsic motivation supported them to persevere in the face of these 
challenges, to make the substantial cognitive effort involved and to experience sufficient confidence to believe in their capacity to make the increasingly difficult judgements involved. In the next section, evidence about the experience of intrinsic motivation by students in response to the fifth stage of the Assignment will be considered.

\subsection{Experience of Intrinsic Motivation}

In this section, the experience by students of intrinsic motivation in the learning tasks of the fifth stage of the Assignment is considered. The fifth and final stage of the Assignment gave students the opportunity to integrate what they had learnt throughout the course into their final valuation of their firm. Students found they actually cared about the learning tasks in the fifth stage of the Assignment and felt completing a valuation of their firm was an authentic achievement that was personally relevant and meaningful. A certain amount of self-confidence was also required to make the extensive and challenging judgements required in the fifth stage of the Assignment. Although it became apparent to students that many in the course were experiencing intrinsic motivation in the learning tasks in the fifth stage of the Assignment, there were also some students who were aware that they were not.

\section{Assignment (stage 5)}

...in my five years at university this is only the second time ever that I have still been working on an assignment at midnight. The last time was when I had a report due in the next day. This time, the deadline is still two days away and I am only working because I WANT to not because I have to! I might not be that good at forecasting yet, but I have found my passion. I have always been interested in investing ... but have never been stimulated to further this interest as I have in this course. I now am confident enough to have a go, putting my money into a company that I have analysed.

Accounting student (Assignment stage 5) (4I) 
The fifth and final stage of the Assignment involved students forecasting the economic and business drivers of their firm. They then needed to connect their forecasts to aspects of their firm's future financial statements and then to apply a valuation framework to value their firm. This involved students 'dreaming dreams' for their firms, seeing a range of potential future realities and carefully linking these qualitative assessments to future accounting numbers and to a considered, thoughtful and reasoned view of the value of their firm:

Feel free to have a play with the spreadsheet; I spent a good few hours dreaming about the future. It's kind of fun.

Accounting student (Assignment stage 5) (2l)

\section{'I actually care'}

As they completed the fifth and final stage of the Assignment there was awareness by students that they (and others in the course) had been experiencing intrinsic motivation in the learning tasks of analysing their firm. Students found completion of an analysis of their firm to be personally rewarding:

...we have had the opportunity to delve into the life of a real business looking past the set of numbers presented in a set of financial statements. This has been both challenging and at the same time very rewarding ... there was more to this assignment than simply getting a grade. I felt more compelled to find an answer to the questions that I had posed to myself at the start of this course when I was given [my firm] to analyze. To do all the hard work ... and to finally come up with ... a valuation ... for my company has been very rewarding ... There has been a constant urge to find out the ... value of my company throughout my time in the course and to finally get there is extremely rewarding.

Accounting student (Assignment stage 5) (49)

Students also found the actual experience of doing the learning tasks in the fifth stage of the Assignment to be fun and enjoyable:

I actually find this really fun... 
I have thoroughly enjoyed using the [valuation] framework and applying it to [my firm]. It has been soooooo interesting. I would not say I have fallen 'in love' with my company but I do feel some sort of a spark, and this is the first company I have ever looked over.

\section{Accounting student (Assignment stage 5)(26)}

Students found they actually cared about the learning tasks and their learning in the course:

This is the first course where I've worried about what my marker will think of me as an academic student and of me as a person. This is the first time I've got physically upset about an assignment. This is the first time I've been compelled to get in a heated conversation about a topic. So I ask myself - why am I doing this? There must be some reason that I am getting upset or heated. It's because I actually care...

Accounting student (Assignment stage 5) (3)

\section{Authentic achievement}

Students also became personally involved with the results of their analysis and of the learning tasks:

I have noticed people becoming more and more defensive of their companies. It really is quite incredible how attached some classmates have become with their company ... [One student] was in an intense battle with [another student] over whose company was better.... [One student] concluding his argument with "my company is $\mathrm{F} * * * * * *$ mint okay!" But [this student] is not alone - whilst [I was] trying to [question] some of the underlying assumptions in [a third student's] analysis, he became extremely defensive implying that I was personally attacking him.

Accounting student (Assigniment stage 5) (42) 
There was a sense of being motivated to give the learning tasks considerable effort and their 'best shot':

...when you do get stuck into your company it's hard to get out until you've given your assignment your best effort.

Accounting student (Assignnent slage 5) (47)

There was experience of enjoyment and personal satisfaction in having met the significant challenges of the fifth stage of the Assignment:

...this is the [stage of the] Assignment that I love the most! I'm very happy with the result of my analysis based on my own judgements! ... I loved it because I felt like I was a real analyst! Accounting student (Assignment stage 5) (32)

There was a sense of personal achievement and worthwhile accomplishment in completing the fifth stage of the Assignment:

The previous [stages of the] Assignment were a build up to this one and therefore completing this [stage of the] Assignment is the most rewarding. The best part was plugging the numbers into the formula to get the [valuation]. At that moment I felt like I had accomplished more than just calculating one number! Accounting student (Assignment stage 5) (33)

\section{Personally relevant}

The experience of a high-level relevance structure supported a strong sense of curiosity about the outcome of future learning tasks in the course:

...what a journey it has been to come out with ... a valuation figure for my company. Throughout this whole semester I have been curious to see what the end result of my analysis would be. Accounting student (Assignment stage 5)(50)

It also supported some tension or anxiety about the valuation they would come up with for their own firm:

So now comes the bit I have been dreading: Forecasting the key economic and business drivers of [my firm], its key accounting drivers and its ... [earnings]. 
Students experienced a high level of interest in their valuation of their firm in the final stage of the Assignment:

Well believe it or not, [I have] conducted a financial analysis of [my firm]!!! I was always looking forward to this analysis and I am now over the moon that I have completed an actual valuation!

Accounting student (Assignment stage 5) (20)

There was also a strong sense by students of personal relevance to them of the learning tasks involved in the Assignment:

I found [each stage of] the assignment ... to be ... really fun and exciting ... Overall I feel that this was an amazing experience for me which will help me so much in the future.

Accounting student (Assignment stage 5) (49)

Students valued the learning they had experienced in completing the five stages of the Assignment:

...the most precious thing for me is that I know [an] approach

to analyse a firm, a real firm!

Accounting student (Assignment stage 5) (28)

Students also had a sense of 'unfinished business' and wanting to continue with the learning tasks after the course was completed:

But, I do not think I am finished. I want to tweak my ... spreadsheets into a generic format that simplifies data entry ...

I'll do this in the next week or so ... for my own use.

Accounting student (Assignment stage 5) (6)

Students wanted to further develop their personal capacities after the course was completed:

I think by further honing my skills, the [valuation] framework can be a very valuable tool that can be used throughout my life when deciding upon wise investment decisions.

Accounting student (Assignment stage 5) (49) 
Students also finished their final stage of the Assignment with a desire to reflect on and think about their firm further:

I must admit I almost feel like sending this final assignment to the board of directors at [my firm] and getting their feedback on my conclusions. It would be so interesting to hear their thoughts.

Accounting student (Assignnent stage 5) (26)

Students also had a desire to follow the future share price of their firm to see if it reflects their view of its value in future years:

I will definitely keep track of my firm over the next few years

to see if my forecasts are reflected in the market.

Accounting student (Assignnent stage 5) (65)

Students were also curious to see if fundamental analysis of their firm actually 'works' and is able to make them money in the share market in the future:

I will be definitely keeping track of [my firm's] share price in the future and see if fundamental analysis has helped me beat the average investor.

Accounting student (Assignment stage 5) (60)

\section{Confidence}

Students experienced increased self-confidence in their abilities and in particular in their abilities to think for themselves and form their own judgements:

It has also helped me ... to trust myself in valuing [my firm]. This has given me confidence in the work I carry out and I value this experience especially when I go to work next year. So far I thought I didn't know anything, but this paper has [made me] realize that I can work independently and still do very well rather than memorizing black and white facts which helps no one.

Accounting student (Assigniment stage 5) (5n) 
This increased confidence supported students to appreciate and enjoy there being 'no answers':

This is the only course that doesn't provide answers to students.

And I appreciate this very much.

Accounting student (Assigunent stage 5) (77)

Students were also aware of having experienced deep learning (the development of understanding and personal meaning) as they completed the learning tasks in the course:

I am actually enjoying doing this last [stage of the] Assignment as I get to incorporate all the other work I have done in the previous [stages of the] Assignment and start to really make sense of everything.

Accounting student (Assignment stage 5) (29)

As they compared their way of experiencing motivation with those of others in the course, students who did not experience intrinsic motivation in the learning tasks in the fifth stage of the Assignment were able to be aware of variation in the ways of experiencing motivation. They were also able to see intrinsic motivation as desirable, while still being aware they were not experiencing intrinsic motivation themselves:

...it seems as though ... students are now experiencing intrinsic value from analysing their firm, they are not just doing it for the marks. That is nice to see, and I wish that was me!

Accounting student (Assignment stage 5) (17)

\section{Conclusion}

Assessment was a central intervention applied in this study. It was applied as part of a course design and delivery that included an integrated set of interventions of Assessment, Teamwork, Teacher-Student Relationship and Instruction. These integrated interventions were focused on adapting aspects of the education literature to support students to experience high-level relevance structures, highlevel conceptions of learning, intrinsic motivation and deep learning in a university accounting course. In this chapter, it has been described how each of 
the five stages of the Assignment supported students to change the way they experience motivation in a university accounting course from extrinsic to intrinsic.

The Assessment design supported students to first engage in the learning tasks. For example, the experience of extrinsic motivation, of a low-level relevance structure of 'gain a job' and of a low-level conception of learning (conceiving learning to be memorising clear-cut facts to reproduce in an assessment) supported students to do the assessed learning tasks in the first place because it contributed to their grade for the course. Once they engaged in the assessed learning tasks, they found them to be interesting, arousing their curiosity, developing a sense of expectation and causing them to ask their own questions and to seek answers to these questions. In this way, the experience of the learning tasks supported them to become intrinsically motivated; that is, to experience intrinsic motivation in the learning tasks. This is a tenuous, difficult process given the extensive previous experience by students of extrinsic motivation; yet in this study, there is clear evidence that this can occur.

This study has shown it is possible for students in a university accounting course to experience intrinsic motivation in the learning tasks in response to Assessment as part of an integrated set of interventions. Each of the five stages of the Assignment has been considered in this chapter. In Chapter 6, the findings on the experience by students of intrinsic motivation in the assessed learning tasks in the five SPAs will be considered. Also the findings on the effectiveness of the interventions of Teamwork and the Teacher-Student Relationship as further key factors influencing the experience of intrinsic motivation by students will be explored. 


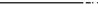

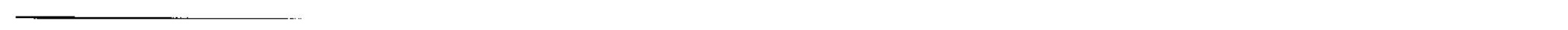






\section{FURTHER INTERVENTIONS TO SUPPORT THE EXPERIENCE OF INTRINSIC MOTIVATION}

I think you shouldn't talk about your company too much ... (you get too excited about this), or you will drive your family away from you haha...

Accounting student (3l)

In this chapter, findings about the experience of intrinsic motivation are further described and discussed. Evidence will be considered on the ways accounting students experienced intrinsic motivation in the remainder of the assessed learning tasks, that is the session preparation assignments (SPAs), including the role of regular formative feedback. Findings about the effectiveness of the interventions of Teamwork and Teacher-Student Relationship on intrinsic motivation will also be considered. Evidence is then outlined about the awareness by students that they were experiencing intrinsic motivation in the learning tasks and were also experiencing the internal relations between intrinsic motivation, relevance structure and deep learning. This chapter concludes with evidence about some of the important interactions with the experience of intrinsic motivation in the learning tasks by students in a university accounting course. These include the experience of developing personal insights, the connection of the learning tasks to Assessment, the positive sense of expectation in future learning tasks generated by the experience of deep learning and intrinsic motivation, and the sense of personal engagement in the learning tasks. The data referred to in this chapter was taken from the Assignments and Session Preparation Assignments (SPAs) completed by the students. The data from the Assignments and SPAs was collected progressively throughout the course. Most of the data referred to in this chapter from the Assignments was collected in Week 12 of the course. The response rates for the Assignments and SPAs are included in Table 3.1 in Section 3.2 in Chapter 3 above. The focus of this chapter within the conceptual framework being used in this study is set out in Figure 6.1 below. 
Figure 6.1: Interventions to Support Accounting Students to Experience Intrinsic Motivation

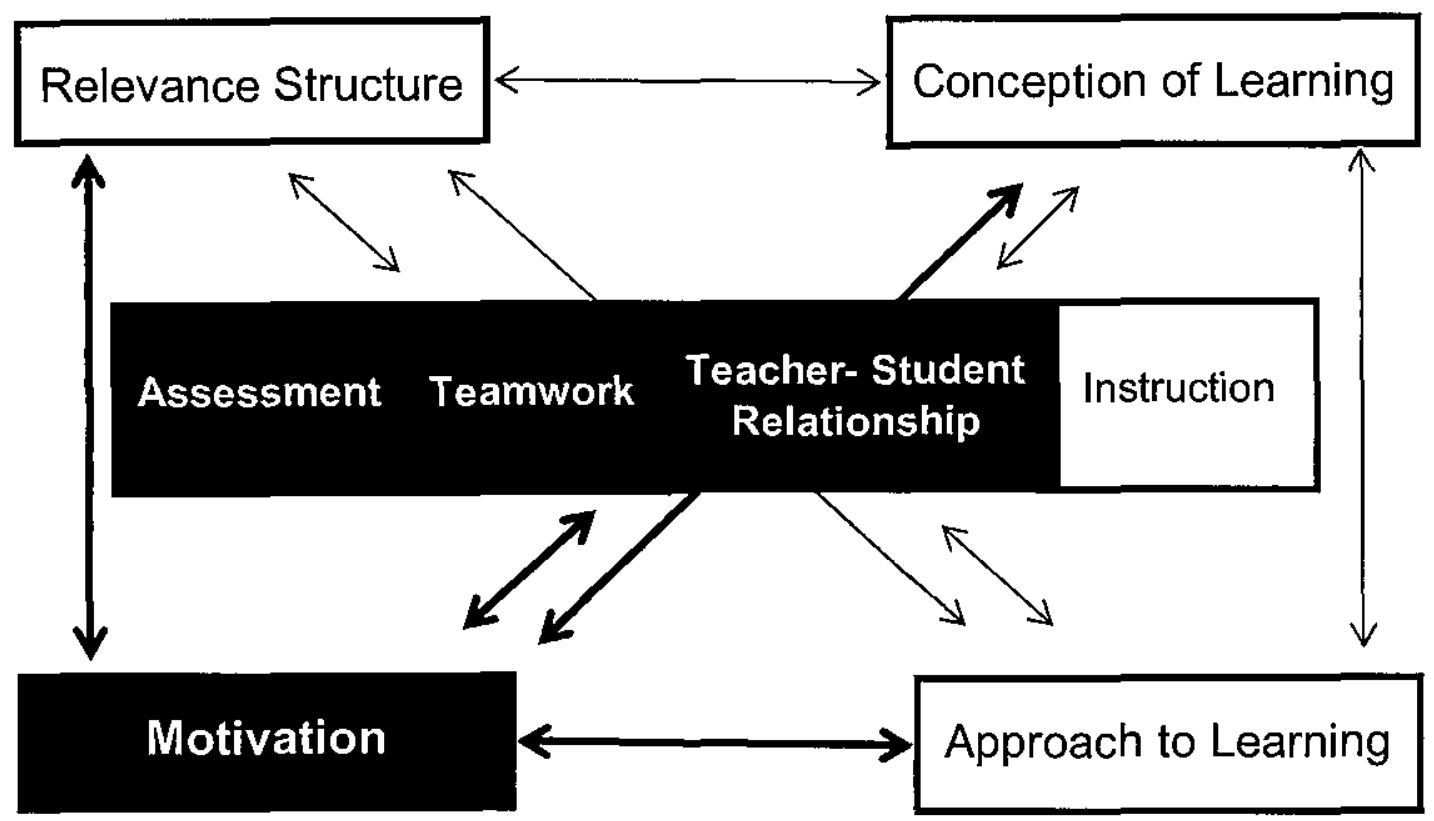

\subsection{Session Preparation Assignments (SPAs)}

...in past papers ... I would have superficially read the chapter with a base understanding of the information but not really understanding and engaging with the information. With this reading (and all the other readings) ... the difference is that I have been intrinsically driven to understand the information. Instead of switching onto autopilot ... I am fully focussed and intent on understanding everything that meets the eye! I can't remember the last time that I was this motivated for ... an accounting paper!!!

Accounting student (20)

In Chapter 5 above, evidence about the experience of motivation by accounting students in response to the learning tasks comprising the five stages of the Assignment was examined. As well as an analysis of their own firms in the Assignment, the assessed learning tasks also included completing the readings before classes and preparing five reflective session preparation assignments (SPAs). In this section, evidence about the experience of motivation by students 
in response to completing reflective readings and of being supported to critically evaluate them will be considered. The readings, rather than the lectures, were the primary vehicle for students to connect to and engage with the content (that is to the concepts, ideas and technical knowledge) of the course. The major reading was Financial Statement Analysis: To Know What Adds Value (TKWAV) (Turner, 2008b). This was an unpublished textbook written by the teacher (who is also the researcher) that presented the central material of the course in a style that supported deep learning. It told stories, repeated itself, used metaphors and illustrations and gave the reader the opportunity to reflect on and seek their own personal understanding of the content and ideas presented in the reading.

In addition, there were a number of other readings by a mixture of academics and practitioners that provided students with the opportunity to consider their own personal reactions to a range of opinions, ideas and evidence provided by a number of different authors. The readings were focused around the particular valuation techniques being used in the course, although there was recognition of and some discussion about a range of other approaches to valuation and financial statement analysis. A key feature of the design of the assessed learning tasks was that the assigned readings had embedded in them a deep approach to learning; that is they were written in such a way that they supported students to experience learning for understanding and developing personal meaning. The readings did not simply present a series of clear-cut, black-and white facts from experts, which would support the experience of surface learning:

I enjoyed this reading ... didn't have the feeling that other accounting ... text[s] give of just throwing facts at you, it actually took me for a ride.

Accounting student (ss)

This [reading] ... is almost like a journey we are taking with [the author].

Accounting student (24)

The session preparation assignments (SPAs) were designed to support students to complete the assigned readings before class, and were usually due by $11.00 \mathrm{pm}$ the night before the first of the series of classes to which the readings related. The lectures were then designed to support students to reflect on and deepen their 
understanding about the material they had read and to have the opportunity to raise questions. In the lectures, the students sat in their study groups, and there were opportunities for the groups to discuss aspects of the material being discussed in the lectures. Thus the readings were written in such a way as to support students to understand and develop personal meaning and to be ready to deepen their understanding of the material in the lectures.

The readings were also connected to the completion of each stage of the Assignment, with the Assignment giving students the opportunity to apply the content in the readings to the analysis of their own firm. Completion of the readings was critical to support students to personally engage with the content of the course and to develop their own understanding and personal meaning. Another interesting finding was the strong personal reaction by students to the readings written by Warren Buffett, arguably the world's most successful investor. This will be discussed later in this section.

\section{Applying content}

Somehow there is more meaning to what I'm learning as I can apply this knowledge to assess my company ... I am not just a spectator anymore, but an active contributor in my own studies! Accounting student (7)

A key aspect in which the SPAs supported students to develop intrinsic motivation was the need to apply the content of the readings to the analysis of their firm in the Assignment. It was necessary to understand the content of the readings to be able to do this. Applying the content to their individual firm made the content more interesting, exciting and relevant:

I really engaged with the material. It gave me so many ideas as what to do with the next part of the analysis of my company ... in the margins of the chapter ... I was writing things that I should look into for my next assignment ... this chapter got me quite excited about my next assignment!

Accounting student (ss) 
Also, as students experienced being able to apply what they were learning to their own firm, which involved them in experiencing deep learning, this supported them to experience a higher-level relevance structure and intrinsic motivation:

Finally, I can see the fruit of applying one's studies to an actual company and produce something of value other than getting a grade, a sense of real achievement.

Accounting student (?)

\section{Personally interesting learning tasks}

The most incredible thing I found in this course is the SPA[s].

This is because they help me to be well prepared for the class; thus, I found [I was] more engaged in what [was] happening in the class.

Accounting student (4s)

The learning tasks in a course need to be perceived by students as personally interesting if doing the learning tasks is to support them to develop understanding and personal meaning. Interest and understanding are inextricably linked and entwined: interest precedes the effort needed to develop understanding; and developing understanding supports and reinforces greater interest. Students expressed a desire to be personally engaged and interested in the learning tasks in the course:

I would also especially like to be engaged with what I am learning which all too often is simply not the case in many of my other courses.

\section{Accounting student (sI)}

Students gained an appreciation of the value of reading before class to help them to focus on personally understanding the material being discussed in lectures:

[At first] I ... wondered what is the objective of doing [the] SPAs. However after 2 to 3 weeks, I have started to realize how important [it] is [to] read those articles before class... I found myself understanding relatively well ... the material in class as a result of doing [my] SPA. 
There was also an appreciation that the SPAs were designed to support students to think for themselves and evaluate the readings, which was experienced as an interesting and challenging learning task:

When doing the readings, you weren't just passively reading we were encouraged to critically evaluate them. If we didn't enjoy or didn't agree with what the author was saying, we were encouraged to give our opinions. I found this a new and challenging experience but one that I enjoyed thoroughly.

\section{Accounting student (47)}

There was also an appreciation of the effectiveness of reading as the primary means for them to engage with and develop their own understanding of the key content in the course:

...I have changed my view of learning; therefore even though we don't need to submit any more ... SPAs, I have to admit ... I will continue reading before lectures, as this is the only way I could engage and gain insights with the materials!

\section{Accounting student ${ }_{(32)}$}

Being personally engaged in the learning tasks supported a sense of enjoyment in doing the learning tasks:

This article was really interesting! I found myself relating the article back to my own experiences...

\section{Accounting student (7)}

Also, enjoyment of the learning tasks was supported by an integrated personal experience of the course as a whole:

My overall experience in doing this course has been fabulous.

\section{Accounting student (3l)}

Students reported limited experience of reading before lectures in their previous accounting university courses (see Figure 6.2 below). In the Pre-Course Survey, over $80 \%$ of students indicated they only 'sometimes', 'rarely' or 'never' read before lectures in previous accounting courses, with over $40 \%$ indicating that they 'rarely' or 'never' read before lectures. Less than $20 \%$ of students indicated they 'always' or 'often' read before lectures. The results of the Pre-Course Survey 
were consistent with the findings of Phillips and Phillips (2007), discussed in Section 1.3 (in Chapter 1) above, that first year accounting students only read $17 \%$ of the assigned readings before class, with many who did read before class only employing a skimming strategy of merely turning pages to reduce anxiety. In this study, the intervention of Assessment (that involved critically reflective session preparation assignments) supported accounting students to experience change in the way they experienced reading before classes. This was consistent with the findings in Bentley et al (2009), discussed in Section 1.3 (in Chapter 1) above, that targeted interventions can support accounting students to read before class.

Figure 6.2: Pre-Course Survey: How Often Do You Read Before Lectures in Your Previous Accounting Courses?

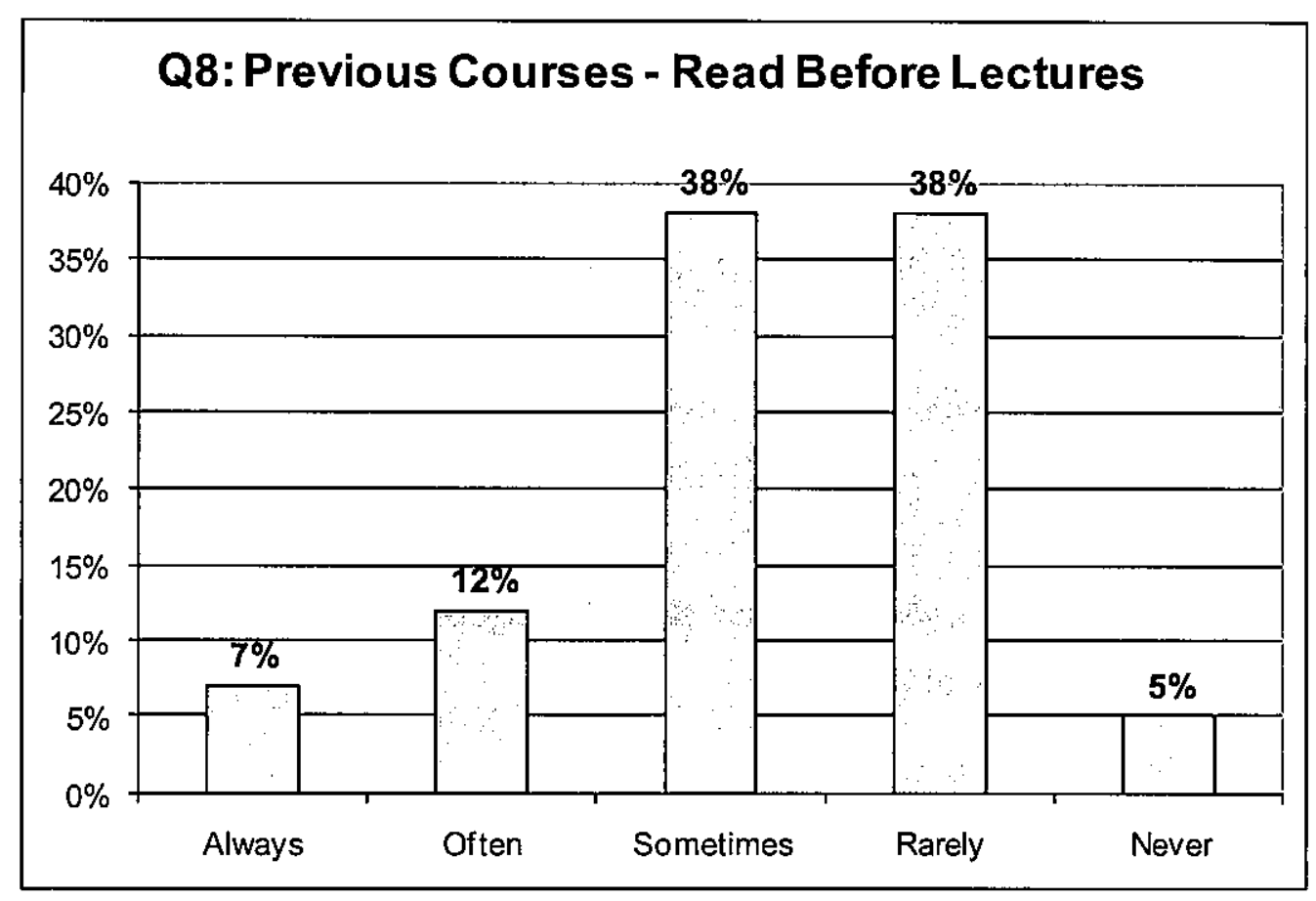

\section{Warren Buffett}

The writing style of Warren Buffett (who wrote a few of the readings) supported students to be interested in and engaged in the readings:

The way Warren [Buffett] has presented some of the ideas through ... analogies has really captured my attention. 
Students also found interacting with Warren Buffett through the readings to be inspirational:

I never stop being inspired by Warren Buffett's writing. It is simply inspirational.

\section{Accounting student (42)}

Warren Buffett is a real person; a highly successful investor who is speaking from actual experience and not from having 'read a textbook'. His readings were thus authentic in the eyes of students, being honest, 'real', grounded in his actual achievement and credible:

It was interesting to see that all of the successes he had with the businesses were not a given and didn't come without risk and mistakes on his part. I love his honesty!

\section{Accounting student (II)}

Students found their curiosity aroused about Warren Buffett the person and also about the source of his ideas. His ideas are sourced from Ben Graham, his lecturer at university, mentor and friend. A chapter of the classic book on fundamental analysis by Ben Graham and David Dodd, Security Analysis (Graham and Dodd, 1940) was also part of the readings:

After viewing this letter, I became curious about his whole life and have done some research about his key concepts and ideas in his successful life.

\section{Accounting student (39)}

Buffett writes very well, he writes in a way that is thoughtful and inspiring to someone like me. The reading makes me want to get a copy of Security Analysis immediately and read through it.

\section{Accounting student (10)}

Students were also able to relate the readings by Warren Buffett to their relevance structure:

One of the main reasons [for doing] my [business] degree is to be involved in a successful business ... [It] is appealing and relevant to me as I am interested in what to look for in making 
a good investment decision. It is especially fascinating when this advice comes from someone who has 'been there and done that' and triumphed.

Accounting student ${ }^{(33)}$

Students were able to understand and develop their own personal meaning from the readings written by Warren Buffett:

Is eye opening and astonishingly enthralling because he [Warren Buffett] makes a lot of sense and just makes you want to read more as you know he has a lot to offer.

Accounting student (sl)

This is one of the best articles I have ever read. As I learn more about Buffett I am continually impressed and astounded by how simple he makes investment decisions sound.

Accounting student (19)

Students found the readings by Warren Buffett motivating to learn more about the course content:

Readings from Warren Buffett fuel my interest for financial statement analysis ... makes me want to learn more so I can make informed value approach investment decisions and beat the market.

\section{Accounting student (ss)}

The readings written by Warren Buffett supported the development of intrinsic motivation by students. He is a real, authentic investor whose writing style supported students to be personally engaged and curious to learn more.

Students who did not experience intrinsic motivation tended to complete simple summaries of the readings and to be concerned with more technical aspects of the readings with limited evidence of personal engagement:

I am interested in how to calculate price to book [and] price to earning [ratios]. 
In this section, the effect on the ways of experiencing motivation by accounting students of assessed learning tasks that involved completing reflective, critical evaluations of readings before classes has been examined. In the next section, the importance of the social context of learning will be considered as two other interventions designed to support the experience of intrinsic motivation by students are examined: regular formative feedback and Teamwork.

\subsection{Relating to Others}

It wasn't until I talked to [another student] that I gained the confidence to begin my valuation and forecasts. [The other student] said to me that the important thing is that 'no one really knows what the specific economic and business trends are going to be', furthermore 'some 'experts' may have a better understanding of certain industries and therefore make a better estimate of future changes than I would, but they still aren't going to be right'. Upon hearing this, I remember feeling excited and enthused about my upcoming forecasts and valuation; I felt excited about making my own mind up about what I believed about [my firm] and taking that leap of faith in my judgments.

\section{Accounting student (20)}

This section focuses on the social aspect of learning accounting in a university accounting course. Firstly, evidence about the impact of regular formative feedback on the ways students experience intrinsic motivation will be considered. This will be followed by an examination of the findings about the central role of Assessment, with its strong links to the experience of relevance structure, as an intervention to support Teamwork between students. Evidence about the effect of engaging in Teamwork on the experience of intrinsic motivation by students will then be considered. The interventions of feedback (an aspect of Assessment) and Teamwork emphasise the importance of quality relationships and the social experience of learning to support intrinsic motivation in the learning tasks. 


\section{Feedback}

[I have] been grateful in reading every single one of [my marker's] feedback, which was individual feedback as well as the general feedback (I enjoyed reading them!).

\section{Accounting student ${ }_{(32)}$}

In Chapter 5 and in Section 6.1 above, we have focused on the individualised, authentic aspects of the intervention of Assessment. The other key attribute of Assessment in this study was the provision of regular formative feedback. The Assignment was broken into five stages and there were also five SPAs, giving each student ten opportunities to receive formative feedback during the course. The feedback was by way of individual feedback (ten times during the course) which was provided to each student by the same marker throughout the course. There were three markers in the course: the teacher and two tutors (who were each top performing students from the previous year's course). An average of about 2 to 2.5 hours per student was spent by the teaching staff in marking the Assessments and giving individual feedback. General feedback from the teacher was also given to all students (again, ten times during the course). Another key aspect of feedback was the regular provision of exemplars of other students' work for each stage of the Assignment and for each of the SPAs.

The provision of regular, individual formative feedback (almost on a weekly basis) by the same marker for each student helped to develop a personal conversation between the student and their marker, as students responded to each piece of formative feedback in their next assessed learning task in the course:

I think the coolest part of this course is that I get to address my assessments to somebody. I know who's going to be marking it and I know they actually care ... It's not just going to be some sad, tired old man who is up to his $100^{\text {th }}$ essay and can't actually read the words anymore and is only doing it because his wife just left him and he needs the money i.e. someone that doesn't actually give a toss about our education. I get to actually build a familiarity with my marker and that is something I doubt I'm ever going to find again in my studies. 
The feedback was also two-way. Not only did students receive regular formative feedback on their assessed learning tasks, they also had regular opportunities to provide their own feedback to the teacher, through regular critical incident questionnaires (CIQs), a range of other surveys and through participation in a focus group. Examples and summaries of the feedback received from students were regularly given to students in the lectures and by way of the online learning management system. There was evidence that sharing, discussing and responding to regular feedback from students by the teacher had a positive effect on supporting the experience of intrinsic motivation by students:

I felt extremely motivated to do well in all my assignments, as [the teacher] respected our feedback and also discussed [it] ... in the lectures. I felt well connected to the lecturer.

\section{Accounting student (32)}

Simply having the opportunity to give feedback and to hear other student's feedback also supported the experience of intrinsic motivation by students:

I also went to [the focus group] ... I really liked giving verbal feedback on the course and it was interesting to hear other people's opinions on the course!

\section{Accounting student (ss)}

As well as the mutual sharing of feedback between the teacher and students and between the students themselves, another key intervention was the support provided for Teamwork between students in the course.

\section{Teamwork}

...by working with other students in this course and bouncing ideas off each other, I found that I easily became engaged in the course and my understanding and satisfaction from the course increased.

\section{Accounting student ${ }_{(68)}$}

A central aspect of the intervention of Teamwork in this study was that students were each assigned to a study group of 3-5 people and they sat in their study groups in the lectures: 
I think the set up of study groups as a closely bonded cell [for] taking on financial statement analysis deserves the highest praises. It has made the course so much more interesting and personal.

\section{Accounting student (so)}

In addition, there were questions in the Assignment and SPAs that required students to talk with other students. There were also a range of online supports (such as discussion board, online journals and wikis) to facilitate teamwork. There were also two study group workshops designed to support team building within the study groups and to address challenges faced by students in experiencing Teamwork.

There was evidence that being engaged in Teamwork with other students in the course was an important aspect of supporting students to experience enjoyment and interest in the learning tasks:

Talking to a lot of people in the class is probably one of the highlights from this course. Never in university have I got to know more than a few people in the class. It is a really good experience.

\section{Accounting student (31)}

If this course was a trip, all friends with their great thoughts did make my trip more interesting and enjoyable.

\section{Accounting student (45)}

There was a two-way interaction between students experiencing enjoyment and interest in the learning tasks and being better able to engage in Teamwork with others:

I found the students that enjoyed analysing their companies, were great people to talk to and provided really useful insights, feedback and generally did quite well in their assignments too. Accounting student (7) 
Further, the social experience of learning with others had an emotional and personally 'connecting' element to it:

When I sat in the last class of the lecture, I felt like I wanted this last lecture to go on longer. And the most emotional thing I found was ... we will all be separated, we all have our own destination to go to, some students will become accountants next year ... some will be continuing their studies ... some will go back to work in their home countries ... This feeling was similar to the feeling when I left my home country; it was the most emotional event [that has] happened [for me]. I left with tears, joy, sadness, from family and friends.

Accounting student ${ }_{(32)}$

\section{Support critical thinking}

Reading [another student's] comment on our study group journal really gave me a different way to think about [an issue] and a new insight.

Accounting student (ss)

There was also an appreciation of the value and importance of Teamwork to support critical thinking and the making of the judgements required in the assessed learning tasks:

[Another student] and I always did our assignments together with [two other students] and sometimes [with another two students]. This was probably the most interesting accounting time I have spent with my fellow students because it enabled us to think for ourselves and made us think 'what if'.

\section{Accounting student (44)}

There was awareness that different people brought different perspectives and insights that were useful and valuable:

...the discussions with other students were extremely helpful;

it provides me more ideas as different students have different thoughts.

Accounting student (32) 
As each student was analysing a different firm, this gave scope for a wider range of insights and perspectives:

Once again I have enjoyed looking at other people's firms as you can get somewhat one track minded with your own firm and it's good to see how the same issues ... affect other firms in different ways.

Accounting student (26)

\section{Awareness of benefits of teamwork}

The experience of Teamwork in the course supported students to develop an increased awareness and appreciation of the benefits of working in teams:

I have learnt to enjoy many great benefits of working in a small group.

Accounting student (no)

There was an awareness of the role of meaningful discussion and interaction with other students (along with the need for intrinsic motivation) to support students to experience learning for understanding and developing personal meaning (deep learning):

In the early weeks of this course, I barely understood the connection between [the accounting drivers and the economic and business drivers] for my firm ... However over time after looking at [them] over and over and after having discussion with [others in the course], I started to understand the relationship, slowly but surely. It shows that the skill can't be gained overnight. Instead it requires us to have strong motivation and desire.

Accounting student (l)

The awareness of the benefits of Teamwork led students to take the initiative to organise interactions with other students and to give time to experience Teamwork:

I was really pleased with the way my study group worked

together; [we] met up on the first Monday of the [mid-trimester

break], I guess we weren't the only ones ... level four of [the]

Library was overflowing with students [from the course]. 
There was also an experience of co-operating with others, helping others in their learning tasks and being helped:

I've enjoyed helping people in this assignment...

Accounting student $(61)$

[Another student] from my study group sent me a press release and a news article on [my firm]. The results and commentary made for interesting reading.

Accounting student (42)

The Assessment involving individualised, authentic learning tasks strongly supported Teamwork (while also retaining individual accountability in the assessments as each student needed to adapt the concepts and ideas in the course to the specific challenges of their own firm):

I also enjoyed discussing the assignment with other members of the class, and hearing about similar and different issues they had with their companies. It is really cool how we all have different companies.

Accounting student ${ }_{(68)}$

After talking with other students I have found it very interesting how the ratios affect each firm differently ... It is also intriguing how we can see how well some companies are doing compared to others.

Accounting student (Io)

There was evidence that the interactions between students about their individual firms and their analyses helped them to be aware of their experience of intrinsic motivation in the course:

...even out of lecture times, myself and other students are always discussing our firms and recent news events that could impact it. This is amazing, definitely not what I expected from studying an [accounting] course.

Accounting student (65) 
These interactions between students contributed to the experience of intrinsic motivation, enabling students to become interested in more than just their own company they were analysing:

I'm really interested to see the final result of [analyses of] other people in the class!

Accounting student (6)

There was also evidence that students who did not engage effectively in Teamwork became aware of the value of working with others:

After ... doing this course I realise ... group work is going to improve [my] thinking and skill ... From this course I realise ... discussion is very important. I am ... not good at this. I was very disappointed [about] that.

Accounting student (79)

In this section, evidence has been considered about the effectiveness of regular formative feedback as part of the intervention of Assessment used in this study. Also considered was the effectiveness of the intervention of Teamwork to support accounting students to experience intrinsic motivation. In the next section, findings about the important intermediating role of the intervention of TeacherStudent Relationship to support accounting students to experience intrinsic motivation will be examined. Evidence about the awareness of variation in experiencing intrinsic motivation by students as they responded to these interventions will also be considered. Also, in the next section evidence will be considered about the issue of accounting students persevering in the experience of intrinsic motivation in a university accounting course.

\subsection{Teacher-Student Relationship and Awareness}

I feel like the penny has dropped in terms of my own individual learning ... In this specific example, I gained my own understanding by searching for an answer rather than being given it. I can see that I have also [been] doing this for the whole paper so far and I am very excited about continuing to do so. 
This section considers the findings about the effectiveness of the intervention of Teacher-Student Relationship to support accounting students to experience intrinsic motivation in a university accounting course. Evidence of the awareness by students that they were experiencing intrinsic motivation in the learning tasks and were also experiencing the internal relations between intrinsic motivation, relevance structure and approach to learning is also considered.

\section{Teacher-student relationship}

The confidence and ability to think for ourselves is a wonderful thing ... Dreams empower us. Dreams give us the strength to persevere, to hang in there, and to fight hard and to never give up. Dreams give us energy. Dreams protect us from being passive, discouraged and aimless ... This learning is part of you and remains with you throughout your life and gives you something to build on: an intellectual and academic foundation for business and for life.

Accounting student (Quoting from part of the General Feedback given by the teacher, who is also the researcher, to all students for one of the stages of the Assignment) (39)

There was evidence the experience by students of the Teacher-Student Relationship is an important intervention or intermediating variable in supporting students to experience intrinsic motivation in a university accounting course. In this study, key aspects of the intervention of Teacher-Student Relationship were an informal, student-centred and facilitative teaching style where 'right' answers were not imposed but curiosity, questioning and exploration were encouraged. There was evidence students were aware that the intervention of Teacher-Student Relationship supported them to experience intrinsic motivation in the learning tasks:

[Teacher's name], even though this course has been ... challenging for me ... I really enjoyed it. Your tireless effort has been greatly appreciated by [me] and all the other ... students ... your motivational emails about life and [the course] make me smile and really appreciate you as a lecturer. Keep teaching and building your relationships with students. 


\section{Accounting student (13)}

I used to be a primary school teacher ... I found we play a very important role in stimulating students' interest [in] their stud[ies] ... establish[ing] a good relationship with students to motivate them and make them willing to share their ideas [is] the most important thing.

Accounting student (39)

There was evidence an aspect of the Teacher-Student Relationship that was important for the experience of intrinsic motivation by students was communication by the teacher to the students of genuine enthusiasm for the content of the course:

...why do I care more about this course? ... because of [the teacher's] enthusiasm for ... the content of this course.

Accounting student (6i)

There was also evidence students experienced being genuinely inspired by their interactions with the teacher:

Thank you [teacher's name] ... you truly have been an inspiration.

\section{Accounting student (so)}

Another important aspect of the intervention of Teacher-Student Relationship was regular interaction and two-way feedback between the teacher and students, as discussed in Section 6.2 above.

There was evidence the Teacher-Student Relationship was an important intermediating variable or intervention to support students to experience intrinsic motivation in the learning tasks. There was also evidence that the small number of students who did not experience intrinsic motivation and deep learning in the course did not respond positively to a teaching style where 'right' answers were not imposed (but curiosity, questioning and exploration were encouraged) and wanted more direction and support from the teacher than was being provided:

...sometimes I need [a] summary ... of each chapter clearly, not

just ... questions. 


\section{Awareness of intrinsic motivation}

I no longer place a huge emphasis on my mark at the end of the

paper. I want to gain perspective out of this paper, to develop my learning capacities and to enjoy this learning experience. Basically, I want to get the most out of this paper that I possibly can.

\section{Accounting student (20)}

During this course, students progressively became aware they were experiencing intrinsic motivation in the learning tasks. This awareness was developed in some of the early learning tasks, such as restating their firm's financial statements (in stage 2 of the Assignment):

To be honest, I found the task of restating the financial statements for my company quite exciting. Yes, exciting!

Accounting student (Assignment stage 2) (so)

Students were aware and able to articulate their change from experiencing extrinsic motivation to experiencing intrinsic motivation in the course:

I have had a complete attitude change during this course. At the beginning I was here to learn a vocation ... but now I am willing to learn just out of interest.

\section{Accounting student (4)}

The students were aware of changes in the way they were approaching and tackling the assessed learning tasks, which they could see were related to their change from experiencing extrinsic motivation to experiencing intrinsic motivation:

I have definitely become more intrinsically motivated in this course to start and have things finished much earlier than the due date and time!

Accounting student (24)

There was also a sense of achievement and accomplishment in completing the learning tasks, particularly on completion of stage 5 of the Assignment when the students came up with their final valuations of their firms: 
I found [stage 5 of the] Assignment ... most challenging but enjoyable ... This is because I was working towards one number - the [value] of [my firm]. The previous [stages of the] Assignment were a build up to this one and therefore completing [stage 5 of the] Assignment is the most rewarding. The best part was plugging the numbers into the formula to get the [value]. At that moment I felt like I had accomplished more than just calculating one number!

Accounting student (33)

As further evidence of awareness of experiencing intrinsic motivation in the leaning tasks, at the end of the course students had a strong emotional reaction about coming to the end of the learning tasks in the course, including wanting the course to continue:

I'm really upset that this course is over!

Accounting student (6)

I'm already missing this course, missing every piece of work done in this course, missing the trip [the teacher] took us on this journey!

\section{Accounting student (32)}

At the end of the course, there was also a sense by students that there remained much more for them to learn, including a sense of wanting to do the course again:

I want to go on this journey again with [this course] because I have a better understanding and there is just so much more I know I can learn which will benefit me.

\section{Accounting student (13)}

As further support of their experience of intrinsic motivation, there was evidence of students wanting to read more in this area and to continue to learn more about the course content:

I'm ... really excited to learn more in this area ... Can you recommend some books ... 
There was also evidence that students had a sense of wanting to continue with the learning tasks in the course after the course was completed and to analyse additional firms:

I have enjoyed and valued what I have learnt; I feel I could apply this framework to some companies over summer just for my own personal interest.

Accounting student (26)

I am considering ... whether to ... undertake my own analysis of [another specific firm] to see the comparisons [with my firm] ... I guess this means ... I have become intrinsically interested in my firm and also my industry ... to [want to] undertake ... [an] analysis of [another firm] without ... extrinsic motivation such as grades.

Accounting student (24)

The students had also experienced personally caring about what they were learning about accounting which continued with them after the course was finished:
Also, BEWARE you will actually care about [financial statement analysis] even AFTER the course is over! I have started nagging my parents to buy me shares as my birthday present! Now when you stop asking for the usual shopping money and start asking for shares you know [the course content] has earned a little spot in your heart.

\section{Accounting student (60)}

This desire to learn more and to continue with their learning experience after the end of the course was strongly indicative of the experience of intrinsic motivation and a decoupling of their motivation from extrinsic motivators such as grades (Ryan and Deci, 2000b). 


\section{Awareness of internal relations}

Students also expressed an awareness of a connection and inter-relationship between their experience of relevance structure for the course (what they expected to gain from completing the learning tasks) and a developing intrinsic motivation:

If people are able to know the purpose of doing something, they will do it voluntarily and happily.

Accounting student (39)

I really enjoyed this journey of financial statement analysis and I want to say that it is a course [where] I actually learnt something useful ... not just for passing the course and getting credits to graduate but also for my future business life.

Accounting student (76)

The students were also aware of the intrinsic value to themselves of the outcomes of the learning tasks:

... very few people [are] able to make meaningful assessments about a firm based on its financial statements ... When I graduate, I want to be one of the 'very few' people.

Accounting student (36)

The students were also aware of the relationship between their experience of intrinsic motivation and learning for understanding and developing personal meaning (deep learning):

... most people are keen and motivated to learn in this course $\ldots$ and $\ldots$ we are understanding and developing our own personal meaning.

Accounting student (39)

Indeed, there was an awareness of the need to experience intrinsic motivation to be able to experience deep learning:

Intrinsic motivation is essential to carry out [the] assignment so as to obtain the greatest value out of it. Otherwise, you will end up doing the ... assignment for the wrong reasons and will not get the most out of it. 
It requires ... internal motivation. In order to succeed, you can't be grade oriented - you need to be intrinsically motivated to learn and gain skills from the course rather than get a good grade. A good grade may or may not be a by-product from such an attitude, but is unlikely to result from a direct focus on [grades].

\section{Accounting student (68)}

Students also had an awareness of variation in the experience of motivation in the learning tasks in a university accounting course:

$\ldots$ one of my friends [said] he lacks motivation to understand deeper about [the course content]. I can see that motivation plays a more important role as we learn more about [the course content] ... I have found myself more motivated to complete this course and [no matter] how hard the [learning task] is, I have been enjoying doing them.

\section{Accounting student (l)}

There was an appreciation by students of the empowering nature of intrinsic motivation to support them to make the substantial cognitive effort to experience deep learning:

You ... feel empowered with an intrinsic motivation to learn this frustratingly subjective yet extremely interesting subject of financial statement analysis.

Accounting student (ss)

A lot of it comes down to motivation in oneself. I know that if someone really wants something, they will sacrifice everything in their path. They will put their brains through the pain of not being able to use a firm's financial statements to meaningfully assess value and perform an important analysis in an effort to gain that understanding. I know that I am certainly doing that for this course.

Accounting student (20) 
In this section, evidence about the effectiveness of the intervention of TeacherStudent Relationship to support accounting students to experience intrinsic motivation in a university accounting course has been considered. Evidence of awareness by accounting students of experiencing intrinsic motivation and of experiencing the internal relations between intrinsic motivation, relevance structure and approach to learning was also discussed. In the next section, findings about some of the important interactions with the experience by accounting students of intrinsic motivation will be discussed, including the use of Assessment to support accounting students to persevere in their experience of intrinsic motivation.

\subsection{Interactions with Intrinsic Motivation}

I have already seen how [the course] is not like any other accounting paper I have done, it teaches you that accounting is not all about absolute truths and about having one definitive answer. We can see this through the readings we have done already and the different core themes developing. Financial statement analysis will help me to develop a higher level of thinking by analysing my company, which I am really looking forward to! In none of my other papers have I been able to analyse my OWN company from scratch and been given the tools to do it in the 4 years I have been studying accounting!

Accounting student ${ }_{(44)}$

In this section, evidence is considered about some of the important interactions with the experience by accounting students of intrinsic motivation. Findings are discussed about how the experience of developing personal insights (deep learning) can support the experience of intrinsic motivation by students in a university accounting course. Also evidence about the importance of Assessment to support students to persevere in their experience of intrinsic motivation is considered. Findings about the effect of the experience of intrinsic motivation in the early learning tasks of the course on a sense of expectation and preparedness to experience intrinsic motivation in later learning tasks are also examined. 


\section{Developing personal insights}

Right now is probably the most poignant moment in this course for me - not poignant as in I need to reach for the tissues ... just in the way that everything comes together.

\section{Accounting student (3)}

As discussed in Section 6.3 above, there was evidence students were aware they were experiencing intrinsic motivation and were also aware of the internal relations between intrinsic motivation and their experience of relevance structure and deep learning. There is evidence the experience of developing personal insights into the content of the course (deep learning) supported their experience of intrinsic motivation:

The interesting part of this assignment is what I discovered while I was restating! These were epiphanies and observations garnered while restating the financials and I'm excited to see what other ones arise while calculating some ratios using the new statements.

Accounting student (21)

Although supportive of intrinsic motivation, the experience of deep learning could also be accompanied by nervousness and a degree of self-doubt about being able to meet the future challenges of experiencing deep learning in the course:

I am excited to grasp these concepts fully. Although I am excited, I am quite nervous and worried at the same time.

\section{Accounting student (33)}

Students could also experience awareness (or meta-cognition) that the course was designed to support deep learning:

Then about week 6, it click[ed] what [the teacher] was trying to do, to make us critically think for ourselves, learn off each other in a social learning environment and never settle for a black and white answer.

Accounting student (ss) 
This awareness could encourage students to expect they will be supported to meet the future challenges of experiencing deep learning in the course, which reinforced their experience of high-level relevance structure, high-level conception of learning and intrinsic motivation:

Personally, I believe that I will learn a lot from this ... course.

As even after just one week of the course I have gained a great insight into what [financial statement analysis] actually is.

Accounting student (65)

I did learn a lot from this paper so far! (More interesting things in the future ... right?)

Accounting student (18)

\section{Strong connection to Assessment}

The strong connection to the Assessment of learning tasks that were intrinsically interesting, was vital to support students with extensive prior experience of lowlevel relevance structures (see Section 4.1 in Chapter 4 above), low-level conceptions of learning (Sharma, 1997; Byrne and Flood, 2004; Lord and Robertson, 2006), extrinsic motivation (Boyce et al, 2001) and surface learning (Eley, 1992; Booth et al, 1999) to first engage with and then persevere in the challenges of the learning tasks:

No longer can I memorise information and regurgitate it in the final exam, in this course I need to engage with the material and apply it in my analysis of my firm. The fact that I will be gaining knowledge which I will take with me after I have finished this course is refreshing...

Accounting student (17)

For students to be able to persevere in their experience of intrinsic motivation, it was important for them to be able to see that their efforts in completing the learning tasks were rewarded with grades in the Assessment:

I can see that motivation plays a more important role as we learn more about financial statement analysis ... I have found myself more motivated to complete this course and [no matter] how hard the assignment or SPA is, I have been enjoying 
doing them ... it is important to translate our judgment ... into figures, so I think the same goes to studying this course; it is important for me to translate those enjoyments into good grades. So far my marks have been pretty good and it only stimulates my interest further.

\section{Accounting student (I)}

An important factor for students who found difficulty in persevering in the experience of intrinsic motivation was feeling they were not being adequately rewarded for their effort by the assessment, particularly in comparison to grades they were receiving in other accounting courses:

...this paper ... has ... been the biggest disappointment. Why? I ... achieved average grades ... I was just average. Stuff that, if I'd have spent even half as much time on ... my other ... papers this trimester, I would ... be performing above average ... To put in so much effort for something and not get the returns, well let's just say this paper failed to meet the required rate of return on equity.

Accounting student (22)

As long as students were receiving a good grade, they did not mind working harder for it than in other accounting courses because they were intrinsically motivated and wanted 'to do well':

It's because I actually care and want to do well more than any other course. In other courses I've found that I can do well (i.e. get A's) without having to do much work but boy did I have to work for it here. And that's great.

\section{Accounting student (3)}

The object of study in this research is a university accounting course. As we will discuss further in Chapters 7 and 8 below, the broader context of the experience by accounting students of their other accounting courses does impact their experience of how they learn in an accounting course. 


\section{Personal engagement}

What does it mean to me?

Accounting student ${ }_{(28)}$

Being able to make personal connections and having a sense of personal, subjective involvement was an important part of the experience of intrinsic motivation that supported students to persevere in experiencing deep learning in the assessed learning tasks:

What I like about this course is that I can use the word ' $\mathrm{I}$ ' and really use my experiences.

Accounting student (13)

The experience of personal involvement in the learning tasks supported students to make connections to their personal lives and to the 'real' world:

The way [the teacher] talks about dreams at first seems rather odd in an accounting textbook. But then, nothing about [the course] has been 'normal' ... I wonder if there is a reason for this way that [the teacher] writes/teaches, quite apart from the fact that it makes learning a much more personal and involved task... Maybe he is trying to get us to understand that life outside of university is not as neat, tidy or organised as we have experienced in previous courses where the predictable term's test is followed by a regurgitation exercise called an exam.

Accounting student (37)

It was actually rather scary to see how some examples mirrored my way of thinking so well. It was as if [the teacher/author] was inside my head.

Accounting student ${ }_{(4 k)}$

The experience of intrinsic motivation in the learning tasks of the course led to a positive expectation of how they may experience later learning tasks: ...once I had separated and classified all of the items as either operating or financing, the layout and restatement became 
exciting! I am now extremely looking forward to the future in

this course.

Accounting student (24)

Their experience of growing insights and their developing sense of expectation also led students to ask their own questions and seek answers to these questions in later learning tasks:

...a key question I want to know about my firm is why does [it] make large sales revenues yet produces little profit? ... hopefully over the next assignments I will get some ideas as to why this is occurring.

Accounting student (30)

In this section, evidence about some of the important interactions with the experience by students of intrinsic motivation in the learning tasks was considered. A key finding is that as students began to experience intrinsic motivation in the assessed learning tasks, they became more likely to respond to an integrated set of interventions designed to support them to experience deep learning in a university accounting course. The important internal relation between intrinsic motivation and deep learning is considered further in Section 8.4 (in Chapter 8) below.

\section{Conclusion}

In this chapter, the discussion commenced in Chapter 5 on the findings about the impact of the intervention of Assessment on the experience of intrinsic motivation by students was completed. Evidence was considered about the impact of the session preparation assignments (SPAs) and also of regular formative feedback on the experience of intrinsic motivation. Also considered was the impact of the interventions of Teamwork and Teacher-Student Relationship.

A key finding is that the learning tasks need to be interesting, challenging and relevant to students for them to experience intrinsic motivation in doing the learning tasks (Amabile, 1993). The study also provides evidence that the experience of extrinsic motivation by accounting students is strongly related to the experience of surface learning; and the experience of intrinsic motivation is an 
important precondition for students to be able to experience deep learning in a university accounting course (Fransson, 1977).

In Chapter 4, accounting students indicated they have extensive previous experience of extrinsic motivation in university accounting courses. This study provides evidence that intrinsic motivation in the learning tasks in a university accounting course is not a common experience for accounting students. This is consistent with findings in the accounting education literature (Mladenovic, 2000; Lucas, 2001; Boyce et al, 2001; Marriott and Marriott, 2003; Byrne et al, 2009). Supporting accounting students to learn how to change their way of experiencing motivation is a central challenge for the design and delivery of university accounting courses. The findings on how the interventions adopted in this study have supported accounting students to experience intrinsic motivation in the context of a university accounting course are central findings of this study.

A key finding from both this chapter and Chapter 5 is that Assessment was a central intervention to support accounting students to change the way they experience motivation. This finding is consistent with findings in the education literature that assessment structures can be developed to support students to develop intrinsic motivation in the subject being studied (Hand et al, 1996; Biggs, 1999); and that, in particular, individualised, authentic learning tasks with regular formative feedback can support students to develop intrinsic motivation in these learning tasks (Entwistle and Ramsden, 1983; Ramsden, 2003). There are no universal solutions and creative, professional judgement (informed by theory) is required by academics to creatively and thoughtfully adapt this finding to the design and delivery of assessments in particular courses.

In this chapter and in Chapter 5, evidence has been provided that individualised, authentic Assessments with regular formative feedback in the context of an integrated set of interventions involving Teamwork, TeacherStudent Relationship and Instruction can support accounting students to experience intrinsic motivation in a university accounting course. The next chapter will focus on evidence about how to support students to experience deep learning. 


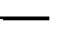





\section{DEEP APPROACH TO LEARNING}

After tak[ing] this course, I have changed [my] way of learning, I have changed from being a passive learner to become an active learner [with an] ability to think for myself, reflect on what I learnt previously and thus make my own judgements!

\section{Accounting student (32)}

The focus of this chapter is on the experience of deep learning by accounting students in a university accounting course (see Figure 7.1 below). The experience of deep learning is a key objective of supporting students to change the way they experience how they learn accounting. This is because an experience of deep learning supports the development of personal capabilities by students, such as critical thinking, which are considered to be strongly related to success as an accounting professional, in business and more broadly in life (Trigwell and Prosser, 1991).

The initial adjustments students made to experience deep learning will be considered. Given their extensive previous experience of surface learning, these adjustments were considerable (Byrne $e t a l, 2010$ ). Aspects of the experience of deep learning by students and how they constructed knowledge in a university accounting course are then examined. Evidence about how the intervention of Assessment (involving individualised, authentic assessments with regular formative feedback) related directly to the experience by students of deep learning will then be considered. The data referred to in this chapter was taken from the Assignments and Session Preparation Assignments (SPAs) completed by the students. The data from the Assignments and SPAs was collected progressively throughout the course, with most of it collected in Weeks 7-12 of the course. The response rates for the Assignments and SPAs are included in Table 3.1 in Section 3.2 in Chapter 3 above. 
Figure 7.1 Interventions to Support Accounting Students to Change the Way They Experience Learning Accounting

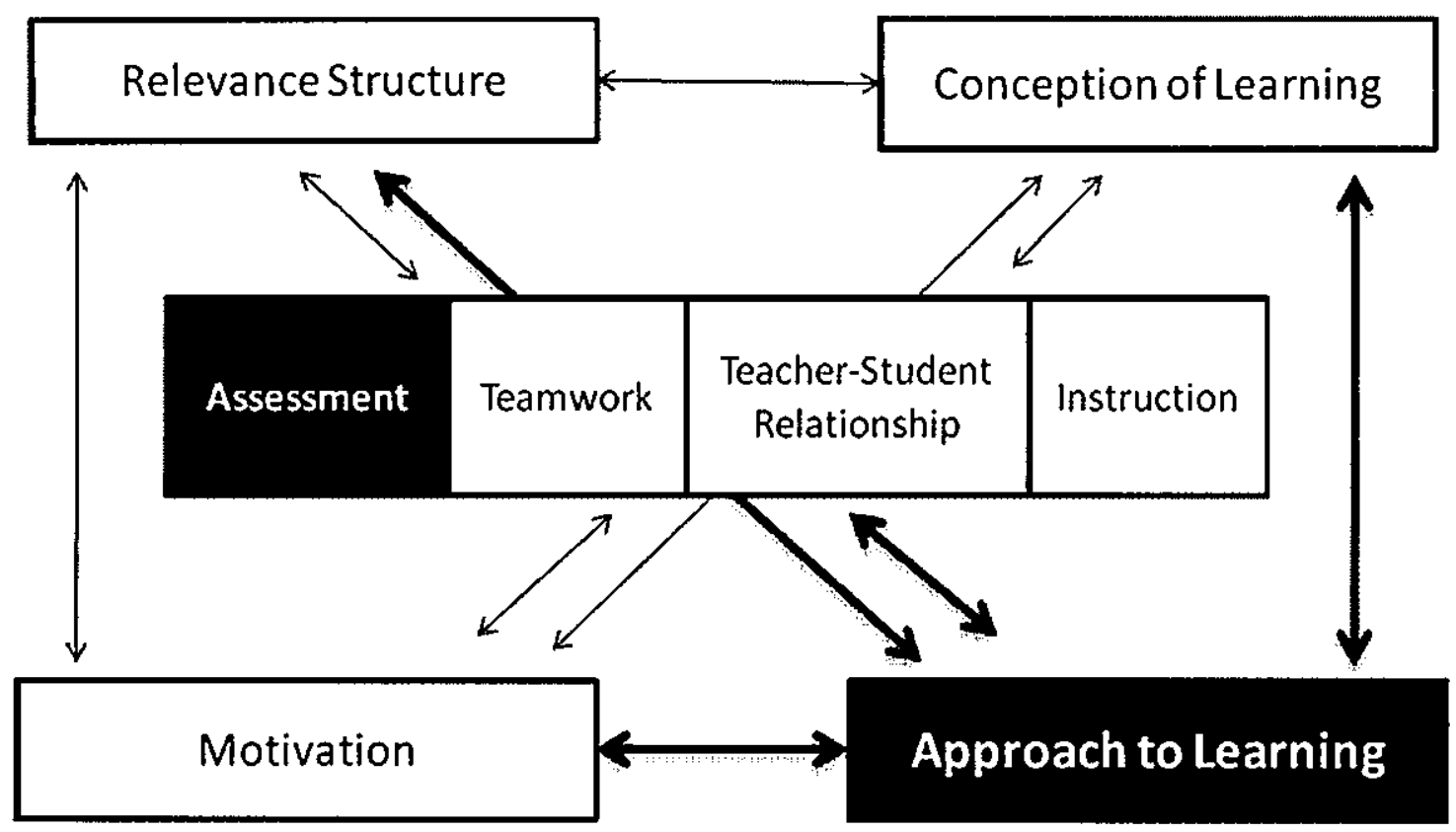

\subsection{Adjusting to Deep Learning}

It took me almost 17 hours to complete [stage two of the] Assignment. I felt horrible about my work ... I have found the hardest thing is reading [the] financial statements ... I need to try to understand them, AND, I have to give my own judgement on which activities are operating activities and which are financial activities. Sometimes I felt really confused, even after discussing with some of [my] classmates, however, the companies we are doing [are] different from one ... another. After discussion, I still need [to] try really hard to understand...

Accounting student (28)

This section sets out the findings on the significant adjustments accounting students made to experience deep learning. These adjustments involved them seeking to understand the concepts (rather than simply reproduce them) and also seeking to understand the meaning behind the accounting numbers they were 
analysing. As they sought understanding, students also experienced confusion and challenges which tested their level of confidence in their own abilities to think for themselves and to learn for understanding and personal meaning.

\section{Understanding concepts}

...I have learnt it is important to understand the concepts we are taught ... the key [is] to actually understand all the material and how to put all the facts together to make sense.

\section{Accounting student (lo)}

Students experienced the value and importance to them of understanding the concepts rather than seeking to memorize and reproduce the concepts without understanding them. The use of different, real companies for each student was a critical element in the design of learning tasks that 'required' students to seek understanding rather than simply regurgitate material. As there are 'shades of grey' and variation between different, real companies students needed to be able to make judgements about the particular issues facing their specific firms based on their understanding of the concepts. It was not possible to adapt and apply the concepts to their firms without first understanding the concepts. This was quite an adjustment for students with extensive previous experience of surface learning. For example, students needed to understand the concept of comprehensive income, which was central to the approach to financial statement analysis and valuation being used in the course:

I was hoping that there is some list that can tell me all items that should be under comprehensive income ... however I have realized that $\ldots$ it is up to me to understand what 'comprehensive income' $(\mathrm{CI})$ is and be able to make a prudent judgement in classifying those items. It takes some time to understand what CI is ... but I do realize that this is the only way for me to really learn from university, instead of just memorising every list and replicate it in the assignment.

\section{Accounting student ( $)$}




\section{Meaning in accounting numbers}

...I actually spent some time looking at the financial statements and trying to figure out what they meant as opposed to just going 'ah, numbers' and skipping over them. And to my surprise, they do actually make sense and I was able to get some useful insights from them...

\section{Accounting student $(21)$}

As well as adjusting to the challenge of understanding concepts rather than reproducing definitions of concepts with little or no understanding, students also experienced going beyond accepting the accounting numbers at face value to seeking to understand their meaning; that is to understand what the accounting numbers tell them about the economic and business realities of their firms rather than solely focusing on the accounting numbers themselves. This involved students moving from a focus on the 'signs' (the accounting numbers) which is the surface level, to a focus on the 'signified' (the meaning behind the accounting numbers) which is the deep level:

...to be able to properly "analyse" a firm's financial statements it is not enough to just look at the numbers and come to a conclusion. Numbers are not enough and only tell part of the story. When looking at these numbers we need to ask ourselves what went on behind the scenes to cause these numbers (what were the 'drivers' of these numbers), we need to look at the business and economic realities of the firm...

\section{Accounting student (55)}

This awareness by students developed a desire, or curiosity, to understand the meaning behind specific aspects of their firm's financial statements:

I want to know the reason behind this!!

Accounting student (3l)

This curiosity and interest to understand was then supported and rewarded by the intervention of Assessment: students knew they were working step-by-step towards an analysis of their own firm which would require them to 'go behind' the accounting numbers of their firm. This supported students to deepen their 
understanding that the accounting numbers themselves were not 'the answer' or the meaning but the meaning lay deeper in the messy, harder-to-pin-down economic and business realities of their firm signified by the accounting numbers:

... accounting ... numbers [by themselves] actually mean nothing.

Only the qualitative factors behind the numbers would be able to tell us the meaning.

Accounting student (34)

\section{Confusion}

....after I finished restating its financial statements ... I found that the explanation in the notes is not really [clear to me], it drives me insane ...

\section{Accounting student (11)}

As students faced the task of understanding concepts and the meaning of their firm's accounting numbers as they analysed their firm, they could feel confused and unsure about how to make the judgements that would be involved. They were also leaving the 'safer' more certain world of apparently clear-cut, black-andwhite answers given by the accounting numbers (the 'signs') to a more uncertain world of qualitative judgements and personal connections (the 'signified'). They were confused about how they might be able to analyse their firms, as it was not a simple task of going through some clear-cut steps. Engaging in deep learning (learning for understanding and developing personal meaning) involved students experiencing confusion, frustration and the need to take more time on the learning tasks in the course than they may have expected or planned to spend based on their previous experiences of university accounting courses.

As discussed in Section 6.3 (in Chapter 6) above, the experience of intrinsic motivation in the learning tasks was essential to support students to persevere and make the significant cognitive effort to overcome these initial barriers to experiencing deep learning:

While reading financial statements can seem daunting at first, I have become far more aware of how extremely useful and interesting they are, if you spend quality time with them. After reading for a while, I found I was actually enjoying reading [my 
firm's] financial statements and I was eager to read further to learn and understand more.

Accounting student (19)

The experience of developing understanding of the concepts and of the meaning of the accounting numbers of their firms supported students to experience intrinsic motivation and to persevere in their experience of deep learning. However, the challenge, frustrations and confusion of tasks involving learning for understanding and developing personal meaning could raise doubts and concerns in students as they grew in their awareness of how much they did not yet understand:

I started to get confused and I doubted myself when I came to the 'Notes to the Financial Statements'. There are a number of things that I do not know when it comes to the mechanics that make up the numbers within the financial statements...

Accounting student $(20)$

Although students were able to begin to experience deep learning, concerns about the uncertainties, the 'lack of clarity' or the sense of darkness ahead of them in this experience of learning did concern them:

By splitting the firm into operating and financial activities I was able to see some obvious aspects of the firm jump out at me, however I'm still not really sure what I'm looking for and not sure that I'm particularly more connected to the business's economic realities.

Accounting student (21)

Accounting as a discipline can also attract people who like clear-cut, black-andwhite answers (Eley, 1992; Booth et al, 1999), and the realisation that there are no clear-cut answers but a reliance on judgements and assumptions that may not turn out to be completely 'right' (for example, with forecasting) can be disturbing to accounting students:

The thing that ... gets me is how many assumptions we are making and will need to make when analysing our firm ... I get so frustrated ... we make assumptions about one thing, and then a combination of that assumption and another one leads to an 
accumulative assumption. It's like playing Chinese whispers one person gets one word wrong, the next person gets another word wrong and then at the end you get a load of crap that makes no sense. I just cannot cope with this amount of speculation and guesswork. Part of the reason I am doing accounting is I like the fact that there is a right or wrong answer...

Accounting student (3)

\section{Confidence}

[The second stage of the] Assignment was one of the most challenging I had ever come across at university, I felt you really had to delve in and thoroughly understand your company as a whole - and it's only the second [stage of the] Assignment! ... I found it quite a challenge. There was no way you could simply copy another student's work ... but a deeper understanding of ... the company ... was required...

Accounting student (47)

There was a degree of discomfort, uncertainty and even distress experienced by students at the apparent vagueness of the assessed learning tasks, with no clear-cut, black-and-white answers. The ways students experienced this initial uncertainty have been categorised as either experiencing 'Lack of Confidence' or 'Empowering Confidence'. Those who experienced 'Lack of Confidence' could feel a sense of inadequacy and a desire for more 'help':

I had so many issues and concerns in this [second stage of the] Assignment!! It is really hard to try and follow a book to teach ourselves how to restate the financial statements $-I$ really wish [the teacher] would have gone over it further in class rather than expecting us to just do it, I am all for trying to make sense of things ourselves so we actually understand the material and I do believe we can learn a lot from others in the class but ... at the moment we're completely left on our own to do things, whereas if we had a little bit more teaching ... 
Alternatively, those who were experiencing 'Empowering Confidence' could at heart feel a degree of personal confidence that they could meet this new challenge:

I am confident the process of analysing [my firm] will bring me to a new dawn.

\section{Accounting student (Assignment stage I) (1)}

The issue of ways of experiencing confidence by accounting students will be examined in greater detail in Chapter 8 below. As noted by Byrne et al (2009:163): "It is important that students are given enough autonomy to allow them to develop as independent learners but not so much freedom that they feel lost, frightened, or disillusioned." Confidence was an issue for students, not just initially as they adjusted to experiencing deep learning, but throughout the course as the demands for making judgements imposed on them by the assessed learning tasks progressively increased. This section has discussed the findings about how students initially adjusted to the experience of deep learning. One key finding of this research is that there was evidence that accounting students could quickly make this initial adjustment to beginning to experience deep learning in the early stages of an accounting course:

I think that students will learn to 'find themselves' in this course. Some may hate it and others may love it. For me, I hated it for the first week but then I saw the benefit of the style of this course and I began to adapt to it...

\section{Accounting student (65)}

The approach to data analysis is discussed in Section 3.1 in Chapter 3 above. The five SPAs and the five stages of the Assignment for each of the 81 students in the course were coded by the researcher using N-Vivo software. One of these predetermined topics was 'Deep approach to learning' and 523 quotes were coded to this theme (see Appendix 4 below). The five SPAs and the five stages of the Assignment were submitted by students in ten of the twelve weeks of the course. This made it possible to identify when in the course each student first provided evidence of experiencing deep learning. This was done in the coding process, by noting for each student in which SPA or stage of the Assignment a quote was first coded to the theme 'Deep approach to learning'. The results of this analysis are set out in Figure 7.2 below. 
Figure 7.2 indicates that about $60 \%$ of students gave evidence of experiencing deep learning by the end of Week 1 of the course, increasing to about $90 \%$ by the end of Week 6 and about $96 \%$ by the end of Week 12 (the last week of the course). Less than $5 \%$ of students gave no evidence of experiencing deep learning. A central finding of this study is that in response to the integrated set of interventions, accounting students were able to make adjustments in just a few weeks to experience deep learning in a university accounting course.

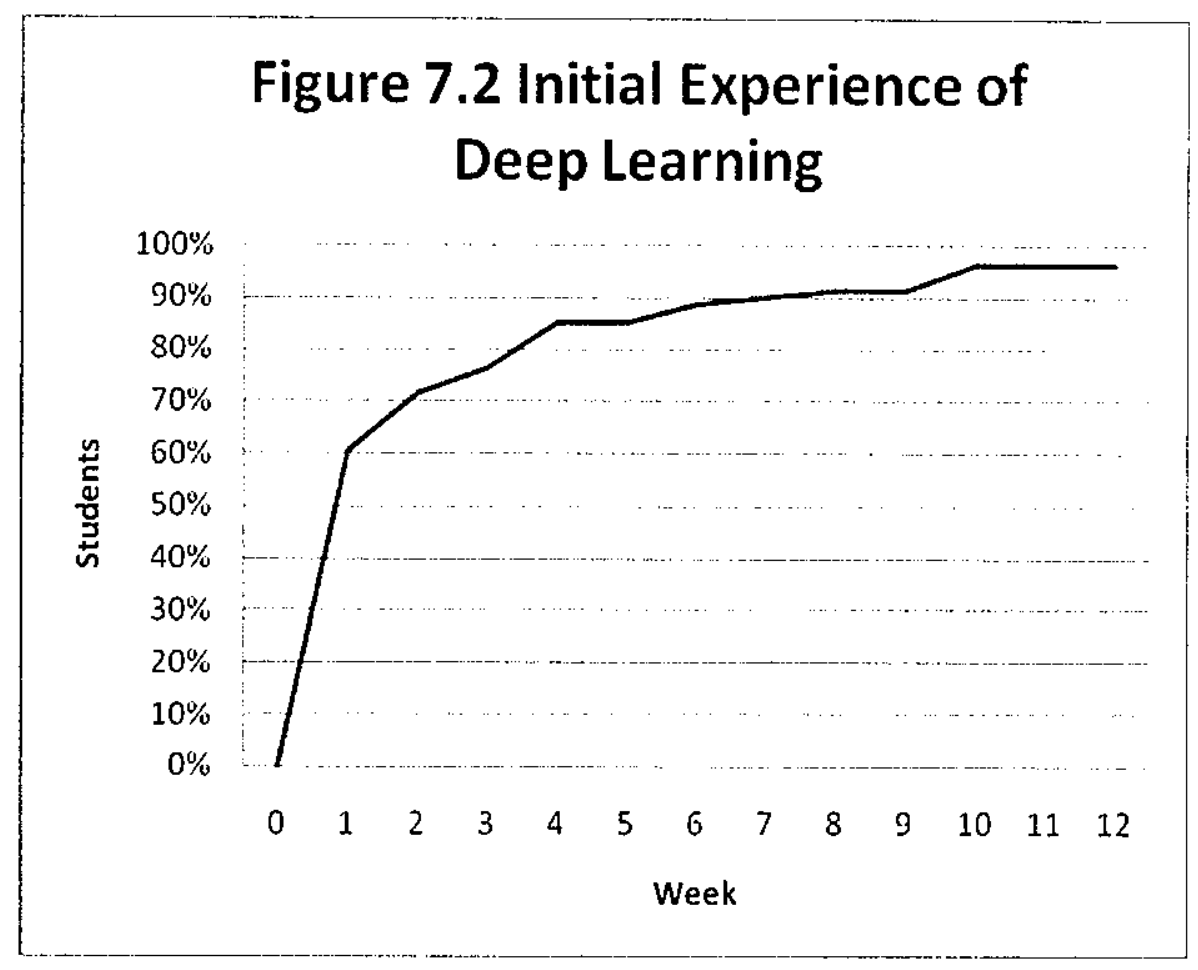

At first sight, this evidence appears to contradict the findings of previous research in the accounting education literature, which found it difficult to support change by accounting students from surface to deep learning: English et al (2004); Hall et al (2004); Ballantine et al (2008); Fox et al (2010). However, these studies involved limited interventions to support deep learning with apparently many aspects of the design and delivery of the courses involving traditional approaches that could be seen as supporting surface learning (see Section 1.3 in Chapter 1 above). The findings of these previous studies suggest limited interventions in the design and delivery of accounting courses have limited (if any) positive impact on the experience of approach to learning by accounting students.

What this study shows is that an integrated set of interventions with each aspect of the course design and delivery carefully designed to support change in 
the way students experience key aspects of how they learn accounting (that is, relevance structure, conception of learning, motivation and approach to learning) can support widespread change in the experience of approach to learning by accounting students in the early weeks of a course. This finding is consistent with suggestions by Marton and Säljö (1997) that supporting a surface approach is relatively easy but supporting a deep approach is much more challenging and that “...influencing students' approaches towards deep learning ... is a complex process" (Baeten et al, 2010: 4). This central finding of this study, which has significant implications for accounting education and tertiary education more generally, will be discussed further in Chapter 9 below.

One reason students were able to begin to experience deep learning in the early weeks of the course when supported to do so by an integrated set of interventions, was that although they had extensive experience of surface learning in their previous university accounting courses (Sharma, 1998; Gow et al, 1994; Byrne et al, 2010) they also had extensive experience of deep learning in other aspects of their lives:

... It almost seemed as though ... [the teacher] thought no one in the class knew how to learn. Sure very few of us were learning at university, but some of us absolutely knew how to learn to begin with. We just found other places in life to do our learning rather than at university.

\section{Accounting student (2t)}

In this section, evidence has been examined about how students were able to begin to experience deep learning in the early stages of a university accounting course, seeking to understand concepts, to explore the meaning behind the accounting numbers and to face the feelings of confusion and challenges to their own confidence in their abilities to think and learn actively for themselves. In the next section, evidence of students experiencing deep learning in the course will be considered. 


\subsection{Experience of Deep Learning}

Now all I'm doing is to try and understand...

Accounting student (7)

The experience of deep learning in the course was evidenced by students seeking to understand and develop personal meaning about the firm they were analysing. This involved them drawing on their previous experience and developing a range of personal insights into the concepts they were studying. The experience of deep learning also developed a self-insight or an awareness of variation in the approach to learning that accounting students could experience in a university accounting course.

\section{Connecting to previous experience}

... I find that when a concept or an idea is related to something that is very relevant to our lives ... it becomes very easy to comprehend.

\section{Accounting student (2)}

Students found it a challenging and rewarding task to seek to understand their own, individual firm for themselves. They needed to personally understand what their firm did and what various items in their firm's financial statements actually meant. To help them understand and make personal sense of their firms, students found themselves drawing on their own previous experience:

I thought the comment about the successful launch of McKenna bourbon in New Zealand [in my firm's annual report] was interesting ... I work in a bar and have never heard of it ... I also know others who work in bars who have also never heard of it.

\section{Accounting student (22)}

Besides being able to connect to their previous experience to help them personally engage with and start to make some judgements about their firms, they were also able to connect to their previous experience to help them understand and develop personal meaning about some of the concepts being studied. For example, one concept studied in the course was the distinction between the company (the 
combined operating and financial activities of a firm) and the enterprise (only the operating activities of a firm):

As a kid I would insist that my parents buy me [a] Kinder Surprise [a small white chocolate egg with a toy inside] so that I could pry the egg open to get the 'bits and pieces' of the toy inside. This is similar to a firm, in which the outer element (white chocolate) is the company and the inside element (the toy) is the enterprise - the firm's operations and activities. Thus in order to be able to directly analyse the firm as an enterprise you need to strip away the 'company' as a whole. This leaves you with the core, value added operations which form the backbone of the firm.

Accounting student ${ }_{(65)}$

\section{Personal insights}

As students began to experience deep learning in the course, they expressed a range of developing personal insights into various aspects of the content of the course, including:

- How to assess a firm's strategy:

I don't think I had a strategy in place when I started university ... sometimes it still stumps me and I think, gosh I'm almost done. Sure there are all sorts of strategies I could place on my studies and how I went about them [in] hindsight, but not so much at the time. In that case, do firms really have strategies? Or is it just something they talk about to attempt to explain their actions.

Accounting student ${ }_{(22)}$

- The subjective nature of share prices:

...capital markets trade on expectations. This means that when an investor buys shares in a company, they are buying into what they expect the outcomes of their business activities to be. I thought it interesting that what an investor 'expects' to occur seldom does. It is very easy to look at a share price and view it as being an accurate representation of what a share in that 
company is intrinsically worth. However, the application of this idea leads one to a very different conclusion.

Accounting student (16)

- The value of separating a firm's operating and financial activities:

In this chapter the author ... discusses the benefits of restating the financial statements in such a way that we can clearly separate $\ldots$ the operating activities from the financial activities ... Although this is such a simple concept, I can see how it would be very helpful and a 'powerful tool' ... letting us view each part individually and, in doing this, stopping us from becoming distracted by the other. This should make it much more clear where profits [are] coming from and allow us to see whether the business is actually being run well or if it's just changes in financial structure that are leading to 'better numbers'. I look forward to separating out and viewing my firm with this approach.

\section{Accounting student (2l)}

- The accounts of a firm (the 'signs') are not themselves reality; a firm's underlying business (the 'signified') is the reality: ...accountants ... really do seem to view the accounts as reality. I admit until taking this course, I unconsciously did this. I have never really given much thought to the underlying business. Prior to [this course], I just assumed that the accounts showed the business as truthfully and fairly as possible ... it is a trap to view the accounts as reality.

\section{Accounting student ( $(1)$}

- The relationship of quantitative financial statements (accounting drivers) and the qualitative economic and business realities of firms (economic and business drivers):

I think it makes very good sense to connect the firm's key accounting drivers to its economic and business drivers. Because 
accounting numbers [have] not dropped from the sky, something must [have] occurred [to] cause the accounting drivers to exist or [to] change from time to time.

\section{Accounting student (Is)}

I feel like I've really connected with my firm; I've left the numbers behind and can really see my firm as a dynamic changing organism, not just a set of financial statements and ratios. I've connected with the business realities ... in doing this I think I have a pretty "real" idea of [my firm] and where its value comes from.

\section{Accounting student ${ }_{(21)}$}

\section{- The idea of good and bad sales growth:}

The distinction between good and bad [sales] growth sorts out a lot of questions in my mind over some cases that firms with a record of growing ... sales [can] result in a bad [financial performance] or even go bankrupt. It is also especially helpful in understanding my company that I have been given. The record of [sales growth] does not tell the whole story.

\section{Accounting student $_{(46)}$}

\section{- The idea of good and bad earnings growth:}

I agree when [the author] says that whether a firm's earnings growth adds value or not depends where the earnings come from. Just like our need to look past the ratios to see where they come from, we also need to look past the earnings to see where they come from and decide using our own judgment and opinion on whether we deem it good or bad [earnings] growth.

Accounting student (20)

\section{- The role of forecasting in valuing firms:}

I remember being extremely disbelieving about predicting the future ... these are a few quotes from my first SPA: "And how can we be sure of the reliability of our expected future abnormal 
earnings? Again is it all just a gamble?" "After all who knows what the future may hold" ... By getting more into this course I began to realise more and more how wrong these assumptions of mine were. Again this quote really put everything into perspective for me: "To be good at financial statement analysis we will need to be good at nothing less than predicting the uncertain future better than some others, better than average." So in actual fact you don't need to know for certain what is going to happen in the future, you just need to have a pretty good rough idea and you need to be better than average to be successful! Beating the market now seems more attainable and especially more credible to me; it is not all just a matter of luck as I tried to argue in my first SPA.

\section{Accounting student (s)}

\section{- Considering the source of risk in business:}

[The reading] goes on to explain that risk comes from [a] firm's operations and not from the capital markets ... I certainly was surprised by this, as what I have learnt in [a previous finance paper], or thought I did, was that risk [is] in [the] capital markets, however I decided to read that particular paragraph twice as I found this conflicting with my understanding. In the end ... I think I ... agree with his reasoning.

Accounting student (so)

- Limitations of using multiples (such as price-earnings multiples) of comparable firms to value a firm:

It confirmed some of the views I already had that simple comparables do not tell [us] anything about value. If it did, then everyone [would] take advantage of this and it would be easy hence what will [be] the point of other valuation [techniques]? Also that it does not lead us away from speculation .... [but] tend[s] to focus on what the market is already expecting. 
These are some examples of students developing personal insights into various aspects of the content of the course, evidence of them experiencing deep learning. This experience supported them to become aware of the possible variation in approach to learning they could experience in a university accounting course.

\section{Awareness of variation}

...I often found that everything in a course would 'click' just before a test or exam, when I was forced to find meaning in the course content. Once I had a decent understanding of what was actually going on, I would suddenly find whatever I was studying a lot more interesting, and wish I had paid more attention during the course itself ... [in this course] the constant assessments ... 'force' us to reflect on what we have taken away from the readings and assignments ... a lot of people have experienced this feeling for the first time in this course, and are reaping the benefits of engaging with a course over a period of time.

\section{Accounting student (68)}

I actually learned quite a bit in this course, and it actually meant something to me. That surprised me.

\section{Accounting student $(6)$}

The experience of deep learning supported an awareness of variation in the approach to learning students could experience in a university accounting course:

Reading [this reading] rekindled memories of studying [a previous course's] lecture notes. Both readings talked about the same thing ... but the feeling I have while reading it now differs from what I felt while reading it for [the previous course]. Perhaps the focus is different - my focus in [the previous course] was to successfully regurgitate in [the] exam whereas my focus now is to learn it.

Accounting student (7)

This awareness of variation can support students to persevere in the experience of deep learning. Also, the experience of deep learning (and their awareness of 
variation of approach to learning) in a university accounting course may provide a foundation for students to more readily experience deep learning in their subsequent accounting courses:

Perhaps people who have enjoyed this process [of deep learning] will be able to take this lesson away from the course and actively engage with future courses.

Accounting student ${ }_{(6,8)}$

This is a critical issue worthy of further research in the future (see Section 9.4 in Chapter 9 below). Transformation of the experience of learning accounting at university will involve not only accounting students learning how to experience change in the way they learn accounting in a single university accounting course (as examined in this study), but also on their ability to transfer this experience to future university accounting courses.

In this section, evidence has been examined about the experience of deep learning by accounting students. Students were able to connect to their prior experience, to express a range of personal insights that evidenced the experience of deep learning in a university accounting course and through this experience develop an awareness of variation in their experience of approach to learning in the course. An important aspect of deep learning is students constructing their own knowledge, rather than passively receiving clear-cut, black-and-white facts from experts. In the next section, evidence that students were supported to construct their own knowledge about accounting as they experienced deep learning in the course will be discussed and its implications examined.

\subsection{Constructing Knowledge}

Throughout this course I am gradually becoming engrossed with the idea of 'getting to understand my firm.' It may seem like a simple concept at first, yet I have found that when I begin to understand [my firm] I also start to question its operations and financials! It appears to be a limitless and never-ending process. 
In this section, evidence that students were supported to construct their own knowledge about accounting as they experienced deep learning in the course will be discussed. The way in which students analysed and understood their firms and the concepts they were studying will be examined. This will include the way students integrated what they were learning in the course, and in their previous courses in their business degree, into a personally meaningful whole.

\section{Analysis and understanding}

I try to turn the knowledge into my own, so I can use it [for] any

firm at any time!

\section{Accounting student $(x)$}

Students expressed their experience of constructing personal knowledge in various ways. This included integrating concepts into a personally meaningful whole:

It is important to understand each individual aspect, and how it fits into the bigger picture.

\section{Accounting student (i)}

The experience of constructing personal knowledge also involved seeking to understand the relationships between the various concepts and ideas being studied: ...the illustrations were used to help me get an idea of how relationships between the key drivers are formed and not see each ratio and driver as an individual number or calculation on its own. Accounting student (7)

...the awesome power of spreadsheets. Not the imaginary numbers pretending to resemble accuracy, but the shear simplicity of how those numbers can all be laid out and connected. I stopped thinking of these numbers as numbers long ago; they are ideas, and spreadsheets allow us to easily link and examine the relationships between these ideas.

Accounting student (21)

As well as integrating concepts into a personally meaningful whole and seeking to understand the relationships between concepts, students also experienced the power of analysis, of breaking a complex firm into smaller key pieces that could be meaningfully understood: 
Every time we chop things into pieces in this course, it gets easier for me to understand what exactly is going on with my firm.

Accounting student (21)

There was also an emphasis by students on seeking their own understanding and personal meaning of what they were studying. This included constructing their own knowledge of the meaning of equations that summarised concepts and relationships between concepts:

Many people can read over equations like they are simple words and immediately make sense of them. I am not one of these people. I don't enjoy reading over equations but just as analysts we are required to look beyond the numbers in financial statements to find the drivers behind them I found myself reading over [the equations] to find what they were actually saying.

Accounting student (25)

It also included seeking their own understanding and personal meaning from the readings:

This is one part of the [reading] that I understood the most. To me it gave real insights into ways to look deep down [beneath] the surface level...

Accounting student (so)

To support accounting students to construct their own knowledge, it was important they were not provided with 'right' answers:

Don't expect "right" and concrete answers - because there are none in this course.

Accounting student (33)

The realisation by students that there were no 'right' or 'wrong' answers both required and enabled them to make their own judgements and to construct their own personal knowledge:

As [the teacher] says, students in [the course] often seek to determine what the right or wrong answer is, especially in the [analysis] of their own companies. At first I was one of these 
students - merely because throughout my studies I have always been told what is right or wrong ... old habits are difficult to change! However, by now I have ... realised that there are no right or wrong answers; some answers might just look more appropriate than others and I need to exercise judgement in reaching a conclusion ... This has enabled me to discover what aspects of the firm I understand, aspects that intrigue me, and areas that still remain 'grey.'

Accounting student (65)

As students came to realise there were no 'right' or 'wrong' answers to be passively received from an 'expert', this gave them the freedom to challenge ideas in the readings and to question their own developing analyses of their firms:

You also have to approach this course using a different mentality. You have to be prepared to engage with the readings given to you and ... to challenge [them] with a convincing argument. This course has a lot of grey areas and you end up questioning your analysis ... You just end up questioning yourself and your work, as there is no one right answer!

Accounting student ${ }_{(60)}$

Thus students left the world of clear-cut, black-and-white answers and instead experienced developing personal understanding:

There are fewer black and white answers for me at the moment, but I do believe that my overall understanding is increasing.

\section{Accounting student $(6)$}

As students engaged in analysis and understanding they had the subjective and personal experience of constructing their own knowledge rather than the impersonal and 'objective' experience of reproducing clear-cut, black-and-white answers:

This assignment has allowed me to formulate my own views on what I believe are the key business and economic drivers of [my firm]. I really enjoyed the subjectivity of the assignment - it is 
an open smorgasbord of ideas, you just need to pinpoint the ones that you believe are important to your firm!

Accounting student $(20)$

Understanding that there is no 'right' answer was empowering for students, supporting them to deal with uncertainty and to make their own judgements and assessments based on evidence:

My perception of art is that there are no correct answers and that anything is correct as long as you "justify" it ... it has become apparent that there is no correct answer in forecasting financial statements simply because the future hasn't happened yet and therefore it is an art form and all we can do is try justifying any decisions we make.

Accounting student (58)

One aspect that assisted students was the growing awareness that learning for understanding and developing personal meaning and making judgements had a subjective aspect to it, or in other words they were constructing their own knowledge (rather than passively accepting some objective 'external' knowledge):

I suppose by the end of this course, I can be confident to some extent in analysing a company, but in reality I think it will be up to my own personal judgment that will matter in the end, e.g. the All Blacks were favourites to win against South Africa and no matter who ... analysed the previous stats ... they would have suggested [the] All Blacks would win the game last Saturday. However, I went against the odds and believed in my judgment and put a bet at [the] TAB....guess who won?

Accounting student (so)

...it comes down to forming accurate and reliable opinions, trusting your own judgments and if you are successful who is to tell you that you [are] wrong.

\section{Accounting student (7)}

Nevertheless, there was an understanding by students that there was an economic and business reality for each of their firms. This was not something simply 
imagined; analysing their firms was not simply a 'game', or pretence or charade of competing human confidences and bluff disconnected to the 'real' world. Rather, there actually was an economic and business reality for their firms that they could personally engage with through their analyses of their firms; although they could not experience this reality as a final, conclusive, objective 'right' answer. When analysing a firm's financial statements, students were dealing with the uncertainties, doubts and 'greyness' of the future. Thus they were compelled to inject themselves into the subjective process of constructing their own knowledge in the intensely competitive environment of the capital markets in which the shares of their listed firms were trading:

...you need to talk to other people, you need to think critically and you will never come across a black and white answer because there isn't one ... It has been these realisations that have made this learning experience so exciting because I have realised in equity investing you don't need to find the correct answer you just need to be closer to the answer than others in the market and you will become a winner.

\section{Accounting student (s:)}

Constructing their own knowledge in a university accounting course can involve not only integrating into a personally meaningful whole the concepts and ideas being studied in a single course; it can also include concepts and ideas they had studied in previous courses. This aspect will now be considered.

\section{Previous courses}

In the third-year accounting course in financial statement analysis that was the subject of this study, students had the opportunity to critically reflect on and integrate a wide range of accounting and finance concepts they had previously studied at university. As students began to experience deep learning and constructing their own knowledge in the course, they also developed the expanded expectation that the course would perhaps support them to experience constructing their own knowledge about the concepts and ideas they had studied throughout their university degree:

I think this course will help me connect key concepts from my previous accounting courses where the technical concepts are 
disconnected when we learn them. This course will hopefully challenge the way I view ... what accounting actually is.

Accounting student (37)

As students connected to their prior knowledge and previous experience to help them understand and develop personal meaning about the concepts in the course, they also experienced seeking to understand and develop personal meaning about some of the concepts they had studied in previous accounting courses, and to integrate the content of their previous courses into a personally meaningful whole:

By culminating all of our other papers into a practical and transferable skill it is like we are activating random soldiers into a single functional military unit...

\section{Accounting student (6)}

The one thing that I most like about this course and the readings we do is the fact that we are building on our knowledge from previous courses ... And this course actually makes us think critically about the concepts we have learnt.

Accounting student (ss)

In this section, evidence that students were supported to experience constructing their own knowledge about accounting in a university accounting course was examined. In the next section, evidence will be discussed about the relationship between the design of the assessed learning tasks and the experience of deep learning by accounting students; and the important role Assessment played as a central intervention to support accounting students to experience deep learning as they completed the assessed learning tasks.

\subsection{Design of the Assessed Learning Tasks}

...it seems to be much easier to understand the technical aspects when you get some experience [of] actually doing it.

Accounting student (4I)

In this section, evidence is considered about the relationship between the design of the assessed learning tasks and the experience of deep learning by accounting 
students. In Sections 5.2, 5.3 and 5.4 (in Chapter 5) and Sections 6.1 and 6.2 (in Chapter 6) above, the experience of intrinsic motivation by accounting students in response to the assessed learning tasks was discussed. Also, the key relation between the experience of intrinsic motivation and deep learning has been discussed in Section 6.4 (in Chapter 6) above and in Section 8.4 (in Chapter 8) below. In this section, evidence will be considered that Assessment not only supported students to experience intrinsic motivation and thus indirectly their experience of deep learning, but also directly supported accounting students to experience deep learning as they completed the assessed learning tasks.

As outlined in Section 3.1 in Chapter 3 above, the assessed learning tasks were different for each student (individualised) and were part of real life and were not contrived or made-up (authentic). Regular formative feedback involving both individual and general feedback from the teaching staff as well as exemplars from other students was provided. Students also had the freedom to openly share and discuss their work on the assessed learning tasks with other students because the tasks were different for each student; and these discussions between students formed an important part of the regular formative feedback (in this case, from each other) that students received as they completed the assessed learning tasks. The assessed learning tasks involved the analysis by students of their own real firm and also involved them critically and reflectively reading the course materials, adapting and applying the concepts from the readings to their analysis of their firm. These individualised, authentic assessments with regular formative feedback established the learning tasks that students needed to complete in the course.

\section{Individual, real firms}

...we're seeking to understand our firms, not to apply techniques unthinkingly to numbers that mean nothing to us.

\section{Accounting student $(6)$}

The application of the concepts in the course to their individual firm supported students to develop understanding and personal meaning about these concepts, such as the use of discounting in the valuation model they applied to their firm: 
This course has also concreted facts and ideas into my head that previously were disconnected and appeared useless ... It's been great. I love learning about things to get to another level. Like discounting [which is part of the valuation model used in the course] ... normally I may have struggled with having to remember how to discount. Because I had used it as a means to an end and not the end point itself, I actually just got down and did it. I think it's really interesting that my mind works that way! ... There's something about the practical application of knowledge that facilitates knowledge in a way that reading and even made-up scenarios (no matter how life-like) could [n]ever achieve.

\section{Accounting student (6)}

Also, the knowledge that they would need to apply to their firm the concepts (or theory) from the readings supported students to experience deep learning when completing the readings:

The readings are not just read to better understand the theory; they are the theory you are going to need to apply practically. I learn things so much better if I have to do them, and because in doing the assignments you need to apply the theory, and go beyond the theory to your own reasoning, I will remember it far better than if I were just rote learning facts.

\section{Accounting student (6)}

There was a two-way interaction between students critically and reflectively reading the course materials and adapting and applying these concepts to their analysis of their own firm:

...I wish I had completed this reading before [the third stage of the] Assignment because I think the discussions ... would have been very useful ... the ironic other side is that I don't think I would have understood the chapter as well as I now do without doing [the third stage of the] Assignment beforehand. 
The calculation and interpretation by students of various financial ratios for their individual firm caused them to reflect on what these ratios told them about the economic and business realities of their firm. Students discovered they needed to make some judgements in the actual calculation of ratios:

The calculation of ratios looked quite technical and straightforward at first as it involved taking different figures from the statements and calculating a ratio. But it's only when I actually started doing it that I found that it is actually not as simple as it seems and there is a whole lot of areas which require judgment and understanding.

Accounting student (2)

Students also realised they could personally connect to the economic and business realities of their firms, or in other words to the meaning behind the accounting ratios and numbers:

After actually doing the restatement $I$ found that [everything] ... made A LOT more sense! I feel like I have a much stronger understanding of ... [my firm]...

Accounting student (ss)

As each student was analysing their own individual firm, they could freely discuss and work with others in the course as each person sought to understand the concepts they were studying so they could apply them to the different situations of each of their firms. Through these discussions and interactions with other students in the course, they were also able to learn about the application of the concepts to a wide range of firms, thus extending and deepening the knowledge they were able to construct for themselves:

...the fact that we all had different companies to study made our analysis so much more in depth. Having different companies and different challenges provided a much wider scope to gain knowledge ... The fact that we all had different companies, helped me gain more understanding from my analysis via interaction with others. Once again, in the accounting profession we deal with a wide range of companies, and having the 
confidence to gain a good understanding of any kind of business is really satisfying.

Accounting student (7)

The need to apply the concepts being studied to their own individual firm in the assessed learning tasks supported students to be active in their own learning:

I'm 'forced' into being more engaged with my chosen company. Somehow there is more meaning to what I'm learning as I can apply this knowledge to assess my company and add value. I am not just a spectator anymore, but an active contributor in my own studies!

Accounting student (7)

Students were also able to focus on applying what they were reading to their own firm:

I began to think over in my mind as I was reading how this could all relate to my firm ... It made me think about what the operating and financial activities are and I started to formulate in my mind ... a "plan of attack" as to how I would ... carry out my future analysis [on my firm].

Accounting student (24)

Because they were each analysing their own real firm, students also had opportunities to think about their firm during their daily lives:

Just the other day, I was driving and pulled up at the traffic lights behind a large advertisement [for my firm] on the back of a bus ... I did think to myself, how many new sales will that advertisement actually generate?

Accounting student (20)

\section{Regular, formative feedback}

Regular, formative feedback supported students to develop and deepen their understanding of the concepts step-by-step as they faced the considerable challenges of analysing their firms: 
In my last SPA I commented that I didn't have a clear understanding of the ... framework. After [the marker's] feedback explaining that the framework can be summarised by key formulas or accounting relationships [it] started to click. However I wasn't alone with this issue. I talked to [another student] and she commented that before she did [the third stage of the] Assignment she was still a bit unsure of what the framework actually was. We both thought after [the third stage of the] Assignment the valuation model ... became a lot clearer. I guess because we were using the model it become much easier to understand the approach we were taking with our analysis.

Accounting student ${ }_{(69)}$

The later stages of the Assignment required students to experience making more judgements and personal assessments, particularly when forecasting their firm's future earnings:

Predicting the future of firms, it requires that we really engage with the firm's economic and business realities!

Accounting student (28)

Regular, formative feedback supported students to continually develop and rethink prior stages of their analysis as they completed later stages of the Assignment:

I find I am continuously modifying my restated statement. It is interesting that I thought my restated statement was perfect at the time I finished [the second stage of the] Assignment. Unfortunately, many problems came out when I was doing [the third stage of the] Assignment.

Accounting student (34)

\section{Reading prior to classes}

...by having to do the SPA's it forced me to actually do the readings, which I somehow doubt I would have done on my own! Accounting student (55) 
The session preparation assignments (SPAs) were also individualised, authentic assessments with regular formative feedback. The SPAs are described in Section 3.1 (in Chapter 3) above and are included in Appendix 1. As noted above, the experience of the learning tasks of the SPAs interacted with the experience of the learning tasks of the five stages of the Assignment to support students to experience deep learning. One way the SPAs did this was through supporting students to read the course materials before classes to give an initial understanding of key concepts and ideas on which they could build further their own understanding and personal meaning:

Completing readings prior to classes aids a deeper understanding of the material: Knowledge and understanding of the material provides a platform for further learning and deep understanding rather than just superficial regurgitation. It is amazing sitting in class and not being under significant duress copying down notes frantically and having no clue what the material is actually about. Accounting student ${ }_{(42)}$

The experience of deep learning by students was supported by progressively reading the course materials throughout the course:

The SPAs in this course ... kept me on my toes ... in some other courses at university, I wouldn't read the textbook until it's close to test or exam time and ... try to memorize facts out of the books.

\section{Accounting student (so)}

The SPAs also supported students to engage with the materials critically and to seek their own understanding and personal meaning:

[The] SPAs ... helped me develop a better understanding of the materials [at] my own pace. SPAs allowed me to spontaneously raise any questions I had about the readings and gave me the scope to engage with the materials at a deeper level by applying some of my personal experiences in the SPAs.

Accounting student (so)

The readings also supported students to experience thinking for themselves: 
...I have rather enjoyed thinking critically about the chapter readings, and in doing so I was actually made to think for myself?

\section{Accounting student (55)}

An important aspect to the design of the SPAs was that the readings were written in such a way as to have a deep approach (and not a surface approach) to learning embedded in them:

... [the author] ... explains difficult technical stuff in normal and everyday terms, and I particularly loved his comparisons and personal touches, also it being an accounting text book it isn't as dry as you would expect it to be. Chapter Five - Predicting the Future, really brought everything together for me, and now I [am] just building more and more onto my knowledge.

Accounting student (s)

In this section, evidence was considered that the assessed learning tasks directly supported accounting students to experience deep learning. A key finding from this study is that interesting, challenging learning tasks that are individualised (different for each student), authentic (part of real life) and with regular formative feedback (individual and general feedback from the teaching staff, exemplars from other students and freedom to share and discuss their own work on the learning tasks with other students because the tasks were different for each student) can directly support accounting students to experience deep learning in a university accounting course.

\section{Conclusion}

In this chapter, evidence was discussed about the experience of deep learning by students in a university accounting course. The significant initial adjustments students faced to experience deep learning in the course were examined and it was seen that a large proportion of students were able to make these adjustments in response to an integrated set of interventions; indeed, there is evidence many students were able to make these adjustments in the early weeks of the course. Previous research has indicated difficulty in supporting accounting students to change the way they experience approach to learning in response to limited 
interventions in the design and delivery of university accounting courses (English et al, 2004; Hall et al, 2004; Ballantine et al, 2008; Fox et al, 2010). This study has shown that a large proportion of students can be supported to experience deep learning in a university accounting course if an integrated set of interventions is introduced where each aspect of the course is carefully designed to support students to change their experience of relevance structure, conception of learning, motivation and approach to learning.

Aspects were also examined of the experience of deep learning by students, such as the connection to previous experience, the development of personal insights and the awareness of variation in the approach to learning that they could experience in a university accounting course. It was seen how students can be supported to construct their own knowledge about accounting as they experience deep learning, including the way students integrate what they were learning in the course, and in their previous courses in their business degree, into a personally meaningful whole. Evidence was also examined about the impact of individualised, authentic assessed learning tasks with regular, formative feedback to support accounting students to make the significant cognitive effort involved to experience deep learning.

In the next chapter, evidence will be examined about the impact of the interventions of Teamwork, Teacher-Student Relationship and Instruction on the experience by accounting students of deep learning and the way they experience confidence in response to the significant cognitive challenges of experiencing deep learning. Also, evidence will be considered about the important internal relation between the experience by students of intrinsic motivation and deep learning in a university accounting course. 


\section{$-$}





\section{CHALLENGES OF DEEP LEARNNG}

[T] he most valuable [thing] I got from this course is the new way to study. My new study method is [to] study actively ... the way that I build up my own knowledge, my own understanding based on what I get from [the] textbook and other sources. Previously, I just received the knowledge by learning by heart and then reproduce them without any interest [to] understand more about them. That is why I forget them immediately after the exam ... However, in this course I have to really understand what I got from the textbook to apply it [to] real life. Thus ... it encourage[s] me to think independently and for myself ... I experienced that changing is painful because ... when I started to apply the new method, I felt really stress[ed] [about] the concept of thinking for myself and constructing my own [knowledge] (which I [have] never done before). However, when I overcame that, I found that the reward, which I get, deserves that change. I now can discuss or express my ideas with my own thoughts and knowledge, not [simply] reproduce them. Through this course, I also found that study is [an] enjoyable process.

\section{Accounting student ${ }_{(45)}$}

In this chapter, evidence is examined about the challenges of deep learning for accounting students in a university accounting course. Firstly, the findings about the impact of the interventions of Teamwork, Teacher-Student Relationship and Instruction on the experience by students of deep learning are considered. Due to their lack of prior experience of deep learning in the context of a university accounting course (Booth et al, 1999; Byrne et al, 2009), the experience of learning for understanding and developing personal meaning presented students with a number of challenges. To meet these challenges requires an experience of confidence by students in their own learning capacities and abilities to make judgements. In this chapter, evidence will be considered about the ways students 
experience confidence in response to the significant cognitive challenges of experiencing deep learning. The findings about the internal relation between the experience by students of relevance structure and of deep learning are then considered.

Evidence will also be examined about the internal relation between the experience by students of intrinsic motivation and deep learning. The experience of deep learning has been found to be strongly related to intrinsic motivation (Fransson, 1977; Marton and Säljö, 1984). In this study, there was evidence the experience of genuine, personal interest in the learning tasks (intrinsic motivation) supported students to experience these learning tasks with a deep approach to their learning. After experiencing struggles, challenges, difficulties and adjustments, there was evidence students found they enjoyed and valued the experience of deep learning which reinforced and supported their developing intrinsic motivation in the learning tasks. The areas focused on in this chapter are highlighted in Figure 8.1 below.

Figure 8.1 Interventions to Support Accounting Students to Change the Way They Experience Learning Accounting

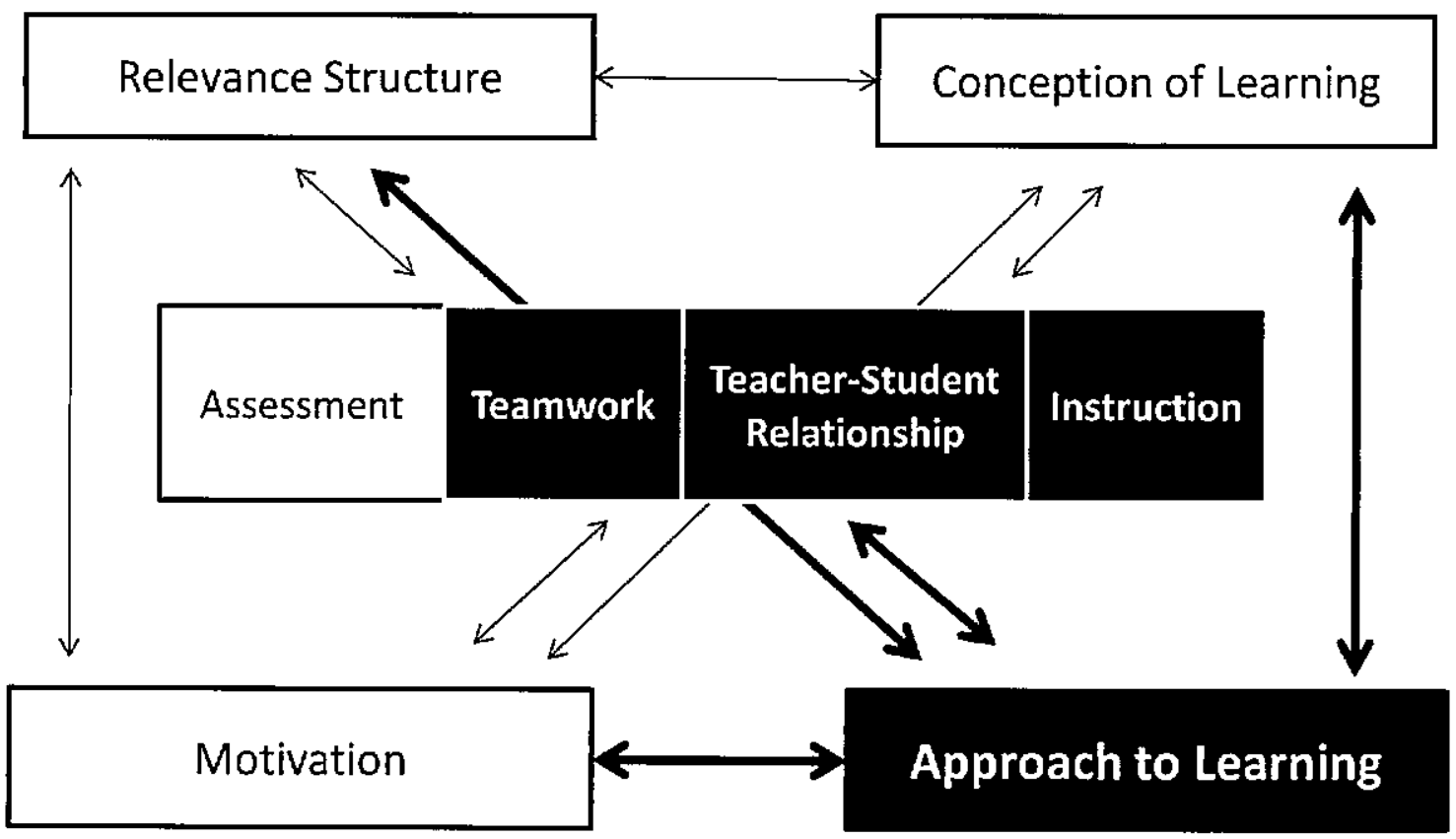




\subsection{Relationships With Others}

The following is an exchange on the online discussion board for the course:

Accounting student 1: Eek. Problemo..

Would you include profit from

discontinued operations in

operating revenue for the year? ...

surely it's operating revenue for

the year, but it won't be continued

so will it mislead profit?

Help?

Teacher: [Student name] - a good issue for you to think about ... my thoughts are this: we look at the historical accounts to find out what happened in the past. As a separate exercise we think about what might stay the same, and what might change, in the future. It seems to me you have identified something that might change in the future. That's fine. Worry about that when you start forecasting (fifth stage of the Assignment).

Accounting student 2: I had the same problem, and I will probably apply the same logic also. It's great to have the views of other people on precisely the same issue that I had.

I suppose ... you would find numerous instances where a firm had generated revenue or lost 
expenditure through an

arrangement that would not be in place for the next accounting period (e.g. a long term contract for supply that is due to expire). So you have to draw the line somewhere. You can't just exclude that revenue from operations, right?

Teacher: [Student name], to be an operating item it does not need to be recurring. A one-off item can be operating. Firms have lots of 'one-off' operating items happening all the time.

Accounting students (and teacher)

The interventions of Teamwork, Teacher-Student Relationship and Instruction not only related to the experience by accounting students of relevance structure, conception of learning and motivation (and thus indirectly affected their experience of deep learning) but these interventions also related directly to the experience by students of deep learning. In this section, we examine evidence about the direct relationship between the interventions of Teamwork and TeacherStudent-Relationship and the experience of deep learning in the course. In a later section, we will examine the direct relationship between Instruction and deep learning.

\section{Teamwork}

I know that I gained a much deeper understanding of [my firm] and financial statement analysis in general than I would have if $I$ had followed my old patterns and worked individually.

Accounting student ${ }_{(68)}$ 
There was evidence Teamwork supported students to experience deep learning by helping them to apply the concepts they were learning to their own firm. For example, Teamwork supported students to make the intuitive judgements needed to connect their firm's accounting drivers and ratios to their firm's economic and business drivers:

Our group discussion about our accounting drivers and ratios was very helpful ... it ... gave me exposure to three other different companies ... our discussion ... quickly turned to questions about what the economic reality was behind the drivers. We were immediately trying to understand what it was that had caused the ratios to be the way they were.

\section{Accounting student (al)}

As students shared their analysis of their firms, this supported their experience of deep learning:

The thing that really ties it together is applying it to my company AND seeing it (and helping) in the application to other people's companies ... I'm certainly getting a lot out of seeing their company's information and their ideas of what's happening.

\section{Accounting student $($ (I)}

There was evidence students were also able to interact meaningfully through online resources such as a discussion board, where students found these interactions could be highly significant in supporting their own experience of deep learning:

These three [students in the course] have a very good understanding of key drivers [for their firms] and how to interpret their results ... I believe they have gained great insights ... and by posting their knowledge on the discussion board they have helped with my learning immensely. 
After reading the awesome comments made by star threader [student name] ... "The light bulb kind of went off for me just then..."

Accounting student (37)

There was awareness by students that meaningful interactions and Teamwork with other students in the course was an important means for them to understand the material being studied and to complete the assessed learning tasks. This awareness supported their motivation to invest the time and effort to experience Teamwork. The interaction between the intervention of Teamwork and deep learning (and also the interaction between the interventions of Teamwork and Assessment) influenced the experience of deep learning by students:

To complete [stage 4 of the] Assignment, I realized my learning style has ... changed, if I was not interacting with other students I would not be able to do this assignment ... discussion with other students ... help[s] me to understand more and learn more things beyond the textbook ... I will have more discussions with my study group mates.

Accounting student (53)

There was evidence students experienced how Teamwork could 'exponentially' improve their learning, that is their construction and use of knowledge:

This social learning that we are doing in this course is fantastic. I have learnt so much through the use of the discussion board and interacting with other students. Some people have some very useful knowledge and collectively this knowledge seems like it can be used exponentially.

\section{Accounting student ${ }_{(72)}$}

Indeed, there was evidence the value of Teamwork in supporting deep learning was a focus of awareness for students, with the internal relation between Teamwork and deep learning coming to the forefront. There was also an awareness of the personal value to them of forming quality relationships with others in the course: 
Discussing with others is the really great way to open my mind and broaden my knowledge.

\section{Accounting student (45)}

I can honestly say that without these people, I would not have been able to do well in the course. The people in class are the ones who have helped me ... gain a better understanding about various concepts that $I$ had no idea of. Thanks to everyone especially ([the teacher and 11 named students] and others). This not only encouraged and built my confidence in what I have learnt in the course, but it also allowed me to get to know a lot of people and form great relationships with them...

\section{Accounting student (si)}

There was also evidence that the focus of awareness by students of the value of the interaction between Teamwork and deep learning, was an important aspect of their learning about how to learn:

This course has also taught me ... how important and valuable it is [to] discuss your ideas and thoughts with other students. I find that when I can explain something to someone I have fully understood it and it actually sticks in my mind, also in discussing with other people you learn more than you would just thinking about a concept or issue by yourself because you get the other person's perspectives and ideas as well as your own.

\section{Accounting student (ss)}

Further, there was evidence Teamwork supported students to overcome some of the barriers to deep learning, including realizing they were not alone in feeling the challenges and difficulties of developing understanding and personal meaning:

...I found this reading incredibly difficult to understand ... Where I have been able to grasp concepts faster in previous readings, it took a lot longer in this reading! I was relieved to find that I was not the only one who 
found it difficult, [three other students] all also found the

reading very intense, [and one student said he] especially

found it 'hard to get his head around [it]'.

Accounting student (20)

The awareness and experience by students of the intervention of Teamwork also occurred within the context of the intervention of the Teacher-Student Relationship.

\section{Teacher-Student Relationship}

To keep your sanity in this course, I think everyone should get it into their system that you are not [going to] get a straight direct answer from [the teacher] like you will with your other lecturers. He will say "discuss with others and YOU let me know your thoughts on this". It's good as it will encourage talking to others and learning from each other.

\section{Accounting student ${ }_{(60)}$}

Surface learning by students involves reproducing clear-cut, black-and-white facts from experts, such as from the teacher in the course (Biggs and Rihn, 1984). It was an important aspect of the intervention of Teacher-Student Relationship that the teacher did not act as 'the expert' and give the students clear-cut, black-andwhite answers that are 'correct'. Rather, to support and foster learning for understanding and developing personal meaning, the teacher asked questions, fostered discussion between students and supported students to develop their own opinions and views, which they can support with personally meaningful evidence:

There was a time when one of my group members complained how [the teacher] is not teaching us anything - he merely posts other people's thoughts and reads them to class (and of course, he comments on those thoughts too). But I explained the benefit of him doing so i.e. we get to know what other people are thinking and what their opinions are. I told her how in this course, opinions really matter. [If the teacher] hadn't done those 
things, I doubt I would know how to even form my own opinion ... he doesn't expect us to reproduce what he said. Instead, he expects us to form our own view of the things he has said, and this is a skill which most of us lack. It sounds like an easy task, but it is actually a skill that requires lots of practice. I'm glad I get to practice this skill in [this course].

\section{Accounting student (77)}

This does not mean that in the intervention of Teacher-Student Relationship there was no 'teaching' being done by the teacher but rather that the teacher did not present simple, clear-cut, black-and-white facts for students to simply reproduce with little or no understanding. Rather, the teacher sought to act as a catalyst for students to reflect on and seek to understand concepts that are presented by the teacher, with strong linkages to authentic examples:

...I like the style of how the content is presented ... it

isn't presented with 'fact after fact' but [the teacher]

states the concept, defines it and then relates it back to a

firm's operations - this is very insightful.

\section{Accounting student ${ }_{(65)}$}

There was also evidence that in the intervention of Teacher-Student Relationship there is a balance for the teacher to strike between 'spoon-feeding' pre-digested and overly simplified black-and-white facts on the one hand and leaving students confused and unsure on the other. There was also evidence of the interaction between the interventions of Teacher-Student Relationship and Teamwork, with students interacting with the teacher and with each other in an integrated web of relationships:

One of the issues a few of us had ... was whether to include ... depreciation ... as an operating expense or not. [Another student] pointed out that because depreciation was related to assets that are used for operating purposes it should be [an operating expense]. We both agreed ... this would be the best way ... However [a third student] from my study group had not classed it as an operating 
expense, as other students she had talked to said that they had not included it [as an] operating expense ... We looked on [the online discussion board] to try to sort out the problem but got even more confused ... we thought the best way to solve the problem was to confirm it with [the teacher]. Thank you for responding [by email] so quickly! It was good to know that what we originally thought was correct.

\section{Accounting student ${ }_{(69)}$}

There was also evidence that it is important for students to feel the teacher is genuinely interested in their opinions, thoughts and reactions and to be encouraged to challenge the ideas being taught. The intervention of Assessment strongly interacts with the intervention of Teacher-Student Relationship in this area. Assessment can powerfully support the experience by students that the teacher is genuinely interested in their perspectives rather than in seeing students simply regurgitate the 'right answers':

Throughout university we have almost been encouraged to accept the theories taught in our courses and not to question them - why would we question what a text book says when we know that it will be marked correctly in the exam? My attitude changed completely when I embarked on [this course] ... there was no exam, and the lecturer was genuinely interested in our thoughts on the various concepts presented to us, we were encouraged to challenge theories and create our own opinions...

\section{Accounting student (l)}

In this section, evidence has been considered about the direct relationship between the interventions of Teamwork and Teacher-Student Relationship and the experience of deep learning by accounting students. Learning is an individual activity in a social context (Ramsden, 2003 ). Students do their own learning, but they do it in interaction with and in relation to other people. Key 'other people' in the course are other students and the teacher. The interventions of Teamwork (supporting meaningful interactions by students with other students) and Teacher- 
Student Relationship (supporting meaningful interactions by students with the teacher) are focused on supporting students to experience relationships with other students and the teacher in such a way that these relationships will support them to experience deep learning (Anderson, 2003). There is evidence provided in this section that Teamwork and Teacher-Student Relationship are important interventions to support deep learning. In the next section, evidence will be considered about the direct relationship between the remaining intervention of Instruction and the experience of deep learning. The experience of deep learning presented accounting students with many personal challenges. In the next section, we will also consider evidence about the experience of confidence by students as they faced the personal demands and challenges of experiencing deep learning.

\subsection{Confidence to Make Judgements}

...I want to be able to analyse a firm to a point where I can confidently say I would like to invest in this company or no, I would not like to invest in this company. So far I feel quite good about my analysis!!

\section{Accounting student (5s)}

Students need confidence to confront the challenges of learning for understanding and developing personal meaning without the 'security' or 'certainty' of clear-cut, black-and-white answers from unquestioned experts (Ramsden, 2003). Also, the experience of deep learning itself can support students to develop confidence to meet the challenges of the assessed learning tasks. The experience of confidence by accounting students in a university accounting course has been categorised into two qualitatively distinct ways: 'Lack of Confidence' and 'Empowering Confidence'. 'Lack of Confidence' is the experience of feeling overwhelmed, disempowered and defeated by the looming uncertainties, lack of clarity and 'shades of grey' involved in learning for understanding and developing personal meaning. 'Empowering Confidence' is the experience of curiosity, interest and confidence to proceed with the assessed learning tasks in the face of the looming uncertainties, lack of clarity and 'shades of grey' involved in learning for understanding and developing personal meaning. 
One of the key areas of learning how to learn accounting in a university accounting course is for students to experience 'Empowering Confidence' in their abilities to experience deep learning, even though they may have extensive previous experience of surface lerning in a university accounting course (Booth et al, 1999; Byrne et al, 2009). Before discussing this important issue, evidence for the direct impact of the intervention of Instruction on the experience of deep learning will be considered.

\section{Instruction}

An important intervention to support students to experience deep learning was the application of concepts in the readings and lectures to a real New Zealand listed company, Ryman Healthcare. There was evidence this aspect of Instruction facilitated students to think conceptually and interacted with the intervention of Assessment to support students to experience intrinsic motivation:

I especially liked how the chapter followed through as an example. It helped me to conceptualise and apply what the words were saying to a real life example. I feel this chapter is going to be invaluable for my future analysis of my firm.

\section{Accounting student (24)}

There was also evidence this aspect of Instruction helped students see the relevance and connection of the concepts to the real world:

Having the Ryman Healthcare example was ... very useful as it provided a tangible illustration of the points being made. The five Ps [of strategy formation] were made much clearer when the Ryman example was used. The majority of textbooks would normally list concepts such as the "five Ps" with definitions. However, the only reason I have taken anything out of the five Ps concepts is because they were made relevant by using Ryman Healthcare.

Accounting student (19) 
The application of the concepts to a real company supported students to think about how the concepts applied to the analysis of their own firm:

The Ryman Healthcare example was a great way to see

this analysis in a practical/real life setting and also helped me get a grasp of the sorts of things I should be thinking about when starting out [on] an analysis [of my firm]...

Accounting student (30)

This supported students without directly giving them clear-cut, black-and-white answers as they needed to understand the concepts to be able to adapt them to the unique features of their own firm:

The Ryman example provided some great insight and things to think about when trying to connect the accounting drivers with the economic and business realities of the firm and then connecting these to forecasting the future. None of the specific accounting drivers, economic and business realities were relevant to my own firm but they definitely got me on a thought path of things to think about for my own firm.

Accounting student (30)

There was evidence the interventions of Assessment, Teamwork, Teacher-Student Relationship and Instruction directly supported students to experience deep learning. This was in spite of evidence of the lack of previous experience by students of deep learning in a university accounting course (Byrne et al, 2010). This often new experience of deep learning in the context of a university accounting course presented students with a number of challenges. To meet these challenges requires an experience of confidence by students in their own learning capacities and abilities to make judgements. The experience of confidence by students has been categorised into two qualitatively distinct ways: 'Lack of Confidence' and 'Empowering Confidence'. Evidence will now be considered about the ways accounting students experience confidence in response to the significant cognitive challenges of experiencing deep learning. 


\section{Experience of confidence}

There was evidence students could experience 'Empowering Confidence' at an early stage in the course, despite having little or no understanding of what may be involved to complete the assessed learning tasks:

At the moment though, I have little idea of where to start ... It looks a little daunting right now and does not make much sense, but I'm confident of producing good work given some time.

Accounting student (SPAHI) (7)

Students were also able to experience 'Empowering Confidence' at an early stage in the course as they began to realise what would be required to make the judgements necessary to complete the learning tasks:

But isn't it pretty risky to follow just your own judgement?

How about if my judgement is wrong? Very hard to learn! After I read more about it, working hard, attention to details and able to take risk, it could actually work.

Accounting student (SPAHI) (3I)

There was also evidence students were supported to experience 'Empowering Confidence' by awareness that careful analysis can give the basis for confidence in making personal judgements:

It is very important to form our confidence to make judgments. Nonetheless, how can we believe the decision is right? ... Do you trust yourself? Why or why not? ... I would like to know how people can develop their confidence to make judgments bravely [and] without hesitation. Fortunately, I found the answer ... Proper analysis ... [gives] our judgments more credibility. Moreover, to agree and disagree with some points could make me ... think more and make judgments independently.

Accounting student (SPA\#I) (39) 
Trust in the scaffolding and support provided by the teacher and by other aspects of the course design (such as the readings) was also an important aspect in supporting students to experience 'Empowering Confidence':

My main question is how to use this information that we obtain from separating the operating and financial information from the past ... to help with our analysis of the future, but I assume as always with [the teacher] he has the answer up his sleeve and am looking forward to what his future chapters have in store!

Accounting student (24)

However, a feeling of lack of practical experience and knowledge to make the judgements necessary to complete the learning tasks, supported students to experience 'Lack of Confidence':

...we do not have enough experience. We do not have ... enough knowledge about different businesses and industries .... Appropriate judgments, estimates and predictions [are] based on professional business knowledge and experience, which comes from lots of ... analysis of financial statements [of] different companies.

Accounting student (35)

\section{A new experience}

...financial statements analysis requires lots of judgements and critical thinking ... which [is] all new to me. I have never used this technique before in my previous study.

\section{Accounting student (32)}

There was evidence a key reason students experienced 'Lack of Confidence' in their capacities to learn for understanding and developing personal meaning and to make the judgements required of them in the assessed learning tasks was their limited previous experience of doing these things in a university accounting course (Booth et al, 1999; Byrne et al, 2009): 
...I am ... sceptical of my abilities, mostly due to the fact

that I have been a passive learner and relied on my abilities to rote learn and regurgitate to the examiner and anticipate what will be expected in assessments to get a good grade.

\section{Accounting student (24)}

This lack of previous experience of learning for understanding and personal meaning in a university accounting course contributed to a sense of confusion, of being lost, or of being overwhelmed by the uncertainties and 'shades of grey' involved in the experience of deep learning:

...it looks like the journey is all uphill from here and I am beginning to doubt that there is a light at the end of the tunnel!

\section{Accounting student (24)}

I have not been able to fully appreciate these readings as ... I feel confused ... I feel I am chopping and changing back and forth with what I am supposed to do. I work better when I can see what I am working towards but at the moment I don't have a clue ... what that is.

\section{Accounting student (9)}

There was also a need for students to be authentic and 'real' when experiencing deep learning. It was no longer possible to 'pretend' that they knew something if all they had was a superficial knowledge of clear-cut, black-and-white facts with little or no real, personal understanding. Deep learning required a degree of personal honesty, authenticity and openness by students about what they really understood:

At the start of this course I was really hesitant and felt reluctant to share my feelings in the SPAs and Assignments. Looking back I think what was lurking underneath this reluctance was embarrassment, and me not wanting to sound stupid by asking 'dumb' questions. I guess I felt silly admitting that I didn't know how to 
interpret financial statements or know what adds value in a firm, because surely at the end of my degree I should be able to.

Accounting student $(6)$

\section{Foundations of confidence}

As students progressed through each stage of the Assignment, there was evidence they were able to experience 'Empowering Confidence' as they developed confidence in their capacity to make judgements based on evidence:

This assignment has given me great insights on how my company is operating and what the internal and external influences are which are driving the firm. I also got the opportunity to see and compare how these drivers are different for my firm compared with other firms within the same industry ... the analysis which I have undertaken ... [has] made me confident about analysing firms because I finally feel like I know what I am doing and all the pieces of the puzzle are falling together.

Accounting student (49)

In this way the developing experience of 'Empowering Confidence' supported students to be able to experience deep learning:

...to simply trust [yourself] in what [you] are doing. Heck I had no idea what I was doing ... in the first couple of SPA's and [first stages of the] Assignment but I gradually got used to the idea ... of what was required of me which consequently built my confidence later in the course ... Hence if I did not believe in what I was doing, I wouldn't have been able to do this well in the course.

Go Me :).

Accounting student (50)

There was also a relationship between the experience by students of understanding their firm - of having experienced understanding and developing personal meaning about the actual activities of their firm, its business environment and the 
reality of its business - and the way they experienced confidence in meeting the later challenges of deep learning of making increasingly difficult judgements, forecasts and assessments about their firm. Personally understanding their firm gave students a sense of having some foundation, something to build on, a basis on which they could form their judgements about the value of their firm:

While I found forecasting reasonably tricky (and had to really think) and time consuming, I didn't feel lost or unconfident about my forecasts. Why? Well because by now I really have come to understand [my firm]! I understand what is driving the business and its key accounting drivers.

Accounting student (7)

In this section, evidence has been examined about how the intervention of Instruction directly supported accounting students to experience deep learning, including use of an exemplar company. Evidence was then considered about how students experienced confidence in the face of the substantial cognitive and emotional challenges of experiencing deep learning. As they experienced 'Empowering Confidence' to persevere with their experience of deep learning, the challenges they faced increased and intensified as the assessed learning tasks became more challenging. In the next section, evidence will be considered about how students experienced the ongoing challenges of deep learning.

\subsection{Ongoing Challenges}

After reading this and having considered everything in the course I am questioning whether ... the underlying business reality is just so far away to be connected with ... It's as though there is always something fake, something manipulated and it seems like there is a hidden agenda behind everything.

Accounting student (5s)

As students began to experience deep learning they were confronted with the experience of on-going challenges, difficulties and emerging new areas which 
they did not understand. This is the nature of the experience of deep learning. It is endless, as there is no end to understanding and developing personal meaning, no 'bottom', no 'final answer', simply more complete, more complex and more convincing personal insights and judgements (Biggs and Rihn, 1984). In this section, evidence will be considered about the ongoing challenges of deep learning experienced by accounting students as they confronted the need to make increasingly more difficult judgements. There was an interplay between students experiencing deep learning as subjective and difficult, requiring cognitive effort and time from them; and as personally satisfying and supportive of their intrinsic motivation.

\section{Confronting challenges}

As students began to experience deep learning in the course they also began to experience the cognitive difficulties and effort experiencing deep learning required of them:

One thing I've learnt from this course is that thinking about things critically and analysing statements takes time (and also hurts and is tiring)...

\section{Accounting student (3)}

These difficulties could lead to a feeling of resentment by students as they struggled to adjust to the unexpected cognitive effort and time involved with experiencing deep learning in the course:

I am finding it hard in this course to move from the listen, read, learn $\&$ regurgitate method of other courses to the thinking and involvement of this paper ... I felt resentment and bitterness at [the teacher's] way of learning...

\section{Accounting student $($ (s)}

As students confronted the cognitive difficulties and effort required of them to experience deep learning they could experience 'Lack of Confidence' and feel a need for more guidance, scaffolding and support in the learning tasks:

I would like some guidance and help to work out what I need to look for, what seems to be important for the firm. 
I don't need it to be spoon fed to me, just a bit of guidance as to where to start.

\section{Accounting student (9)}

I haven't gained insights on what I probably should be gaining insights on! I know [the teacher] said choose ratios that you think are appropriate for your firm. How will I know? It's my first time! From what I have heard, some people are not calculating ratios that they are just not familiar with or ... lack [the] knowledge ... to calculate ... This shouldn't be happening. We need more guidance!

\section{Accounting student $(60)$}

There was evidence regular, formative feedback and Instruction each week supported students to experience a growing sense of 'Empowering Confidence' in their capacities to understand and make judgements:

I think I will be able to complete an analysis on my firm by the end of this course. From the look of this course we are going to go through the analysis in a step by step process building more knowledge of our firm each week...

Accounting student (ss)

\section{Subjective and difficult}

Students also experienced that seeking understanding and developing personal meaning takes time and effort and is 'hard work':

From a technical perspective, calculating the ratios is easy enough. I had no real problems with this. It's understanding [them] that takes time and effort (numbers keep floating in my head while I try to sleep) ... learning is hard work. I'm enjoying it and finding it to be extremely valuable, but I'll admit I'm looking forward to the [Mid-Trimester break].

Accounting student (6I) 
Students also had a sense of the future challenges ahead of them in their analysis, aware that each stage of the Assignment required them to make increasingly difficult judgements and analysis. One of these challenges is the need to quantify subjective judgements:

It's easy enough to identify my firm's economic drivers and "connect" them in a qualitative sense to the parts of the firm's operations that they drive. What I'm having trouble understanding, is how we are going to move from the qualitative to the quantitative. Even if I can forecast these economic drivers (and some of them are going to be near impossible to do) how do I go about numerically relating them to the accounting drivers? And somehow we do need to do this. For our ... model to operate, we need numbers...

Accounting student (21)

Another challenge of deep learning is that it is never-ending, it is 'messy', not 'clear-cut', confusing, with 'shades of grey' and lack of clarity as each student seeks their own understanding and personal meaning:

I still do not fully understand all of the material of the course and feel that my brain is all over the place. I am finding it difficult to grasp each of the theories/formulas/ideas of fundamental analysis and combine them to generate an accurate and succinct analysis.

\section{Accounting student (ln)}

As students experienced deep learning they were also able to observe other students in the course experiencing deep learning. This could be both challenging and encouraging as they compared their own capacities to experience deep learning with those of other students in the course:

I found this whole exercise to be rather challenging. I thought this especially after reading some of the discussions on [the] discussion board. Some people are amazing with thinking outside the square and are able to 
really look at the whole picture. I think personally, I am

not good at doing that. However, in saying that $I$ feel my analysis which I have undertaken in this assignment [is] quite in depth and covers a lot of the different factors (internal and external) which affect the firm.

\section{Accounting student (49)}

Also, as students experienced deep learning they sought to understand and develop personal meaning about the subjective process of making judgements:

...forming our own judgments [is] vital ... during the process of ... analysis. However ... to give a sound and convincing judgment, we have to gain adequate evidence ... What's more, I noticed that different people have different values and opinions and therefore, they may have different views [when] judging the same things. I ... work ... in New World Metro [a supermarket] as a checkout operator ... Before we sell ... alcohol and cigarettes we have to ask our supervisors to approve the transaction. The interesting [thing] I found was, some people I [felt] they looked old enough but my supervisor [would] want to check their ID .. [and] ... some people [I felt] [did] not [look] mature enough, but they could escape their obligation to show [their] ID. More interestingly, I realized [one] supervisor didn't ask for a young guy to show [his] ID, [but a second] supervisor asked him when he came back to buy the same thing [a] second time ... I found different people really [have] different logical thinking when ... making judgments.

Accounting student (39)

\section{Experience of deep learning}

As students were experiencing change in aspects of how they learn accounting in a university accounting course, they were also experiencing the personal benefits of experiencing these changes. Students enjoyed the experience of making 
personal judgements, thinking for themselves and engaging in independent thought rather than simply regurgitating clear-cut, black-and-white facts:

Determining the economic and business drivers was enjoyable. I was able to think on my own as to what I thought the drivers were and also what others thought based on their direct experience of [my firm].

Accounting student (33)

Meeting the challenges of deep learning involved in completing the assessed learning tasks was personally satisfying to students:

For me it is challenging and self satisfying in connecting the accounting drivers of my firm to its key economic and business drivers ... determin[ing] what key economic and business realities of [my firm] are adding true value to its equity investors.

\section{Accounting student (70)}

As they experienced deep learning, aspects of the learning tasks that were challenging and difficult, such as a lack of there being clear-cut, black-and-white answers, became no longer negatives but positives for students:

Another thing that I enjoyed when I [did] my assignment is that there is no right or wrong answer...

Accounting student (45)

As will be discussed in the next section in greater detail, a benefit of deep learning was the development of personal capacities which supported students to experience a high-level relevance structure and intrinsic motivation:

I've enjoyed this course because it really challenged me to challenge myself ... I became a critical thinker and no other course has helped me become this till now.

Accounting student (5)

In this section, evidence about how students faced the ongoing challenges of experiencing deep learning in a university accounting course has been considered. There was an interplay between increasing challenges and personal satisfaction as they experienced deep learning. In the next section, evidence will be examined 
about how the two key internal relations between the experience of deep learning and each of relevance structure and intrinsic motivation supported students to meet the ongoing challenges and persevere in their experience of deep learning.

\subsection{Two Key Internal Relations and Deep Learning}

...it has been an insightful learning process and as the course has developed [the teacher] has taught me (and other students) to truly engage with and understand the material that we are learning. In doing so, I have now 'caught the train' and I realise that I have learnt much more than I expected about [my firm] (and we [are] only [at] the half way point of the course!). Active learning has 'gently nudged' me towards putting in the effort and determination to pursue my own learning rather than rely on a lecturer's material. This has allowed me to not only understand [my firm's] operations and financial statements, but to question and closely analyse aspects [of my] firm.

\section{Accounting student (65)}

This section will focus on evidence about the effect of two key internal relations on the experience of deep learning by accounting students in a university accounting course: the internal relation between deep learning and relevance structure; and between deep learning and intrinsic motivation. Given their limited previous experience of deep learning in a university accounting course, these two internal relations are found to be important to support accounting students to persevere in their experience of deep learning.

\section{Relevance structure}

...skills are the most important thing to pick up from a course rather than knowledge of technical detail ... anyone can pick up a standards book ... and find out what the relevant accounting standard ... says. But what everyone can't do is know how to apply that standard ... 
to a particular situation, which requires you to understand what the ... standard actually means, and what it is aiming to do. And what everyone doesn't have is the necessary judgment to interpret what the consequences of the standard ... [are].

\section{Accounting student $(6:)$}

Students found the experience of deep learning to be personally relevant to them and to be connected to their experience of relevance structure:

I found this assignment extremely helpful in my understanding of financial statements, and feel better prepared to enter the workforce next year. It's good to have to think critically about things now so it's not such a big shock learning how to do your job.

\section{Accounting student (43)}

There was evidence of the internal relation between the experience of deep learning and the experience of relevance structure by students:

Through this course I have realised how everything I've learned in economics, commercial law, accounting and finance become very useful and I value my knowledge in these areas of my study more. At some point in my university study I have thought that a lot of what I learned will not be very useful to me. But ... I ... see it is relevant to our everyday life. We are surrounded by businesses...

\section{Accounting student (29)}

In particular, students experiencing deep learning also experienced high-level relevance structure such as 'develop personal capacities':

My overall learning experience in this course is totally different to the papers that I have done in ... university. These experiences ... gave me a different insight on my approach to learning which ... I can say that I am just so lucky to experience this new approach of learning as it 
has a good impact on me not only to my learning but also

to my daily life including at work.

Accounting student $($ (70)

As a result of experiencing deep learning, students developed a sense of the lasting, personally changing nature of deep learning and this supported them to experience a more complex and complete relevance structure:

The most important thing is that those skills that I learn are actually owned by myself rather than just holding them for a while and get rid of them after finishing this course.

\section{Accounting student (76)}

I don't actually want to impress anyone, I want to get something out of the paper for myself, to foster my own ability and gain perspective.

\section{Accounting student (20)}

The awareness by students of their experience of deep learning became an important part of their experience of relevance structure:

The realisation that we are using more than just financial information and using a lot of our own experiences and judgements was the best realisation and this made [the course] the most worthwhile course I have ever done, it has taught me skills to learn and now I can actually be in charge of my own learning. This skill of evaluating and analysing information for myself using my own experience and knowledge (and drawing from others) was the most valuable thing I have learnt - ever probably.

\section{Accounting student (72)}

The making of personal judgements as part of their experience of deep learning also interrelated with the relevance structure of students:

I know that reading this kind of material is beneficial to me, not only just to aid me in passing this course, but also in the real world - it is comforting to know that what I 
am reading and learning in this course can get transferred into 'reality' and I can use what I learn to make 'real life' decisions.

Accounting student (17)

There was evidence the experience of deep learning supports accounting students to experience a more complex and complete relevance structure in a university accounting course; which in turn supports students to experience deep learning. Another critical internal relation was between deep learning and intrinsic motivation.

\section{Intrinsic motivation}

You may lose all ... material things one day; nevertheless, you won't lose a deep understanding of knowledge in your life if you really put effort to know it more.

\section{Accounting student (39)}

The experience of deep learning not only supported students to experience more complete and complex relevance structure but also supported them to experience intrinsic motivation; which in turn helped them to persevere and meet the ongoing challenges of deep learning:

It is motivating to read from the article ... It really provides motivation and drive to continue business study and perhaps reconsider my future career! I guess your success is not really dependent on your education [i.e. 'grades'] but [on] your application of your knowledge and experience to reality in order to become financially successful.

Accounting student (65)

Students found the experience of deep learning rewarding and enjoyable, which reinforced and supported their developing intrinsic motivation and connected to their experience of more complex and complete relevance structure:

...the encouragement this course has given students to question everything and [to] think through their 
answers ... I've thoroughly enjoyed doing it this way - I

really do understand ratios more than I would ever have completing ten assignments that required filling in numbers in formulas. Even if my analysis so far of [my firm] is wrong, in some ways I don't mind. I have learnt skills I can now apply to other companies and I value this knowledge/experience more than I first thought possible.

\section{Accounting student (4l)}

One finding in this study is that the experience of deep learning by students has a powerful effect on their experience of intrinsic motivation, including on their confidence and expectation to learn more. Students found the subjective and personally meaningful aspects of deep learning intrinsically interesting and personally worthwhile:

[In stage 2 of the] Assignment ... I learnt new stuff that I never really thought about and this is really fascinating. Comparing the actual and the restate[d] [financial statements] really surprised me because the difference is really transparent. I cannot wait to do the next step of the analysis ...

\section{Accounting student (3I)}

As students experienced the benefits of deep learning they also experienced the challenges of deep learning as discussed in Sections 8.2 and 8.3 above. There is evidence that their strengthening experience of intrinsic motivation supported them to be willing to make the cognitive effort to meet these challenges and to persevere and continue with their experience of deep learning:

...I do realise now that I need to stop being such a passive learner. Life isn't easy. There is never going to be someone always there telling me how to allocate an item to either operating or financing and I think this is the message that [the teacher] is putting to us. I'm third year now! ... There is this 'real world' out there away from the safe walls of the university and I am slowly coming to grips with this. The [reading] ... gave us the beginning 
insights but still allowed me to really think about what is going on in the business and let me have the ability to use my judgement and to stop being this passive learner! I'm on my way...!

Accounting student (24)

There was also evidence that students were able to experience 'Empowering Confidence' in response to their experience of deep learning and intrinsic motivation:

As well as problems I also have learned a lot and so I am already looking forward to learning more as we continue. Not only am I learning about the [concepts] but the more time I spend with the financial statements [of my firm] the more I realise how all the numbers link together and affect each other. As I learn more I am sure I will start to gain a much clearer view of, not only [how] the numbers on the page are connected, but also how ... the actual business activities link in together too.

\section{Accounting student (l(9)}

Evidence has been provided about the importance of the internal relation between deep learning and intrinsic motivation to support students to change the way they experience learning about accounting in a university accounting course. A key aspect of this internal relation is the way the experience of deep learning can support students to experience intrinsic motivation in the assessed learning tasks; and how, in turn, this experience of strengthening intrinsic motivation supports students to make the substantial cognitive effort and to persevere to meet the increasing challenges of their experience of deep learning. Given their limited previous experience of deep learning in a university accounting course, it is important to support accounting students to progressively experience the challenges of deep learning and to support them through these increasing challenges (Booth et al, 1999; Byrne et al, 2010). In this process, the internal relation between deep learning and intrinsic motivation is critical. The experience of the positive interaction between deep learning and intrinsic motivation is central to students being able to persevere in their experience of deep learning and 
thus be able to develop desirable 'graduate attributes' such as critical thinking and life-long learning in the context of studying accounting in a university accounting course.

\section{Meta-reflections on motivation}

Students showed evidence of reflecting on the central role of motivation in their learning:

A huge thing I have learnt $\ldots$ is that we are in control of our own learning ... Not learning in relation to asking questions $\ldots$ but learning in terms of being driven and having a passion to learn .... but passion is nothing without willingness; willingness to learn, willingness to get help, willingness to change. I have come to realise that change is one of the most important things when trying to advance or succeed in anything. You need to be willing to change e.g. your habits, or how or what you are learning or studying ... willingness comes from self. You cannot teach, or try to tell someone they need to be driven. In saying that, the biggest benefit to come of willingness is that it is created by yourself, and you have control over it, which in essence can create something much greater than anyone else can give you.

Accounting student (ss)

This included gaining insight and awareness about the variation they could experience in motivation in a university accounting course:

I have mostly been working towards 'getting a degree' (assuming I may just happen to learn something along the way), but during this course I am slowing beginning to change my point of view. For me in university there are two motivations now: good grades (extrinsic motivation) and understanding things that interest me (intrinsic motivation).

Accounting student (6l) 
In this section, evidence has been provided that the internal relations between deep learning and each of relevance structure and intrinsic motivation are important enablers for accounting students to change the way they experience learning accounting in a university accounting course. The experience by students of high-level relevance structure, intrinsic motivation and deep learning mutually interact, with the internal relations between each of these key aspects of learning supporting accounting students to meet the challenges of deep learning in a university accounting course.

\section{Conclusion}

In this chapter, evidence has been considered that Teamwork between students to support them to meet the challenges of deep learning; a Teacher-Student Relationship characterised by respect for students' opinions and by the teacher not seeking to impose clear-cut, black-and-white facts; and Instruction that uses real life examples can directly support accounting students to experience deep learning in a university accounting course. Evidence was also examined about the ways students can experience confidence as they face the challenges to persevere in experiencing deep learning and also how students can be supported to experience 'Empowering Confidence'. Evidence was also considered about the key internal relations between the experience of deep learning, relevance structure and intrinsic motivation.

This chapter completes the discussion in Chapters 4 to 8 of the evidence about how accounting students can change the way they experience learning in a university accounting course. In the next and final chapter, the key findings of this study and their implications in the context of approach to learning research in the accounting education literature will be considered. 


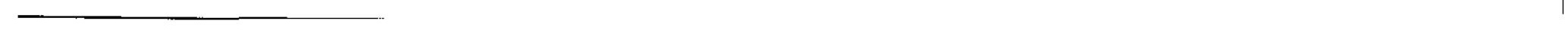


<smiles>[Li]</smiles> 
(2) 


\section{FINDINGS AND CONCLUSIONS}

While I realise this course was aimed at "learning" by critically thinking about concepts for me it was a downfall. Not to say I don't enjoy learning, I do, or teaching myself, I do ... but I like guidelines, an idea of what to do, maybe a "this is how it is, critically examine it". This paper was structured a lot like a BA paper, which is fine if you're studying Accounting because you live and breathe it ... unlike a [business degree] people study those subjects out of interest rather than say for a job ... I am tired, sick of this paper, which has drained me more than any other university paper and been the biggest disappointment. Why? I went to more classes for [this course] than I have ... for any other university paper, ever. I participated in group discussions via blackboard usually due to my completely malfunctioning study group. I spent the required amount of time on all SPAs and Assignments if not more ... thought critically about what was being said, rather than just summarising information, applied my knowledge possibly not as best I could, but quite a lot, and consistently achieved average grades ... Stuff that, if I'd have spent even half as much time on one of my other three papers this trimester, I would guaranteed be performing above average ... To put in so much effort for something and not get the returns, well let's just say this paper failed to meet the required rate of return on equity...

\section{Accounting student (22)}

The university accounting course that was the unit of study of this research had 81 students. Each of these students experienced their own personal, and different, journey through the course. These individual journeys were documented in a series of reflective assignments (five SPAs and five stages of the Assignment), student surveys and a focus group. There was evidence that interventions through Assessment, Teamwork, Teacher-Student Relationship and Instruction supported 
students to experience variation in their experience of relevance structure, conception of learning, motivation and approach to learning. These targeted interventions were grounded firmly in education theory (see Section 3.1 in Chapter 3 above). There was evidence of widespread experience of high level relevance structure, high level conception of learning, intrinsic motivation and deep learning. There was also evidence, as in the quote above, that a small number of students never quite made the change in the way they experience how they learn, particularly in relation to intrinsic motivation.

This chapter revisits the research question and the key findings that answer this question. The implications of these findings are then discussed. The findings suggest it is possible to transform the design and delivery of a single university course to support a large proportion of students to experience change in the way they experience how they learn. It will be noted that the transformation of the experience of learning by students in accounting education (and, more generally, in tertiary education) may involve more than individual academic teachers implementing change on a course-by-course basis. This leads to a discussion of suggestions for future research to support, among other things, widespread change in the experience of learning by students in the early weeks of first year at university as a foundation for them to be able to develop personal capabilities throughout entire accounting programs within individual tertiary institutions.

\subsection{Key Findings}

My strategy for learning is completely changed after I take this course. I thought that [to] study hard by reading [the text]book and [to] remember everything is the best way. Now I realize that I cannot memorise everything. Instead, I should understand deeply by raising questions and engaging what I am studying with what I have learnt. I should get the knowledge more actively rather than agree with all other opinions.

Accounting student (45) 
This section discusses the key findings of this study about the change in the ways students experience learning in a university accounting course. The research question was:

In what ways can accounting students be supported to experience high-level relevance structure, high-level conception of learning, intrinsic motivation and a deep approach to learning in the context of a university accounting course?

The answer to the research question provided by evidence from this study is that through the careful application of insights from the education literature, an integrated set of interventions can be designed and delivered in a university course to transform how students experience learning accounting and to support them to experience high-level relevance structure, high-level conception of learning, intrinsic motivation and a deep approach to learning. This conclusion is supported by the four key findings in this study. Each of these findings (and the respective 'sub-findings') are as follows.

\section{Finding 1: Experience of Deep Learning}

A large proportion of students can experience deep learning in a university course, with most starting to experience deep learning at an early stage of the course.

\subsection{The widespread experience of deep learning by students has been documented in this study (Chapter 7)}

There was evidence of widespread experience of deep learning by students in response to the context of the course in this study, with about $96 \%$ of students giving evidence of experiencing deep learning. It is understood this is the first time such a widespread experience of deep learning by students has been documented in the accounting education literature. 
1.2 Students can experience deep learning at an early stage in a course (Chapter 7 and Section 1.3)

There was evidence students can experience deep learning at an early stage in a course. As shown in Figure 9.1 below (which reproduces Figure 7.2 from Section 7.1 ), there was evidence about $60 \%$ of students experienced deep learning by the end of Week 1 , leading to $90 \%$ experiencing deep learning by the end of Week 6 and $96 \%$ by the end of the course.

Findings 1.1 and 1.2, contrast with findings of limited experience of deep learning by students in the accounting education literature. This literature suggests there is a widespread experience of surface learning by accounting students (Eley, 1992; Carland et al, 1994; Sharma, 1998; Booth et al, 1999; Byrne et al, 2010) and that studying accounting can encourage students to experience a surface approach to learning (Gow et al, 1994).

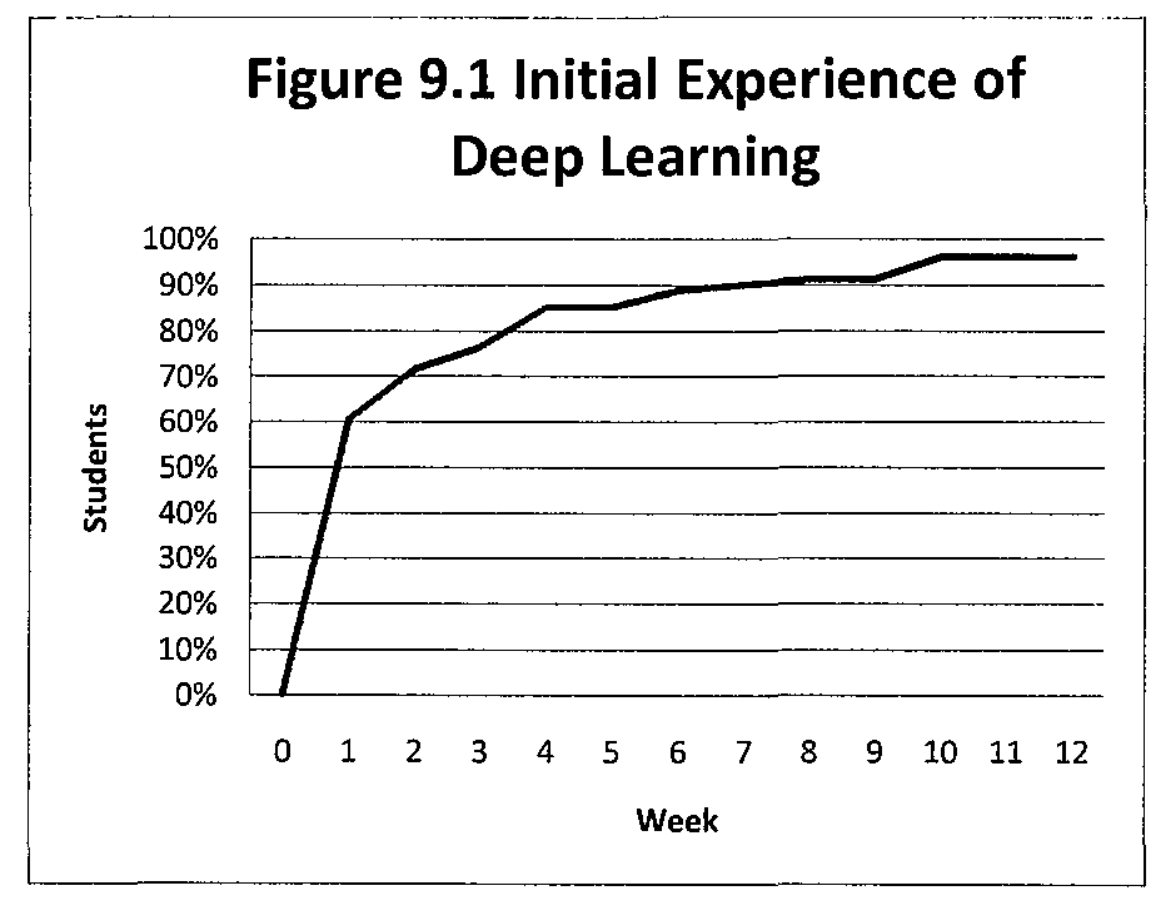

Four empirical studies identified in the accounting education literature have sought to support students to change from surface to deep learning, and each found it difficult (English et al, 2004; Hall et al, 2004; Ballantine et al, 2008; Fox et al, 2010). In this study, a large proportion of students experienced deep learning, with most starting to experience deep learning by the end of the first week of the course. The three key differences between this study and the previous studies are: 
- Use of comprehensive and integrated interventions, rather than more limited interventions;

- Supporting change in each of relevance structure, conception of learning, motivation and approach to learning, rather than focusing solely on supporting change to approach to learning; and

- Use of phenomenographic research methods, rather than self-test inventories.

\section{Use of comprehensive and integrated interventions}

The interventions used in the previous studies are as follows:

- English et al (2004): use in tutorials of interactive reading guides and problem-solving activities involving case studies and also the type of exam questions asked in the course.

- Hall et al (2004): use in tutorials of group problem-solving exercises, group presentations and group assignments.

- Ballantine et al (2008): use of a case study method.

- Fox et al (2010): use of peer mentoring.

To the extent it was possible to determine, the remainder of the course design for all four studies was largely along more traditional lines. It has been suggested that traditional methods of teaching accounting support surface learning (Boyce et al, 2001). In this study, a comprehensive and integrated set of interventions were made, involving Assessment, Teamwork, Teacher-Student-Relationship and Instruction.

Supporting change in each of relevance structure, conception of learning, motivation and approach to learning

English et al (2004), Hall et al (2004), Ballantine et al (2008) and Fox et al (2010) each focused on supporting students to change their experience of approach to learning and not also on supporting them to change their experience of relevance structure, conception of learning and motivation. As discussed in Section 1.3, the approach to learning research in the accounting education literature has tended to utilise in isolation specific approach to learning concepts from the educational psychology literature; for example, examining students' conceptions of learning in isolation to other aspects of how they learn (Byrne and Flood, 2004). This has meant the important internal relations between these concepts have tended to be ignored, 
even though these concepts cannot be defined independently of these internal relations (Martin and Svensson, 1979; Van Rossum and Schenk, 1984); and there is strong evidence that experiencing high-level relevance structure (Marton and Booth, 1997), high-level conception of learning (Van Rossum and Schenk, 1984) and intrinsic motivation (Fransson, 1977; Marton and Säljö, 1984) are important preconditions for students to experience deep learning. This study supported change in each of relevance structure, conception of learning, motivation and approach to learning, through the integrated set of comprehensive interventions introduced into the university course. In this study, there was evidence the internal relations between each of these concepts were important (for example, see Section 8.4).

\section{Use of phenomenographic research methods}

English et al (2004), Hall et al (2004), Ballantine et al (2008) and Fox et al (2010) each used self-test inventories. This supported these studies to focus on the variable of approach to learning, without considering the internal relations between approach to learning and other variables or concepts describing ways students experience aspects of their learning. This study has used a phenomenographic research method which has permitted the documentation of the experience by students of relevance structure, conception of learning, motivation and approach to learning and the internal relations between them. Phenomenography is particularly effective for handling research questions (such as the one in this study) where the variables or concepts describing ways students experience phenomenon can only be defined in terms of the internal relations between them (Sections 2.3 and 3.2).

\subsection{A theoretical model has been provided and tested to support the application of concepts from the education literature to the context of a university accounting course (Section 1.1)}

There was evidence the theoretical model used in this study can support the careful design of an integrated set of interventions firmly grounded in education theory. This model emphasises the following interventions:

- Assessment: individualised and authentic, with regular formative feedback (Hand et al, 1996; Biggs, 1999; Entwistle and Ramsden, 1983; Thomas and Bain, 1984; Struyven et al, 2005). 
- Teamwork: a comprehensive range of cooperative learning techniques, including use of study groups (described in further detail in Section 3.1) (Cottell and Millis, 1993).

- Teacher-Student Relationship: informal, student-centred and facilitative teaching style characterised by respect for students' opinions, where curiosity, questioning and exploration were encouraged (Ramsden and Entwistle, 1981; Entwistle and Ramsden, 1983).

- Instruction: direct instruction on conceptions of learning; use of reading materials with a deep approach to learning embedded in them; and use of authentic examples (including application of concepts to an exemplar company) in both classroom teaching and reading materials (Biggs and Rihn, 1984; Martin and Ramsden, 1987; Marton et al, 1993; Weimer, 2002; Ramsden, 2003; Nijhuis et al, 2005).

The model emphasises the importance that each of these interventions be integrated (Fink, 2003). Most importantly, it is critical that the Assessment carefully supports each of the other interventions (Biggs, 1999). For example, in this study the importance of experiencing high-level conception of learning to be able to successfully negotiate the Assessment in the course was emphasised in the Instruction on conception of learning (see Section 3.1). This model is set out in Figure 9.2 below.

Figure 9.2: Interventions to Support Accounting Students to Change the Way They Experience Learning Accounting

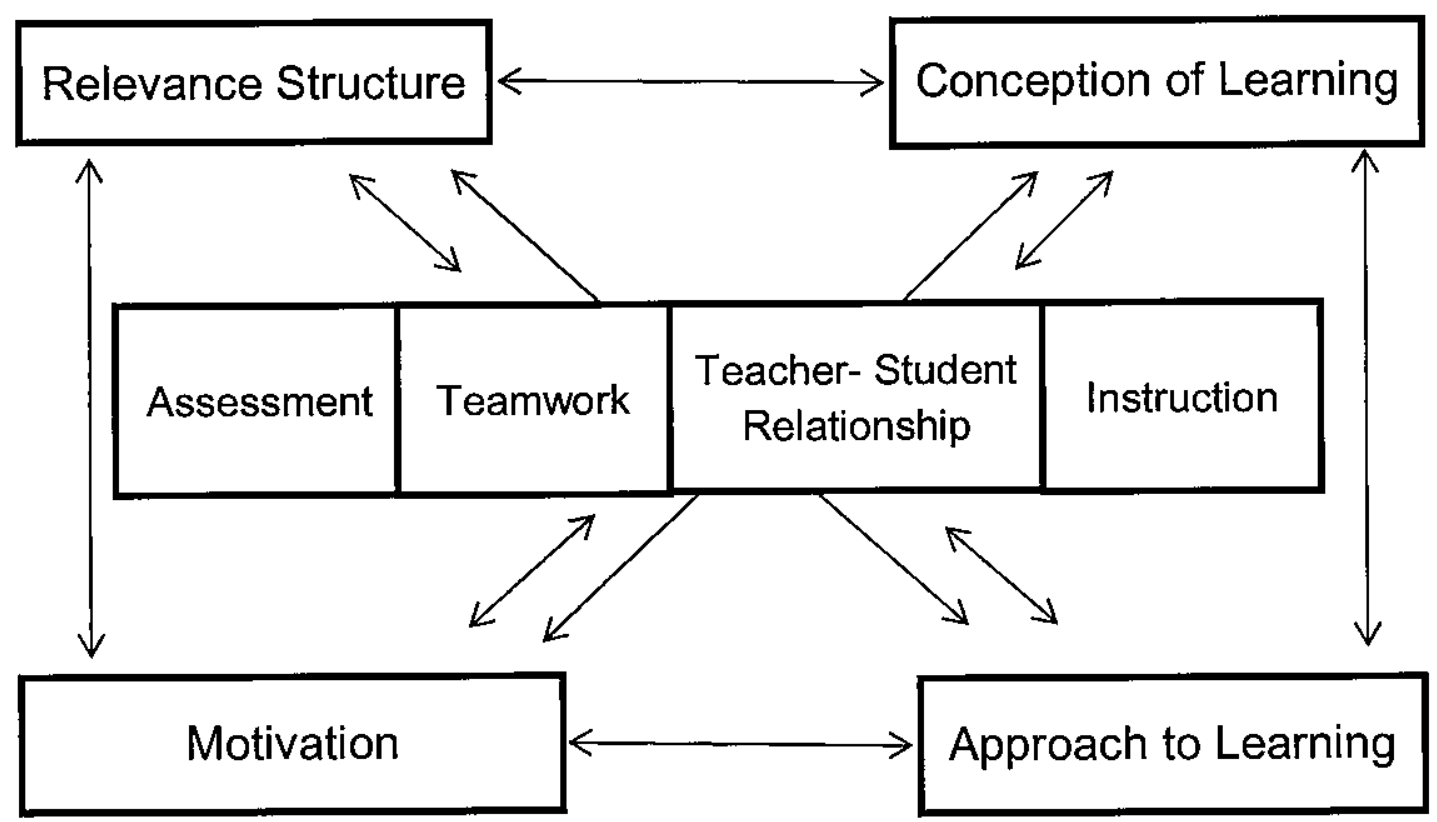


I was challenged to develop some relative weighting to this chart. The research experience has led me to a greater appreciation of the central importance of the internal relation between motivation and approach to learning; of the importance of the relationship between Instruction and conception of learning, and of the internal relation between conception of learning and deep learning; the central relationship between Assessment and each of relevance structure, conception of learning, motivation and approach to learning; and the important relationship between Teamwork and each of Assessment, motivation and approach to learning. Yet the key insight has been an appreciation of the importance of each of the internal relations in Figure 9.2 and the power of supporting a mutually reinforcing change in the experience by students of each of relevance structure, conception of learning, motivation and approach to learning through the careful implementation of an integrated set of interventions in the learning context to meet the considerable challenge of supporting students to experience deep learning.

As noted by Baeten et al (2010:4) in their recent literature review of various studies across a range of disciplines designed to stimulate deep approaches to learning: "[the] mixed findings [from these studies] make clear that influencing students' approaches towards deep learning ... is a complex process". This underlines the value of an evidence-based model (as outlined in Figure 9.2 above) to support the integrated application of findings from the education literature into the design and delivery of a university course. This study has demonstrated that such a carefully targeted approach supported by this model can address the 'profound' difficulties involved in supporting students to experience a deep approach to their learning (Marton and Säljö, 1997). It seems likely this insight may be relevant and valuable for all tertiary education, not just accounting education.

\section{4 'Empowering Confidence' supports deep learning}

Confidence in being able to make personal judgements, to construct one's own knowledge and to learn actively is important to be able to experience deep learning (Section 7.1). There was evidence awareness by students that careful analysis can give the basis for confidence in making personal judgements supported them to experience 'Empowering Confidence' (Sections 8.2 and 8.3). Trust in the scaffolding and support provided by the teacher (Teacher-Student Relationship) and by other aspects of the course design, for example the readings (Instruction), was 
also an important aspect in supporting students to experience 'Empowering Confidence' (Sections 8.2 and 8.3).

Finding 2: Experience of Relevance Structure

Categories of variation of relevance structure experienced by accounting students were identified; and the widespread experience of low-level relevance structure was identified as an important aspect of learning accounting that needs to be challenged. There was evidence the interventions of Instruction and Assessment were effective in supporting students to experience high-level relevance structure (Section 4.2).

\subsection{Categories of variation of relevance structure experienced by accounting} students in a university accounting course were identified (Sections 4.1 and 5.2)

Four categories of variation of relevance structure were identified: 'gain a job'; 'do a job'; 'run a business/invest'; and 'develop personal capacities'. The first two relevance structures ('gain a job' and 'do a job') are seen as low-level relevance structures and to be supportive of low-level conceptions of learning, extrinsic motivation and surface learning. The third and fourth relevance structures ('run a business/invest' and 'develop personal capacities') are seen as high-level relevance structures and supportive of high-level conceptions of learning, intrinsic motivation and deep learning. It is understood this study is the first approach to learning research in the accounting education literature to identify categories of variation of relevance structure by accounting students. This is an important finding of this study.

There was evidence the low-level relevance structure of 'gain a job' dominated, with evidence that this experience strengthened as students progressed through their accounting studies at university while the experience of the low-level relevance structure of 'do a job' declined (Section 4.1). There was very limited evidence of students experiencing high-level relevance structures in their previous courses (Section 4.1). 
2.2 Interventions are needed to support accounting students to experience change in the way they experience relevance structure (Section 4.1)

Evidence of widespread previous experience of low-level relevance structure and of the internal relations between the ways of experiencing relevance structure and each of conception of learning, motivation and approach to learning have been described in Section 4.1. This evidence indicates it is important the experience of low-level relevance structure by students be directly challenged and support provided to help them experience high-level relevance structure.

\subsection{The interventions of Instruction and Assessment were effective in supporting students to experience high-level relevance structure (Section 4.2)}

There was evidence the interventions of Instruction (using the credibility of past students in the course combined with formal learning objectives) and Assessment (including discussing clearly how the assessment design would require the experience of deep learning and critical thinking) supported students to experience high-level relevance structure (Section 4.2).

\section{Finding 3: Experience of Conception of Learning}

Students can quickly become aware of, and experience, high-level conception of learning in response to the intervention of Instruction, supported by Assessment (Section 4.3).

\subsection{The experience of low-level conception of learning by students dominated in the context of their previous university courses.}

There was evidence students had extensive previous experience of low-level conception of learning in their university courses (Section 4.3). This finding was consistent with previous research which provided evidence that large numbers of students in accounting courses experience low-level conception of learning (Sharma, 1997; Byrne and Flood, 2004; Lord and Robertson, 2006). There was evidence the experience of low-level conception of learning was supported by assessment designs in previous university courses that supported surface learning and low-level relevance structure (Section 4.3). 


\subsection{The intervention of Instruction was effective in supporting students to}

experience high-level conception of learning (Sections 4.3 and 4.4).

An important finding of this study was that students can readily understand, appreciate and become aware of high-level conception of learning in response to the intervention of Instruction (direct instruction on conception of learning integrated into the content of the course). This finding is consistent with findings in the education literature (Marton, 1976; Marton et al, 1994; Säljö, 1975; Martin and Ramsden, 1987). Students were able to gain awareness of the way they experience conception of learning when studying accounting (Section 4.3); of the variation possible in their experience of conception of learning (Section 4.3); and of the need for high-level conception of learning as a precondition to successfully negotiate the assessment structure and to experience deep learning (Section 4.4). There was evidence students had experience of high-level conception of learning in contexts of their lives outside of university and that this supported them to respond to the intervention of Instruction (Section 4.3).

\section{Finding 4: Experience of Motivation}

Evidence was provided of widespread experience of extrinsic motivation by students and how they can be supported to experience intrinsic motivation through the intervention of Assessment (Sections 5.2, 5.3, 5.4 and 6.1). Evidence was also provided of the central importance of the internal relation between intrinsic motivation and deep learning to support change in the way students experience how they learn (Section 6.4). In addition, there was evidence the experience of high-level relevance structure and high-level conception of learning supported students to experience intrinsic motivation in the assessed learning tasks (Section 5.1).

\subsection{Evidence in this study supports contentions (and some empirical evidence) in the accounting education literature of widespread experience of extrinsic motivation by students in university accounting courses (Boyce et al, 2001; Byrne et al, 2009; Section 4.4)}

Evidence was provided that students have widespread experience of extrinsic motivation in accounting courses; and that intrinsic motivation in the learning tasks 
appears to be an unusual and novel experience for accounting students (Section 4.4). This finding supports contentions (and some empirical evidence) in the accounting education literature that this is the case, as discussed in Section 1.3 (Boyce et al, 2001; Byrne et al, 2009). As the experience of a deep approach to learning is strongly related to experiencing intrinsic motivation (Fransson, 1977; Marton and Säljö, 1984), this study provides evidence that supporting students to experience intrinsic motivation is a significant challenge for accounting education (Section 4.4).

\subsection{Students can be supported to experience intrinsic motivation in a university} course through the intervention of Assessment (Sections 5.2, 5.3, 5.4 and 6.1)

A key finding of this study is that personally interesting, challenging and relevant assessed learning tasks that are individualised (different for each student), authentic (part of real life) and with regular formative feedback (individual and general feedback from the teaching staff, exemplars from other students and freedom to share and discuss their own work on the learning tasks with other students because the learning tasks are different for each student) can support students to experience intrinsic motivation (Sections 5.2, 5.3, 5.4 and 6.1). The assessed learning tasks in this study are described in Section 1.1 and in Section 3.1, and are included in Appendix 1.

It has been suggested in the education literature that individualised, authentic learning tasks with regular formative feedback can support students to develop intrinsic motivation in these learning tasks (Entwistle and Ramsden, 1983; Ramsden, 2003; Struyven et al, 2005). This study has carefully examined such an intervention and confirmed this to be the case. This finding highlights the importance of Assessment in the design and delivery of university courses to support intrinsic motivation and demonstrates that Assessment can be used to powerfully support students to experience intrinsic motivation (Biggs, 1999). 
4.3 Assessment can be a powerful intervention to support accounting students to experience intrinsic motivation, because of their widespread previous experience of low-level relevance structure, low-level conception of learning and extrinsic motivation (Sections 5.2, 5.3, 5.4 and 6.1)

\subsubsection{Assessment is seen by students as central to their experience of learning accounting}

The dominant previous experience of relevance structure identified in this study was 'gain a job', which focused students on their grades as a way of supporting them to gain a job (Section 4.1 and Finding 2.2). The dominant previous experience of conception of learning was learning clear-cut, blackand white facts to reproduce in assessments (Finding 3.1). The evidence that students see Assessment as central to their experience of learning accounting at university, suggests Assessment (as part of an integrated set of interventions) can be a powerful intervention to support students to experience change in the way they learn (Biggs, 1999; Fink, 2003).

\subsubsection{Intrinsically interesting learning tasks strongly connected to Assessment can support students to first engage with and then persevere in the challenges of these learning tasks (Section 6.4)}

The widespread experience of extrinsic motivation and of low-level relevance structure of 'gain a job' (Section 5.1) by accounting students initially supports them to complete assessed learning tasks for the purpose of gaining a grade. In this study, the assessed learning tasks were designed to support students to experience increasing intrinsic motivation and deep learning as they progressively completed each learning task. Completion of these learning tasks supported students to begin to experience intrinsic motivation because they experienced the learning tasks to be personally interesting and relevant (Sections 5.2, 5.3, 5.4 and 6.1). The strong connection to Assessment of learning tasks that were intrinsically interesting was vital to support students, with extensive prior experience of low-level relevance structure, low-level conception of learning, extrinsic motivation and surface learning to first engage with and then persevere in the challenges of deep learning involved with the learning tasks (Section 6.4). 
4.4 The rewarding of the experience of deep learning with grades in the Assessment supports students to persevere in their experience of intrinsic motivation (Section 6.4)

Students can be supported to persevere in their experience of intrinsic motivation, by being rewarded with grades in the Assessment for completing learning tasks involving deep learning (Section 6.4). This is consistent with the notion that intrinsic motivation does not preclude an awareness and experience of extrinsic motivation, but can include and add a qualitatively distinct dimension to extrinsic motivation (Pintrich and Garcia, 1991; Byrne and Flood, 2005). An important factor for students who found difficulty in persevering in the experience of intrinsic motivation was feeling they were not being adequately rewarded for their effort by the Assessment, particularly in comparison to grades they were receiving in other courses (Section 6.4). This is important given the increased cognitive effort (and time) required of students to experience deep learning as they completed the learning tasks, compared to that required to experience surface learning.

\subsection{As students begin to experience intrinsic motivation in the assessed learning tasks they become more likely to respond to an integrated set of interventions designed to support them to experience deep learning (Sections 6.4 and 8.4)}

This is a key finding of this study. Evidence was provided (in Sections 6.4 and 8.4) that the experience of intrinsic motivation is an important precondition for students to be able to experience deep learning in a university course, which is consistent with the educational psychology literature (Fransson, 1977; Marton and Säljö, 1984). There is evidence the experience of intrinsic motivation in the learning tasks is essential to support students to persevere and make the significant cognitive effort to overcome the initial barriers to experience deep learning (Section 6.4). Evidence of widespread experience of extrinsic motivation by accounting students (Finding 4.1) and evidence about the central role Assessment can play in supporting students to experience intrinsic motivation (Findings 4.2, 4.3 and 4.4), suggests the use of Assessment to support change in the experience of motivation by students should be a central focus in the design and delivery of university accounting courses. 


\subsection{Teamwork can support students to experience intrinsic motivation (Section}

6.2). There was also evidence that Assessment involving individualised, authentic learning tasks can support Teamwork (Section 6.2); and that the small number of students who did not engage effectively in Teamwork in the course did not experience intrinsic motivation and deep learning (Section 6.2).

This finding suggests that the intervention of Teamwork is important to support the experience of intrinsic motivation by students in a university course. There was evidence the interactions between students about their analyses of their individual firms helped them to be aware of their experience of intrinsic motivation in the course (Section 6.2). These interactions between students also contributed to the experience of intrinsic motivation, enabling students to become interested in more than just their own company they were analysing (Section 6.2). There was evidence that the intervention of Assessment involving individualised, authentic learning tasks supported Teamwork, while also retaining individual accountability in the assessments as each student needed to adapt the concepts and ideas in the course to the specific challenges of their own firm (Section 6.2). There was also evidence that the small number of students who did not engage effectively in Teamwork in the course did not experience intrinsic motivation and deep learning (Section 6.2).

4.7 The experience of high-level relevance structure and high-level conception of learning supports students to experience intrinsic motivation in the assessed learning tasks (Section 5.1)

As students experience high-level relevance structure and high-level conception of learning in a university course, the internal relations between relevance structure, conception of learning and motivation mutually support students to experience intrinsic motivation (Section 5.1).

An interesting question to consider is whether there is a relationship between the students who provided a larger number of quotes included in this thesis and the development of a deep approach to learning.

As noted in Appendix 4, a large number of quotes $(3,360)$ were coded to various themes using $\mathrm{N}-\mathrm{V}$ ivo software. Although more quotes were coded from some students' Assignments and SPAs than others, there were nevertheless many quotes coded from each student. A relatively small proportion of the quotes coded 
(about one-eighth) have been included in the thesis. There were usually a number of quotes that could have been used for each quote included in the thesis. The quotes were usually selected to be included because they better articulated or were clearer than perhaps some other quotes from students. Given the widespread experience of deep learning by students in the course, it does not appear that the ability to articulate clearly the experience of various aspects of their learning (relevance structure, conception of learning, motivation and approach to learning) in the research instruments was related to their experience of a deep approach to learning. However, in the research design, it was necessary for students to be able to sufficiently clearly articulate their experience of learning for the researcher to be able to identify their experience of learning.

This section has outlined the findings of this study. This study provides evidence that students can be supported to experience change in the ways they experience key aspects of how they learn (relevance structure, conception of learning, motivation and approach to learning) and provides insights into how to design university courses to achieve this, including the central role of individual, authentic assessments with regular formative feedback. The next section discusses some of the implications of these findings for the practice of accounting education.

\subsection{Implications for Accounting Education}

This section discusses three implications of the findings of this study (set out in Section 9.1 above) for accounting education. The findings suggest that a transformation in the experience by students of how they learn in a university course is achievable through changes that can be made by individual academics in the design and delivery of individual courses. This can be achieved through an integrated set of interventions guided by the theoretical model proposed in this study. It is an implication of the findings of this study that the introduction of limited interventions in the context of a university course (that may continue to contain other aspects in its course design and delivery that support low level relevance structure, low-level conception of learning, extrinsic motivation and surface learning) are unlikely to be effective. 


\section{First implication: Transforming a single course}

\section{Implication 1: Students are able to experience deep learning in a single university course in response to an integrated set of interventions (focused on supporting students to change the ways they experience relevance structure, conception of learning, motivation and approach to learning) (Finding 1)}

This study provides evidence students are more readily able to experience deep learning than suggested by previous approach to learning research in the accounting education literature (English et al, 2004; Hall et al, 2004; Ballantine et al, 2008; and Fox et al, 2010).

A major challenge facing accounting education is how to support students to develop personal capabilities in areas such as critical thinking, creative thinking, problem-solving, communication and teamwork, rather than simply supporting students to reproduce technical accounting rules. This challenge has been recognised through calls for fundamental change in accounting education, which have come from both the accounting profession and from accounting academics (see Section 1.2 above). These calls for change are an expression of long-standing dissatisfaction with the quality of learning outcomes for accounting students in relation to the development of personal capabilities. However, before such calls for change in accounting education can be implemented by accounting academics, the qualitative experience of how students learn accounting needs to be transformed. This is because students will not make the substantial cognitive effort to develop personal capabilities unless they first experience deep learning (Trigwell and Prosser, 1991); and the experience of deep learning is strongly related to the experience of high-level relevance structure (Marton and Booth, 1997), high-level conception of learning (Van Rossum and Schenk, 1984) and intrinsic motivation (Fransson, 1977; Marton and Säljö, 1984; Thomas and Gadbois, 2007). It is necessary to first change the experience by students of the 'how' of learning before interventions designed to support change in the experience by students of the 'what' of learning (such as the development of personal capabilities) can be successful.

It is for this reason that the widespread experience of surface learning by accounting students (Eley, 1992; Carland et al, 1994; Sharma, 1998; Booth et al, 1999; Byrne et al, 2010) combined with the difficulty of supporting them to change 
to a deep approach to learning (English et al, 2004; Hall et al, 2004; Ballantine et al, 2008; and Fox et al, 2010) presents a major challenge for accounting education. The widespread experience of surface learning would suggest the various documented interventions in accounting courses designed to support the development of personal capabilities such as critical thinking (see Section 1.2 above) would be unlikely to be successful because they generally do not seek to first support change in the 'how' of learning; that is, in the way students experience approach to learning in response to the total learning context of a course, within which the specific interventions were made. Indeed, evidence suggests little has been achieved to support accounting students to develop personal capabilities rather than the transfer of technical knowledge (Sharma, 1998; Albrecht and Sack, 2000; Howieson, 2003; Ahern et al, 2007; Jackling and De Lange, 2009).

It is in this context that the finding that a large proportion of students can experience deep learning in a course, with most starting to experience deep learning by the end of the first week, is significant. Evidence has been provided that this can be achieved through an integrated set of interventions where each aspect of the course is carefully designed to support change in the experience of students of four key aspects of how they learn (relevance structure, conception of learning, motivation and approach to learning); and that the theoretical model provided in this study can be used to support the careful adaptation of key insights and concepts from the education literature to the design and delivery of a university course.

\section{Second implication: Assessment, Teamwork and intrinsic motivation}

\section{Implication 2: A central focus of the interventions to support deep learning is}

the use of Assessment and Teamwork to support the experience of intrinsic motivation (Findings 4.2, 4.3, 4.4 and 6.2)

In this study, evidence was provided that individualised, authentic assessments with regular formative feedback (as part of an integrated course design where each aspect of the course is aligned to support the desired learning outcomes) can support students to change the way they experience how they learn in a university course, and in particular how they experience motivation (Findings 4.2, 4.3 and 4.4). However, these findings concerning the role of Assessment need to be adapted creatively and thoughtfully to the design and delivery of assessments for particular 
courses. There are no universal, 'cookie-cut' solutions. The specific application of this general concept to actual learning tasks designed to be part of assessments will require creative, professional judgement (informed by theory) by academics for each individual university course.

There was also evidence that Assessment needs to be part of an integrated course design, where each aspect of the course is aligned to support the desired learning outcomes of students. In particular, the intervention of Teamwork is important to support the experience of intrinsic motivation by students (Finding 4.6). In this study, there was evidence the intervention of individualised, authentic assessments with regular formative feedback supported Teamwork; and that the interactions between students about their individual firms and their analyses helped them to be aware of their experience of intrinsic motivation in the course (Section 6.2). There was also evidence that the small number of students who did not engage effectively in Teamwork in the course did not experience intrinsic motivation and deep learning (Section 6.2).

It is an implication of the findings of this study that considerable attention needs to be given to supporting students to experience intrinsic motivation in the learning tasks. This represents a central challenge to support change in the way students experience how they learn. In this study, evidence has been provided that Assessment can be used to support students to experience intrinsic motivation in personally interesting, challenging and relevant assessed learning tasks; and guidance has also been provided on how to design assessments in a university course to achieve this.

\section{Third implication: Change experience of relevance structure and conception of learning}

Implication 3: Students can be supported to change the way they experience relevance structure and conception of learning in the early stages of a university course through the interventions of Instruction and Assessment (as part of an integrated set of interventions) (Findings 2.3 and 3.2; Sections 4.2, 4.3 and 4.4).

It is an implication of the findings in this study that attention needs to be given at the beginning of a course to support students to experience high-level relevance 
structure and high-level conception of learning. This can be achieved through the interventions of Instruction and Assessment which need to be carefully and creatively designed by academics for each individual course. The theoretical model provided in this study can support the careful and thoughtful adaption of education theory to this task of using Instruction and Assessment to support students to experience high-level relevance structure and high-level conception of learning.

As students experience change in the way they experience relevance structure and conception of learning, the internal relations between relevance structure, conception of learning and motivation can mutually support students to experience intrinsic motivation. The support students receive in the early stages of a university course to change the way they experience relevance structure and conception of learning can be seen to indirectly support their experience of intrinsic motivation in the assessed learning tasks. This is an example of the importance of introducing an integrated set of interventions in the design and delivery of a university course to ensure that the internal relations between each of the concepts mutually support change in the way students experience each of these aspects of how they learn.

This section has outlined three implications of the findings of this study. These findings suggest the experience by students of how they learn can be transformed within the confines of a single course. It is not an easy process and will require an integrated set of interventions carefully targeted to support change by students in key aspects of how they learn. In particular, the use of Assessment and Teamwork to support students to experience intrinsic motivation in the assessed learning tasks is of central importance. Also, there is evidence students can be supported to experience high-level relevance structure and high-level conception of learning at an early stage of a course through the interventions of Instruction and Assessment, which can support students to experience intrinsic motivation and deep learning.

\subsection{Institutional Context}

This study provides evidence about how the ways students experience learning accounting can be transformed. However, learning occurs in a broader context than a single university course; it also occurs within the context of the institutional environment of a tertiary institution. Although surface learning is a less complex 
and complete way of experiencing learning compared to deep learning, the change from surface to deep learning often cannot be achieved incrementally. Rather, a change in approach to learning involves a fundamental shift in the experience by students of how they learn (Marton and Säljö, 1976a). It involves awareness that surface learning (reproducing clear-cut, black-and-white facts) is a form of 'imitation' learning, too simple and incomplete to be considered by itself to be 'real' learning; and that traditional teaching methods that support surface learning are inadequate and in need of substantial reform and change (Boyce et al, 2001; and see Section 2.1). This can be unsettling for students, academics and middle managers (Heads of Schools and professors) in tertiary institutions. For this reason, resistance is possible particularly at the level of individual schools or departments in tertiary institutions towards attempts to support students to experience deep learning.

Comprehensive changes to the design and delivery of courses as used in this study will likely result in a degree of upheaval as individual courses are progressively changed. It is the view of the researcher that these changes in practice will prove to be far more positive and unthreatening to students, academics and middle managers once their benefits become apparent, understood and accepted; although the initial adjustments that will be needed should not be underestimated. Many tertiary institutions encourage improvement in teaching methods with quality assurance mechanisms monitoring and assessing student learning outcomes. There are also large numbers of academic staff committed to engaging with student learning outcomes and effective course delivery. As the benefits involved with having large numbers of students experiencing deep rather than surface learning become apparent, and also the opportunities this opens up not only for the quality of student learning but also for teaching practice, this should encourage academics to understand, support and become involved with such changes.

This also raises the question as to which university courses in a degree or overall academic program should be the focus of substantial change in their design and delivery to support students to learn how to learn. The course studied in this research was a third year accounting course; with many students completing their university studies at the end of the course. As a number of students in the study pointed out, might it not be better to provide students with the opportunity to experience change in how they learn in first year, so they could continue to experience deep learning in their subsequent university courses? 
The findings of this study suggest first year courses could be designed to support students to experience high-level relevance structure, high-level conception of learning, intrinsic motivation and deep learning (see Section 9.1 above). Supporting change in how students experience their learning could be a central focus in the design and delivery of first year courses (also note English et al, 2004, Hall et $a l, 2004$ and Fox et al, 2010 each studied $1^{\text {st }}$ year accounting courses). If these experiences prove to be transferrable by students to their subsequent courses, this process of supporting change in the way students experience how they learn would not need to be repeated in subsequent courses. Second and third year courses could then be designed to support students to develop personal capabilities, with the necessary pre-condition of experiencing deep learning already in place for most students as a result of their experience of studying in first year. The next section will consider suggestions for future research. One of these areas of potential future research is to examine how to change the way students learn in first year courses and the transferability of these experiences to their subsequent courses.

\subsection{Future Research}

This section discusses three potential areas for future research suggested by the findings of this study: how to change the way students learn in first year courses and the transferability of these experiences to their subsequent courses; the experience of relevance structure by accounting students throughout their university studies; and use of approach to learning concepts and phenomenographic research methods to assist in 'contextualised' evaluations of changes to university courses.

\section{First year accounting courses}

Potential future research: How to support change in the way students learn in first year courses; and how transferable is this experience to subsequent courses.

This study researched a third year university accounting course. This permitted the study of the previous experience by students of learning accounting prior to that course. In this study, there was evidence of widespread experience by students of low-level relevance structure (Section 4.1), low-level conception of learning (Section 4.3), extrinsic motivation (Section 5.1) and surface learning (Section 7.1) in their

previous university courses. Given the evidence provided in this study of change by 
students of their experience of how they learn in a single university course, this suggests future research into the experience of students in first year courses could be productive. This study provides a theoretical model and other evidence to support research into the design and delivery of first year courses that could transform the experience of how students learn at the beginning of their university experience. As noted by Ballantine et al (2008:198): "Ramsden (2003) ... argues that by the final year of university study, students' approaches to learning may be less dynamic and amenable to change, as learning strategies adopted in early university study have proved to be successful." As students in first year courses could be expected to be less established in their experience of learning at university than students in third year courses, it would be interesting to explore whether they are more easily able to experience change in the way they learn than students in this study (Entwistle, 1991; Lindblom-Yiänne and Lonka, 1999; Gijbels et al, 2005b).

Also, a question it would then be worthwhile to explore is whether the experience of high-level relevance structure, high-level conception of learning, intrinsic motivation and deep learning in the context of learning in a first year course could support students to experience their subsequent courses in a different way to the existing dominant experience of low-level relevance structure, low-level conception of learning, extrinsic motivation and surface learning. If this proved to be the case, it would support the effectiveness of interventions in their subsequent courses designed to support the 'what' of learning, such as the development of personal capabilities.

\section{Relevance structure}

Potential future research: Confirmation or otherwise of the categories of variation of relevance structure experienced by accounting students that were identified in this study; and how the experience of relevance structure may change throughout their business degree.

There is limited research into the experience of relevance structure by accounting students in a university accounting course. This study has identified categories of variation of the experience of relevance structure by accounting students. Further research into these categories of variation could confirm, challenge or develop further these categories of variation identified in this study. 
In this study, there was some evidence that the ways accounting students experience relevance structure may currently change throughout their business degree. For example, is there a shift in relevance structure from 'do a job' to 'gain a job' by students as they progress in their business degree? And if so, what implications might this have for the experience by students of the practical relevance of the content of accounting courses to professional accounting practice and to business in general? Further research into possible trends in the experience of relevance structure by accounting students as they progress through a number of university courses in their business degree could provide valuable insights into the perceptions of students about the practical relevance of accounting courses. This would be of particular interest in relation to learning accounting, with its practical focus of supporting students to lay the academic and intellectual foundations for their accounting and business careers.

\section{'Contextualised' evaluations of course design and delivery}

Potential future research: Use of approach to learning concepts and phenomenographic research methods to assist in 'contextualised' evaluations of changes to university courses, including for example capstone courses.

A third area of potential future research suggested by this study, is research using approach to learning concepts and phenomenographic research methods to assist in 'contextualised' evaluations of the design and delivery of university accounting courses. This research could evaluate courses based on how students experience learning in response to interventions introduced into the design and delivery of courses; focusing on the internal relationship between a student and the learning task they are experiencing within a university course, rather than looking at interventions in a 'decontextualised' way. This would help focus attention on how learning tasks in the course are experienced by students. Specific interventions in course design and delivery could thus be evaluated (at least in part) based on identified variations in the ways students experience a learning task or other aspect of a university course in response to those interventions.

One fruitful area for this type of future research could be the design and evaluation of capstone courses. Supporting students to construct their own knowledge is particularly vital for a capstone course at the end of a university degree. Capstone courses seek to give students the opportunity to critically reflect on and 
integrate into a personally meaningful whole the concepts and ideas they had been learning throughout their university studies, becoming aware of linkages and connections between different aspects of the content they had learned in a range of different courses. Experience of high-level relevance structure, high-level conception of learning, intrinsic motivation and deep learning would be necessary preconditions for students to make the cognitive effort required of them to integrate knowledge across a number of courses they had previously studied. The theoretical model provided in this study could be useful to both develop, and measure the effectiveness of, interventions in the design and delivery of capstone courses.

Another fruitful area for this type of future research could be to help evaluate what constitutes 'good' formative feedback. Nicol and Macfarlane-Dick (2006: 209) have noted:

The literature on external feedback is underdeveloped in terms of how teachers should frame feedback comments, what kind of discourse should be used, how many comments are appropriate and in what context they should be made.

Much more research is required in this area.

Future research could help develop 'contextualised' methods of evaluating interventions such as the use of formative feedback and other aspects of the design and delivery of courses and how students can be supported to experience how they learn in more effective ways. Further, the theoretical model, set out in Figure 1.2 in Section 1.1 (in Chapter 1) above, could be used in future research to focus the evaluation of courses on certain aspects of how students learn, namely relevance structure, conception of learning, motivation and approach to learning and on the effectiveness of the interventions in the design and delivery of a course to support students to experience in more complete or complex ways these aspects of learning.

\section{Conclusion}

This chapter sets out the research question and the four key findings in this study, relating to the experience of deep learning, relevance structure, conception of learning and motivation by accounting students. The over-arching conclusion of this study is that significant change in the experience of learning by students can be achieved through the careful adaptation of education theory to the design and 
delivery of individual university accounting courses. How this can be achieved has been carefully documented and supported with evidence in Chapters 4 to 8 . The institutional context was only briefly considered in this study; and it is noted that the transformation of accounting education may involve more than individual accounting academics implementing change on a course-by-course basis. This was followed by a discussion of suggestions of fruitful areas for future research, including in relation to first year courses.

The learning of accounting is much more than reproducing clear-cut, blackand-white technical rules from experts; students also need to develop personal capabilities when studying at university. For this to happen, students first need to experience deep learning. This study has examined the challenges involved in supporting accounting students to make the changes in 'how' they learn accounting, and in doing this, has provided some valuable insights into how to implement some of the powerful ideas and concepts from the education literature to accounting education and to tertiary education more generally. 



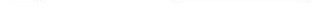




\section{REFERENCES}

AAEC. (1990). Objectives of Education for Accountants: Position Statement Number One. Issues in Accounting Education, 5(2), 307.

Abhayawansa, S., \& Fonseca, L. (2010). Conceptions of Learning and Approaches to Learning - A Phenomenographic Study of a Group of Overseas Accounting Students from Sri Lanka. Accounting Education: an international journal, 19(5), 527-550.

Adler, R., \& Milne, M. (1997a). Translating ideals into practice: an examination of international accounting bodies' calls for curriculum changes and New Zealand tertiary institutions' assessment methods. Accounting Education: an international journal, 6(2), 109-124.

Ahern, J., Kujil, J., \& Marrian, I. (Eds.). (2007). GAE 2007: Trends in global accounting education. Amsterdam: Royal NIVRA.

AICPA. (1999). Core competency framework for entry into the accounting profession. Available from $\underline{h t t p: / / w w w . a i c p a . o r g / e d u / c o r e c o m p . h t m . ~}$

Albrecht, W., \& Sack, R. (2000). Accounting education: Charting the course through a perilous future (Vol. \#16). Sarasota, FL American Accounting Association.

Amabile, T. (1993). Motivational synergy: Toward new conceptualizations of intrinsic and extrinsic motivation in the workplace. Human Resource Management Review, 3(3), 185-201.

Anderson, T. (2003). Getting the mix right again: An updated and theoretical rational for interaction. The International Review of Research in Open and Distance Learning, 4(2). Retrieved from http://www.irrodl.org/index.php/irrodl/article/view/149/708

Angelo, T., \& Cross, K. (1993). Classroom Assessment Techniques: A Handbook for College Teachers (2nd ed.). San Francisco: Jossey-Bass.

Ashworth, P., \& Lucas, U. (1998). What is the 'World' of Phenomenography? Scandinavian Journal of Educational Research, 42(4), 415.

Ausubel, D. (1968). Educational psychology: a cognitive view. New York: Holt, Rinehart and Winston.

Baeten, M., Dochy, F., \& Struyven, K. (2008). Students' approaches to learning and assessment preferences in a portfolio-based learning environment. Instructional Science, 36, 359-374.

Baeten, M., Kyndt, E., Struyven, K., \& Dochy, F. (2010). Using student-centred learning environments to stimulate deep approaches to learning: Factors encouraging or discouraging their effectiveness. Educational Research Review, 5(3), 243-260.

Balasooriya, C., Hughes, C, \& Toohey, S. (2009a). Impact of a new integrated medicine program on students' approaches to learning. Higher Education Research \& Development, 28(3), 289-302.

Balasooriya, C., Toohey, S., \& Hughes, C. (2009b). The cross-over phenomenon: unexpected patterns of change in students' approaches to learning. Studies in Higher Education, 34(7), 781-794.

Ballantine, J., \& Larres, P. (2009). Accounting Undergraduates' Perceptions of Cooperative Learning as a Model for Enhancing their Interpersonal and Communication Skills to Interface Successfully with Professional Accountancy Education and Training. Accounting Education: an international journal, 18(4), 387-402. 
Ballantine, J., Duff, A., \& Larres, P. (2008). Accounting and business students' approaches to learning: A longitudinal study. Journal of Accounting Education, 26(4), 188-201.

Ballantine, J., \& Larres, P. (2004). A critical analysis of students' perceptions of the usefulness of the case study method in an advanced management accounting module: the impact of relevant work experience. Accounting Education: an international journal, 13(2), 171 - 189.

Ballantine, J.A. \& McCourt, P.L. (2007). Final year accounting undergraduates'attitudes to group assessment and the role of learning logs. Accounting Education: an international journal, 16(2): 1-21.

Baril, C., Cunningham, B., Fordham, D., Gardner, R., \& Wolcott, S. (1998). Critical thinking in the public accounting profession: aptitudes and attitudes. Journal of Accounting Education, 16(3/4), 381-406.

Beattie, V., Collins, B., \& McInnes, B. (1997). Deep and surface learning: a simple or simplistic dichotomy? Accounting Education: an international journal, 6(1), 1-12.

Bedford. (1986). Special Report Future Accounting Education: Preparing for the Expanding Profession (No. 1): American Accounting Association.

Bentley, K., Brewer, P., \& Eaton, T. (2009). Motivating students to prepare for class and engage in discussion using the hot seat. Journal of Accounting Education, 27(3), 155-167.

BEWP. (1989). Perspectives on Education: Capabilities for Success in the Accounting Profession. New York: Arthur Andersen and Company, Arthur Young, Coopers and Lybrand, Deloitte Haskins and Sells, Ernst and Whinney, Peat Marwick Main and Company, Price Waterhouse, and Touche Ross.

Biggs, J. (1978). Individual and group differences in study processes. British Journal of Educational Psychcology, 48, 266-279.

Biggs, J. (1996). Enhancing teaching through constructive alignment. Higher Education, 32, 347-364.

Biggs, J. (2003). Teaching for quality learning at university: What the student does. Buckingham, United Kingdom: Society for Research into Higher Education.

Biggs, J., Kember, D., \& Leung, D. Y. P. (2001). The revised two-factor Study Process Questionnaire: R-SPQ- 2F. British Journal of Educational Psychology, 71(1), 133.

Biggs, J., \& Moore, P. (1993). The process of learning (3rd ed.). New York: Prentice Hall.

Biggs, J. (1979). Individual differences in study processes and the quality of learning outcomes. Higher Education, 8, 381-394.

Biggs, J. (1987). Student approaches to learning and studying. Hawthorn, Vic: Australian Council for Educational Research.

Biggs, J. B. (1993). What do inventories of students' learning process really measure? A theoretical review and clarification. British Journal of Educational Psychology, 83, 3-19.

Biggs, J. (1999). Teaching for Quality Learning at University: What the Student Does. Buckingham: SRHE and Open University Press.

Biggs, J., \& Rihn, B. (1984). The effects of intervention on deep and surface approaches to learning In J. R. Kirby (Ed.), Cognitive strategies and educational performance. Florida: Academic Press. 
Birenbaum, M. (1996). Assessment 2000: Towards a pluralistic approach to assessment. In M. Birenbaum, F. Dochy \& E. Cascallar (Eds.), Alternatives in assessment of achievements, learning processes and prior knowledge (pp. 3-29). Boston: Kluwer.

Birkett, W. (1993). Competency Based Standards for Professional Accountants in Australia and New Zealand: Institute of Chartered Accountants in Australia and the New Zealand Society of Accountants Sydney.

Bisman, J. (2010). Engaged pedagogy: a study of the use of reflective journals in accounting education. Assessment \& Evaluation in Higher Education.

Bonk, C., \& Smith, S. (1998). Alternative instructional strategies for creative and critical thinking in the accounting curriculum. Journal of Accounting Education, 16(2), 261-293.

Booth, P., Luckett, P., \& Mladenovic, R. (1999). The quality of learning in accounting education: the impact of approaches to learning on academic performance. Accounting Education: an international journal, 8(4), 277 - 300.

Booth, S. (1997). On Phenomenography, Leaming and Teaching. Higher Education Research \& Development, 16(2), 135 - 158.

Boulton-Lewis, G., Marton, F., Lewis, D., \& Wilss, L. (2004). A longitudinal study of learning for a group of indigenous Australian university students: Dissonant conceptions and strategies. Higher Education, 47(1), 91-111.

Boyce, G. (1996). The conceptual framework in VCE accounting: challenging the bean-counting mentality. Compak, 4 October, 20-25.

Boyce, G., Williams, S., Kelly, A., \& Yee, H. (2001). Fostering deep and elaborative learning and generic (soft) skill development: the strategic use of case studies in accounting education. Accounting Education: an international journal, 10(1), 37-60.

Brookfield, S. (1987). Developing critical thinkers: Challenging adults to explore alternative ways of thinking and acting. San Francisco: Jossey-Bass.

Brookfield, S. (1995). Becoming a Critically Reflective Teacher. San Francisco: Jossey-Bass.

Burchfield, C., \& Sappington, J. (2000). Compliance With Required Reading Assignments. Teaching of Psychology, 27(1), 58.

Byrne, M., Finlayson, O., Flood, B., Lyons, O., \& Willis, P. (2010). A comparison of the learning approaches of accounting and science students at an Irish university. Journal of Further \& Higher Education, 34, 369-383.

Byrne, M., \& Flood, B. (2004). Exploring the conceptions of learning of accounting students. Accounting Education: an international journal, 13 (4 supp 1), 25 - 37.

Byrne, M., \& Flood, B. (2005). A study of accounting students' motives, expectations and preparedness for higher education. Journal of Further and Higher Education, 29(2), 111-124.

Byrne, M., Flood, B., \& Willis, P. (1999). Approaches to learning: Irish students of accounting. Irish Accounting Review, 6(2), 1-29.

Byrne, M., Flood, B., \& Willis, P. (2002). The relationship between learning approaches and learning outcomes: a study of Irish accounting students. Accounting Education: an international journal, 11, 27-42.

Byrne, M., Flood, B., \& Willis, P. (2004). Validation of the approaches and study skills inventory for students (assist) using accounting students in the USA and Ireland: a research note. Accounting Education: an international journal, 13(4), 449 - 459. 
Byrne, M., Flood, B., \& Willis, P. (2009). An Inter-Institutional Exploration of the Learning Approaches of Students Studying Accounting. International Journal of Teaching \& Learning in Higher Education, 20, 155-167.

Campbell, J., Smith, D., Boulton-Lewis, G., Brownlee, J., Burnett, P., Carrington, S., et al. (2001). Students' Perceptions of Teaching and Learning: the influence of students' approaches to learning and teachers' approaches to teaching. Teachers \& Teaching, 7, 173-187.

Carland, J., Carland, J., \& Dye, J. (1994). Accounting education: a cooperative learning strategy. Accounting Education: an international journal 3(3), 223-236.

Case, J., \& Gunstone, R. (2002). Metacognitive development as a shift in approach to learning; an in-depth study. Studies in Higher Education, 27(4), 459-470.

Chiang, B. (2008). Integrating a Service-learning Project into Management Accounting Coursework - A Sharing of Implementation Experience and Lessons Learned. Accounting Education, 17(4), 431 - 445.

Chizmar, J. (2005). The effectiveness of assignments that utilize a time-efficient grading scheme. Journal on Excellence in College Teaching, 16(1), 5-21.

Clump, M., Bauer, H., \& Bradley, C. (2004). The Extent to which Psychology Students Read Textbooks: A Multiple Class Analysis of Reading across the Psychology Curriculum. Journal of Instructional Psychology, 31, 227-232.

Cooper, B. (2004). The enigma of the Chinese learner. Accounting Education: an international journal, 13(3), 289-310.

Cope, C., \& Staehr, L. (2005). Improving students' learning approaches through intervention in an information systems learning environment. Studies in Higher Education, 30(2), $181-197$.

Cottell, P., \& Millis, B. (1992). Cooperative learning in accounting. Journal of Accounting Education, 10(1), 95-111.

Cottell, P., \& Millis, B. (1993). Cooperative Learning Structures in the Instruction of Accounting. Issues in Accounting Education, 8(1), 40-59.

Cottell, P., \& Millis, B. (1994). Cooperative learning and accounting. Cincinnati, OH: South-Westem Publishing Co.

Cotton, W., Rainsbury, E., \& Scott, G. (2002). Competency-based professional accounting certification in New Zealand. Paper presented at the American Association Conference.

Dahlgren, L. (1984). Outcomes of Learning. In F. Marton (Ed.), The Experience of Learning. Edinburgh: Scottish Academic Press.

Dahlgren, L. (1985). Higher education: impact on students. In T. Husén \& T. N. Postlethwaite (Eds.), The international encyclopaedia of education (pp. 2223-2226). Oxford: Pergamon Press.

Dart, B. (1998). Teaching for improved learning in small classes. In B. Dart \& G. Boulton-Lewis (Eds.), Teaching and learning in higher education. Melboume: ACER.

Dart, B., Burnett, P., Purdie, N., Boulton-Lewis, G., Campbell, J., \& Smith, D. (2000). Students' Conceptions of Learning, the Classroom Environment, and Approaches to Learning. Journal of Educational Research, 93, 262.

Davidson, R. (2002). Relationship of study approach and exam performance. Journal of Accounting Education, 20(1), 29-44. 
Davis, H., Hwang, L., \& Shoaf, V. (2001). The use of individualized problems to improve students' learning. Journal of Accounting Education, 19(3), 189-210.

De Lange, P., Jackling, B., \& Gut, A. (2006). Accounting graduates' perceptions of skills emphasis in undergraduate courses: an investigation from two Victorian universities. Accounting \& Finance, 46, 365-386.

De Lange, P., \& Mavondo, F. (2004). Gender and motivational differences in approaches to learning by a cohort of open learning students. Accounting Education: an international journal, 13(4), 431 - 448.

Deci, E. (1971). Effects of externally mediated rewards on intrinsic motivation. Journal of Personality and Social Psychology, 18, 105-115.

Deci, E., \& Ryan, R. (1985). Intrinsic motivation and self-determination in human behavior. New York: Plenum Press.

Deci, E., \& Ryan, R. (2000). The 'What' and 'Why' of Goal Pursuits: Human Needs and the Self-Determination of Behavior. Psychological Inquiry, 11(4), 227.

Deppe, L., Sonderegger, E., Slice, J., Clark, D., \& Streuung, G. (1991). Emerging competencies for the practice of accountancy. Journal of Accounting Education 9 , 257-290.

Dochy, F., \& McDowell, L. (1997). Assessment as a tool for learning. Studies In Educational Evaluation, 23(4), 279-298.

Doney, L., \& Lephardt, N. (1993). Developing critical thinking skills in accounting students. Journal of Education for Business, 68(5), 297.

Duff, A. (1997). Validating the learning styles questionnaire and inventory of learning processes in accounting: a research note. Accounting Education: an international journal, 6(3), 263.

Duff, A. (1999). Access policy and approaches to learning. Accounting Education: an international journal, 8(2), 99-110.

Duff, A. (2004a). Understanding academic performance and progression of first-year accounting and business economics undergraduates: the role of approaches to learning and prior academic achievement. Accounting Education: an international journal, 13(4), 409 - 430.

Duff, A. (2004b). The role of cognitive learning styles in accounting education: developing learning competencies. Journal of Accounting Education, 22(1), 29-52.

Duff, A., \& McKinstry, S. (2007). Students' Approaches to Learning. Issues in Accounting Education, 22(2), 183-214.

Edmunds, R., \& Richardson, J. (2009). Conceptions of leaming, approaches to studying and personal development in UK higher education. British Journal of Educational Psychology, 79, 295-309.

Eizenberg, N. (1988). Approaches to learning anatomy: Developing a programme for preclincal medical students. In P. Ramsden (Ed.), Improving learning. New perspectives (pp. 178-198). London: Kogan Page.

Ekroth, L. (1990). Why professors don't change. In L. Ekroth (Ed.), Teaching Excellence: Towards the Best in the Academy. Stillwater, Oklahoma: Professional and Organizational Development Network in Higher Education.

Eley, M. (1992). Differential adoption of study approaches within individual students. Higher Education, 23, 231-254. 
Elias, R. (2005). Students' Approaches to Study in Introductory Accounting Courses. Journal of Education for Business, 80, 194-199.

English, L., Luckett, P., \& Mladenovic, R. (2004). Encouraging a deep approach to learning through curriculum design. Accounting Education: an international journal, 13(4), $461-488$.

Entwistle, N. (1976). The verb "to learn" takes the accusative. Editorial introduction to symposium: Learning processes and strategies. British Journal of Educational Psychology, 46, 1-3.

Entwistle, N. (1984). Contrasting perspectives on learning. In F. Marton, D. Hounsell \& N. Entwistle (Eds.), The experience of learning (pp. 1-18). Edinburgh: Scottish Academic Press.

Entwistle, N. (1988). Motivational factors in students' approaches to learning. In R. Schmeck (Ed.), Learning strategies and learning styles. New York: Plenum.

Entwistle, N. (1995). Frameworks for understanding as experienced in essay writing and in preparing for examination. Educational Psychologist, 30(1), 47.

Entwistle, N. (1997). Introduction: Phenomenography in Higher Education. Higher Education Research \& Development, 16(2), 127 - 134.

Entwistle, N. (1998a). Approaches to learning and forms of understanding. In B. Dart \& G. Boulton-Lewis (Eds.), Teaching and Learning Higher Education. Melbourne: Australian Council for Educational Research.

Entwistle, N. (1998b). Improving teaching through research in student learning. In J. J. F. Forest (Ed.), University teaching: International perspectives (pp. 73-112). New York: Garland.

Entwistle, N., \& Marton, F. (1984). Changing conceptions of learning and research. In F. Marton, D. Hounsell \& N. Entwistle (Eds.), The experience of learning. Edinburgh: Scottish Academic Press.

Entwistle, N., \& Marton, F. (1994). Knowledge objects: Understandings constituted through intensive academic study. British Journal of Educational Psychcology, 64, 161-178.

Entwistle, N., McCune, V., \& Hounsell, J. (2003). Investigating ways of enhancing university teaching-leaming environments: Measuring students' approaches to studying and perceptions of teaching. In L. DeCorte, N. Verschaffel, N. Entwistle \& J. van Merriënborer (Eds.), Powerful learning environments: Unravelling basic components and dimensions (pp. 89-107). Oxford: Elsevier Science Ltd.

Entwistle, N., \& Ramsden, P. (1983). Understanding student learning. London: Croom Helm.

Entwistle, N., \& Tait, H. (1990). Approaches to learning, evaluations of teaching, and preferences for contrasting academic environments. Higher Education, 19, 169-194.

Entwistle, N. (1991). Approaches to Learning and Perceptions of the Learning Environment: Introduction to the Special Issue. Higher Education, 22(3), 201-204.

Entwistle, N., McCune, V., \& Hounsell, D. (2002). Occasional report 1: Approaches to study and perceptions of university teaching-learning environments: concepts, measures and preliminary findings. Universities of Edinburgh, Coventry and Durham: Available from: http://www.ed.ac.uk/etl.

Entwistle, N., Thompson, J., \& Wilson, J. (1974). Motivation and Study Habits. Higher Education, 3(4), 379-395. 
Entwistle, N., \& Wilson, J. (1977). Degrees of excellence: The academic achievement game. London: Hodder and Stoughton.

Fink, L. (2003). Creating Significant Learning Experiences: An Integrated Approach to Designing College Courses. San Francisco: Jossey-Bass.

Fink, L. (2007). The Power of Course Design to Increase Student Engagement and Learning. Peer Review, 9(1), 13-17.

Finkelstein, M. (2008). Predictors of volunteer time: the changing contributions of motive fulfilment and role identity. Social Behavior \& Personality: An International Journal, 36, 1353-1364.

Finkelstien, M. (2009). Intrinsic vs. extrinsic motivational orientations and the volunteer process. Personality and Individual Differences, 46(5-6), 653-658.

Flood, B., \& Wilson, R. (2008). An exploration of the learning approaches of prospective professional accountants in Ireland. Accounting Forum, 32(3), 225-239.

Foran, M., \& Olds, P. (2002). Using the Wall Street Joumal and the Internet to implement the AECC's introductory accounting recommendations. Advances in Accounting Education, 4, 21-39.

Fox, A., Stevenson, L., Connelly, P., Duff, A., \& Dunlop, A. (2010). Peer-mentoring undergraduate accounting students: The influence on approaches to learning and academic performance. Active Learning in Higher Education, 11(2), 145-156.

Fransson, A. (1977). On qualitative differences in learning: IV - Effects of intrinsic motivation and extrinsic test anxiety on process and outcome. British Journal of Educational Psychology, 47, 244-257.

Frederiksen, N. (1984). The real test bias, influences of testing on teaching and learning. American Psychologist, 39(3), 193-202.

Gibbs, G. (1992). Improving the Quality of Student Learning. Oxford: Oxford Centre for Staff Development.

Gibbs, G. (1999). Using assessment strategically to change the way students learn. In S. Brown \& A. Glasner (Eds.), Assessment Matters in Higher Education: choosing and using diverse approaches. Buckingham: Open University Press.

Gibbs, G., Morgan, A., \& Taylor, E. (1984). The world of the learner. In F. Marton, D. Hounsell \& N. Entwistle (Eds.), The experience of learning (pp. 165-188). Endinburgh: Scottish Academic Press.

Gibbs, G., \& Simpson, C. (2004). Does your assessment support your students' learning? Journal of Learning and Teaching in Higher Education, 1(1), 3-31.

Gijbels, D., Coertjens, L., Vanthournout, G., Struyf, E., \& Van Petegem, P. (2009). Changing students' approaches to learning: a two-year study within a university teacher training course. Educational Studies, 35(5), 503-513.

Gijbels, D., \& Dochy, F. (2006). Students' assessment preferences and approaches to learning: can formative assessment make a difference? Educational Studies, 32, 399-409.

Gijbels, D., Segers, M., \& Struyf, E. (2008). Constructivist learning environments and the (im)possibility to change students' perceptions of assessment demands and approaches to learning. Instructional Science, 36(5-6), 431-443.

Gijbels, D., Van De Watering, G., Dochy, F., \& Van Den Bossche, P. (2005a). The relationship between students' approaches to learning and the assessment of learning outcomes. European Journal of Psychology of Education, 20, 327-341. 
Gijbels, D., van de Watering, G., \& Dochy, F. (2005b). Integrating assessment tasks in a problem-based learning environment. Assessment \& Evaluation in Higher Education, 30(1), 73-86.

Gordon, C., \& Debus, R. (2002). Developing deep learning approaches and personal teaching efficacy within a preservice teacher education context. British Journal of Educational Psychology, 72, 483.

Gow, L., Kember, D., \& Cooper, B. (1994). The Teaching Context and Approaches to Study of Accounting Students. Issues in Accounting Education, 9(1), 118.

Graham, B. \& Dodd, D. (1940). Security Analysis: Principles and Technique. (2nd ed.). New York and London: McGraw-Hill.

Gulikers, J., Kester, L., Kirschner, P., \& Bastiaens, T. (2008). The effect of practical experience on perceptions of assessment authenticity, study approach, and learning outcomes. Learning and Instruction, 18(2), 172-186.

Haggis, T. (2003). Constructing Images of Ourselves? A Critical Investigation into 'Approaches to Learning' Research in Higher Education. British Educational Research Journal, 29(1), 89-105.

Hall, M., Ramsay, A., \& Raven, J. (2004). Changing the learning environment to promote deep learning approaches in first-year accounting students. Accounting Education, 13(4), $489-505$.

Hand, L., Sanderson, P., \& ONeil, M. (1996). Fostering deep and active learning through assessment. Accounting Education: an international journal, 5(2), 103-119.

Hassall, T., Joyce, J., Arquero, J., \& Donoso, J. (1999). Vocational skills and capabilities for management accountants: a CIMA employer's perspective. Management Accounting (CIMA), 17(11), 52-56.

Heikkila, A., \& Lonka, K. (2006). Studying in higher education: Students' approaches to learning, self regulation, and cognitive strategies. Studies in Higher Education, 31, 99-117.

Heinrich, E. (2004). Electronic repositories of marked student work. Journal of Educational Technology \& Society, 7(3), 82-96.

Heinrich, E., \& Lu, J. Y. (2005). Opportunities in learning from marked student work. Paper presented at the ED-Media 2005 World Conference on Educational Multimedia.

Heinrich, E., Milne, J., \& Moore, M. (2009). An Investigation into E-Tool Use for Formative Assignment Assessment - Status and Recommendations. Journal of Educational Technology \& Society, 12, 176-192.

Herington, C., \& Weaven, S. (2008). Action Research and Reflection on Student Approaches to Learning in Large First Year University Classes. Australian Educational Researcher, 35, 111-134.

Herrington, J., \& Herrington, A. (1998). Authentic Assessment and Multimedia: how university students respond to a model of authentic assessment. Higher Education Research \& Development, 17(3), 305 - 322.

Herrington, J., \& Kervin, L. (2007). Authentic Learning Supported by Technology: Ten suggestions and cases of integration in classrooms, Educational Media International (Vol. 44, pp. 219-236): Routledge.

Higgins, R., Hartley, P., \& Skelton, A. (2002). The Conscientious Consumer: reconsidering the role of assessment feedback in student learning. Studies in Higher Education, 27, 53. 
Hoque, Z. (2002). Using journal articles to teach public sector accounting in higher education. Journal of Accounting Education, 20(3), 139-161.

Hounsell, D. (2003). Student feedback, learning and development. In M. Slowey \& D. Watson (Eds.), Higher education the lifecourse (pp. 66-78). Buckingham: SRHE and Open University Press.

Hounsell, D., McCune, V., Hounsell, J., \& Litjens, J. (2008). The quality of guidance and feedback to students. Higher Education Research \& Development, 27, 55-67.

Howieson, B. (2003). Accounting practice in the new millennium: is accounting education ready to meet the challenge? The British Accounting Review, 35(2), 69-103.

ICAA/ASCPA. (1996). Guidelines for joint administration of accreditation of tertiary courses by the professional accounting bodies Melbourne and Sydney: ASCPA and ICAA.

ICAEW. (2005). Institute of Chartered Accountants in England and Wales (ICAEW), 2003-04 Total Student Intake Analysed by Entry Category \& UCAS Points, ICAEW. London: ICAEW.

IFAC. (1994). 2000 and Beyond: A Strategic Framework for Prequalification Education for the Accountancy Profession in the Year 2000 and Beyond. New York: International Federation of Accountants.

IFAC. (1996). Prequalification Education, Assessment of Professional Competence and Experience Requirements of Professional Accountants. New York: IFAC.

IFAC. (1998). Competence-based approaches to the professional preparation of accountants (Discussion paper).

IFAC. (2001). Competence-based approaches to the preparation and work of professional accountants (Exposure draft discussion paper).

Jackling, B. (2005). Perceptions of the learning context and learning approaches: Implications for quality learning outcomes in accounting. Accounting Education: an international journal, 14(3), 271 - 291.

Jackling, B., \& De Lange, P. (2009). Do Accounting Graduates' Skills Meet The Expectations of Employers? A Matter of Convergence or Divergence. Accounting Education: an international journal, 18(4), 369-385.

Johnson, D.W., Johnson, R.T., Holubec, E.J. and Roy, P. (1984) Circles of of Learning. Alexandria, VA: Association for Supervision and Curriculum Development.

Johnson, D.W. and Johnson, R.T. (1989). Leading the Cooperative School, Edina, MN: Interaction Book Company.

Jones, C., \& Hassall, T. (1997). The approaches to learning of first year accounting students: some empirical evidence. In C. Rust (Ed.), Improving student learning: Improving student learning through course design (pp. 431-438). Oxford: OCSD.

Kagan, S. (1989). Cooperative Learning Resources for Teachers. San Capistrano, CA: Resources for Teachers.

Kember, D., Wong, A., \& Leung, D. (1999). Reconsidering the dimensions of approaches to learning. British Journal of Educational Psychology, 69(3), 323-343.

Kennedy, F., \& Dull, R. (2008). Transferable Team Skills for Accounting Students. Accounting Education, 17(2), 213-224.

Kern, B. (2000). Structuring financial statement analysis projects to enhance critical thinking skills development. Journal of Accounting Education, 18(4), 341-353. 
Kimmel, P. (1995). A framework for incorporating critical thinking into accounting education. Journal of Accounting Education, 13(3), 299-318.

Laurillard, D. (1979). The processes of student learning. Higher Education, 8(4), 395-409.

Laurillard, D. (1984). Styles and Approaches in Problem Solving. In F. Marton, D. Hounsell \& N. Entwistle (Eds) The experience of learning. Edinburgh: Scottish Academic Press.

Laurillard, D. (2002). Rethinking University Teaching (2nd ed.). London: RoutledgeFalmer.

Lepper, M., Greene, D., \& Nisbett, R. (1973). Undermining children's intrinsic interest with extrinsic reward. Journal of Personality and Social Psychology, 28, 129-137.

Leung, S. F., Mok, E., \& Wong, D. (2008). The impact of assessment methods on the learning of nursing students. Nurse Education Today, 28(6), 711-719.

Lindblom-Ylänne, S., \& Lonka, K. (1998). Individual ways of interacting with the learning environment -- are they related to study success? Learning and Instruction, 9(1), $1-18$.

Linder, C., \& Marshall, D. (1997a). Introducing and evaluating metacognitive strategies in large-class introductory physics teaching. In C. Rust (Ed.), Improving student learning: Improving students as learners. Oxford: Oxford Centre for Staff and Learning Department.

Linder, C., \& Marshall, D. (1997b). Linking physics students' development as independent and reflective learners with changes in their conceptions of science. In C. Rust (Ed.), Improving student learning: improving students as learners. Oxford: Oxford Centre for Staff and Learning Department.

Lizzio, A., \& Wilson, K. (2004). Action Learning in Higher Education: an investigation of its potential to develop professional capability. Studies in Higher Education, 29, 469-488.

Lord, B. R., \& Robertson, J. (2006). Students' experiences of learning in a third-year management accounting class: Evidence from New Zealand. Accounting Education, $15(1), 41-59$.

Lucas, U. (1996). Student approaches to learning--a literature guide. Accounting Education: an international journal, 5(1), 87.

Lucas, U. (2000). Worlds apart: Students' experiences of learning introductory accounting. Critical Perspectives on Accounting, 11(4), 479-504.

Lucas, U. (2001). Deep and surface approaches to learning within introductory accounting: a phenomenographic study. Accounting Education, 10(2), 161-184.

Lucas, U. (2002). Contradictions and uncertainties: Lecturers' conceptions of teaching introductory accounting. The British Accounting Review, 34(3), 183-203.

Lucas, U. (2008). Being "pulled up short": Creating moments of surprise and possibility in accounting education. Critical Perspectives on Accounting, 19(3), 383-403.

Lucas, U., \& Ashworth, P. (2000). Acheiving empathy and engagement: a practical approach to the design, conduct and reporting of phenomenographic research. Studies in Higher Education 25(3), 295-308.

Lucas, U., Cox, P., Croudace, C., \& Milford, P. (2004). 'Who writes this stuff?': students' perceptions of their skills development. Teaching in Higher Education, 9, 55-68.

Lucas, U., \& Meyer, J. (2004). Supporting student awareness: understanding student preconceptions of their subject matter within introductory courses. Innovations in Education and Teaching International, 4l(4), 459 - 471. 
Lucas, U., \& Meyer, J. (2005). 'Towards a mapping of the student world': the identification of variation in students' conceptions of, and motivations to learn, introductory accounting. The British Accounting Review, 37(2), 177-204.

Lucas, U., \& Mladenovic, R. (2004). Approaches to learning in accounting education. Accounting Education: an international journal, 13(4), 399 - 407.

Lucas, U., \& Mladenovic, R. (2006). Developing New 'World Views': Threshold concepts in introductory accounting. In J. H. F. Meyer \& R. Land (Eds.), Overcoming barriers to student understanding: Threshold concepts and troublesome knowledge (pp. 148-159). Oxford: Routledge.

Marrian, N., \& Lothian, I. (1992). New Zealand Society of Accountants International Review of Admission Policy: NZSA Wellington.

Marriott, P., \& Marriott, N. (2003). Are we turning them on? A longitudinal study of undergraduate accounting students' attitudes towards accounting as a profession. Accounting Education: an international journal, 12(2), 113-133.

Martens, R. L., Gulikers, J., \& Bastiaens, T. (2004). The impact of intrinsic motivation on e-learning in authentic computer tasks. Journal of Computer Assisted Learning, 20, 368-376.

Martin, E., \& Ramsden, P. (1987). Learning skills or skill in learning. In I. T. E. Richardson, M. W. Eysenck \& D. W. Piper (Eds.), Student Learning. Milton Keynes: Open University Press.

Martin, E., \& Ramsden, P. (1993). An expanding awareness: how lecturers change their understanding of teaching. Research and Development in Higher Education, 15, $148-155$.

Marton, F. (1976). On non-verbatim learning. IV: Some theoretical and methodolgical notes. Scandinavian Journal of Psychology, 17, 125-128.

Marton, F. (1981). Phenomenography - Describing conceptions of the world around us. Instructional Science, 10, 177-200.

Marton, F. (1986). Phenomenography - a research approach to investigating different understandings of reality. Journal of Thought, 21(28-49).

Marton, F. (1988). Describing and improving learning. In R. Schmeck (Ed.), Styles and strategies of learning (pp. 53-82). New York: Plenum.

Marton, F. (1988). Exploring Different Conceptions of Reality. In P. M. Fetterman (Ed.), Qualitative approaches to evaluating education: A silent scientific revolution (pp. 176-205). New York: Praeger.

Marton, F. (1992). Phenomenography and "the art of teaching all things to all men". International Journal of Qualitative Studies in Education, 5, 253-267.

Marton, F. (1993). Phenomenography. In T. Husén \& T. N. Postlethwaite (Eds.), The international encyclopaedia of education (pp. 4424-4429). Oxford: Pergamon Press.

Marton, F. (1994). On the structure of teachers' awareness. In I. Carlgren, G. Handal \& S. Vaage (Eds.), Teachers' minds and actions: Research on teachers' thinking and practice (pp. 28-42). London: Falmer Press.

Marton, F., Asplund-Carlsson, M., \& Halász, L. (1992). Difference in understanding and the use of reflective variation in reading. British Journal of Educational Psychcology, 62, $1-16$. 
Marton, F., Asplund-Carlsson, M., \& Halász, L. (1994). The reverse effect of an attempt to shape reader awareness. Scandinavian Journal of Educational Psychology, 38, 291-298.

Marton, F., \& Booth., S. (1997). Learning and awareness. Mahwah, NJ: L. Eribaum Associates.

Marton, F., Dall'Alba, G., \& Beaty, E. (1993). Conceptions of learning. International Journal of Educational Research, 19(3), 277-300.

Marton, F., Hounsell, D., \& Entwistle, N. (Eds.). (1997). The experience of learning (2nd ed.). Edinburgh: Scottish Academic Press.

Marton, F., \& Säljö, R. (1984). Approaches to learning. In F. Marton, D. Hounsell \& N. Entwistle (Eds.), The Experience of Learning. Edinburgh: Scottish Academic Press.

Marton, F., \& Säljő, R. (1976a). On Qualitative Differences in Learning - 1: Outcome and Process. British Journal of Educational Psychology, 46, 4-11.

Marton, F., \& Säljő, R. (1976b). On Qualitative Differences in Learning - 2: Outcome as a function of the learner's conception of the task. British Journal of Educational Psychology, 46, 115-127.

Marton, F., \& Säljö, R. (1997). Approaches to learning. In F. Marton, D. Hounsell \& N. Entwistle (Eds.), The Experience of Learning: Implications for Teaching and Studying in Higher Education (2nd ed.). Edinburgh: Scottish Academic Press.

Marton, F., \& Svensson, L. (1979). Conceptions of Research in Student Learning. Higher Education, 8(4), 471-486.

Mattick, K., Dennis, I., \& Bligh, J. (2004). Approaches to learning and studying in medical students: validation of a revised inventory and its relation to student characteristics and performance. Medical Education, 38, 535-543.

McCarthy, P. R., \& McCarthy, H. M. (2006). When Case Studies Are Not Enough: Integrating Experiential Learning Into Business Curricula. Journal of Education for Business, 81(4), 201-204.

McDowell, L. (1995). The impact of innovative assessment on student learning. Innovations in Education and Training International, 32(4), 302-313.

McGuigan, N., \& Kern, T. (2009). The Reflective Accountant: Changing Student Perceptions of Traditional Accounting through Reflective Educational Practice. International Journal of Learning, 16, 49-68.

McKeachie, W., \& Hofer, B. (2002). McKeachie's teaching tips: Strategies, research, and theory for college and university teachers. Boston: Houghton Mifflin Co.

Milne, M. J., \& McConnell, P. (2001). Problem-based learning: a pedagogy for using case material in accounting education. Accounting Education: an international journal, $10(1), 61-82$.

Mintz, S. (2006). Accounting ethics education: Integrating reflective learning and virtue ethics. Journal of Accounting Education, 24(2-3), 97-117.

Mladenovic, R. (2000). An investigation into ways of challenging introductory accounting students' negative perceptions of accounting. Accounting Education: an international journal, 9(2), 135-155.

Moneta, G., \& Spada, M. (2009). Coping as a mediator of the relationships between trait intrinsic and extrinsic motivation and approaches to studying during academic exam preparation. Personality and Individual Differences, 46(5-6), 664-669. 
Montano, J., Luis, A., Cardoso, S., \& Joyce, J. (2004). Skills development, motivation and learning in financial statement analysis: an evaluation of alternative types of case studies. Accounting Education: an international journal, 13(2), 191 - 212.

Nichols, J., \& Miller, R. (1994). Cooperative Learning and Student Motivation. Contemporary Educational Psychology, 19(2), 167-178.

Nicol, D., \& Macfarlane-Dick, D. (2006). Formative assessment and self-regulated learning: a model and seven principles of good feedback practice. Studies in Higher Education, $31(2), 199-218$.

Nijhuis, J., Segers, M., \& Gijselaers, W. (2008). The extent of variability in learning strategies and students' perceptions of the learning environment. Learning and Instruction, 18(2), 121-134.

Nijhuis, J., Segers, M., \& Gijselaers, W. (2005). Influence of Redesigning a Learning Environment on Student Perceptions and Learning Strategies. Learning Environments Research, 8(1), 67-93.

Nikolai, L. (2006). How to integrate a business plan into your introductory accounting course. Journal of Accounting Education, 24(2-3), 72-84.

Orsmond, P., Merry, S., \& Reiling, K. (2002). The Use of Exemplars and Formative Feedback when Using Student Derived Marking Criteria in Peer and Self-assessment. Assessment \& Evaluation in Higher Education, 27, 309-323.

Oxford, R. (1997). Constructivism: Shape-shifting, substance, and teacher. Peabody Journal of Education, 71(1), 35-66.

Paver, B., \& Gammie, E. (2005). Constructed gender, approach to learning and academic performance. Accounting Education: an international journal, 14(4), 427 - 444.

Perry, W. (1970). Forms of Intellectual and Ethical Develoment in the College Years. New York: Holt, Rinehart and Winston.

Perry, W. (1988). Different worlds in the same classroom. In P. Ramsden (Ed.), Improving Learning: New Perspectives. London: Kogan Page.

Phillips, B., \& Phillips, F. (2007). Sink or Skim: Textbook Reading Behaviors of Introductory Accounting Students. Issues in Accounting Education, 22(1), 21-44.

Pintrich, P., \& Garcia, T. (1991). Student goal orientation and self-regulation in the college classroom. In M. Maehr \& P. Pintrich (Eds.), Advances in motivation and achievement: motivation enhancing environments. Greenwich, CT: JAI Press.

Prosser, M., \& Millar, R. (1989). The how and what of learning physics. European Journal of Psychology of Education, 4(4), 513-528.

Quinton, S., \& Smallbone, T. (2010). Feeding forward: using feedback to promote student reflection and learning - a teaching model. Innovations in Education \& Teaching International, 47(1), 125-135.

Ramburuth, P., \& Mladenovic, R. (2004). Exploring the relationship between students' orientations to learning, the structure of students' learning outcomes and subsequent academic performance. Accounting Education: an international journal, 13(4), 507 527.

Ramsden, P. (1985). Student learning research: retrospect and prospect. Higher Education Research and Development, 4(1), 51-69.

Ramsden, P. (1987). Improving teaching and learning in higher education: The case for a relational perspective. Studies in Higher Education, 12(3), 275-286. 
Ramsden, P. (1988a). Context and strategy: Situational differences in learning. In R. R. Schmeck (Ed.), Learning Strategies and Learning Styles. New York: Plenum.

Ramsden, P. (1988b). Improving Learning: New Perspectives. London: Kogan Page.

Ramsden, P. (1998). Learning to Lead in Higher Education. London: Routledge.

Ramsden, P. (2003). Learning to Teach in Higher Education (2nd ed.). London: Routledge.

Ramsden, P., Beswick, D., \& Bowden, J. (1986). Effects of learning skills interventions on first year university students' learning. Human Learning, 5(151-64).

Ramsden, P., \& Entwistle, N. (1981). Effects of academic departments on students' approaches to studying. British Journal of Educational Psychology, 51, 368-383.

Ramsden, P., \& Martin, E. (1996). Recognition of good university teaching: Policies from an Australian study. Studies in Higher Education, 21, 299-315.

Reid, W., Duvall, E., \& Evans, P. (2005). Can we influence medical students' approaches to learning? Medical Teacher, 27(5), 401-407.

Rossum, E. v., Deijkers, R., \& Hamer, R. (1985). Students' Learning Conceptions and Their Interpretation of Significant Educational Concepts. Higher Education, 14(6), 617-641.

Rowntree, D. (1981). Developing Courses for Students. London: McGraw-Hill.

Rowntree, D. (1987). Assessing students: how shall we know them? (2nd ed.). London: K. Page.

Rust, C., Price, M., \& O'Donovan, B. (2003). Improving Students' Learning by Developing their Understanding of Assessment Criteria and Processes. Assessment \& Evaluation in Higher Education, 28, 147.

Ryan, R., \& Deci, E. (2000a). Self-determination theory and the facilitation of intrinsic motivation, social development, and well-being. Amercian Psychologist, 55, 68-78.

Ryan, R., \& Deci, E. (2000b). Intrinsic and Extrinsic Motivations: Classic Definitions and New Directions. Contemporary Educational Psychology, 25(1), 54-67.

Ryan, T. (2006). Motivating Novice Students to Read their Textbooks. Journal of Instructional Psychology, 33, 136-140.

Sadler, D. (1989). Formative assessment and the design of instructional systems. Instructional Science, 18(2), 119-144.

Sadler, D. (1998). Formative assessment: Revisiting the territory. Assessment in Education: Principles, Policy \& Practice, 5(1), 77-84.

Sadler, D. (2009a). Transforming holistic assessment and grading into a vehicle for complex learning. In G. Joughin (Ed.), Assessment, learning and judgement in higher education (pp. 49-64). Dordrecht: Springer.

Sadler, D. (2009b). Indeterminacy in the use of preset criteria for assessment and grading. Assessment \& Evaluation in Higher Education, 34, 159-179.

Sadler, D. (2010). Beyond feedback: developing student capability in complex appraisal. Assessment \& Evaluation in Higher Education, 35, 535-550.

Saemann, G., \& Crooker, . (1999). Student perceptions of the profession and its effect on decisions to major in accounting. Journal of Accounting Education, 17, 1-22.

Säljö, R. (1979). Learning in the Learner's Perspective: 1: some commonplace misconceptions. Reports from the Institute of Education, University of Gothenburg.

Säljö, R. (1984). Learning from reading. In F. Marton, D. Hounsell \& N. Entwistle (Eds.), The Experience of Learning. Edinburgh: Scottish Academic Press. 
Säljö, R. (1997). Talk as Data and Practice - a critical look at phenomenographic inquiry and the appeal to experience. Higher Education Research \& Development, 16(2), 173 190.

Sambell, K., McDowell, L., \& Brown, S. (1997). "But is it fair?": An exploratory study of student perceptions of the consequential validity of assessment. Studies In Educational Evaluation, 23(4), 349-371.

Samkin, G., \& Francis, G. (2008). Introducing a Learning Portfolio in an Undergraduate Financial Accounting Course. Accounting Education: an international journal, 17(3), $233-271$.

Sandbergh, J. (1997). Are Phenomenographic Results Reliable? Higher Education Research \& Development, 16(2), 203 - 212.

Sandelowski, M. (1994). The use of quotes in qualitative research. Research in Nursing \& Health, 17, 479-482.

Scouller, K. (1998). The Influence of Assessment Method on Students' Learning Approaches: Multiple Choice Question Examination versus Assignment Essay. Higher Education, 35(4), 453-472.

Sharma, D. (1997). Accounting students' learning conceptions, approaches to learning, and the influence of the learning-teaching context on approaches to learning. Accounting Education: an international journal, 6(2), 125-146.

Sharma, D. (1998). Addressing the student quality problem: some directions for accounting education research. Asian Review of Accounting, 6(1), 1-29.

Smith, S., \& Miller, R. (2005). Learning Approaches: Examination type, discipline of study, and gender. Educational Psychology, 25, 43-53.

Snelgrove, S. (2004). Approaches to learning of student nurses. Nurse Education Today, 24(8), 605-614.

Stein, S., Isaacs, G., \& Andrews, T. (2004). Incorporating authentic learning experiences within a university course. Studies in Higher Education, 29, 239-258.

Stewart, J., \& Dougherty, T. (1993). Using case studies in teaching accounting: a quasi-experimental study. Accounting Education: an international journal, 2(1), $1-10$.

Stice, E., \& Stice, J. (2006). Motivation on day one: The use of Enron to capture student interest. Journal of Accounting Education, 24(2-3), 85-96.

Stipek, D. (2002). Motivation to Learn. Integrating Theory and Practice (4th ed.). Boston: Allyn and Bacon.

Struyven, K., Dochy, F., \& Janssens, S. (2005). Students' perceptions about evaluation and assessment in higher education: a review. Assessment \& Evaluation in Higher Education, 30, 325-341.

Struyven, K., Dochy, F., \& Janssens, S. (2010). 'Teach as you preach': the effects of student-centred versus lecture-based teaching on student teachers' approaches to teaching. European Journal of Teacher Education, 33, 43-64.

Struyven, K., Dochy, F., Janssens, S., \& Gielen, S. (2006). On the dynamics of students' approaches to learning: The effects of the teaching/learning environment. Learning and Instruction, 16(4), 279-294.

Sullivan, E. (1996). Teaching financial statement analysis: A cooperative learning approach. Journal of Accounting Education, 14(1), 107-111. 
Sundem, G., Williams, D., \& Chironna, J. (1990). The revolution in accounting education. Management Accounting 49-53.

Svensson, L. (1977). On qualitative differences in learning: III-study skill and learning. British Journal of Educational Psychology, 47, 233-243.

Svensson, L. (1997). Theoretical Foundations of Phenomenography. Higher Education Research \& Development, 16(2), 159 - 171.

Svensson, L., \& Hogfors, C. (1988). Conceptions as the content of teaching: Improving education in mechanics. In P. Ramsden (Ed.), Improving learning: New perspectives (pp. 162-177). London: Kogan Page.

Tan, K., \& Choo, F. (1990). A note on the academic performance of deep-elaborative versus shallow-reiterative information processing students. Accounting and Finance, 30(1), 67-81.

Tan, L., \& Laswad, F. (2009). Understanding Students' Choice of Academic Majors: A Longitudinal Analysis. Accounting Education: an international journal, 18(3), 233-253.

Thomas, C., \& Gadbois, S. (2007). Academic self-handicapping: The role of self-concept clarity and students' learning strategies. British Journal of Educational Psychology, 77, 101-119.

Thomas, P., \& Bain, J. (1984). Contextual dependence of learning approaches: The effects of assessments. Human Learning, 3, 227-240.

Tonge, R., \& Willett, C. (2009). Learning to Think: Using Coursework to Develop Higher-order Academic and Practitioner Skills among Final Year Accounting Students. Accounting Education: an international journal, 18(2), 207 - 226.

Torrance, H. (Ed.). (1994). Evaluating authentic assessment: Problems and possibilities in new approaches to assessment. Buckingham: Open University Press.

Torrance, H., \& Pryor, J. (1998). Investigating formative assessment: Teaching, learning and assessment in the classroom. Buckingham: Open University Press.

Trigwell, K. (1997). Phenomenography: an approach to research. In J. Higgs (Ed.), Qualitative Research: Discourse on Methodologies. Sydney: Hampton Press.

Trigwell, K., Martin, E., Benjamin, J., \& Prosser, M. (2000). Scholarship of teaching: a model. Higher Education Research and Development, 19, 155-168.

Trigwell, K., \& Prosser, M. (1991). Improving the quality of student learning: the influence of learning context and student approaches to learning on learning outcomes. Higher Education, 22, 251-266.

Trigwell, K., \& Prosser, M. (1997). Towards an Understanding of Individual Acts of Teaching and Learning. Higher Education Research \& Development, $16(2), 241$ 252.

Trigwell, K., Prosser, M., Ramsden, P., \& Martin, E. (1998). Improving student learning through a focus on the teaching context. In C. Rust (Ed.), Improving student learning: Improving students as learners (pp. 97-103). Oxford, United Kingdom: The Oxford Centre for Staff and Leaming Development.

Tripp, D. (1993) Critical Incidents in Teaching: The Development of Professional Judgement, London and New York: Routledge.

Turner, M. (2008a). Designing assessments to support critical thinking in accounting. Unpublished manuscript: research project for post graduate certificate in higher education learning and teaching. Victoria University of Wellington. 
Turner, M. (2008b). Financial Statement Analysis: To Know What Adds Value. Unpublished manuscript of draft textbook.

Tynjälä, P. (1997). Developing education students' conceptions of the learning process in different learning environments. Learning and Instruction, 7(3), 277-292.

Tynjälä, P. (1999). Towards expert knowledge? A comparison between a constructivist and a traditional learning environment in the university. International Journal of Educational Research, 31(5), 357-442.

Valde, G. (1997). Promoting student participation and learning through the use of weekly writing assignments. Journal on Excellence in College Teaching, 8(3), 67-76.

van der Laan Smith, J., \& Spindle, R. (2007). The impact of group formation in a cooperative learning environment. Journal of Accounting Education, 25(4), 153-167.

Van Rossum, E., \& Schenk, S. (1984). The Relationship Between Learning Conception, Study Strategy and Learning Outcome. British Journal of Educational Psychology, 54(1), 73-83.

Vermunt, J., \& Vermetten, Y. (2004). Patterns in Student Learning: Relationships Between Learning Strategies, Conceptions of Learning, and Learning Orientations. Educational Psychology Review, 16(4), 359-384.

Vermunt, J., \& Rijswijk, F. v. (1988). Analysis and Development of Students' Skill in Selfregulated Learning. Higher Education, 17(6), 647-682.

Volet, S. (2001 a). Understanding learning and motivation in context: A multi-dimensional and multi-level cognitive-situative perspective. In S. E. Volet \& S. Jarvela (Eds.), Motivation in learning contexts: Theoretical advances and methodological implications (pp. 57-82). London: Pergamon.

Volet, S. (2001b). Emerging trends in recent research on motivation in learning. In S. E. Volet \& S. Jarvela (Eds.), Motivation in learning contexts: Theoretical advances and methodological implications (pp. 57-84). Amsterdam: Pergamon.

Volet, S., \& Chalmers, D. (1992). Investigation of qualitative differences in university students' learning goals, based on an unfolding model of stage development. British Journal of Educational Psychology, 62, 17-34.

Volet, S., Renshaw, P., \& Tietzel, K. (1994). A short-term longitudinal investigation of cross-cultural difference in study approaches using Biggs' SPQ questionnaire. British Journal of Educational Psychology, 64, 301-318.

Vygotsky, L. (1997). Educational psychology. Delray Beach, FL: St Lucie Press.

Walberg, H., \& Haertel, G. (1992). Educational psychology's first century. Journal of Educational Psychology, 84, 16-19.

Watkins, D., \& Hattie, J. (1981). The learning processes of Australian university students: investigations of contextual and personological factors. British Journal of Educational Psychology, 51, 384-393.

Watson, S., Apostolou, B., Hassell, J., \& Webber, S. (2003). Accounting education literature review (2000-2002). Journal of Accounting Education, 21(4), 267-325.

Watson, S., Apostolou, B., Hassell, J., \& Webber, S. (2007). Accounting education literature review (2003-2005). Journal of Accounting Education, 25(1-2), 1-58.

Watty, K., Jackson, M., \& Yu, X. (2009). Students' Approaches to Assessment in Accounting Education: The Unique Student Perspective. Accounting Education: an international journal, 19(3), 219-234. 
Weaver, M. (2006). Do students value feedback? Student perceptions of tutors' written responses. Assessment \& Evaluation in Higher Education, 31, 379-394.

Webb, G. (1997). Deconstructing deep and surface: towards a critique of phenomenography. Higher Education, 32, 195-212.

Webb, L., De Lange, P., \& O'Connell, B. (2009). A Programme to Expose Students to Senior Executives in the World of Accounting: An Innovative Learning Method. Accounting Education, 18(2), 183 - 205.

Weimer, M. (2002). Learner-centred teaching: Five key changes to practice. San Francisco: Jossey-Bass.

Weiss, R. (1994). Learning from strangers. The art and method of qualitative interview studies. New York: Free Press.

Wilson, K., \& Fowler, J. (2005). Assessing the impact of learning environments on students' approaches to learning: comparing conventional and action learning designs. Assessment \& Evaluation in Higher Education, 30, 87-101.

Woods, P. (1993). Critical incidents in education. British Journal of Sociology of Education, 14(4), 355-371.

Zeegers, P. (2001). Approaches to learning in science: A longitudinal study. British Journal of Educational Psychology, 71(1), 115-132.

Zeegers, P. (2002). A Revision of the Biggs' Study Process Questionnaire (R-SPQ). Higher Education Research \& Development, 21(1), 73 - 92. 

(1) 


\section{APPENDIX 1}

\section{SPAS AND ASSIGNMENTS}

This appendix sets out assessments designed for the course:

- Five session preparation assignments (SPAs\#1-5)

- Five stages of an Assignment (labelled ASS\#1-5)

The SPAs and Assignments were submitted electronically through the Learning Management System software (Blackboard). 
ACCY306 FINANCIAL STATEMENT ANALYSIS

Session Preparation Assignment (SPA) \#1

FOCUS ON REALITY

RYMAN HEALTHCARE 2008 ANNUAL REPORT

\section{DUE: 11.00pm Sun 13 July (Week 2)}

Estimated (max.) time required: $420-500$ minutes (that is, about $7-81 \frac{1}{2}$ hours)

1. Read Student Notes: TKWAV, Chapter 1. Read Chapter 1 quickly, perhaps skimming some parts, looking for the meaning of the author. What is the author trying to say? While you do this note on your copy of Chapter 1 key concepts and questions (KCQs) that occur to you. Include a summary of your KCQs in your SPA\#1.

\section{Please allow 100 - 120 minutes to complete Step 1.}

2. Read Student Notes Reading 2: "Chairman's Letter to Shareholders of Berkshire Hathaway Inc." by Warren Buffett. Read this quickly, skimming and also jumping over parts that may be of less interest to you. You might find particularly interesting pages 6-9 in this reading. There is no need to read it all he does talk quite a bit about some of the businesses of Berkshire Hathaway. What do you find most interesting about what Warren Buffett has to say? Why dc you think so many people are interested in what Warren Buffett has to say? Include some of your observations and thoughts on this Reading in your SPA\#1.

\section{Please allow 60 - 80 minutes to complete Step 2.}

3. Ryman Healthcare 2008 Annual Report.

Ryman Healthcare Limited is a New Zealand listed company involved in the re:irement and healthcare sector. It has a market capitalisation of about $\$ 900$ million and is one of New Zealand top 20 listed companies by market capitalisation.

The Ryman Healthcare 2008 Annual Report is a glossy document with photos and some glowing words from the chairman and managing director. There are a winole lot of numbers and accounts in the back, which have been put together in a particular way (called 'accounting') that, for many, can seem to make it difficult to figure out what is really going on in the company.

There can also be the residual thought that the company's management (and accountants) have prepared Ryman Healthcare's 2008 Annual Report. They are not disinterested parties and may not be telling us the 'whole story' in their accounts. The auditors, Deloitte, an internationally-recognised firm of accountants, have provided an unqualified audit opinion. But what reliance can we place on that? 
There are also a lot of footnotes and detailed disclosures. The relevant accounting standards and conventions have been complied with according to the auditor's opinion, but how can we use all this information to help us come to grips with the economic and business realities of Ryman Healthcare?

Complete the following tasks:

3.1 Download the Ryman Healthcare 2008 Annual Report from the Ryman Healthcare website: rymanhealthcare.co.nz.

3.2 Read through the Ryman Healthcare 2008 Annual Report. That's right: read through it. Like you would a novel, an article or a newspaper. Familiarise yourself with what is inside it - but do not get 'hung up' with trying to understand everything. Focus on getting some sense, or overall feel, for what is happening to the company.

3.3 Make a few notes as you read through the Ryman Healthcare 2008 Annual Report, under the following headings:

Questions: Those questions or concerns or things you would like to know more about.

Interesting Observations: Those aspects of Ryman Healthcare's business and financial statements that appear interesting to you.

Major Aspects: Those major aspects of Ryman Healthcare's business that 'jump out at you'. You could list them under positives and negatives.

These observations would be simply tentative, initial observations on your part. There are no right or wrong answers; simply more interesting or potentially more insightful observations and preliminary thoughts.

Later, you will find it interesting to compare your insights on Ryman Healthcare's business that you have at the end of the course with those you have at the beginning. The question you will then be able to ask yourself at the end of the course is "has what I have learnt about financial statement analysis in this course helped me to gain a better understanding of the economic and business realities of Ryman Healthcare - and if so, how'?

Include your notes from 3.3 above (under the headings 'Questions', 'Interesting Observations' and 'Major Aspects') in your SPA\#1. These can be presented as a series of bullet points.

Please allow 260-300 minutes to complete Step 3.

Your SPA \#1 should be submitted as a Word document and be named as follows: "[your name] SPA\#1.doc" (for example, "Sarah Jones SPA\#1.doc"). Include:

- Your KCQs from Reading 1 (Step 1).

- Your observations and thoughts from Reading 2 (Step 2).

- Your notes on Ryman Healthcare's 2008 Annual Report under the headings 'Questions', 'Interesting Observations' and 'Major Aspects' (Step 3). 


\section{Session Preparation Assignment (SPA) \#2}

\section{HOW A FIRM ADDS VALUE}

\section{DUE: 11.00pm Sun 20 July (Week 3)}

\section{Estimated (max.) time required: 300 - 360 minutes (that is, 5 - 6 hours)}

1. Read Student Notes: $T K W A V$, Chapter 2. Read Chapter 2 quickly, perhaps skimming some parts, looking for the meaning of the author. What is the author trying to say? While you do this note on your copy of Chapter 2 key concepts and questions (KCQs) that occur to you. Include a summary of your KCQs in your SPA\#2. Also consider Q2-1 and Q2-5 from the Reading. Write down briefly your current opinions or thoughts about these questions, perhaps in a few bullet points. Include your short answers to Q2-1 and Q2-5 in you SPA\#2.

Please allow 180 - 220 minutes to complete Step 1.

2. Read Student Notes TKWAV, Appendix 1: "Firms Have Strategies". Read this quickly, skimming and also jumping over parts that may be of less interest to you. While you do this note on your copy of Appendix 1 key concepts and questions (KCQs) that occur to you. What insights have you gained about how your firm might approach its strategy? Also, what insights have you gained about the strategies you have been using for your own learning at university? Include some of your KCQs in your SPA\#2.

\section{Please allow 60 - 80 minutes to complete Step 2.}

3. Read Student Notes Reading 3: "Ryman Healthcare: Press Article". What insights about Ryman Healthcare did you gain from the article about its 2008 financial results?

Compare your comments to this question with your answer to item 3.3 in Step 3 in your SPA\#1. Did you find it more useful to read a press article on Ryman Healthcare's 2008 financial results (which was largely taken from a press release from Ryman Healthcare) or to read its 2008 Annual Report for yourself?

If you are near completing your business degree, perhaps majoring in accounting, do you think you should be able to use a firm's financial statements to engage with its economic and business realities for yourself? Why or why not (in other words, state your reasons for your response)? Also, discuss this with other students in the course and include some of their responses (and their reasons for their responses) in your SPA\#2. What range of opinions is there on this question? How much do you think you can learn in a course on financial statement analysis that might be able to help you actually analyse a firm's financial statements for yourself? Do you think you will be 
able to complete an analysis of your firm by the end of this course? Why or why not?

Please allow 60 minutes to complete Step 3. 


\section{ACCY306 FINANCIAL STATEMENT ANALYSIS}

\section{Session Preparation Assignment (SPA) \#3}

\section{UNDERSTANDING THE PAST}

\section{DUE: 11.00pm Sun 3 Aug (Week 5)}

Estimated (max.) time required: 240 - 300 minutes (that is, $4-5$ hours)

1. Read Student Notes: $T K W A V$, Chapter 4. Read Chapter 4 quickly, perhaps skimming some parts, looking for the meaning of the author. What is the author trying to say? While you do this note on your copy of Chapter 4 key concepts and questions (KCQs) that occur to you. Include a summary of your KCQs in your SPA\#3. Also consider Q4-2, Q4-4 and Q4-5 from the Reading. Write down briefly your current opinions or thoughts about the benefit of carefully separating a firm's operating and financial activities. Professional analysts actually have a range of views on this. Indeed, there are no right or wrong answers, simply answers that are more (or less) considered and insightful about the issues involved. Include your short answers to Q4-2, Q4-4 and Q4-5 in you SPA\#3.

Please allow 180 - 220 minutes to complete Step 1.

2. Read Student Notes Reading 5: "The Superinvestors of Graham-and-Doddsville" by Warren Buffett. Read this quickly, skimming and also jumping over parts that may be of less interest to you. While you do this note on your copy of Reading 5 key concepts and questions (KCQs) that occur to you. Include some of your KCQs in your SPA\#3.

Consider the following as you read Reading 5: What is Warren Buffett's main point in Reading 5? Do you agree with him? If Warren Buffett was not the wealthiest person in the world and the most successful living investor in the world do you think his opinions would be less credible? Why or why not? How do you think Warren Buffett compares to, say, Gordon Gekko (and his well-known line "greed is good") as played by Michael Douglas in the popular 1987 movie Wall Street:

"The point is, ladies and gentleman, that 'greed' -- for lack of a better word -- is good. Greed is right. Greed works. Greed clarifies, cuts through, and captures the essence of the evolutionary spirit. Greed, in all of its forms -greed for life, for money, for love, knowledge -- has marked the upward surge of mankind. And greed -- you mark my words -- will not only save Teldar Paper, but that other malfunctioning corporation called the USA."

Please allow 60 - 80 minutes to complete Step 2. 


\section{ACCY306 FINANCIAL STATEMENT ANALYSIS}

\section{Session Preparation Assignment (SPA) \#4}

\section{PREDICTING THE FUTURE}

\section{DUE: 11.00pm Sun 31 August (Week 7)}

Estimated (max.) time required: $300-380$ minutes (that is, $5-6 \frac{1}{2}$ hours)

1. Read Student Notes: $T K W A V$, Chapter 5. Read Chapter 5 quickly, perhaps skimming some parts, looking for the meaning of the author. What is the author trying to say? While you do this note on your copy of Chapter 5 key concepts and questions (KCQs) that occur to you. Include some of your KCQs in your SPA\#4. Also consider Q5-3 and Q5-4 from the Reading. Include your short answers to Q5-3 and Q5-4 in your SPA\#4.

Please allow 180 - 220 minutes to complete Step 1.

2. Read Student Notes Reading 4: "Example of a Broker's Report: Ryman Healthcare". How has the analyst approached valuing Ryman Healthcare? What 'dreams' about the future does he rely on in his broker's report? How are these 'dreams' similar or different to those of Martin Turner (me) in TKWAV, Chapter 5 ? What sense do you make of all of this? Is it really possible to forecast Ryman Healthcare's earnings or cash flows and thus value its equity? Discuss this issue with other students and include their responses in your SPA\#4.

\section{Please allow 60 - 80 minutes to complete Step 2.}

3. Read Student Notes Reading 6: "Fundamental Elements in the Problem of Analysis". You may find Reading 6 to be more difficult to read. Read it quickly looking for the meaning of the author, skimming and also jumping over parts that may be of less interest to you. While you do this note on your copy of Reading 6 key concepts and questions (KCQs) that occur to you. Include a summary of your KCQs in your SPA\#4. This reading will not suit everyone. There is no need to read it all. You can certainly just skim through it very briefly, if you wish. You can just say you did not get much out of reading it and give me your brief reasons why. The authors of Reading 6 will not be offended - they both died long ago.

On the other hand, some of you may really like this reading and may wish to read the rest of this classic text. One of the authors of Reading 6 (Benjamin Graham) taught Warren Buffett when he was a young man at university. Reading 6 is a chapter from the classic book Security Analysis. This book ran to many editions, but the $2^{\text {nd }}$ edition printed in 1940 (and most recently reprinted in 2003) is generally considered to be the "best" edition of the book. It is still widely read today (nearly 70 years later) and is one of the recommended readings on this course. I love re-reading this book from time 
to time. I have even been known to read it on holidays at the beach (I know that is sad - but I find it compelling reading all these years after it was written). The classic second edition is available on Closed Reserve in the Commerce Library: check it out.

Please allow $60-80$ minutes to complete Step 3. 
ACCY306 FINANCIAL STATEMENT ANALYSIS

Session Preparation Assignment (SPA) \#5

FOCUS ON THE ENTERPRISE

DUE: 11.00pm Sun 14 September (Week 9)

Estimated (max.) time required: $160-200$ minutes (that is, about $2 \frac{1}{2}-3 \frac{1}{2}$ hours)

1. Read Student Notes: $T K W A V$, Chapter 6. Read Chapter 6 quickly, perhaps skimming some parts, looking for the meaning of the author. What is the author trying to say? While you do this note on your copy of Chapter 6 key concepts and questions (KCQs) that occur to you. Include a summary of your KCQs in your SPA\#5.

Please allow 100 - 120 minutes to complete Step 1.

2. Read Student Notes Reading 7: "Handling Valuation Models". Read it quickly, skimming and also jumping over parts that may be of less interest to you. While you do this note on your copy of Reading 7 key concepts and questions (KCQs) that occur to you. Include a summary of your KCQs in your SPA\#5.

Please allow 60 - 80 minutes to complete Step 2. 
ACCY306 FINANCIAL STATEMENT ANALYSIS

\section{ASSIGNMENT 1: GETTING STARTED WITH YOUR LISTED COMPANY AND WITH $m y$ FSA $^{\circledR}$ TOOL}

\section{DUE: 11.00pm Sun 27 July (Week 4)}

Estimated (max.) time required: $630-780$ minutes (that is, 101/2 - 13 hours)

1. Go to Blackboard and click on the 'Assignments' button. You will see there is a folder where you have been matched with a company listed on the New Zealand Stock Exchange or Australian Securities Exchange. You will be getting to know and understand this firm during the course.

Note: Take care to select the company next to your name. If you use the 'wrong' company your assignment will NOT be marked and you will be asked to re-submit the assignment using the company you have been allocated.

Once you have identified your firm, click on the URL for your firm on the company list. This will take you to your firm's website, where you should be able to find you firm's annual reports under the Investor Relations section. This section might be called Shareholders' Information, Financial Information or something similar. Save a soft copy and print out the last two years' Annual Reports for your firm. For example, if the firm's last Annual Report is as at 31 March 2008, save and print out its 2008 and 2007 Annual Reports. Only save its end of year Annual Reports. Do NOT save its interim or half-yearly reports. You can ignore these.

Note: If you wish to exceed my expectations, you can also save a soft copy and print out an additional two years' financial statements (for example, a firm's 2005 and 2006 Annual Reports), if they are available for your firm, and complete the assignments using this more extended history. There is no need to go beyond a firm's last four years' Annual Reports.

You are required to submit soft copies of your firm's Annual Reports by 5.00 pm Friday 18 July (Week 2). Please allow about 30 minutes to complete Step 1.

\section{2. $m y F S A$ : your financial analysis spreadsheet.}

You will also notice on Blackboard under the Assignments button there is a file called $m y$ FSA. Save this file on to your computer. It is a simple Excel spreadsheet. It is the equivalent of a blank sheet of paper. I have "ruled a few lines" into it to help you get started. You can adjust and develop this spreadsheet as you see fit.

This course is a practical one. Some people tell me that when I leave Wellington's business district and walk down Featherston St to the Pipitea Campus of Victoria University of Wellington that I am leaving the 'real world' and entering the university campus. This is not true. It is all real. 
Business disciplines, such as accounting and finance, are all connected strongly to the economic and business realities of firms, and people, and markets. We need the practical outworking of good thinking - both working together. This course helps you to make some connections between your accounting and finance 'theory' and 'practice' in the 'real' world - what you do with the facts and theory you may have learnt.

Your myFSA spreadsheet will be your tool to help you apply some good thinking from accounting and finance to your analysis of your listed company. In Week 1 download the tool and save it on to your computer. It is your 'new friend' who might even become a 'lifetime companion' and 'supporter' to help you increasingly become a truly skilful analyst of financial statements.

The challenge for you in this course is to take this empty spreadsheet and make it myFSA spreadsheet. You need to make it your own and turn it into something that can really work for you. This course is about helping you start to learn how to use financial statements to help you engage with the world of business: on your terms.

Open up your saved copy of myFSA spreadsheet and go to the Worksheet labelled "Financial Statements".

Manually enter your firm's Balance Sheet (Statement of Financial Position), Income Statement (Statement of Financial Performance) and Statement of Movements in Equity (if your firm has one, or something similar). There is no need to enter the Statement of Cash Flows as we will not be focusing on a firm's cash flows in this course.

You can adapt and adjust your myFSA spreadsheet as you wish. For example, some people may like to include each financial statement in its own worksheet, for example by creating worksheets labelled Balance Sheets (or Statements of Financial Position); Income Statements (or Statements of Financial Performance); and Statements of Movements in Equity. Other people may prefer to include them in the one worksheet; perhaps with page breaks so that each financial statement can easily be printed separately. For each financial statement show each of the years as separate columns. Some items in the financial statements may occur in some years but not in others.

You will need to enter three (3) years of data (or up to a maximum of 5 years of data, if you are seeking to exceed my expectations). For example, if your firm's last two years of financial statements are as at 31 March 2008 and 31 March 2007, input data for 2008 from the 31 March 2008 Annual Report and input data for 2007 and 2006 from the 31 March 2007 Annual Report. Note that two years of financial statements are shown in each year's Annual Report. If, like Ryman Healthcare, your firm has adopted IFRS during this period, include two columns for the year when IFRS and GAAP figures are both provided by your firm and show both IFRS and GAAP figures for that year in two separate columns. For Ryman Healthcare that would be the year ended 31 March 2007.

Typically, your firm's accounts will show consolidated (or group) and parent financial statements. If they do, only input data from the consolidated financial statements. Do NOT input data from the parent's financial statements. Where we have a group of companies, we are interested in analysing the consolidated group, not the parent company (see the section on consolidated accounting in TKWAV, Appendix 2 'Accounting Primer'). 
You are required to submit your myFSA spreadsheet with you firm's Annual Reports entered by 5.00pm Thursday 24 July (Week 3). Please allow about 200 - 300 minutes to complete Step 2.

3. Carefully and thoughtfully read through your firm's last two year's Annual Reports: words and numbers. While you do this note on your print out of the Annual Reports key concepts and questions (KCQs) that occur to you. In particular, identify areas of your firm's financial statements you are having difficulty understanding, areas of its business that seem most important or critical to you, key challenges the firm appears to be facing, how successful it appears to be in meeting these challenges, its apparent strategy and any initial areas of concern you may have with the firm's accounting treatments.

Discuss your KCQs with other people in your Study Group (and also, if you wish, with others in the course). What similarities or differences are there between your firm and the firms of other people and between the presentations of their financial statements? How happy are you with the firm you have been given to analyse? What concerns, if any, do you have at this stage?

Please allow about $\mathbf{4 0 0}-\mathbf{4 5 0}$ minutes to complete Step 3.

4. Submission of Assignment\#1 is required by 11.00pm Sunday 27 July (Week 4).

You will need to submit your KCQs on your firm's Annual Reports and the results of your discussions with other students in a Word document. Your Word document should be named as follows: "Your name Ass\#1.doc" (for example, "Sarah Jones Ass\#1.doc"). You are also required to resubmit:

a. your myFSA spreadsheet with your inputted data; and

b. soft copies (that is, electronic copies) of your firm's Annual Reports which you downloaded from your firm's website.

5. Please contact Martin Turner, Thu Phuong Truong, Chris King or Mandie Marks well before the due date if you are having difficulty with any aspect of this assignment. The best way is for you to email one of us with your specific concerns.

Please allow about 30 minutes to complete Step 1; about 200-300 minutes to complete Step 2; and about 400 - 450 minutes to complete Step 3 of this assignment. Thus the total time you can expect to spend on this assignment is about $630-780$ minutes.

Please note: Since each of us works at an individual pace, the above estimates should be considered as rough guidelines only. Some people may be able to complete this work in less time. Some may take more time for some of these tasks. 


\title{
ACCY306 FINANCIAL STATEMENT ANALYSIS
}

\section{ASSIGNMENT 2: RESTATED FINANCIAL STATEMENTS}

\author{
DUE: 11.00pm Friday 15 August (Week 6) \\ You are able to submit Assignment \#2 during the Mid-Trimester Break \\ but prior to $11.00 \mathrm{pm}$ Friday 22 August without penalty. Otherwise, late \\ penalties accrue from Friday 15 August.
}

Estimated (max.) time required: 480 - 540 minutes (that is, 8 - 9 hours)

Go to the 'Restated Financial Statements' tab in your myFSA spreadsheet. In this worksheet input your firm's restated financial statements. For each of the restated financial statements show each of the years as separate columns. You may wish to include each restated financial statement in its own worksheet. Alternatively, you may wish to include them in one worksheet; perhaps with page breaks so that each financial statement can easily be printed separately. The $m y$ FSA spreadsheet is set up with the latter configuration.

Restate your firm's financial statements based on material covered in Chapter 4, $T K W A V$. You may see items in your firm's financial statements such as minority interests; investments in associates; futures, options, hedges or derivatives; deferred tax; or movements in foreign currency translation reserves. You may wonder what these are and whether they relate to your firm's operating or financial activities. Read Appendix 2, "Accounting Primer" in TKWAV. This will help you figure out these types of items in your firm's financial statements. I encourage you to discuss with other students any issues you (and they) may face in restating your firm's financial statements.

Include in your assignment (as a separate Word document) a brief commentary on any issues or concerns you had in restating your firm's financial statements and the results of your discussions with other students. You also may have some reflections from reading Appendix 2, TKWAV. Also submit your myFSA spreadsheet with your restated financial statements included.

Please allow about $480-540$ minutes to complete this assignment. Restating the financial statements of your first firm can be quite time consuming and, at times, a little frustrating. However, in your future career or personal investing life when you find yourself restating the financial statements of your third or fourth firm it should be a largely mechanistic exercise which you can do quite quickly. Restating your firm's financial statements will save you a lot of time and effort in the later stages of your analysis of your firm. 


\section{ACCY306 FINANCIAL STATEMENT ANALYSIS}

\section{ASSIGNMENT 3: ACCOUNTING DRIVERS}

\section{DUE: $11.00 \mathrm{pm}$ Sunday 7 September (Week 8)}

Estimated (max.) time required: 600 - 660 minutes (that is, $10-11$ hours)

1. Go to the 'Ratios' tab in your myFSA spreadsheet. In this worksheet is a blank table for you to calculate a range of ratios for your firm. A list of possible ratios is included in the worksheet. Please feel free to calculate just a few of these ratios or to calculate a few other ratios as you feel might be appropriate to your firm. You are certainly not expected to calculate all of these ratios, but to calculate just a few ratios that you think might be useful. You can also get some ideas on other possible ratios from the websites referred to in Appendix 3,TKWAV. Calculate these key ratios for the past three years for your firm by linking formulae back to items in your firm's financial statements and restated financial statements as appropriate. Some ratios you may only be able to calculate for two years if they require opening year figures. Alternatively, you could look at your firm's earlier financial statements to get the requisite opening figure in order to calculate these ratios for 3 years.

Once you have calculated a few ratios for your firm sit back and have a look at them. What do these ratios tell you about your firm? How do you make sense of them?

Many people who enrol in a university course on financial statement analysis think they will be studying how to calculate financial ratios. Well, as you can see from the websites in Appendix 3,TKWAV, all you need to do to find out all the financial ratios you will ever want to know about and how to calculate them is to google "Financial Ratios". No need to study a university course on financial statement analysis to find this out. So, if you wished, you could calculate a whole heap of ratios for your firm. But what would they tell you about what is really going on with your firm? How would you make sense of them? How would you use them to analyse, engage with and connect to your firm's economic and business realities? Well, to find this out will take more effort, strain and risk on your part than simply googling "How to make sense of financial ratios".

You have calculated a few financial ratios for your firm. Tell me what sense you can make of them.

2. Calculate abnormal earnings for the past two years (and preferably for the past 3 years).

3. Identify the key accounting drivers of your firm's past abnormal earnings. 
4. Comment on your firm's key accounting drivers. Which are the most important or critical? Discuss your thoughts on your firm's key accounting drivers with other students. What similarities or differences are there between your different firms' key accounting drivers? Why is this? What insights have you gained by 'breaking into bits' your firm's financial statements? What insights have you not gained?

5. Include in your assignment your myFSA spreadsheet, including your firm's ratios that you have calculated, as well as a Word file setting out your brief commentary on your firm's key accounting drivers and similarities or differences you have noted with the key accounting drivers of firms being analysed by other students. Include a discussion of the insights you have gained, and not gained, at this stage in your analysis.

Please allow about $600-660$ minutes to complete this assignment. 


\title{
ACCY306 FINANCIAL STATEMENT ANALYSIS
}

\section{ASSIGNMENT 4: ECONOMIC AND BUSINESS DRIVERS}

\author{
DUE: 11.00pm Sun 28 September (Week 11)
}

Estimated (max.) time required: 720 - 780 minutes (that is, 12 - 13 hours)

1. Calculate your firm's Abnormal OI for the past two years (and preferably for the past 3 years). Consider the key accounting drivers of your firm's past Abnormal Ol. Does this differ to your consideration of the key accounting drivers of abnormal earnings in Assignment 3? Why or why not?

2. You are cow getting into the more difficult stages of your analysis of your firm's financial statements. Using your firm's financial statements plus any useful sources of information you may be able to obtain (you do not need to go to a great effort to identify other sources of information; if necessary, you can simply assume external information you may want to rely on), identify what you see as the firm's key economic and business drivers. What do you think are actually driving the key aspects of your firm's financial statements?

3. You might like to include comments on how you have gone about connecting your firm's accounting drivers to your view of its economic and business drivers. How have you gone about doing this? How have you been learning to do this? How difficult, or easy, are you finding this? Why is that, do you think?

Do you think it is possible for you to connect your firm's key accounting drivers to its economic and business drivers? Why or why not? Some people at this stage in the course may be starting to come to the view that fundamental analysis may have 'feet of clay' or be critically flawed as a useful way of valuing their particular firm (or, indeed, firms in general). Others may be starting to feel that maybe, just perhaps, this whole idea of forming my own view of the value of a firm may actually make some sense and 'work' for me with my firm. Both reactions are perfectly 'acceptable'. I am interested in what you are actually thinking and feeling about this central issue that divides many experienced, capable professionals in our capital markets. And remember, you can keep changing your mind. After all, that is what learning is all about: changing.

This assignment will require considerable thought and discussion on your part. Discuss your thoughts with people you know, including other students in the course. What differences and similarities are there between your view of your firm's key economic and business drivers and those of other students about their firms?

How do you feel about your analysis at this point? Do you feel confused, nervous, confident, worried? How much do you really feel you understand about what is really going on with your firm? How 'successful' would you describe your firm? Why?

Submit in a Word file a description of the key economic and business drivers of your firm that you have identified. Comment on how they are linked to the key accounting 
drivers of your firm. Include commentary on your reactions to your analysis at this point.

Please allow about $720-780$ minutes to complete this assignment. 


\title{
ACCY306 FINANCIAL STATEMENT ANALYSIS
}

\section{ASSIGNMENT 5: FORECASTING}

\author{
DUE: 11.00pm Fri 10 October (Week 12)
}

Students are able to submit Assignment \#5 prior to $11.00 \mathrm{pm}$ Tuesday 14 October without penalty. Otherwise, late penalties accrue from Friday 10 October.

\author{
Estimated (max.) time required: 780 - 840 minutes (that is, 13 - 14 hours)
}

Now we come to the 'business end' of your analysis of your firm. In this assignment you will forecast the key economic and business drivers of your firm, its key accounting drivers and its Abnormal OI. You will need to decide on an appropriate forecast horizon for your firm, for example it might be between three and five years. Provide reasons for your choice of forecast horizon. Also, outline your views of the future underlying your forecasts. How many visions of the future of your firm do you have?

Include your forecasts in your myFSA spreadsheet, under the 'Forecasts' tab.

When you have completed your forecasts, incorporate them into a valuation of your firm. This will require you to calculate a continuing value for your firm. Include your valuation in your myFSA spreadsheet under the 'Valuation' tab.

You might like to compare your valuation for your firm with its current and past share price. There are many websites that can give you share price histories. For example, go to http://www.directbroking.co.nz/directtrade/static/home.aspx . Type in your firm's company code either for the NZX or the ASX under "Quick Quotes". (Go to the NZ Stock Exchange website: http://www.nzx.com/markets/all securities for codes of NZ firms; or to the Australian Securities Exchange website for codes of Australian listed firms: http://www.asx.com.au/asx/research/CompanyListed.jsp ). You will see you can get the share price history of your firm for a few years. There are many other websites you can use to get past share price histories. Discuss with other students which websites they find useful.

Have a look at your firm's current share prices, its share price in November 2007 (recent peak in share markets) and in March 2008 (recent trough in share markets). Some people feel 'great' if they have ended up valuing their firm at close to its current share price; and 'worried' if their value significantly diverges from the current share price. But share prices move around a lot. Ryman Healthcare was trading at up to about $\$ 2.75$ in May 2007 and down at around $\$ 1.38$ (that is about half of $\$ 2.75$ ) just 10 months later in March 2008. Yet Ryman Healthcare grew its business strongly and 'added value' to its customers, suppliers, employees and equity investors during this period. So why did its share price halve over 10 months? Did Ryman Healthcare's intrinsic value really 'halve' during this time?

Include any commentary you wish to include about your valuation in a Word file.

Submit your myFSA spreadsheet along with a Word file that includes any comments or thoughts you wish to include about your forecasts and valuation. In particular, how confident are you with the results of your analysis? Would you make investment 
decisions based on your analysis? Why or why not? You may wish to comment about how effective you have found the DAE approach to be in valuing your firm. At the end of your analysis, please recommend whether you think equity investors should BUY, SELL or HOLD their shares in your firm, after considering your valuation of the firm and its current share price.

You can write your comments in any form you wish. As a suggestion only, you could use the following headings: Background; Financial Highlights; Key Aspects of Forecasts; Valuation; Recommendation. Please feel free to write up your view of the value of your firm using whatever headings or formats you wish. I am interested in your considered opinions with supporting evidence. Please keep your comments reasonably brief. You can use bullet points where appropriate.

The end of the course is also a good time to reflect on your experience of learning in this course. Please include in your ASS\#5 your brief comments on the following:

1. An overall summary of the common themes about your learning experiences in your responses to the critical incident questionnaires (CIQs), your SPAs and your Assignments. You may include examples of, or extracts from, these if you wish.

2. A description of your contributions to small group activities you were involved in. What role or roles did you tend to play in these groups? Were you an initiator who came up with good project ideas, a monitor who kept the group on track, a resource person who tracked down material related to group activities, a cheerleader who kept up others' morale when energy began to flag, or a 'free loader' seeking to contribute as little as possible to others? Or maybe you played other roles. For each role you played and each contribution you made, please give as specific a description as you can of what you did. You may want to include copies of anything that helps me understand your contribution to your groups.

3. What did you find useful about the online support on Blackboard for your small group activities? What did you not find useful? What suggestions do you have for how online support for your small group activities could be improved in future?

4. A summary of your learning in this course. What can you do now, and what do you know now, that you couldn't do and didn't know when you first came into this course? If I asked you to be a co-teacher for part of this course next year, what topic, task, or activity would you volunteer to teach to a new student? And what happened to you in this course that makes you think you'd be a possible coteacher? Also, what was your more important realisation concerning the subject matter of the course? Why did you judge this to be of particular importance to you? What was the most important skill you learned? Again, what was it that was so significant about this skill? What is the primary learning that you feel you need to undertake the next time you have the opportunity to study in this area?

5. A summary of what you think students who show up next year should know about how to survive and flourish in this course. Some themes you might consider writing about are: "What I know now about this course that I wish I'd known when I came in," and "The three most important things you should make sure you do to keep your sanity in this course". Feel free to discard these themes and just write about whatever comes into your head around the theme of survival.

\section{Please allow 780 - 840 minutes for this assignment.}





\section{DISCUSSION BOARD}

This appendix sets out the usage of the discussion board in the course. There were 557 posts under 11 forums on the discussion board, with 53 accounting students $(65 \%$ of students in the course) making at least one post. Also, there was considerable observation of the discussion board by almost every student in the course (as recorded by the learning management system). Details of the number of posts made and the number of participants under each forum are set out in the table below:

\begin{tabular}{|l|c|c|}
\hline \multicolumn{1}{|c|}{ Forum } & $\begin{array}{c}\text { Total } \\
\text { Posts }\end{array}$ & $\begin{array}{c}\text { Total } \\
\text { Participants }\end{array}$ \\
\hline ASS\#1 & 19 & 12 \\
\hline ASS\#2 & 125 & 21 \\
\hline ASS\#3 & 98 & 29 \\
\hline ASS\#4 & 129 & 26 \\
\hline ASS\#5 & 117 & 25 \\
\hline SPA\#1 & 19 & 7 \\
\hline Class Lunch & 24 & 20 \\
\hline Word 2007 Files & 9 & 7 \\
\hline Excel & 8 & 6 \\
\hline CFA Global Challenge & 6 & 5 \\
\hline Questions for [the lecturer] (Wed Wk 12 Class) & 3 & 1 \\
\hline
\end{tabular}




\section{$-$}


IDENTIFIERS OF ACCOUNTING STUDENTS AND NUMBER OF NARRATIVES QUOTED FROM EACH STUDENT

\begin{tabular}{|c|c|c|c|}
\hline Nos & Ethnicity & Gender & $\begin{array}{l}\text { Nos of } \\
\text { Quotes }\end{array}$ \\
\hline 1 & Other Asian & $M$ & 7 \\
\hline 2 & Other Asian & M & 5 \\
\hline 3 & New Zealand European/Pakeha & $\mathrm{F}$ & 11 \\
\hline 4 & New Zealand European/Pakeha & $M$ & 1 \\
\hline 5 & New Zealand European/Pakeha & $M$ & 0 \\
\hline 6 & New Zealand European/Pakeha & $\mathrm{F}$ & 9 \\
\hline 7 & Other & $M$ & 15 \\
\hline 8 & Dutch & $M$ & 0 \\
\hline 9 & New Zealand European/Pakeha & $M$ & 4 \\
\hline 10 & New Zealand European/Pakeha & $\mathrm{F}$ & 4 \\
\hline 11 & Chinese & $\mathrm{F}$ & 2 \\
\hline 12 & Chinese & $\mathrm{F}$ & 1 \\
\hline 13 & Chinese & $\mathrm{F}$ & 3 \\
\hline 14 & Chinese & $\mathrm{F}$ & 0 \\
\hline 15 & Chinese & $M$ & 0 \\
\hline 16 & New Zealand European/Pakeha & M & 1 \\
\hline 17 & New Zealand European/Pakeha & $\mathrm{F}$ & 10 \\
\hline 18 & Chinese & $M$ & 4 \\
\hline 19 & New Zealand European/Pakeha & $M$ & 7 \\
\hline 20 & New Zealand European/Pakeha & M & 20 \\
\hline 21 & New Zealand European/Pakeha & $M$ & 18 \\
\hline 22 & New Zealand European/Pakeha & $\mathrm{F}$ & 5 \\
\hline 23 & New Zealand European/Pakeha & $\mathrm{F}$ & 1 \\
\hline 24 & New Zealand European/Pakeha & $\mathrm{F}$ & 20 \\
\hline 25 & New Zealand European/Pakeha & $M$ & 6 \\
\hline 26 & Australian & M & 4 \\
\hline 27 & Chinese & M & 1 \\
\hline 28 & Chinese & M & 4 \\
\hline 29 & Other & $\mathrm{F}$ & 5 \\
\hline 30 & New Zealand Maori & $M$ & 3 \\
\hline 31 & Other Asian & M & 8 \\
\hline 32 & Cambodian & $\mathrm{F}$ & 32 \\
\hline 33 & Chinese & $\mathrm{F}$ & 16 \\
\hline 34 & Chinese & M & 2 \\
\hline 35 & Chinese & $F$ & 1 \\
\hline 36 & Chinese & $\mathrm{F}$ & 1 \\
\hline 37 & Chinese & M & 5 \\
\hline 38 & Chinese & $\mathrm{F}$ & 0 \\
\hline 39 & Chinese & $F$ & 7 \\
\hline 40 & Chinese & $M$ & 0 \\
\hline 41 & New Zealand European/Pakeha & $M$ & 8 \\
\hline 42 & New Zealand European/Pakeha & M & 5 \\
\hline 43 & New Zealand European/Pakeha & $F$ & 3 \\
\hline 44 & Chinese & $\mathrm{F}$ & 0 \\
\hline
\end{tabular}




\begin{tabular}{|c|c|c|c|}
\hline 45 & Vietnamese & $\mathrm{F}$ & 7 \\
\hline 46 & Vietnamese & $\mathrm{F}$ & 2 \\
\hline 47 & New Zealand European/Pakeha & $\mathrm{F}$ & 3 \\
\hline 48 & New Zealand European/Pakeha & M & 1 \\
\hline 49 & Indian & $\mathrm{F}$ & 13 \\
\hline 50 & Fijian & M & 13 \\
\hline 51 & Indian & M & 2 \\
\hline 52 & Indian & M & 1 \\
\hline 53 & Chinese & M & 1 \\
\hline 54 & New Zealand European/Pakeha & M & 1 \\
\hline 55 & Other European & $\mathrm{F}$ & 20 \\
\hline 56 & New Zealand European/Pakeha & M & 3 \\
\hline 57 & Other Pacific Peoples & $F$ & 4 \\
\hline 58 & New Zealand European/Pakeha & M & 10 \\
\hline 59 & Chinese & M & 1 \\
\hline 60 & Indian & $\mathrm{F}$ & 6 \\
\hline 61 & New Zealand European/Pakeha & M & 10 \\
\hline 62 & Other Southeast Asian & M & 0 \\
\hline 63 & Chinese & M & 0 \\
\hline 64 & Other & $\mathrm{F}$ & 0 \\
\hline 65 & Chinese & $\mathrm{F}$ & 14 \\
\hline 66 & Other Pacific Peoples & M & 2 \\
\hline 67 & Vietnamese & M & 1 \\
\hline 68 & New Zealand European/Pakeha & $\mathrm{F}$ & 15 \\
\hline 69 & New Zealand European/Pakeha & $\mathrm{F}$ & 4 \\
\hline 70 & Filipino & M & 2 \\
\hline 71 & Chinese & $\mathrm{F}$ & 0 \\
\hline 72 & New Zealand European/Pakeha & M & 3 \\
\hline 73 & Chinese & $\mathrm{F}$ & 0 \\
\hline 74 & Chinese & $\mathrm{F}$ & 0 \\
\hline 75 & Chinese & M & 0 \\
\hline 76 & Chinese & $M$ & 2 \\
\hline 77 & Other Southeast Asian & $F$ & 4 \\
\hline 78 & Chinese & M & 3 \\
\hline 79 & Chinese & $\mathrm{F}$ & 2 \\
\hline 80 & Chinese & $\mathrm{F}$ & 4 \\
\hline 81 & Chinese & $\mathrm{F}$ & 2 \\
\hline 0 & Anonymous & - & 11 \\
\hline
\end{tabular}




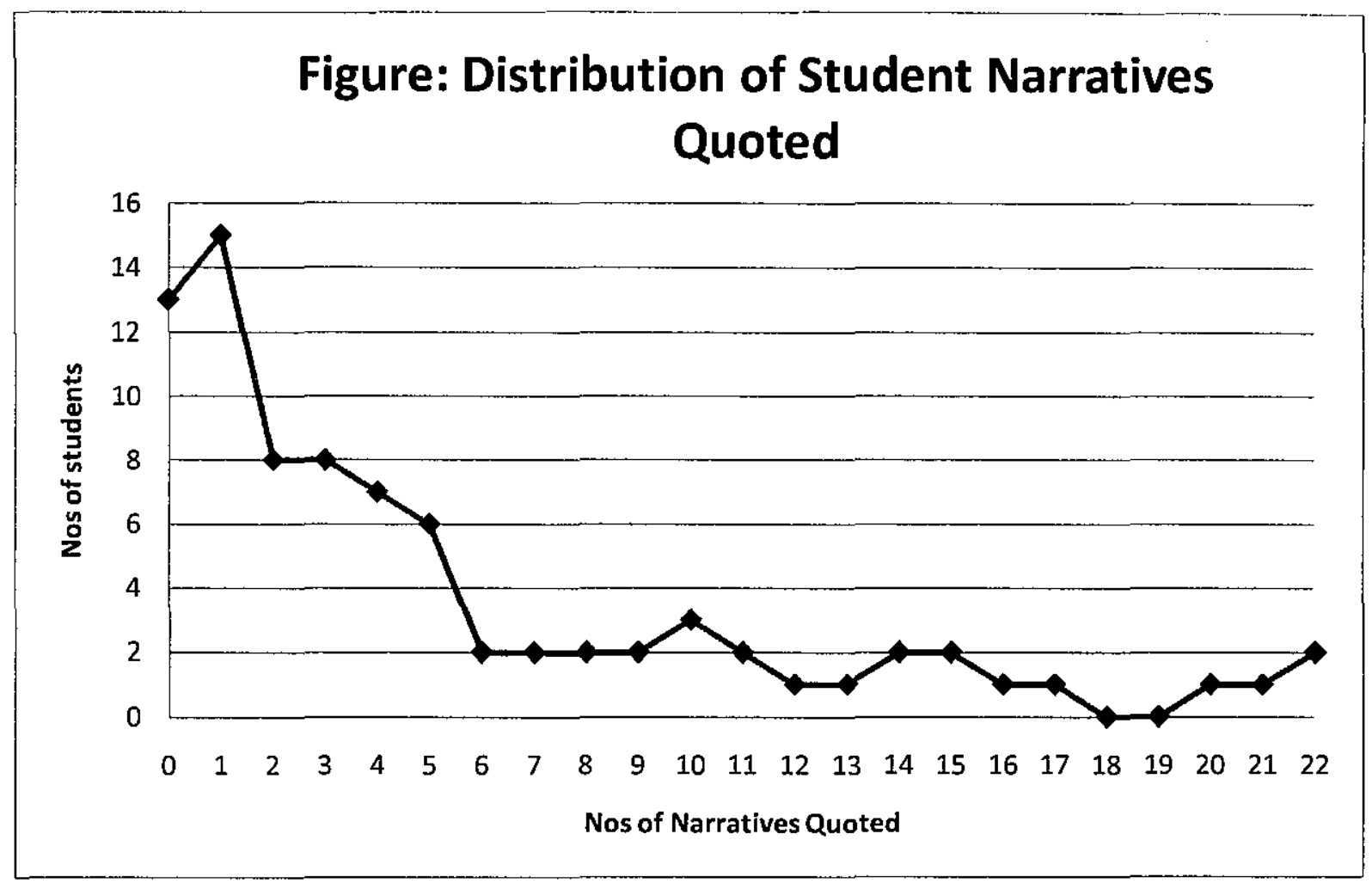





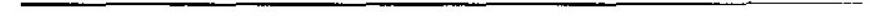




\section{DATA ANALYSIS OF 10 REFLECTIVE ASSIGNMENTS USING N-VIVO SOFTWARE}

This appendix sets out the themes used for the coding of data from the five stages of the Assignment and the five Session Preparation Assignments (SPAs) for each of the 81 students in the course and the number of quotes included under each theme. NVivo software was used to facilitate the data analysis. For some themes, further coding was completed into sub-themes (parent-child) and into sub-sub-themes (parent-child-grandchild) using the N-Vivo software. Many quotes were coded under more than one theme. A total of 3,360 quotes were coded to these themes.

\begin{tabular}{|l|r|}
\hline \multicolumn{1}{|c|}{ Theme } & $\begin{array}{r}\text { Nos of } \\
\text { Quotes }\end{array}$ \\
\hline Previous surface approach to learning & 181 \\
\hline Conception of learning & 56 \\
\hline Intrinsic motivation & 379 \\
\hline Deep approach to learning & 523 \\
\hline Meaningful teamwork & 334 \\
\hline Difficulties in teamwork & 95 \\
\hline Online tools & 151 \\
\hline CIQs & 42 \\
\hline SPAs & 239 \\
\hline Assignments & 336 \\
\hline Feedback & 39 \\
\hline Lectures & 26 \\
\hline Improve course & 100 \\
\hline Linking accounting \& business drivers & 104 \\
\hline Overall response to the course & 79 \\
\hline Personal change & 23 \\
\hline Critical thinking & 456 \\
\hline Competencies \& attitudes & 76 \\
\hline Ethics & 63 \\
\hline Other categories & 58 \\
\hline Total & $\mathbf{3 , 3 6 0}$ \\
\hline
\end{tabular}




\section{$-$}



APPENDIX 5

\section{INSTRUCTION TO SUPPORT ACCOUNTING STUDENTS TO DEVELOP AWARENESS ABOUT CONCEPTION OF LEARNING}

This appendix sets out some of the material used in lectures by the lecturer to support the direct instruction to accounting students of highlevel conception of learning. 


\section{Reason for the Seasons}

In one lecture the lecturer asked students in groups of about four to answer the question: 'What is the reason for the seasons? Why does it get hot in summer and cold in winter?' Responses from the groups were then discussed. Typically, students displayed a common misconception that the seasons are related in some way to the earth coming closer to the sun in summer and further away in winter. The lecturer then outlined how the seasons are caused by a change in the angle of the sun in the northern and southern hemispheres of the earth as the earth orbits the sun each year, and not in its distance from the sun. Indeed, the earth's orbit around the sun is close to circular. The lecturer then said that science graduates from Harvard would know this, as they are taught this in first year Astronomy course in their Science degree. The lecturer then showed a video produced by Harvard where they asked science graduates of Harvard on their graduation day the question: what is the reason for the seasons? The Harvard video is at this URL (last accessed on 8 March 2010): http://www.learner,org/resources/series28.html?pop=yes \&vodid=670078\&pid=9\#

In the video the Harvard science graduates simply state the common misconception (shared by many accounting students in the course) that the earth gets closer to the sun in summer and further away from the sun in winter.

\section{Pre-Course Survey Question}

The lecturer discussed with the Accounting students the results of one of the questions (Q.12) from the Pre-Course Survey: 'If a company owns $60 \%$ of the equity in another company it will typically include $60 \%$ of the assets, liabilities and profits of that company in its group accounts - True, False or Don't Know?' It was explained to the accounting students that the correct answer is False. It is a fundamental aspect of consolidated accounting for subsidiaries that we include $100 \%$ of the assets, liabilities and profits of subsidiaries regardless of whether they are $100 \%, 75 \%, 65 \%$ or $51 \%$ owned by the parent company. It was also pointed out to the accounting students that typically every listed company on the local share market could be expected to be a group of companies and have consolidated accounts. So this is a foundational piece of knowledge about accounting, similar to the reasons for the seasons being a foundational piece of knowledge about the physical world of our solar system. The accounting students were then shown their aggregate responses to this question in the Pre-Course Survey: True: 50\%; False 41\%; and $9 \%$ Don't Know. Thus only $41 \%$ got the correct answer to a true/false question - less than could be expected from just guessing! It was then pointed out to the students that about $50 \%$ of those in the course had recently completed the course in which consolidated accounting was taught. Indeed, they had completed the final exam for this course a few weeks before completing the Pre-Course Survey for this course. Thus surely this group would have done 
better on this question compared to the other half of students in the course who had not done this particular course. The lecturer then showed the aggregate responses of accounting students in the course who had completed the course in which consolidated accounting had been taught: True: 65\%; False: 30\%; and Don't Know: 5\%. Those who had completed the previous accounting university course on consolidated accounting actually answered the question worse than those who had not attended the course! Indeed, they answered the question much worse than simply guessing, with only $30 \%$ answering a true-false question correctly. The slides shown to the accounting student setting out this were as follows:

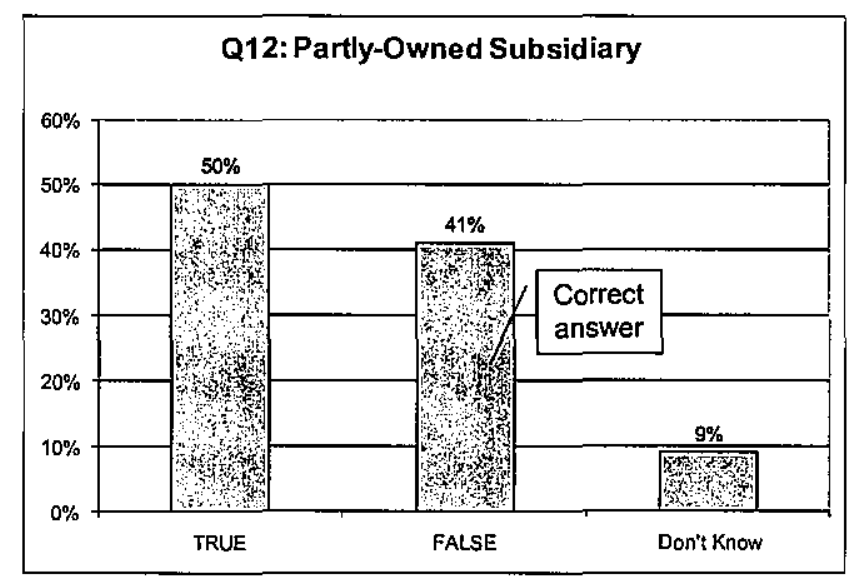

Worse than Guessing

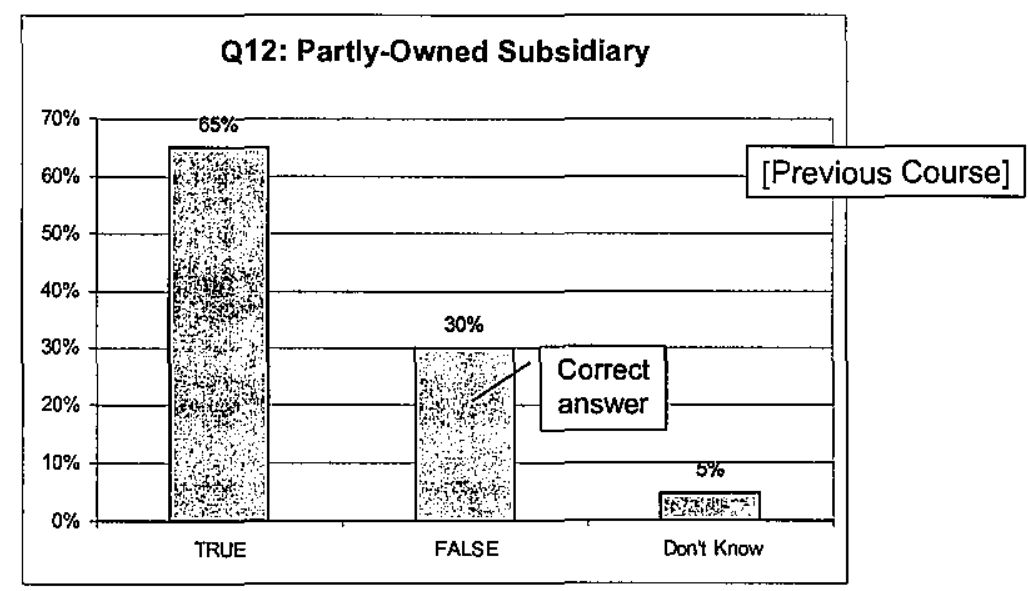

What Has Gone Wrong? 
The lecturer then discussed with the accounting students how university students could retain their common-sense misconceptions in the discipline they are studying at university and not change the way they see aspects of the world (either aspects of the physical world or aspects of the world of business and accounting). This lead into a discussion about conceptions of what learning is - and that real learning is about learning for understanding and developing personal meaning; it is not about regurgitating and reproducing clear-cut black-and-white facts from experts which are usually quickly forgotten. The lecturer emphasised that in this course every accounting student in the course will need to see learning as learning for understanding and developing personal meaning in order to negotiate successfully the assessments in the course. 
$-$ 


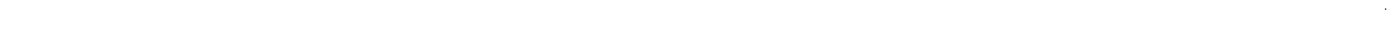




\section{SURVEYS AND QUESTIONNAIRES}

This appendix lists the questions used in each student survey. 


\section{Assessment Experience Questionnaire (AEQ) Questions}

The full set of questions included in the AEQ is set out in this section. The same questions were included in 2007 and 2008. For each question, students were asked to either Strongly Agree; Agree; Neither Agree Nor Disagree; Disagree; Strongly

Disagree; or Not Applicable.

Q1: I only study things that are going to be covered in the assignments.

Q2: I have to study regularly if I want to do well in the course.

Q3: In this course, it is possible to do quite well without studying much.

Q4: Tackling the assignments really makes me think.

Q5: I learn more from doing the assignments than from studying the course material.

Q6: In completing the assignments you can get away with not understanding and still get high marks.

Q7: The assignments give very clear instructions about what you are expected to do.

Q8: When I tackle an assignment it is not at all clear what would count as a successful answer.

Q9: The assignments are not very challenging.

Q10: In this course I get plenty of feedback about how I am doing.

Q11: The feedback comes back very quickly.

Q12: There is hardly any feedback on my assignments when I get them back.

Q13: When I get things wrong or misunderstand them I do not receive much guidance about what to do about it.

Q14: Whatever feedback I get comes too late to be useful.

Q15: The feedback helps me to understand things better.

Q16: The feedback shows me how to do better next time.

Q17: Once I have read the feedback I understand why I got the mark I did.

Q18: I do not understand some of the feedback.

Q19: I can seldom see from the feedback what I need to do to improve.

Q20: I read the feedback carefully and try to understand what the feedback is saying.

Q21: I use the feedback to go back over what I have done in the assignment.

Q22: The feedback does not help me with any subsequent assignments.

Q23: The feedback prompts me to go back over material covered earlier in the course.

Q24: I do not use the feedback for revising.

Q25: I tend to only read the marks. 


\section{Pre-Course Survey}

Q1: What degrees(s) are you doing? (mark as many boxes as are relevant):
BCA
LLB
$\mathrm{BSc}$
BA
Other degree

Q2: What major(s) are you doing in your BCA degree? (mark as many boxes as are relevant)

Accounting

Money \& Finance

Commercial Law

Other BCA major

Not doing a BCA

Q3: Is English your first language?
Yes
No

Q4: Which of these university courses are you studying in Trimester 2 this year? (mark as many boxes as are relevant)

ACCY 302 Advanced Management Accounting

ACCY303 Advanced Auditing

ACCY314 Accounting \& Society

ACCY316 Advanced International Taxation

COML303 Law of Organisations

None of the above

Q5: Which of these courses have you completed? (mark as many boxes as are relevant)

ACCY308 Advanced Financial Accounting

ACCY 231 Financial Accounting (or its predecessors ACCY221 or

ACCY222)

MOFI 201 Finance

None of the above.

Q6: How have you generally found your learning experience at university? (mark as many boxes as are relevant)
Wonderful
Boring
Challenging
Can't wait to get out of university
Tedious
Exciting
OK, I suppose
Disappointing 
Q7: In your previous courses at university, have you generally attended lectures:
Always (or nearly always)
Often
About half of the lectures
Less than half of the lectures
Rarely attended lectures.

Q8: In your previous courses at university, have you usually read the assigned readings:

Always (or nearly always) before lectures

Often before lectures

Sometimes before lectures

Rarely before lectures

Never before lectures.

Q9: Do you expect to complete your university studies at the end of Trimester 2 this year?

Yes

No

Not sure - might do Honours

Not sure - for other reasons.

Q10: How many hours each week do you expect to spend studying in this course (including attending classes)?

$0-4$ hours

5-8 hours

9-11 hours

$12+$ hours

Q11: How many hours each week do you expect to work in paid employment during Trimester 2?

$0-4$ hours

$5-8$ hours

9-11 hours

$12+$ hours

Q12: If a company owns $60 \%$ of the equity in another company it will typically include $60 \%$ of the assets, liabilities and profits of that company in its group accounts.

True

False

Don't Know

Q13: What do you think 'financial statement analysis actually is?

Q14: What do you expect to get out of doing this course?

Q15: How familiar with Excel (spreadsheet software) are you?

Never used Excel

I have used Excel a bit, but not much

I am quite comfortable using Excel

I am an Excel 'expert'. 
Q16: Which of the following can you do using Excel? (mark as many boxes as are relevant)

I can enter data and use simple formulae

I can use the NPV formula in Excel

I can link cells in different worksheets

None of the above.

\section{Course Outline Feedback}

Q1: What in the Course outline do you particularly like?

Q2: What in the Course Outline do you find unclear?

Q3: What changes would you like to see in the course?

\section{Critical Incident Questionnaires (CIQs)}

Students completed nine CIQs during Weeks 1-9 of the course. Each of the nine CIQs asked the same questions.

Q1: At what moment in the classes this week did you feel most engaged with what was happening?

Q2: At what moment in the classes this week did you feel most distanced from what was happening?

Q3: What action that anyone (teacher or student) took in classes this week did you find most affirming and helpful?

Q4: What action that anyone (teacher or student) took in classes this week did you find most puzzling or confusing?

Q5: What surprised you the most about the classes this week? (This could be something about your own reactions to what went on, or something that someone did, or anything else that occurs to you.)

\section{Informal Feedback on Learning Environment}

Q1: Name up to three things you enjoyed the most in this course so far.

Q2: Name up to three things that have not worked for you in this course.

Q3: Name up to three things you would like to see done differently in this course.

\section{Formal Feedback on Teaching and Course}

\section{Teaching}

Q1: I have attended the following number of lectures/classes taught BY THIS TEACHER in this course: 
Q2: The way this teacher organised his/her teaching helped me learn.
Always
Usually
Sometimes
Rarely
Never
No Opinion

Q3: This teacher communicated ideas and information clearly.
Always
Usually
Sometimes
Rarely
Never
No Opinion

Q4: This teacher stimulated my interest in learning more about this subject.
Always
Usually
Sometimes
Rarely
Never
No Opinion

Q5: This teacher treated students and their ideas with respect.
Always
Usually
Sometimes
Rarely
Never
No Opinion

Q6: Overall, I would rate this teacher's effectiveness as

Excellent

Very Good

Good

Poor

Very Poor

No Opinion

Q7: This teacher has encouraged me to think critically about the subject.

Strongly Agree

Agree

Neither Agree Nor Disagree

Disagree

Strongly Disagree

Not Applicable 
Q8: This teacher has encouraged me to think critically about the subject.

Strongly Agree

Agree

Neither Agree Nor Disagree

Disagree

Strongly Disagree

Not Applicable

Q9: This teacher achieved and maintained good rapport with me

Strongly Agree

Agree

Neither Agree Nor Disagree

Disagree

Strongly Disagree

Not Applicable

\section{Course}

Q1: I have attended the following number of lectures/class session in this course:
$1-2$
3-5
6-9
10-15
$16-20$
$21+$
All

Q2: The way this course is organised has helped me to learn.

Strongly Agree

Agree

Neither Agree Nor Disagree

Disagree

Strongly Disagree

Q3: Important course information - such as learning objectives, deadlines, assessments and grading criteria - was communicated clearly

Strongly Agree

Agree

Neither Agree Nor Disagree

Disagree

Strongly Disagree

Q4: Preparing for the assessments has helped me to learn.

Strongly Agree

Agree

Neither Agree Nor Disagree

Disagree

Strongly Disagree

Not Applicable 
Q5: Comments and feedback I received during the course have helped me learn more effectively.

Strongly Agree

Agree

Neither Agree Nor Disagree

Disagree

Strongly Disagree

Not Applicable

Q6: The amount of work required in this course was:

Far Too Much

Too Much

About Right

Too Little

Far Too Little

No Opinion

Q7: This course encouraged me to think CRITICALLY.

Strongly Agree

Agree

Neither Agree Nor Disagree

Disagree

Strongly Disagree

Not Applicable to This Course

Q8: This course encouraged me to think CREATIVELY.

Strongly Agree

Agree

Neither Agree Nor Disagree

Disagree

Strongly Disagree

Not Applicable to This Course

Q9: This course has helped me to develop my COMMUNICATION SKILLS.

Strongly Agree

Agree

Neither Agree Nor Disagree

Disagree

Strongly Disagree

Not Applicable to This Course

Q10: This course has stimulated my interest in learning more about this subject.

A Great Deal

Quite a Bit

Somewhat

A Little

Not At All

No opinion 
Q11: I value highly what I have learned from this course.

Strongly Agree

Agree

Neither Agree Nor Disagree

Disagree

Strongly Disagree

Q12: Overall, I would rate the quality of this course as:

Excellent

Very Good

Good

Poor

Very Poor

No Opinion

Q13: Textbooks/student notes contributed to my learning.

Strongly Agree

Agree

Neither Agree Nor Disagree

Disagree

Strongly Disagree

Not Applicable

Q14: Online components of this course contributed to my learning.

Strongly Agree

Agree

Neither Agree Nor Disagree

Disagree

Strongly Disagree

Not Applicable

\section{Post-Course Survey}

Q1: How have you generally found your learning experience in this course (ACCY306 Financial Statement Analysis)? (mark as many boxes as are relevant)

Wonderful

Boring

Challenging

Can't wait to get out of university

Tedious

Exciting

OK, I suppose

Disappointing 
Q2: How have you generally found your leaning experience at university

EXCLUDING this course? (mark as many boxes as are relevant)

\author{
Wonderful \\ Boring \\ Challenging \\ Can't wait to get out of university \\ Tedious \\ Exciting \\ OK, I suppose \\ Disappointing
}

Q3: How many hours in total have you spent at FSA Happy Hours?

Q4: How many hours in total have you spent completing your Assignments (including your estimate for time spent on ASS\#5, if you have not yet completed this assignment?) (estimated max: $60 \mathrm{hrs}-5 @ 12 \mathrm{hrs}$ )

Q5: How many hours in total have you spent completing your SPAs (Session Preparation Assignments) (estimated max: 30 hrs -5 @6 hrs)

Q6: How many hours in total have you spent interacting with other students and reading and responding to course related Blackboard postings (that you have not already included as time spent on SPAs or Assignments?) (estimated max: $36 \mathrm{hrs}$ $-2-3 \mathrm{hrs} / \mathrm{wk}$ over 12 weeks)

Q7: Sitting in Study Groups in lectures helped my learning.

Strongly Agree

Agree

Neither Agree Nor Disagree

Disagree

Strongly Disagree

Q8: How many weeks of lectures in this course should it have been a mandatory course requirement to attend?

None

1-2 weeks

3-4 weeks

5-8 weeks

$8+$ weeks

Q9: I used the discussion board on Blackboard to (mark as many boxes as are relevant):

Share my course work with other students

Seek feedback from other students

Look at what other students were working on

Give feedback to others

Socialise with other people in the course

I did not use the discussion board on Blackboard in this course 
Q10: I used the online journals and wikis on Blackboard to (mark as many boxes as are relevant):

Share my course work with other students

Seek feedback from other students

Look at what other students were working on

Give feedback to others

Socialise with other people in the course

I did not use online journals \& wikis in this course

Q11: I used 'other' online tools (such as Facebook) to (mark as many boxes as are relevant):

Share my course work with other students

Seek feedback from other students

Look at what other students were working on

Give feedback to others

Socialise with other people in the course

I did not use 'other' online tools (such as Facebook) in this course

Q12: List up to three things you liked about using the discussion board and the online journals and wikis on Blackboard and/or 'other' online tools (such as Facebook) in this course.

Q13: List up to three things that didn't work well when using the discussion board and the online journals and wikis on Blackboard in this course.

Q14: List up to three things that you think should be done differently with the discussion board and the online journals and wikis on Blackboard in this course.

Q15: Interacting with students in this course helped me with my Assignments and SPAs.

Strongly Agree

Agree

Neither Agree Nor Disagree

Disagree

Strongly Disagree

Q16: The online journals and wikis on Blackboard facilitated collaboration in my study group.

Strongly Agree

Agree

Neither Agree Nor Disagree

Disagree

Strongly Disagree

Q17: The online journals and wikis on Blackboard were useful in sharing individual course work.

Strongly Agree

Agree

Neither Agree Nor Disagree

Disagree

Strongly Disagree 
Q18: How useful did you find the support and feedback from the tutors (Mandie Marks and Chris King) and the duty tutor (Thu Phuong Truong)? What suggestions do you have to improve this support and feedback in fature courses?

Q19: How did you find the Study Group Workshops (SGWs)? Would you have preferred more or less tutorials/SGWs?

Q20: What do you consider you primarily got out of this course?

Q21: Martin Turner should stop being an academic and return to working full-time in his previous career in private equity. Please comment, giving your opinions and reactions to this statement.

Q22: What other comments/feedback would you like to give about this course?

\section{One-Year-On Survey}

Q1: What do you think learning is?

Q2: How would you describe your learning experience in ACCY306 Financial Statement Analysis last year?

Q3: What did you gain from studying this course?

Q4: How could the course be improved?

Q5: What else would you like to tell me? 